\title{
REWORKING RECIPES
}

Reading and Writing Practical Texts in the Early Modern Arts

Thijs Hagendijk 
Reworking Recipes 
ISBN: 978-94-6375-916-8

Cover illustration: The Bald-Headed Alchemist. Oil on canvas, 160o-1699. Science History Institute. Philadelphia.

Cover design by Renske Hortensius | persoonlijkproefschrift.nl Lay-out and design by Renske Hortensius | persoonlijkproefschrift.nl Printed by Ridderprint | www.ridderprint.nl

Copyright $\left({ }^{2} 2020\right.$ by Thijs Hagendijk 


\section{Reworking Recipes}

Reading and Writing Practical Texts in the Early Modern Arts

\section{Recept in uitvoering}

Lezen en schrijven van praktische teksten in de vroegmoderne kunsten (met een samenvatting in het Nederlands)

\section{Proefschrift}

ter verkrijging van de graad van doctor aan de

Universiteit Utrecht

op gezag van de

rector magnificus, prof.dr. H.R.B.M. Kummeling, ingevolge het besluit van het college voor promoties

in het openbaar te verdedigen op

maandag 29 juni 2020 des avonds te 6.00 uur

door

\section{Thijs Hagendijk}

geboren op 20 oktober 1989

te Rotterdam 


\section{Promotor:}

Prof. dr. S.G.M. Dupré

\section{Copromotor:}

Dr. M.J.N. Stols-Witlox

Dit proefschrift werd (mede) mogelijk gemaakt met financiële steun van de European Research Council (ERC), binnen het European Union's Horizon 2020 Research and Innovation Programme (grant agreement no. 648718). 


\section{Manuscript committee:}

Prof. dr. M.A. Bleeker

Prof. dr. H.H.M. Hermens

Prof. dr. W.W. Mijnhardt

Prof. dr. M.R. Prak

Prof. dr. L.M. Principe 


\section{Contents}

1. Introduction 9

1. The Study of Historical Practical Texts 11

2. Practical Texts, Identities and Motivations $\quad 15$

3. Apprenticeship Learning and the Transmission of

$\begin{array}{ll}\text { Practical Knowledge } & 16\end{array}$

4. Learning from Practical Texts 18

5. Practical Texts, Formats and Writing Strategies 21

6. Reading and (Re)writing Practical Texts 25

7. Case Studies 27

8. An Ecological Approach to Making, Practical Knowledge,
and Texts

9. Overview 33

2. Learning by Doing 37

1. Introduction $\quad 38$

2. Text and RRR 40

3. Case Study. Looking for Skill and Identifying Learning Processes $\quad 46$

4. Materials and Immaterialism in RRR 54

5. Ecology in RRR. Materials, Tools and the Environment 58

6. Case Study. The Impact of Environment and Tools 60

7. A Further Exploration of Tools and Environment in RRR 67

8. Case Study. Chasing the Impact of Furnaces 69

9. The Social and Affective Sides of RRR 74

10. Conclusion 78

3. Don't Blame the Text $\quad 83$

1. Introduction $\quad 84$

2. Rosichiero Glass. Objects, Recipes, and Ingredients 86

3. Crocus Martis and the Quest for Perfect Rust 96

4. Furnace Histories 105

5. The Fire and the Furnace 111

6. Ambivalence in Kunckel's Commentary 123

7. Don't Blame the Text 129

8. Conclusion 131 
4. Unpacking Recipes and Communicating Experience 135

1. Introduction 136

2. Simon Eikelenberg and his Notes on the Art of Painting 140

3. The Recipe and the Ervarenis 145

4. Unpacking Recipes 153

5. Communicating Experience 156

6. Expressive Instructions 161

7. Conclusion 163

5. Learning a Craft from Books $\quad 167$

1. Introduction 168

2. Text and Practice 171

3. The Guidebook in Context 174

4. Re-enactment as a Method to Assess Historical Usage $\quad 178$

5. Historical Conditions and Limits of Re-enacting 181

6. "On the casting of both silver and gold" 183

7. Choreographies, Temporality and Tools $\quad 185$

8. Sensory Indicators 190

9. Learning Through Trial and Error 193

10. Learning a Craft from Books 194

6. Conclusion 201

1. The Challenges of Text 202

2. Writing Strategies 206

3. Readers' Resources 209

4. Final Remarks 211

Appendix I - Rosichiero Recipes and Commentaries $\quad 216$

Appendix II - Overview of Eikelenberg's Ervarenissen 225

Appendix III - Van Laer's Remarks on Casting $\quad 227$

Bibliography 231

Nederlandse samenvatting $\quad 252$

Acknowledgements $\quad 258$

Curriculum Vitae 261 



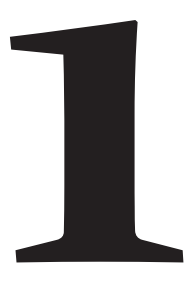

\section{Introduction}


Kitchens are stacked with cookbooks. Flat-pack furniture comes with assembly instructions. And high school chemistry practicals are carefully orchestrated by means of written protocols. Practical texts are everywhere. But how do they work exactly? How do you effectively communicate know-how in text? And how does one actually learn from reading written instructions? These questions have a long and rich history.

While reading and writing practical texts has been of all ages, interest in these texts increased specifically during the early modern period. Starting around 1400, the growth of practical texts was catalyzed by the invention of the printing press in the 1460 s, took further shape through a steady supply of wildly popular books of secrets that flooded Europe since the publication of Alessio Piemontese's De' secreti (1555), and rippled further into the seventeenth and eighteenth centuries. These practical texts dealt with a variety of topics including medicine, cosmetics, cooking, alchemy, metallurgy and the arts. They were collected and exchanged, published and translated, and circulated amongst households, learned societies and artisanal workshops alike. Practical texts travelled great distances and promised readers they would learn to create unknown substances, master new skills, and become acquainted with foreign practices. But with the spread of practical texts, awareness rose too of the potential issues and challenges that texts as a medium posed for the communication of practical knowledge. For example, when the Dutch silversmith Willem van Laer (1674-1722) published a manual on his trade, he warned his readers that "it is not possible to put everything on paper with such clarity that one would be able to understand it fully without hands-on instruction." Indeed, what could be written down and what could not? And how should a practical text be read?

The early modern period offers a particularly exciting view on the history of practical writing. Not only because the production of practical texts was growing, but more importantly because this growth pushed authors to explore different formats and strategies for conveying practical knowledge. Authors of practical texts began to adopt textual formats that were traditionally used in scholarly writing, such as commentaries and observations. Notions such as failure increasingly found their way into practical texts and ideas about the epistemic value of experiential and artisanal knowledge were shifting. ${ }^{3}$ In short, the early modern period was a period of textual experimentation, which was at its height in the seventeenth century. But how did these developments in practical writing relate to the issue that was addressed by Van Laer and likeminded authors?

$1 \quad$ Smith, "Why Write a Book?".

2 Van Laer, Weg-Wyzer (1721), p. *3r.

3 E.g. Smith, The Body of the Artisan; Dupré, "Doing it Wrong”; Pomata, "Sharing Cases";

Dupré and Somsen, "The History of Knowledge". 
Practical writing was in motion, but what did this mean for the relation between text and practice?

The central question answered in this dissertation is: Which reading and writing strategies were used and developed in the early modern arts to mediate the challenges that came with the communication of practical knowledge in text? I develop the answer through three case studies, each of which introduces and discusses a practical text that was written in the long seventeenth century (roughly between 1610-1730). Each text describes practices belonging to a different art - i.e. glassmaking, painting and gold- and silversmithing - to enable mutual comparison and to obtain a better understanding of the different ways in which authors and readers perceived and mediated the relation between text and practice. To study these texts, I not only resort to traditional historical methods such as close-reading and archival research, but also deploy hands-on approaches to explore the material, sensual and embodied dimensions that are inherent to practical texts. Even though performative methods have a long-standing history in individual fields - including archaeology, musicology, history of science and conservation and restoration, and more recently anthropology - debate and reflection on this methodology is in full development, while it is only recently that an interdisciplinary conversation has started among different fields that compares and discusses good practices. ${ }^{4}$ Because of these new developments, an elaborate discussion of the methodology in this dissertation is presented separately in chapter two: Learning by Doing. This introduction presents an overview of the current body of scholarship on historical practical texts. Moreover, I develop the research questions, introduce the case studies, and discuss an ecological approach to practices of making as the heuristic backbone that runs through this study.

\section{The Study of Historical Practical Texts}

The study of historical practical texts is not new. Already in the eighteenth century, scholarship of historical practical texts was emerging, specifically in relation to art history and art technology. Archives were overturned to scrutinize medieval and early modern manuscripts for technological information, and similarly, interest grew in the practical texts that rolled from the presses in Europe from the fifteenth century onwards. Bibliographies were compiled and monumental studies subsequently introduced these historical practical texts to a wider audience. Important examples include, but are not limited to, C.L. Eastlake's Materials for a History of Oil Painting (1847-69), M.P. Merrifield's, Original Treatises dating from the XIIth to XVIIIth Centuries on the Art of Painting (1849), E. Berger's Beiträge 
zur Entwicklungs-Geschichte der Maltechnik (1879-1909) or John K. Ferguson's two-volume Bibliographical Notes on Histories of Inventions and Books of Secrets (1898).5 The rediscovery and publication of historical practical texts intensified during the first half of the twentieth century, notably through authoritative editions of medieval and renaissance artisanal manuscripts, of which Daniel V. Thompson's translation of Cennino Cennini's Il libro dell'arte (c.140o) is perhaps the best known example today. ${ }^{6}$ Other editions include Theophilus' De Diversis Artibus (ca.1130), or translations of early modern books on metallurgy, mining and fire-related crafts, such as Vannoccio Biringuccio's De la pirotechnia (1540), or Georgius Agricola's De Re Metallica (1556).7

Significant shifts in the study of practical texts occurred during the last decades of the twentieth century. First of all, scholarship of practical texts became a more developed and recognized research strand within the field of conservation and restoration, and in the emerging field of technical art history. Particularly in combination with scientific analysis of historical objects and hands-on approaches such as reconstructions of past techniques and materials, practical texts are appreciated here as a rich source of information that aids in the interpretation and preservation of cultural heritage. ${ }^{8}$ For example, historical practical texts provide insight into the studio practices of artisans and craftspeople. ${ }^{9} \mathrm{~A}$ famous example is the written accounts that the physician Théodore de Mayerne (15731655) gave of his visits to Peter Paul Rubens' workshop (1577-1640) in what is currently referred to as the 'Mayerne Manuscript.' This has become a muchconsulted source for art historians and conservators in studying the practices of seventeenth-century oil painting. ${ }^{10}$ Life-casting is another technique that is now better understood through historical source research. Widespread and fashionable in the sixteenth century, life-casting is a metalworking technique where casts were made from killed insects, small dead reptiles, flowers and plants. It was only recently, however, that scholars learned how these casts were actually made, when they stumbled across detailed instructions in a contemporary French recipe collection. ${ }^{11}$

5 Nadolny et al., "Art technological source research".

6 Thompson, The Craftman's Handbook. Already in the nineteenth century, translations of Cennino Cennini's manuscript were prepared and published, for instance by the mentioned M.P. Merrifield. For a recent translation and edition, see: Broecke, Cennino Cennini.

7 Dodwell, The Various Arts; Hawthorne and Smith, Theophilus; Smith and Teach Gnudi, The Pirotechnia; Agricola, De Re Metallica.

8 Nadolny et al., "Art technological source research", p. 7. Clarke, "Asymptotically approaching the past", p. 2o. Hermens, "Technical Art History".

9 Wallert et al., Historical Painting Techniques.

10 Boulboullé, "Drawn up by a learned physician".

11 Beentjes and Smith, "Sixteenth-Century Life-Casting Techniques"; Smith and Beentjes, "Nature and Art". 
A landmark in the study of practical texts in technical art history and conservation and restoration was the establishment of the Art Technological Source Research (ATSR) group in 2002, which acts as a platform for the exchange, dissemination and interpretation of sources, including texts, in relation to historical artisanal practices. ${ }^{12}$ Characteristic of the approach by which practical texts are studied is the creation and use of databases that enable comparison between large numbers of texts. Researchers argue that individual sources or recipes often do not contain sufficient information to gain a comprehensive overview of a historical technique. The "documentary evidence," therefore, is combined and complemented with other sources. Hence, databases have been created to study historical painting materials and techniques, preparatory grounds in historical oil painting, or historical compositions of inks. ${ }^{13}$ Another method employed to fill in the documentary gaps in historical recipes is making reconstructions of recipes. These reconstructions are valued especially in order to acquire a sensual and practical experience that cannot be accessed through reading. To quote Arie Wallert, "the study of documentary technical evidence is intimately interlinked with the making of reconstructions. ${ }^{{ }^{14}}$ The foundation of the ATSR study group also reinforced awareness of historiographical and interpretative issues that arise in the context of historical practical texts. Topics like authorship, translation and edition histories, authority and intended audience are discussed as a means to help establish the relevance of a source to a given artist, object, locale or period. ${ }^{15}$

In the history of science, medicine and technology too, attention paid to practical texts has grown rapidly, in particular over the past two decades. ${ }^{16}$ This interest can be partially explained through the material turn in the humanities, which has led to a reevaluation of the material dimensions of our past. ${ }^{17}$ In addition, the emergence of the history of knowledge means that questions concerning different historical knowledge systems, their hierarchies, boundaries, interactions, and mutual constitution have been put on the agenda. ${ }^{18}$ In particular, one of the results is renewed attention paid to the history of practical and artisanal knowledge. In relation to that, the assumption of a straightforward and causal

Stijnman et al., "Foreword" in Art of the Past. For a general overview of the distinct approaches used to study practical texts in the art-related fields, see Stijnman, "Style and technique are inseparable".

Oltrogge, "The Cologne database for painting materials"; Stols-Witlox, A Perfect Ground; Stijnman, "Reconstructions of iron-gall ink recipes".

Wallert, "Reading technical sources", p. 39.

Clarke, "Asymptotically approaching the past".

E.g. Hendriksen, "Rethinking Performative Methods".

E.g. Guerrini, "The Material Turn".

Dupré and Somsen, "The History of Knowledge”, p. 187; Daston, "The History of Science". 
relationship between theory and practice is also actively disputed. Drawing on a vast array of historical cases and examples, scholars argue that both practice and theory reciprocally affected and informed each other in complex ways. Indeed, several and previously clear-cut dichotomies have been broken down, including but not limited to making-knowing, science-art, mind-body. ${ }^{19}$

This new historical interest in the hybridity of making and knowing, and practice and theory, is well illustrated by the craftsman-thesis that has lately been revived in the history of science. ${ }^{20}$ First developed in the 1940 by Edgar Zilsel, it seeks to understand the origination of modern science around 1600 as a natural outcome of preceding artisanal practices and knowledge. ${ }^{21}$ Sixteenthcentury artisans increasingly positioned themselves as the ultimate experts on nature. Their knowledge was not bookish, but arose from their bodily engagement with nature. Pamela H. Smith investigated this artisanal epistemology as a category sui generis and revived Zilsel's thesis by connecting it to the emergence of modern science in the seventeenth century. A similar reading is offered by Pamela O. Long, who situates the beginnings of modern science in the epistemic exchanges that became possible between fifteenth and sixteenth-century artisans and scholars. ${ }^{22}$ The interest in the historical overlap and interaction between making and knowing is also reflected in a growing body of scholarly literature in which different aspects of their hybridity are explored. Think for instance about the historical interplay between alchemy and the arts - both concerned with material transformations - or the role of practical experience and trials in early modern medicine and science. ${ }^{23}$ Indeed, it is in this academic climate, and in deferring the binary oppositions between making and knowing, theoretical knowledge and know-how, that the study of historical practical texts too could emerge and flourish.

Especially since William Eamon published his seminal study on early modern books of secrets, Science and the Secrets of Nature (1996) - which elaborated upon Ferguson's nineteenth-century work on Books of Secrets - historians have delved into a rich body of early modern practical texts, comprising topics including alchemy, medicine, cooking, metallurgy and the arts. ${ }^{24}$ A recurrent theme in the study of practical texts is how these texts related to historical material practices. Whereas practical texts have been interpreted in terms of standardization and straightforward dissemination of practical knowledge, scholars have also warned

19 E.g. Smith, The Body of the Artisan; Klein, "Technoscience avant la lettre”; Roberts, et al., The mindful hand.

20 Smith, The Body of the Artisan; Long, Artisan/Practitioners.

21 Zilsel, The Social Origins of Modern Science.

22 Long, Artisan/Practitioners, pp. 94-126. See also Long's recent discussion of early modern trading zones: Long, "Trading Zones".

23 Dupré, Laboratories of Art; Ragland, “Making Trials”.

24 Eamon, Science and the Secrets of Nature. 
that the transition from practice to text and vice versa was not a straightforward or linear process. ${ }^{25}$ It is in the absence of a linear relation between text and practice, that the very interplay between material and textual practices emerges as a topic of interest. How should we understand this interplay between text and practice?

\section{Practical Texts, Identities and Motivations}

One of the reasons why practical texts cannot simply be taken as unequivocal accounts of early modern practices is the fact that authors and readers were heterogeneous groups of people with diverging motives for engaging with texts. Authors and readers of practical texts varied from figures in the domestic sphere such as housewives and families, to persons that moved between scholarly, artisanal and craft cultures. ${ }^{26}$ If anything, the involvement with practical texts was not confined to one group, but cut through various social domains and classes. ${ }^{27}$ Scholars have coined several terms to acknowledge the fluid identity of figures involved in practices of making and knowing, and doing and reading. Zilsel preferred for instance to write about 'superior craftsmen' to denote highereducated writing artisans like Leonardo da Vinci (1492-1519). ${ }^{28}$ Pamela O. Long distanced herself from this term and introduced the 'artisan/practitioner' - a term that underlines the practice of making as a common denominator. ${ }^{29}$ In a similar manner, the term 'author-practitioner' is used by the New York based Making and Knowing Project to denote the French figure who around 1580 compiled a unique manuscript of recipes, larded with personal remarks and references to his own experience..$^{30}$

Historians have suggested several motives authors had for writing practical texts, arguing that early modern practical texts were used to show off skill and know-how in writing; to convey didactics of making; to instruct on the 'ability to improvise'; as aide mémoires; to codify errors; to preserve knowledge that was going out of practice or, occasionally, to facilitate the transmission of knowledge

25 William Eamon and Jack Goody have addressed practical texts in terms of standardization and dissemination of practical knowledge. See Eamon, Science and the Secrets of Nature, p. 131; Goody, The Domestication of the Savage Mind, p. 143. For remarks on the relation between practice and text, see Clarke, "Asymptotically approaching the past"; Smith, "Why Write a Book?", p. 48; Stols-Witlox, “'From reading to painting”", pp. 75-76; Pennell and DiMeo, "Introduction" in Reading and Writing Recipes Books, pp. 5, 7.

26 Leong, Recipes and Everyday Knowledge; Dupré. "Doing it Wrong”; Stols-Witlox, "“From reading to painting"; DiMeo and Pennell, Reading and writing recipe books; Smith, The Body of the Artisan; Long, Artisan/Practitioners.

27 This point is beautifully illustrated by Leong, Recipes and Everyday Knowledge.

28 Zilsel, The Social Origins, p. 13.

29 Long, Artisan/Practitioners, p. 130.

30 Smith and The Making and Knowing Project, "Historians in the Laboratory". 
between cultures or over long distances. ${ }^{31}$ Indeed, scholarship has demonstrated that not every early modern practical text was necessarily written with the intent to accurately and straightforwardly reflect and convey the material practices it discussed. Sometimes, practical texts were deliberately written in an allegorical or secretive style, as Lawrence M. Principe showed with respect to alchemical texts. ${ }^{32}$ Other practical texts were painfully inaccurate, prompting Pamela $\mathrm{H}$. Smith to wonder what "such useless information" was actually doing in "howto books?"33 In response, she argues that practical texts could serve rhetorical purposes as well, among other things to establish or promote the expertise and authority of their authors. Sometimes, the correspondence between text and practice seems easier to detect. How representative practical texts were of certain practices can be assessed through comparison with historical objects and object-based research. A study of a specific set of recipes for preparatory ground layers in paintings, for example, revealed that a significant number of these recipes indeed reflected demonstrable trends in contemporary painting and workshop practices. ${ }^{34}$ A similar correspondence between text and practice can also be detected in several texts written by artisans who specifically aimed to communicate and teach artisanal know-how to "young students" or "lovers". In the Dutch context, several manuals were published around the turn of the eighteenth century, such as Wilhelmus Beurs' The Big World Painted Small (1692), Gerard de Lairesse's Great Book of Painting (1707), or Willem van Laer's Guidebook for upcoming gold- and silversmiths (1721), the latter of which is explored as a case study in this dissertation. ${ }^{35}$

\section{Apprenticeship Learning and the Transmission of Practical Knowledge}

Practical texts did not always present unequivocal accounts of early modern practices. But there is another argument to investigate the interplay between text and practice and to revisit an interpretation of practical texts in terms of standardization and dissemination of practical knowledge. Next to practical texts, there was a sophisticated and well-functioning infrastructure in place through

31 Smith, "Why Write a Book?"; Long, Openness, Secrecy, Authorship, pp. 102-4; Goody, The Domestication of the Savage Mind; Sennett, The Craftsman; Pennell and DiMeo, "Introduction" in Reading and Writing Recipes Books; Yeo, Notebooks; Dupré, "Doing it Wrong"; Hendriksen, "Necessary, Not Sufficient”; Hanson and Pomata, "Medicinal Formulas and Experiential Knowledge".

32 Principe, The Secrets of Alchemy.

33 Smith, "Why Write a Book?", p. 32.

34 Stols-Witlox, "From reading to painting".

35 Wallert, "De groote waereld in't kleen geschildert"; De Vries, How to Create Beauty. 
which know-how was transferred. Teaching and learning how to make something with your hands traditionally took place in the close proximity of a workshop, as an apprenticeship under the guidance of a master. One might wonder what role practical texts played in relation to these processes. How did they relate to everyday artisanal and crafts practices? Current examples of this apprenticeship model have been studied by anthropologists and sociologists, who, for instance, have identified the manners by which skill is communicated on the shop floor, and have shown that practical skill grows with the ability to "navigate" and "foresee" making processes and anticipate material transformations. ${ }^{36}$ Historians too have been concerned with apprenticeship learning. ${ }^{37}$ With the establishment of the guilds in the late Middle Ages, a widespread infrastructure came into existence through which apprenticeship learning was overseen and regulated, which is simultaneously understood as the guilds' primary purpose. This system proved particularly stable and did not change significantly between roughly 1400 and $1800 .^{38}$ In order to learn a certain craft or art, a novice enrolled with a master. Even though little is known about the precise contents and the ways in which the apprenticeships were designed, a few things have been clarified. First, apprenticeship learning was by no means standardized. Instead, and prior to the apprenticeship, contracts were drawn up that stipulated the precise contents of what the apprentice would learn and under what conditions the education would take place. Research into these contracts has revealed that the agreements varied from case to case. Also the durations of the apprenticeships varied widely, indicating that there was no such thing as a standardized training program. ${ }^{39}$

Second, learning happened on the job. Apprentices joined in the daily routine of the workshop, and gradually moved from running errands and performing simple tasks to more demanding tasks. Time and materials were costly and preferably not wasted on special treatment for novices. ${ }^{40}$ Third, craftsmen and artisans tended to specialize within their field, and these specializations were reflected in the apprenticeships. ${ }^{41}$ Rather than acquiring a general schooling for each aspect of a craft or art, the apprentice generally appropriated the

36 Marchand, "Muscles, Morals and Mind”; O'Connor, "Embodied Knowledge”; Ingold, Making.

37 De Munck et al., Learning on the Shop Floor; De Munck, Technologies of Learning; Epstein and Prak, Guilds, Innovation and the European Economy; Prak and Wallis, Apprenticeship in Early Modern Europe; Dietz and Dupré, Youthful minds and hands.

38 Epstein and Prak, "Introduction. Guilds, Innovation, and the European Economy"; Epstein, "Craft Guilds, Apprenticeships and Technological Change". Even though the majority of apprenticeships were regulated and overseen by the guilds, apprenticeship learning could also be organized without involvement of the guilds. De Munck, Technologies of Learning; Schalk, "Apprenticeships with and without Guilds".

39 De Munck, Technologies of Learning.

40 Lane, Apprenticeship in England.

41 De Munck, Technologies of Learning, p. 51. 
knowledge and skills inherent to these sub-specializations. To put it differently, not everything could be learned in one place. Looking at seventeenth-century Dutch painting as an example, some masters were found to specialize in drawing lessons, others taught the art of painting to advanced novices, while masters could also be sought out for training in specific styles or genres. ${ }^{42}$ To widen their scope and to advance their education, young artisans had to travel to different places, which relates to the fourth and final point. A major route through which transmission and dissemination of practical knowledge took place over distances was through tramping journeymen and moving artists and artisans. ${ }^{43}$ Indeed, moving around and gaining experience in other workshops with different masters became increasingly common in the early modern period and was often considered a compulsory step for those apprentices who wanted to properly finish their training. Archival research and calculations have revealed for instance that journeymen accounted for significant proportions of the active urban population; Reinhold Reith gives numbers of $28 \%$ for Nuremberg in 1449 , or $25 \%$ for Strasbourg in 1444 , and argues that earlier and more generalized numbers of about $5 \%$ are really on the low side. ${ }^{44}$ These numbers underscore the commonality of tramping and reinforces the idea that moving people were paramount to moving knowledge. ${ }^{45}$

Given that apprenticeship-learning and physical movement such as tramping journeymen were the major routes through which the transmission of practical knowledge took place, the question is how practical texts fit into this picture.

\section{Learning from Practical Texts}

The idea has been uttered that texts might have played a role in standardizing, formalizing or streamlining apprenticeship learning, but there is little evidence that substantiates this. ${ }^{46}$ Few books have been found that potentially fulfilled this role. Examples such as Richard Dafforne's The Apprentices Time-entertainer (1640), or Joseph Moxon's Mechanick Exercises (1683) are scarce and appear to be exceptions to the rule. A more recent example is Willem van Laer's Guidebook for upcoming gold- and silversmiths (1721). But, as I will show in this dissertation, it

42 Prak, "Painters, Guilds, and the Art Market"; Kirby, "The Painter's Trade in the Seventeenth Century".

43 Reith, "Know-How, Technologietransfer und die Arcana Artis"; Reith, "Circulation of Skilled Labour".

44 Reith, "Circulation of Skilled Labour", p. 115.

45 Wallis, "Between Apprenticeship and Skill” (2019), p. 157.

46 Idem, p. 163. 
seems unlikely too that this book was an attempt to standardize apprenticeship learning.

More likely is the suggestion of Patrick Wallis that practical texts facilitated self-instruction and self-improvement of more advanced apprentices and artisans. ${ }^{47}$ This explanation presumes that readers possessed prior experience before opening a book and operates under the assumption that books had relatively little to offer when it came to the teaching and acquisition of basic skills and techniques. Indeed, what could be learned in text was only part of education; combining it with practice was crucial in acquiring artisanal skill. It is precisely this issue that has already frequently been addressed by historical authors. Perhaps the most famous example is the French potter Bernard Palissy (c.1510 - c.1589), who remarked:

Even if I used a thousand reams of paper to write down all the accidents that have happened to me in learning this art, you must be assured that, however good a brain you may have, you will still make a thousand mistakes, which cannot be learned from writings, and even if you had them in writing, you would not believe them until practice has given a thousand afflictions. ${ }^{48}$

Like Palissy, various historical authors of practical texts tried to convince their readers of the necessity of complementary hands-on practice and instruction to make the most of these texts. ${ }^{49}$ Scholars have argued that practical knowledge is often tacit in nature, which explains why text in itself is a suboptimal medium to teach and learn practical knowledge..$^{\circ}$ Michael Polanyi, who drew attention to the tacit dimensions of knowing in the late 1950s, started from the idea that "we can know more than we can tell." ${ }^{11}$ This applies in particular to practical knowledge, often a complex amalgam of physical techniques and sensorial experiences, which resists full articulation and is therefore best shown and imitated. Other terms such as gestural, bodily and embodied knowledge have also been used to indicate the tension between what is implicitly known and what can be made explicit..$^{22}$ Semantic differences aside, it is clear that there is a limit to what can be put into words. Reading and using a practical text in order to learn new things thus demands readers to fill in what cannot be articulated in

47 Idem.

48 Bernard Palissy in Smith, The Body of the Artisan, p. 103.

49 Pamela H. Smith has written about the "inadequacy of words": Smith and The Making and Knowing Project. "Historians in the Laboratory", pp. 211-2; Smith, The Body of the Artisan, pp. 8o-2. See also Wallis, "Between Apprenticeship and Skill” (2019).

50 E.g. Sennett, The Craftsman, p. 94; Smith, "What Is a Secret?", p. 50; Smith, "In the Workshop of History"; De Munck, "Artisans as knowledge workers".

51 Polanyi, The Tacit Dimension, p. 4.

52 Sibum, "Science and the Knowing Body"; O'Connor, "Embodied Knowledge". 
the texts. Reading and using practical texts forces readers to make sense of the text's implicit dimensions, its omissions and silences. That is why one might speak of the "complicity between text and reader".53 This interpretation underscores the complementary nature of practical texts, or as Patrick Wallis argues: "Using a recipe book built upon a basis of manual ability that was acquired outside the text." ${ }_{54}$ Looking at more advanced stages of learning, at those apprentices and young artisans that already possessed basic knowledge of their arts and crafts, books may have been a convenient medium to help them look beyond the confines of the workshop, to learn new things that were not facilitated or taught by their masters and to engage in new knowledge cultures. To productively engage with practical texts, reading thus had to be complemented with practical experience. But building on what they already knew, artists and artisans could use books to broaden their horizons. ${ }^{5}$

While the complementary nature of practical texts has been addressed in the literature, less is known about the interplay between text and practice itself. What were the boundaries, constraints and possibilities that determined how the interplay between text and practice could evolve? How did text as a medium determine the playing field for authors and readers? What were, in other words, the particular challenges and affordances that text as a medium brought to the communication of practical knowledge? In as far as the challenges of textual communication have been mentioned in previous scholarship, the focus has primarily been on the tacit, gestural or embodied character of practical knowledge. A few other examples include the culture-specific or local character of practical knowledge that remain difficult to account for in text. ${ }^{6}$ However, in virtually every case the focus has been on the writer's perspective. The challenges texts as a medium pose to the communication of practical knowledge thus appear to only complicate the writer's task, while the reader's perspective has received almost no attention at all. In this dissertation, I include the reader's perspective and study practical texts as a medium that brought specific challenges and affordances, not only to the authors but also to the readers.

53 Pennell and DiMeo, "Introduction" in Reading and Writing Recipes Books, p. 7.

54 Wallis, "Between Apprenticeship and Skill" (2019), p. 157.

55 Dietz and Dupré, "Introduction. Youthful minds and hands", p. 116; De Munck, "Artisans as knowledge workers".

56 E.g. Smith, "What Is a Secret?"; Smith, "In the Workshop of History"; De Munck, "Artisans as knowledge workers"; Smith, "The Codification of Vernacular Theories"; Dupré, "The Role of Judgment". 


\section{Practical Texts, Formats and Writing Strategies}

The preceding sections addressed the interplay between text and practice from various angles. I touched on the identity and motivation of authors, and the role of hands-on learning and tacit knowledge. But there is another issue that shapes and affects the relation of texts and material practice, and that concerns the text itself. The body of historical practical texts is diverse. Not only does it comprise a great variety of topics, it also presents a range of textual formats and occasionally blends in with other sorts of texts, such as those dealing with natural history, natural philosophy, art theory and medicinal case histories. ${ }^{57}$ The diversity of practical texts is also displayed in the various terms that are currently used in historiography to describe them. Where I refer to practical texts, others have referred to technical writing, practical writing, handbooks, technical manuals to how-to books, and how-to-do-it books. ${ }^{8}$ Some of these terms have a rich etymological history. For example, we currently understand handbook as something similar to a practical manual, but this does not coincide with early modern usage of the term, where handbook was understood to denote handheld books, most notably portable prayer books or books of hours. ${ }^{59}$ If anything, these terms reflect how difficult it is to adequately encapsulate the great diversity of historical practical texts. Yet, this has not stopped scholars from further distinguishing and mapping the different types that are out there. In general, there seems to be one feature that is commonly shared across practical texts; they are concerned with action, i.e. they communicate practical knowledge that facilitates readers in making and producing certain materials, objects, and effects, or in performing certain tasks or operations.

The archetypical example of a practical text is the recipe. It is also one of the earliest formats for writing down practical knowledge. Ancient examples are the so-called Leiden and Stockholm Papyri (ca. 300 AD) that among other things contain recipes for color-making, dyeing, and metallurgy. ${ }^{60}$ In the early modern period, the recipe format became one of the major vehicles for the

57 See for instance: Pomata, "The Recipe and the Case".

58 This selection of terms has been taken from only two sources: Smith, "Why Write a Book?"; Eamon, Science and the Secrets of Nature. In the fields of technical art history and conservation and restoration, the term art technological sources is consistently used to denote, among other things, the discussed body of practical texts. The use of this term diverges however in two important aspects from the way in which the previous terms are employed. It expresses a focus on sources that exclusively relate to artisanal practices, and it does not exclusively refer to textual sources, but "anything that gives information on the material aspects of the subject, work of art or craft under study." See Stijnman, "Style and technique are inseparable", p. 1.

59 Boulboullé, "The Manual as Artifact".

6o Wallert, "Alchemy and Medieval Art Technology"; Martelli, "The Alchemical Art of Dying". 
written communication of practical knowledge. Perhaps the best examples are the so-called 'secrets' and the hugely popular 'books of secrets' that contained instructions for a wide range of topics, including culinary cooking, medicine, the arts and alchemy. ${ }^{61}$ Several attempts have been made to carefully determine what a recipe is. A strict analysis of seventeenth- and eighteenth-century English recipes has revealed that they consist of a selection of recurring elements, such as a title, ingredients, preparation, application, evaluation/efficacy, storage, expiry date, and virtues. ${ }^{62}$ Other scholars have come up with three criteria to describe a corpus of medical recipes, arguing that they need to contain a stated purpose, ingredients and a verb in the imperative that demands the reader take action. ${ }^{63}$ Regardless, lots of variations are still possible within these frameworks, while the term recipe paraphrase has been introduced to generously include the exceptions that do not fully adhere to the given descriptions. ${ }^{64}$ While I agree with these formal characterizations of recipes, they are of little analytical benefit. They describe what a recipe looks like but provide little information as to what it is that a recipe does. How do recipes work as practical texts?

Another way of describing and understanding recipes is by pointing out contrasts with other sorts of practical texts. A recipe is generally prescriptive in nature and can, according to William Eamon, be distinguished from other means of communicating practical information, such as the "descriptive-historical method" found in the Renaissance technical books - for instance, Agricola's De Re Metallica (1556) or Biringuccio's Pirotechnia (1540). ${ }^{65}$ The descriptive-historical method narrates technical processes as past events that are anchored in time. The recipe, by contrast, has an almost "general, universal quality," is depersonalized, and exists independently of its origins. ${ }^{66}$ A consequence of this 'generalized' format of communication, is that the information contained in recipes is condensed. Accordingly, recipes have been described as "sets of short matter-offact instructions," while terms like rules, and formulas have been employed too ${ }^{67}$

The concise and rule-like character of recipes has led to two very different opinions on how recipes operate in practice. Echoing Jack Goody's anthropological analysis of recipes, William Eamon argued that in their codification of practical

61 Leong and Rankin, Secrets and Knowledge; Eamon, Science and the Secrets of Nature.

62 Alonso-Almeida, "Genre conventions in English recipes".

63 Mäkinen, "Efficacy Phrases".

64 Idem. Others have introduced a distinction between Vollrezepte and Kurzrecepte - detailed and abbreviated recipes respectively. See: Neven, "Transmission of Alchemical and Artistic Knowledge”, p. 39.

65 Eamon, Science and the Secrets of Nature, p. 131.

66 Goody, The Domestication of the Savage Mind, p. 136. Eamon, Science and the Secrets of Nature, p. 131.

67 Leong and Rankin, "Introduction. Secrets and Knowledge", p. 8; Eamon, Science and the Secrets of Nature, pp. 9, 131-2. 
knowledge, recipes narrowed down possibilities and imposed constraints regarding making procedures and ingredients. Following a recipe is like following orders, thus limiting the flexibility of the practitioner. ${ }^{68}$ More recent studies that inquired into the reading practices of early modern recipe users, have shed a different light on the rule-like character of recipes. Certainly, rules can be understood as constraints, thus emphasizing their rigid character, but also as abstractions that are so general that they regain flexibility, thus allowing for multiple interpretations. ${ }^{69}$ Hence, Elaine Leong has drawn attention to the "thinness" of a recipe, which, as she explains, "enables it to map onto different systems of explanation." ${ }^{\circ}$ The manner in which a recipe is read and executed ultimately depends on the reader who, as Sara Pennell and Michelle DiMeo observed, is "complicit" with the text. ${ }^{11}$ It is precisely the thinness of recipes that may also explain why this format particularly was the go-to format for most early modern authors to communicate practical knowledge in text. Detached from teachers, and unlike oral instruction that took place in the locality of workshops, recipes could roam the world and find new contexts to which they were adapted. Recipes travelled lightly.

The study of early modern practical texts has gradually moved on to discuss other textual formats as well. This includes for example the study of practical manuals or treatises that did not necessarily adhere to the recipe's condensed and prescriptive character..$^{2}$ A recent and interesting development is the shift towards exploring the recipe's boundaries and its interaction with other textual formats. Most notably, perhaps, is Gianna Pomata's and Marta Hanson's work on recipes as an "epistemic genre". Even though recipes might be generally associated with practices of making, viewing them as an epistemic genre reveals another side of recipes and shows how they can be "deliberately cognitive in purpose". ${ }^{73}$ As such, Pomata and Hanson argue, recipes were key in the exchange of medicinal knowledge between China and Europe. ${ }^{74}$ Elaine Leong has demonstrated the importance of recipes in the domestic sphere as a means to learn about the natural world in the seventeenth century. ${ }^{75}$ Interpreting recipes as an epistemic genre also explains how they blend in with other, more distinct scholarly and learned formats. For instance, recipe-like formats were used by members of

68 Eamon, Science and the Secrets of Nature, p. 132. Goody, The Domestication of the Savage Mind, p. 140.

69 See also the (yet unpublished) work of Lorraine Daston on rules, for example the following lecture: Daston, "Mechanical Rules before Machines".

70 Leong, "Brewing Ale", p. 72.

71 Pennell and DiMeo, "Introduction" in Reading and Writing Recipes Books, p. 7.

72 See for instance: Den Otter, Naar inzicht en vakmanschap.

73 Pomata, "The Recipe and the Case", p. 133.

74 Hanson and Pomata, "Medicinal Formulas".

75 Leong, Recipes and Everyday Knowledge. 
the Royal Society to communicate instructions in order to facilitate readers in the replication of experimental findings. ${ }^{76}$ But not only were practical formats appropriated for cognitive purposes, the opposite also occurred. Sven Dupré has shown how artisans adopted typical humanist formats, such as commentaries and observations, to communicate artisanal knowledge. ${ }^{77}$ In sum, the early modern body of historical practical texts was diverse. Various formats were used, and recent studies have underscored how blurry the lines between these textual formats actually were. But how can we make sense of this great diversity?

In this dissertation, I discuss the strategies that writers of practical texts employed to effectively communicate their knowledge in text. How did authors deal with the challenges of textual communication? And how were these strategies reflected in text and textual format? These questions have received relatively little attention in the historical study of practical texts, but they have been posed by Richard Sennett in the context of contemporary craftmanship. In a discussion of cooking recipes, Sennett wonders what authors can do "to make written instructions communicate - to create expressive instructions." 78 These expressive instructions are not always visible on the level of textual format, but concern first of all the verbal means and "imaginative tools" that authors use to get their message across, such as narratives, metaphors, adverbial color, similes, loose analogies, and sympathetic illustrations. An interesting outcome of this approach is that Sennett detects significant differences within recipes as a given format. Some recipes are paralyzingly precise in their language, others can be revelatory in the metaphors they employ. Even though Sennett's notion of "expressive instructions" is not a literary historical concept, it does have great heuristic benefit for the study of historical practical texts. First, it helps to detect new patterns and commonalities amongst the great variety of practical texts and the textual formats they feature. Take for instance "the scene narrative," a way to contextualize the instructions in a recipe to help readers get into the right frame of mind. Whereas William Eamon previously contrasted recipes with the descriptive-historical or narrated accounts in Agricola's De Re Metallica (1556), a focus on writing strategies emphasizes what both formats have in common. In that sense, Sennett's expressive instructions operate on a different level than the concept of "epistemic genres" that Gianna Pomata introduced to distinguish between textbooks, essays, medicinal recipe encyclopedias etc. ${ }^{79}$ Sennett looks beyond genres and textual formats and focusses on the level of verbal expression instead. Second, Sennett's notion of expressive instructions underscores that

76 Dear, "Totius in Verba”; Eamon, "How to Read a Book of Secrets", p. 42.

77 Dupré, "Doing it Wrong". See also Pomata, "Sharing cases"; Pomata, "Observation rising".

78 Sennett, The Craftsman, pp. 179-193.

79 Pomata, "The Recipe and the Case". 
authors had the means to mediate the challenges that came with the use of text. Moreover, he provides the analytical markers that aid in the identification of these means.

In this dissertation, I engage with Sennett's notion of expressive instructions and apply it to the study of historical practical texts. I will, however, specifically employ the term writing strategy, to also include textual format as a tool that authors could use in correspondence with expressive instructions. What writing strategies did early modern authors use to communicate practical knowledge in text and how did they anticipate the needs of their readers?

\section{Reading and (Re)writing Practical Texts}

Practical texts were not only written, printed and produced. They were also used and read. ${ }^{80}$ Yet it is precisely the readers' perspective that has been neglected in historiography, and for obvious reasons. Despite a wealth of practical texts that has survived the ages, historical evidence such as marginalia, annotations and other signs of usage that illustrate how readers engaged with these texts is comparably rare. Indeed, precisely those copies of texts that had been worn through practice were the least likely to make it into our libraries. ${ }^{81}$ Regardless, several scholars have argued that the study of readership would be fruitful. Pamela O. Long, for instance, stated recently that "[m] uch more work needs to be done on the readership and uses of practical and technical books in the early modern centuries, as well as on the practices of reading and writing among artisans." ${ }_{2}$ William Eamon concluded in a similar fashion that "we know surprisingly little about how they were actually used." ${ }_{3}$

Eamon's note might seem a little pessimistic, especially since a growing number of studies have meanwhile been published that demonstrate the different ways in which readers engaged with practical texts. First of all, recipes were subjected to processes of testing to establish their efficacy and readers availed themselves of several linguistic qualifiers for that purpose. As Wendy Wall points out in a study of a collection of household recipes, readers would write "approved," "pro. myself," or "probatum est" to testify to the recipe's quality. ${ }^{84}$ Jenny Boulboullé gives us another example in her analysis of the seventeenthcentury Mayerne manuscript. Its author frequently used the Latin term "vidi"

8o Readership could for instance be analyzed using book sales catalogues, lists of books prepared for book auctions, see: Stols-Witlox, A Perfect Ground.

81 Glaisyer and Pennell, "Introduction" in Didactic Literature in England, p. 7.

82 Long, "Trading Zones", p. 846.

83 Eamon, "How to Read a Book of Secrets", p. 42.

84 Wall, Recipes for Thought, p. 239. 
to indicate that he had witnessed certain procedures and to assert the validity of recipes. ${ }^{85}$ These annotating practices were widespread. Moreover, it has been shown that specifically the contexts of medicine and pharmacy were instrumental to the evolvement of early modern practices of recipe testing, trial-making and the associated linguistic constructions. ${ }^{86}$

Other recipe collections and practical texts display more drastic interventions of readers. Compilers and collectors of recipes were often engaged in processes of editing, annotating, translating, modifying, improving and rewriting, thus establishing long and complex lines of transmission. ${ }^{8}$ As Elaine Leong showed, household recipe collections were passed down from generation to generation, with every generation customizing, individualizing and adapting the recipes to their own needs, thus producing multilayered texts. ${ }^{88}$ Reading and writing were part of the same spectrum. ${ }^{89} \mathrm{Or}$, as Sara Pennell puts it, "The practitioner would become a recipe's author and owner for the moment."9o This was particularly true with respect to the translation of recipes and practical texts. Translating texts was not just a matter of putting phrases from one language into the other. Translators had to account for different cultures and different knowledge systems too. ${ }^{9^{1}}$ For example, seventeenth-century translations of Chinese medicinal formulas were structured and formatted as contemporary European recipes so that readers would immediately recognize them as such despite their exotic contents..$^{92}$ More rigorous adjustments to recipes were also made in processes of translation, for instance when recipe's procedures and ingredients had to be adapted to account for the new circumstances under which the recipe had to be used. ${ }^{93}$

The line between reading and writing is thin. Perhaps this is inherent to the historical study of reading practices, for which we can only rely on readers who actually wrote down their own reading experiences. But more than that, reading has always been writing to some extent. The complementary nature of practical texts required readers to fill in the silent omissions, to adjust for different circumstances and to decipher the instructions using the keys of their own experiences and trained judgement. Reading a recipe is rewriting it into

85 Boulboullé, "Drawn up by a learned physician", p. 228.

86 Ragland, "Making Trials"; Pugliano, "Pharmacy, Testing”.

87 Leong, Recipes and Everyday Knowledge, pp. 118-12o. For a study of premodern recipes and lines of transmission, see Neven, "Transmission of Alchemical and Artistic Knowledge".

88 Leong, "Collecting Knowledge for the Family".

89 Notebooks and commonplace books are two other excellent examples in which reading and writing practices intersect: Yeo, Notebooks.

90 Pennell, “Perfecting Practice?”, p. 250.

91 Dupré, "Introduction. Science and Practices of Translation"; Frumer, "Translating Words, Building Worlds".

92 Hanson and Pomata, "Medicinal Formulas".

93 Dupré. "Doing it Wrong". 
one's own terms. But while the complicity of practical texts and readers has been addressed in the literature, it is less known what this complicity actually entailed. To put it differently: what did the interplay between texts and practice look like from the readers' end? And how did readers cope with the challenges posed by the textual communication of practical knowledge? To understand how readers unpacked and productively engaged with written instructions, I will study the resources that early modern readers brought to a text in order to take something from it. Reading a practical text implies that the reader brings it into harmony with his/her environment and with the material and cognitive resources that are available in that context.

\section{Case Studies}

This dissertation is about practices of writing and reading in the early modern arts. To explore these practices, I turn to three distinct texts written in the seventeenth and early eighteenth centuries. The first of these texts, the Ars Vitraria Experimentalis (1679), was published by the German alchemist and glassmaker Johann Kunckel (1630-1703) and contains practical instructions for the production of different types of glass. It is an extended edition and translation of previous editions, which were originally published in Italy (1612) and translated into English (1662). The second text is a manuscript collection, Aantekeningen over de schilderkunst [Notes on the Art of Painting], that was compiled by the Dutch polymath and amateur painter Simon Eikelenberg (1663-1738) around the turn of the eighteenth century. Eikelenberg was an avid collector of notes and recipes that dealt with contemporary painting practices. His extensive accounts give insight into his own workshop experiences as a painter and reflect his reading practices. The third text is a manual, Weg-wyzer voor aankoomende goud en zilversmeeden [Guidebook for Upcoming Gold- and Silversmiths] (1721), aimed at young apprentices in the art of gold- and silversmithing, and published by the Dutch silversmith Willem van Laer (1674-1722).

The texts were selected, first, because they feature different arts, which allows for mutual comparison and helps to build a comprehensive overview of the different strategies that authors and readers developed and used to mediate the challenges that came with the communication of practical knowledge in text. Second, the texts feature different textual formats. Kunckel wrote commentaries on earlier recipes. Eikelenberg wrote extensive accounts, ervarenissen, to communicate with his readers, and Van Laer wrote a manual. The choice of different textual formats too, facilitates a better and more complete understanding of reading and writing practices in the early modern arts. But most importantly, these texts were selected because they can be related to practice, either because 
their authors wrote from their own experience, or because readers demonstrably worked with these texts in their own practice. Both Kunckel and Eikelenberg experimented with recipes in their workshop and wrote down their experiences. Van Laer, on the other hand, wrote his Guidebook based on over twenty-five years of practical experience as a silversmith. Moreover, there are several indications that the Guidebook was purposefully employed on the shop floor, even up until the twentieth century.

\section{An Ecological Approach to Making, Practical Knowledge, and Texts}

The practical texts central to this dissertation are concerned with making things. But what does it mean to create something? How should we understand practices of making? Developing a thorough understanding of making is important to ultimately assess the roles texts can play in these practices. In the fields of anthropology and archaeology, the topic of making has received considerable attention, specifically in relation to notions of skill, enskilment, apprenticeships, and the social and political dimensions of manual work. ${ }^{94}$ Of particular interest to this dissertation is Tim Ingold's anthropology of making, which he understands as a fundamental way by which humans inhabit, engage and interact with their environment. ${ }^{95}$ Central to his approach is his stance against a modern, Western division between culture and nature. Human life, Ingold argues, is not something that takes place against a silent decor of inanimate things and non-human animals. Rather, humans are inextricably intertwined with their surroundings. Human beings inhabit a world and it is through interaction and correspondence with this world that life unfolds. Humans build, dwell and live, they learn to read their environment, they make and grow things and navigate through their surroundings. The relations that unfold in these contexts are pre-eminently ecological in nature: living, dwelling and making mean that a human being is situated "in the context of an active engagement with the constituents of his or her surroundings." ${ }^{96}$ But what does it mean to understand practices of making from Ingold's ecological perspective?

Making processes, Ingold argues, should be understood as processes of growth. ${ }^{97}$ Rather than reproducing the modern division between culture and nature, where makers force their preconceived ideas on passive lumps of matter

94 Sennett, The Craftsman; Kuijpers, An Archaeology of Skill; Marchand, "Muscles, Morals and Mind"; Gowlland, "Thinking through Materials".

95 Ingold, The Perception of the Environment; Ingold, Being Alive; Ingold, Making.

96 Ingold, The Perception of the Environment, p. 5.

97 Hallam and Ingold, Making and Growing; Ingold, Making, p. 21. 
in a world that is 'out there', Ingold positions the maker in an ecological relation with his materials, tools and the forces he works with. Whereas the former view is known as hylomorphism - i.e. making is just an afterthought to the forms and designs in the mind - Ingold's alternative here is to regard makers as part of a world to which they are attentive and to which they respond. Of the maker he says: "Far from standing aloof, imposing his designs on a world that is ready and waiting to receive them, the most he can do is to intervene in worldly processes that are already going on ... adding his own impetus to the forces and energies in play." ${ }^{8}$ Just as crop-growing is a continuous interplay between the earth, weather, seeds and the plowing, fertilizing, sowing, sprinkling and harvesting farmer, making processes too can be explained as a "confluence of forces and materials". ${ }^{99}$ Elsewhere, Ingold describes this continuous joining and intertwining of forces, materials and currents as a "meshwork", as the coming together of different "lines of life, growth, and movement" as part of the world that we live in. ${ }^{100}$ In that sense, making processes are always situated; they arise in response to our environment.

An implication of this view is that materials are active entities. This touches on the topic of material agency, which has been elaborately explored by Bruno Latour and students of the Actor Network Theory. Material agency means that not only humans can act, but non-human things such as speed bumps too; simple objects that nonetheless cause drivers to slow down. ${ }^{101}$ Ingold distances himself from the idea of material agency, arguing that to bestow humans and non-humans with agency as if it were a property, does not explain why materials are active in the first place. ${ }^{102}$ Rather, activity unfolds in correspondence with other materials and forces. The activity of materials is always inter-activity. ${ }^{103}$

This also means that making processes are always open-ended and open to surprise, rather than preconceived. ${ }^{104}$ An experienced and skilled maker is characterized by his attentiveness and his anticipatory attitude. Being skilled at reading materials, and being perceptive to the clues that materials provide during a making process - e.g. how paint flows from a brush in response to the force that is exerted on it, or how metals react to the heat in a forge - is crucially important for judging and telling whether someone is on the right track, or when

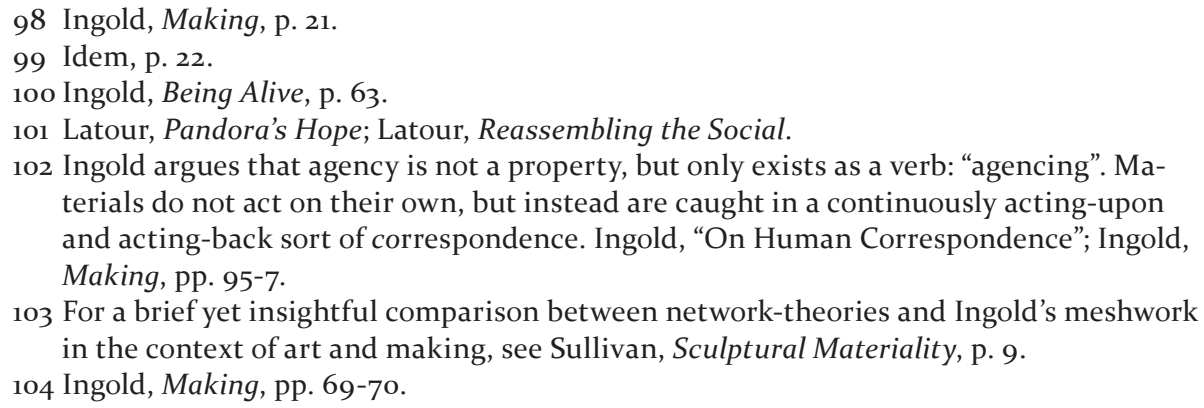


adjustments should be made. ${ }^{105}$ For Ingold, moreover, there is no fundamental difference between a craftsman who is attentive to his materials and a hunter who reads the landscape to track down an animal. Both are "forms of skilled, attentive 'coping' in the world" ${ }^{106}$ Others too, have underscored the importance of attentiveness and trained perception. ${ }^{107}$ Cristina Grasseni, for instance, argues that vision is more than just a gaze, and reconsiders it "as an embodied, skilled, trained sense that characterises (certain) practices". ${ }^{108}$ However, being attentive is not worth much without the ability to sense how the perceived state of affairs is going to unfold. Makers must be able to anticipate what their materials are going to do. This point too has been stressed by others. Richard Sennett, for instance, explains that the craftsman is "always one step ahead of the material."1o9 Erin O'Connor argues that anticipation "carries practice beyond the moment of action". ${ }^{110}$ It is important to note that anticipation is not the same as seeing into the future. Anticipation is always responsive, Ingold argues, "following and reconciling the inclinations of alternately pliable and recalcitrant materials." ${ }^{111}$ In sum, understanding making as ecological practice means that making is a way by which we engage with the world around us; we take part in a meshwork of active materials, forces and currents that constitute our environment.

It is important to note that Ingold's discussion of making practices does not encompass practical texts. Indeed, in as far Ingold discusses text and writing, these are first and foremost the products and expressions of skill, like calligraphy, rather than mediums in the communication of practical knowledge. ${ }^{12}$ Ingold does not further explain why he stays away from practical texts. His ecological anthropology, however, moves away from a modern division between knowing and making, and one could see how Ingold might fear to see this division reproduced in practical texts. Learning and teaching knowledge, according to Ingold, goes hand-in-hand with doing. Ingold argues that “...it is wrong to think of learning as the transmission of a ready-made body of information, prior to its application in particular contexts of practice." ${ }^{113}$ Codifying knowledge in text means that it is removed from practice, away from the intimate engagement with materials in an environment. Yet, Ingold's silence on the matter does not mean that practical texts cannot be brought into harmony with an ecological

105 Ingold, Making, pp. 109-124.

106 Ingold, The Perception of the Environment, p. 59.

107 Gibson, The Ecological Approach to Visual Perception; Kuijpers, "A Sensory Update to the Chaîne Opératoire".

108 Grasseni, "Skilled Vision”; Grasseni, Skilled Visions.

109 Sennett, The Craftsman, p. 175.

110 O’Connor, “Embodied Knowledge”, p. 200.

111 Ingold, Making, p. 70.

112 Ingold, Being Alive, pp. 181-195.

113 Ingold and Lucas, “The 4 A's”, p. 288. 
approach to making. On the contrary, Richard Sennett's discussion of expressive instructions is a carefully orchestrated attempt to achieve precisely that. True, texts codify knowledge and dis-embed it from practice, but at the same time, texts can show readers how to re-discover and re-embed practical knowledge into their own material engagements with the world. In this dissertation, I employ Ingold's ecological approach as a heuristic tool, but I explicitly include practical texts in the meshwork of forces and materials that constitute processes of making.

How can practical knowledge be understood in this context? Several definitions of practical knowledge have been suggested, some maintaining a problematic distinction between making and knowing or reproducing a form of hylomorphism that runs counter to an ecological approach of making. ${ }^{114}$ I would like to follow Pamela H. Smith's definition here, specifically because she carefully packed into it several themes that resonate with the ecological stance that I adopt:

Practices and techniques are one component of practical knowledge. Practical knowledge itself seems to lie in the ability to cause external and real world effects, usually in the production of a tangible thing. It usually means engaging with the materials that humans find around them in their natural or human-cultivated or-influenced environment. To move from individual "practices" to "practical knowledge," there must be an ability to produce with an expectation of success, that is, with a fair degree of reliability. Thus, the proof of practical knowledge is, in the end, a tangible object or production that is the expected and sought-for outcome of a series of techniques and practices. ${ }^{115}$

114 Possible definitions of practical knowledge can be given along the lines of Joel Mokyr's "prescriptive knowledge," or "knowing what without necessarily knowing why." Mokyr, The Gifts of Athena. This definition has been criticized because it maintains a problematic distinction between knowing and making. De Munck, "Artisans as knowledge workers", p. 229. Another possible definition comes from Matteo Valleriani: "Practical knowledge is the knowledge needed to obtain a certain product - for instance, an artistic of mechanical artifact, or specific outputs, such as healing practices or mathematical results - that follows a defined workflow. The workflow can be a construction procedure, a recipe, or even an algorithm, which are, from a formal point of view, all equivalent to one another." Valleriani, "The Epistemology of Practical Knowledge", p. 1. In my opinion, the problem here lies specifically with the "defined workflow" in the second half of the definition. While there is no denying that making practices exhibit workflows, the question remains to what degree they can be defined, and to what extent recipes, as one of the examples, can indeed be understood as defined workflows. This touches on the problems that I take up in this dissertation.

115 Smith, "The Codification of Vernacular Theories," p. 372. 
Smith disentangles practical knowledge from its components such as practices, techniques - or 'skills' for that matter. ${ }^{116}$ Practical knowledge does not equal these components, rather it is the considerate deployment of practices, skills, and techniques to successfully see a making process to its end. This distinction is important, especially when we try to understand practical knowledge in relation to practical texts. Whereas practical texts are able to convey extensive information about practices and techniques, Smith argues that they do not provide access to skill: "There is no textual shortcut to skill" ${ }^{117}$ Instead, skill is something that needs to be trained and grown, through trial-and-error and through repetitive practice. The main reason for that is that skills fundamentally depend on the body, the senses and hands-on experience. ${ }^{118}$ This is why skills generally resist verbalization and codification in text. They are personal and intimate, often referred to as the tacit, embodied and gestural components of practical knowledge that are grounded in the maker. ${ }^{119}$ The experiential, sensual and manual aspects of practical knowledge are not easily put into a propositional form, and every attempt to do so would dis-embed it from a practitioner's personal involvement with the world and hence imply its devaluation. ${ }^{120}$

Smith further ascribes a temporal quality to practical knowledge. Practical knowledge means knowing how to arrange this series of techniques, skills, and practices, knowing what needs to be done to stay on track, and knowing how to respond to the unpredictable behavior of materials. Erin O'Connor even goes as far as stating that "proficient practical knowledge is this ability to anticipate the regularities of a system, and enact schemata to manage irregularities in virtue of having already incorporated the dispositions of that system". ${ }^{121}$ But as we have seen before, anticipation stands in close relation to the trained perception of the world around us. Indeed, Smith also relates practical knowledge to the environment in which humans find and engage with materials, which involves the "acculturation of the practitioner to the behavior of the materials". ${ }^{122}$ Practical knowledge is situated knowledge in that sense, and requires attention to the inclusive meshwork of materials and forces that constitutes processes of making. This is also where Smith sees a possible role for practical texts. It is clear to

116 The terms practices, skills and techniques are used in a modern sense here. As Marieke Hendriksen argued, the term "technique" is a neologism that gained currency from ca. 1750 onwards, which before was often described as "art". Hendriksen, "Art and Technique Always Balance the Scale"”.

117 Smith, "In the Workshop of History", p. 7; Smith, "The Codification of Vernacular Theories", p. 373.

118 Kuijpers, An Archaeology of Skill, p. 41.

119 See section on "Learning from Practical Texts".

120 Ingold, Perception, p. 99.

121 O'Connor, “Embodied Knowledge”, p. 200.

122 Smith, "The Codification of Vernacular Theories", p. 373. 
her that texts cannot communicate and convey skills as such, but words, either written or spoken, can guide processes of enskilment by showing where and when to look and how to perceive the world around us. ${ }^{123}$ 'Telling' is the modality that Ingold uses in this context, which not only implies recounting stories, but also the ability to recognize and 'tell' differences in the world around us. Telling is a way of verbalizing what one knows without further explication, articulation and specification. But precisely because telling itself defies articulation, it allows people to grow into knowledge of the world and to discover skills for themselves. Telling is showing the way to others, rather than explicating the world as it is. Growing into practical knowledge and becoming skilled implies the trained perception of one's environment and learning to discern the subtle signs and cues of materials. ${ }^{124}$ And texts can foster this knowledge through an "education of attention" as Smith aptly describes. ${ }^{125}$ Texts can tell stories too. They can tell readers the way without explicating how to go about it.

Finally, it is important to note that in the context of this dissertation I do no fundamentally distinguish between other possible terms such as artisanal knowledge, craft knowledge or know-how. The reason for this is simple. An ecological understanding of practical knowledge underscores the commonality of making practices across different fields and situations. Seen from an ecological perspective, there is no formal difference between practical knowledge in the worlds of arts and crafts, or between practical knowledge involved in early modern mining or beer-brewing.

\section{Overview}

The dissertation is structured as follows. In chapter 2, Learning by Doing, I discuss the performative or hands-on methodologies I employ to access the tacit, experiential and sensual dimensions behind practical texts. I review the different ways by which hands-on methodologies can be designed and compare the choices I made with current practices across different fields. One of the greater benefits of a performative approach is that it helps in the exploration and uncovering of the ecologies in which practical texts were once embedded.

The other chapters present in-depth studies of Kunckel's Ars Vitraria Experimentalis (1679), Eikelenberg's Notes on the Art of Painting (ca. 1700), and Van Laer's Guidebook for upcoming gold- and silversmiths (1721). It is important to note that every chapter engages with the research questions that have been

123 Sennett, The Craftsman, pp. 179-193.

124 Ingold, Making, pp. 109-124; Ingold, Being Alive, p. 162; Ingold, The Perception of the Environment, p. 5.

125 Smith, "Why Write a Book?", p. 46; Smith, "In the Workshop of History”, p. 25. 
outlined above. This means that each chapter can be read on its own - the order in which they are presented does not represent a series of subsequent steps that lead to answering the central question of this thesis. However, the chapters do have important thematic nuances that shift throughout this dissertation, moving from an exploration of the challenges of textual communication and the writing strategies that authors used to cope with these challenges, to writing strategies and the resources that readers employed and required to successfully work with practical texts.

In chapter 3, Don't Blame the Text, I discuss Kunckel's Ars Vitraria Experimentalis (1679). Reproductions of four recipes for rosichiero glass - a transparent red glass - revealed a myriad of variables that determine what glass looks like once it comes out of the furnace. For instance, the color and composition of glass are affected by the ways in which ingredients are prepared and by the design of glass furnaces and the manner in which they are operated. The question is to what extent these variables could be accounted for in text, specifically because the situation in which a recipe is written usually differs from the situation in which it is read. How do you communicate color in the absence of a standardized color system? And how do you communicate temperature in the absence of thermometers? Kunckel's strategy was to support his readers by explaining the underlying mechanisms behind glassmaking. He helped his readers gain an experimental understanding of these processes by showing them where and when to intervene to make the recipes work in the locality of their own workshops.

Chapter 4, Unpacking Recipes and Communicating Experience, discusses Eikelenberg's Notes on the Art of Painting (ca. 1700). This manuscript is a typical illustration of the fact that reading was always writing to some extent. Eikelenberg, upon encountering remarkably short and unspecific instructions for a varnish, decided to figure out how this varnish can be prepared. In the end, fifteen words of instruction culminated into an account that ran over three folio pages. Interestingly, Eikelenberg called such accounts ervarenissen, a textual format that he modelled on the experimental essay form used by proponents of the New Sciences. Whereas recipes have been identified as the ubiquitous textual vehicles for practical knowledge in the early modern period, Eikelenberg wrote ervarenissen instead to unpack the ineffable dimensions of practical knowledge in text and to illustrate the resources that he deployed to that effect. This chapter explores the ervarenissen as a writing strategy that enabled Eikelenberg to create expressive instructions. He emphasized the specificity and idiosyncrasy of an act of making, tried to establish a sympathetic relationship with his readers, and showed how vulnerability, failure and improvisation belong to the workshop.

In chapter 5, Learning a Craft from Books, I explore a comprehensive and wellreceived Guidebook for upcoming gold-and silversmiths (1721) that was written in 
Dutch by silversmith Willem van Laer. Similar to Eikelenberg, Van Laer broke away from the traditional recipe format in his book and adopted a didactic voice instead. He leads with his own personal experiences, preferences and practices, and shows what works best in his opinion, while simultaneously positioning himself as an expert amidst his colleagues. Assuming that the Guidebook could be employed in apprenticeship learning, historical re-enactments were used to assess the role of this book in the acquisition of practical skill. This not only revealed that effective use of the Guidebook was greatly facilitated by complementary hands-on instruction or prior experience, more importantly, it illustrated the different types of explanatory gaps that exist in the text and the resources that readers needed to fill in these gaps, ranging from trial-and-error to learning from self-evident affordances of materials and tools. Finally, this chapter provides a preliminary answer to the question of what books might have contributed to apprenticeship learning. To understand Van Laer's instructions and to put them to good use, apprentices needed prior experience and understanding of the craft. But once they had arrived at this level, texts like the Guidebook presented an apprentice with an opportunity to extend his knowledge independently from a master, not hindered by possible didactical clumsiness on the shop floor or by impediments posed by craft specializations.

In this dissertation I argue that reading and writing practices in the early modern arts evolved in response to the challenges and affordances of text as a medium. Writers employed different strategies to effectively communicate practical knowledge in text and readers drew on a vast array of material and cognitive resources to unpack these written instructions for use in their own practices. What a practical text stands for, what it means, and what it communicates, only emerges in response to the resources that the reader brings to it. This historical conclusion has big methodological consequences. Not only are performative methods invaluable tools to gain a thorough understanding of historical practical texts, what we take away from these performances depends on the resources that we bring to these texts in the first place. 



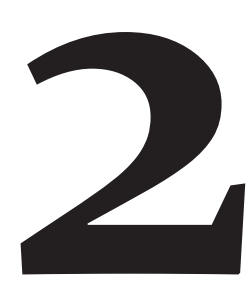

\section{Learning by Doing}

A Methodological Reflection 


\section{Introduction}

How do you study texts that primarily deal with practical knowledge and instruct readers on how to make something with their hands? The premise of this chapter is that understanding these sources is difficult without actually engaging with the instructions yourself. Indeed, seeing that these texts contain practical knowledge, it is only natural that the very practices that undergird these texts become part of the equation too. In general, interest in hands-on approaches has been growing for quite some years now and has found its way into a variety of academic fields. For example, conservators and restorers use reconstructions to understand and investigate the material properties of paintings, sculptures and other forms of cultural heritage that they safeguard. Experimental archaeologists recreate techniques of the past to complement and better understand the material remains found in excavations. And perhaps closest to this study, historians of science have deployed various hands-on approaches, for instance as an aid for close-reading historical texts, to clarify textual ambiguities or documentary gaps, or as a tool to uncover the tacit dimensions of the past that just never made it into text. While some fields have a longer history of employing hands-on approaches than others, a recent and shared development is the beginning of an interdisciplinary conversation to critically reflect on this type of methodology. ${ }^{1}$ Critical reflection has enabled the identification of a set of persistent themes across fields - e.g., the struggle with authenticity; how does a reconstruction relate to the original and how does re-enactment relate to past practice? - but most of all, it has underscored the versatility of hands-on approaches.

This versatility, as well as the rich history of hands-on approaches, is reflected in a wide variety of different terms that have come to designate this methodology, ranging from reconstruction, re-enactment, reperformance, and replication, to reworking, reproducing, and recreating. ${ }^{2}$ Some fields consistently prefer certain terms over others (e.g., reconstruction in conservation and restoration), but a different preference does not indicate profound methodological differences, nor are different terms mutually exclusive. Rather, they subtly highlight a spectrum of methodological possibilities, with terms like reworking and reenactment expressing an interest in the performative sides of the method - e.g., the re-enactment of a past event or process - and terms like reconstruction and reproduction focusing on the final objects or materials that are created as such, like a reconstructed historical pigment. In this chapter I will use the abbreviation

1 Dupré et al., Reconstruction, Replication and Re-enactment. For another collection of papers that illustrates the versatility of this method: Staubermann, Reconstructions.

2 For more background on terminology, see Dupré et al., "Introduction" in Reconstruction, Replication and Re-enactment. A similar overview can be found in Fors et al., "From the Library to the Laboratory", p. 93. 
(RRR) to refer to hands-on approaches in general, and resort to individual reterms depending on context. ${ }^{3}$ Moreover, I will often use the term 'performance' in connection with 'RRR,' simply to draw attention to the performative aspects of the method, which, as I will show, best reflects how I shaped RRR in this study.

The versatility of RRR also means that there is no golden rule when it comes to this methodology. Instead, the specific value of RRR depends on the questions asked and the topics under investigation. The aim of this chapter is to show how I tailored RRR specifically to help answer the questions asked in this dissertation. I compare the choices I made with current practices across different fields and critically assess what RRR as a method has contributed to this study. This methodological analysis will be further illustrated with examples picked from my own practice, more specifically with three elaborate case studies.

The chapter is structured as follows. In the first section, I compare how texts are used and read in relation to hands-on approaches in different fields. Using RRR as a method to understand the nature of historical written instructions carries with it characteristics that can be contrasted with other hands-on approaches that are currently used across different fields. Even though texts regularly feature in $R R R$ approaches, RRR is less often geared towards understanding the dynamics that are entangled with the text itself. I illustrate this point with a case study and show how RRR could specifically help to get a better understanding of the learning processes, the pedagogical conditions, and skills that are entangled with historical instructive texts. In the next sections, I discuss the role of materials and the appropriate attention they require in RRR. I furthermore propose an ecological approach to RRR, which recognizes that a performance is not only shaped by the performer, but also by the materials, tools and the environment in which it takes place. Two case studies illustrate how different tools and surroundings not only determine the outcome of a performance, but also shape the interpretation of a text. The last section is concerned with the social sides of RRR performances. The performing historian is not a neutral observer but walks onto the stage of his/her own performance. The appreciative reactions that emerge during a performance can be insightful and even help reveal unarticulated assumptions and expectations that govern the interpretation of a text.

3 I use this abbreviation following Dupré et al., Reconstruction, Replication and Re-enactment. 


\section{Text and RRR}

\subsection{RRR and the Availability of Text}

Reconstructions, re-enactments or replications - whether they concern historical experiments, objects, practices or events - depart from and are always based on some type of source material. For historians the availability of texts as source materials might be self-evident, but this can be less so in other fields. Experimental archaeologists for example, usually have to make do without the luxury of historical text and need to rely on often incomplete records of material remains instead. ${ }^{4}$ This has consequences for the way RRR is designed and what it can do. If material remains are the primary source of a performance, RRR usually proceeds through the controlled testing of conditions and circumstances under which these materials might have been produced. By comparing authentic objects and modern recreations - e.g., in terms of material composition or of traces inscribed in the materials by processes of making - further information can be deduced about the choices practitioners have faced and the techniques they have used in the past. 5 This means that the experimental archaeologist starts from the object and is forced to work his or her way backward to better understand ancient processes of making or communities of practice.

The availability of texts as source material opens up the possibility to organize RRR in other ways too. Textual instructions enable the performing historian to start with processes of making and to work toward the end-products. In contrast to the material remains in experimental archaeology, texts are sometimes the only remaining evidence that testify to the existence of historical objects and materials that have been lost. The availability of texts as source materials thus greatly determines how RRR can be designed. Still, texts can be deployed in various ways and a series of alternative attitudes can be discerned toward the role of texts in RRR. For example, are historical texts used to feed RRR in order to arrive at a better understanding of historical practices, materials and objects? Or is RRR used to better understand the historical texts themselves? Or is it a combination of both?

\subsection{RRR and Text in Conservation and Restoration}

In the field of conservation and restoration, historical recipes and instructions are first and foremost employed to enhance understanding of historical objects, their material composition, and their degradation. As a consequence, historical texts qualify as input for RRR approaches as long as they are considered 'reliable'

4 Hilditch, "Bringing the Past to Life".

5 Outram, "Introduction to Experimental Archaeology"; Knappett, "Materiality". 
or taken to be 'representative' of historical objects or practices. ${ }^{6}$ The relative value of a historical text depends on the technical information that can help support current conservation and restoration practices. Bits of technical information are extracted from the text, while the overall structure and properties of the text are of secondary importance and employed only as an auxiliary means to shed light on the relative worth of the text itself. For instance, from a conservator's point of view, historical texts or recipes can be 'incomplete', which justifies an inductive approach in which 'eclectic' or 'standard recipes' are distilled from sets of individually complementing recipes. ${ }^{7}$ Moreover, to facilitate the search for technical data in textual sources, large databases are built in which recipes are tagged for potentially valuable information. ${ }^{8}$ In the context of conservation and restoration, processes of tagging often mean that recipes are metonymically reduced to the compounds or practices they mention. Yet, whereas textual features fade away into the background, working with large sets of complementing recipes has the advantage that historical technical procedures can be compared, while long-term historical developments in practices of making can be mapped out that would otherwise remain largely invisible. ${ }^{9}$

Historical texts are not the only source material employed in the field of conservation and restoration. It is important to note that RRR is often fed by multiple sources, such as data derived from chemical or physical analyses of historical objects, which, complemented by texts, can help to arrive at a more comprehensive view of the studied object. ${ }^{10}$ A combinatory interpretation of the source material enables the identification of different variables and parameters of historical processes of making, which can be further determined, studied and shaped by RRR. In the end however, all source material is deployed specifically to better understand the material conditions and genesis of the object that needs

6 Carlyle and Stols-Witlox, "Historically Accurate Reconstructions"; Carlyle, "Historical Accuracy"; Stols-Witlox, "“From reading to painting".

7 Carlyle and Stols-Witlox, "Historically Accurate Reconstructions"; Carlyle, "Practical considerations", p. 106; Van Bommel and Fantini, "Unravelling the Colour Palette", p. 51. Kirby et al., Natural Colorants for Dyeing and Lake Pigments, pp. 41-2. On 'eclectic' or 'standard' recipes, Maarten van Bommel writes for instance that it proceeds through the identification of "similarities and differences in the recipes, in order to determine the most important parameters and to arrive at a standard recipe" The standard recipe "had in any event to cover the most significant parameters, and the effects of these parameters could then be investigated by varying them individually." Van Bommel and Fantini, "Unravelling the Colour Palette", p. 51.

8 Oltrogge, "The Cologne database"; Stols-Witlox, A Perfect Ground; Stijnman, "Reconstructions of iron-gall ink recipes"; Carlyle, "Historical Accuracy".

9 Attempts are made to minimize the 'reducing' effect of the databases. The incorporation of full-page images of original sources, for example, allows users of databases to surpass the interpretations that are codified in the database-entries and to 'see for themselves.' See: Clarke and Carlyle, "Page-image recipe databases".

10 Stijnman, "Style and Technique Are Inseparable". 
to be treated. This means that the conservator, much like the experimental archaeologist, works backwards: from the historical object, through textual research, scientific analyses and RRR, toward a better understanding of underlying making processes. ${ }^{11}$

Working with historical texts, also in the context of RRR, is inevitably tied up with issues of interpretation. How should one deal with puzzling terminology and unclear passages? The founding of the Art Technological Source Research working group (ATSR) has fueled a growing historiographical awareness in the field of conservation and restoration, meaning that issues of authorship, translation, intended audience and so forth are now actively considered in the interpretation of historical sources. ${ }^{12}$ The need for heuristic tools has drawn attention to another side of RRR, the potential of which is recognized as a method to clarify interpretative issues by simply testing them in practice. ${ }^{13}$ In general, the interpretation of textual sources in the field of conservation and restoration functions on two levels that are explicitly distinguished from one another. The first level concerns issues concerning terminology, measurements, ambivalent instructions, or ambiguous passages, and so forth, which stand in the way of immediate comprehensibility. ${ }^{14}$ The interpretation of these issues might be viewed as making repairs to a text so that it can be readily employed in the conservator's laboratory. A different level of interpretation concerns what Mark Clarke describes as 'historiographical':

While the history of transmission, corruption, representation, misrepresentation and interpretation of sources may be interesting to an historian of ideas as a study in itself, art technological source research is usually an attempt to extract some reliable information as to the actual workshop practices of a specific time, place or artist, and all the historiographic research is simply a means to strip away any irrelevant and misleading accretions, to date and contextualize information securely, and to interpret that information correctly in terms of terminology and techniques that we understand today. ${ }^{15}$

As Clarke explains, even though 'historiographical research' is valued as an important tool in the interpretation of historical texts in the field of conservation and restoration, it remains however first and foremost auxiliary in nature, meaning that the research is primarily undertaken to provide metadata by which

11 Carlyle, "Exploring the grammar of oil paint", p. 38.

12 Clarke et al., Arts of the Past: Sources and Reconstructions; Clarke, "Asymptotically approaching the past".

13 Oltrogge, "The Cologne database", p. 12.

14 Oltrogge, "The Cologne database"; Stijnman, "Style and Technique Are Inseparable".

15 Clarke, "Asymptotically approaching the past", p. 20. 
technical information can be further categorized, cleared of redundancies, and assessed for reliability. This also means that historiographical interpretations are largely carried out and finished before RRR is performed, thus limiting the interaction between the two.

\subsection{RRR and Text in Education}

Deliberately emphasizing one level of interpretation is not only inherent to conservation and restoration, but can also be a useful choice when RRR is employed in educational settings. For instance, one approach to text and RRR, in which interpretive issues remain largely and deliberately confined to ambiguous and unclear elements in historical texts, can be found in a course taught at University College Utrecht. On this course, chemistry students are encouraged to make reconstructions of sixteenth-century recipes for artisanal materials such as inks and pigments. ${ }^{16}$ A variety of textual features, such as the ambiguity of historical recipes, the absence of metric units, and occurrences of historical nomenclature, are specifically used to confront students with a perspective on the material world that differs greatly from the one that dominates modern chemistry textbooks. Students make reconstructions of historical texts, not in order to learn more about these texts themselves, but to experience how seemingly unequivocal concepts and nomenclature are in fact relative and the products of history. Interpretative problems concerning the interpretation of terminology and textual ambiguities are thus exploited, whereas the interest in historiographical issues remains limited. The aim of the course taught in Utrecht is ultimately to reflect with students on the nature of chemical research and to stimulate debate on the role of failure and trial-and-error in laboratory work.

\subsection{RRR and Text in the History of Science}

The above examples of conservation and education illustrate how texts can be used to feed RRR. In both cases, texts are essentially a means to an end, for instance to facilitate object-based research or to help reflect on the nature of scientific study. While in both cases it is recognized that texts cannot be taken at face-value, interpretative issues play a role only up to a point where texts start to make sufficient sense to be employed in practices of RRR and show themselves to have value for object-based research. As Clarke indicates, it is precisely here that several historians tend to take an alternative approach, specifically within the field of history of science and knowledge. Practical texts are not studied with the sole purpose of extracting technical information, but to understand the cultures - material, experimental, or artisanal - from which these texts originated. This

16 Hagendijk et al., "Reworking Recipes and Experiments". For another example of a similar approach, see: Exarchakos and Skordoulis, "The Educational Applications". 
also determines much of how historians deal with the interpretation of their sources. Rather than technical reading - i.e., with an eye to extracting technical information - interpreting practical texts becomes an exercise in studying, mapping and questioning the very conditions that constituted and shaped the text in the first place, ranging from worldviews to workshop practices, and from social dimensions to pedagogical situations. It also means, as I set out to do in this dissertation, that the interplay between textual and material practices can be studied and historized as one of the conditions that determines why a text looks the way it does.

The performance of RRR in the history of science is seen, first of all, as a methodology that can help improve the interpretation of a text through practice. ${ }^{17}$ Illustrative of this mindset is how the historians of the Making and Knowing Project, despite the very practical and material nature of the reconstructions they undertake, still describe the performance of RRR as an act of close-reading. ${ }^{18}$ The RRR-driven interpretation of texts thus becomes a way of reading between the lines - i.e., a way to uncover dimensions of texts that would otherwise remain silent. For instance, H. Otto Sibum argues that behind the so-often coherent textual narratives of historical experiments, lies the messier "lived experience" which is better comprehended through RRR. ${ }^{19}$ Sibum's reworking of the historical heat experiments of James Joule elucidated for example that the role of assistants and Joule's artisanal experience as a brewer were indispensable for the success of his experiments. None of these made it into Joule's account of the experiment, which shows that text and material practice do not necessarily overlap. ${ }^{20}$ Similarly, the Making and Knowing Project, while studying a sixteenth-century manuscript recipe collection, found that reconstructions of these recipes not only opened a window onto historical workshop practices, but that RRR also functioned as a tool to comprehend "systems of belief," or "hidden realms of practical and material knowledge" that constitute the text. ${ }^{21}$ For example, the author of the manuscript frequently described materials such as sands and salt by invoking the binary qualities of 'fat' and 'lean.' While it would be tempting to explain the author's use of these terms by invoking early modern chymical theory, it was only upon executing the recipes that the historians of the Making and Knowing Project found that 'fat' and 'lean' made even more sense in sensory terms. The performance of RRR thus revealed how these qualities resulted from the artisan's

17 Fors et al., "From the Library to the Laboratory", pp. 85-97.

18 Bilak et al., "The Making and Knowing Project", pp. 41, 46; Smith and the Making and Knowing Project, "Historians in the Laboratory", p. 228.

19 Sibum, "Science and the Knowing Body"; Sibum, "Reworking the Mechanical Value of Heat".

20 Sibum, "Reworking the Mechanical Value of Heat".

21 Bilak et al., "The Making and Knowing Project", pp. 41, 46; Smith and the Making and Knowing Project, "Historians in the Laboratory", p. 228. 
bodily intimacy with materials, rather than his theorizing about them. ${ }^{22}$ But perhaps the most dramatic example of RRR-driven reinterpretation is found in Lawrence M. Principe's study of a corpus of alchemical texts. For a long time, the historiography of alchemy has been characterized by different schools of interpretations among which the dominant Jungian-psychological school had a tendency to distance alchemy from material and laboratory practices. Through RRR, Principe was able to show that alchemical texts, despite their highly allegorical style and extravagant imagery, described actual experimental practice. Methods of RRR exposed a realm of experimentalism behind such texts, thus tipping the balance in favor of an experimental view of alchemical knowledge. ${ }^{23}$

A connecting theme between most of the dimensions that historians have revealed behind their sources, is the presence of sensual information - e.g., smell, feel, colors, and taste - as well as tacit, embodied, or gestural knowledge. ${ }^{24}$ Over the past years, historians have shown a more than average interest in these types of non-propositional knowledge, which either characterize, or at least interlard the mentioned 'systems of belief,' 'lived experience,' and 'realms of experimentalism'. This interest could be explained by the fact that the recovery of non-propositional knowledge is greatly advanced by RRR-methodologies, whereas more traditional historical methods, such as archival research, critical source research and close-reading have achieved little in this respect. Use of RRR and interest in the tacit dimensions of our past are thus intimately connected, or to phrase it differently: RRR is not just another historical tool but leaves its mark on historiography more generally. ${ }^{25}$ Indeed, much in contrast to traditional historical methodologies, the application of RRR in academic studies is often accompanied by extensive reflection, as scholars are generally very aware of the consequences this methodology carries for the way we perceive our past. This is also why people have warned against an over-zealous implementation of this methodology, in which tacit and material dimensions of our past are disproportionally addressed and understood in spite of, and not in connection to, its intellectual dimensions. ${ }^{26}$

In this dissertation, RRR is used to investigate the nature of written instructions and more generally the role of texts in the early modern transmission of artisanal knowledge. To phrase it differently, historical texts are scrutinized to identify learning processes and analyze how texts create the pedagogical conditions necessary for the teaching and learning of skills. This has consequences for the way RRR is designed. First, textual integrity is of great importance, meaning

22 Smith et al., "Historians in the Laboratory", pp. 226-7.

23 Principe, The Secrets of Alchemy, pp. 137-171; Principe, "Apparatus and Reproducibility".

24 Fors et al., "From the Library to the Laboratory", p. 90; Sibum, "Science and the Knowing Body"; Hagendijk, "Learning a Craft from Books".

25 Sibum, "Science and the Knowing Body".

26 Principe, "Chymical Exotica”, p. 143. 
that a text should be taken and judged on its own merits. Given that written instructions stand or fall by the metaphors they employ, the level of detail they exhibit or the context in which they are presented, it is desirable to identify and analyze these textual features, rather than interpreting them immediately in anticipation of an end-product. Second, understanding the place of historical texts in the transmission of artisanal knowledge only works when the historian is capable of actually assessing and evaluating the artisanal knowledge that is being taught or acquired. Here, specifically, RRR starts to assume an essential role, because it is only by doing that one is able to obtain a realistic view of learning processes and the skills involved, which is shown in the following case study.

\section{Case Study. Looking for Skill and Identifying Learning Processes}

\subsection{The Apprentice-style Method of Inquiry. Learning How to Cast}

One way to design RRR is through an apprentice-style method of inquiry. Inspired by the anthropology of craft, this method of inquiry is a type of participant observation in which the investigator takes on the role of the apprentice. Learning how to do something with your hands or learning how to master a certain art or craft is an excellent way to identify and test the pedagogical qualities of a text. While acquiring practical knowledge, one inevitably runs into points at which educational resources such as hands-on education, prior knowledge, additional explanation or plain trial-and-error become critical in order to proceed. Moreover, being sensually and corporally caught up in a process of learning, the investigator is also in a position to experience the non-propositional knowledge and sensual information that is communicated in training. ${ }^{27}$ Successful application of this mode of inquiry as RRR means that it is necessary to forge a connection between a twenty-first-century enactment of an apprenticeship and the craft described in the historical text that is being studied. Modelling RRR after the apprentice-style method is a way to identify routes along which certain practical knowledge is taught and acquired. Once familiar with these routes, the historian can compare his or her experiences with the historical text itself. It is important to stress that the outcome of RRR bears little to no relation with the historical text at hand in the sense that this method does not culminate in a reproduction or reconstruction of passages described in the text. Instead, having identified routes of learning and acquiring skill in a staged apprenticeship, the historian looks for similar situations in the text itself and evaluates if and how the text deals with

27 Marchand, "Muscles, Morals and Mind”, p. 249; O’Connor, "Embodied knowledge”; Atkinson, "Blowing Hot"; Grasseni, "Skilled vision"; Pink, Doing Sensory Ethnography; Ingold, The Perception of the Environment. 
these critical pedagogical issues. With the apprentice-style method of RRR, the historian thus works in parallel with a text, instead of working directly from the text itself. As a consequence, one should make sure that the performed procedures are historicized to a degree that enables comparison with the procedures described in the text. How this could be done is discussed elaborately in the following sections. For now it suffices to say that some crafts or practices are more suitable than others for apprentice-style methods of RRR simply because they have changed relatively little over the past centuries, which, for instance, is largely true for gold- and silversmithing.

An apprentice-style mode of RRR was employed in the study of the eighteenthcentury Guidebook for gold- and silversmiths (1721), written by the Dutch silversmith Willem van Laer (1674-1722), which I undertook together with metals conservator and practicing silversmith Tonny Beentjes. ${ }^{28}$ After having explored the book to see how we could best approach it, we decided to design RRR as an apprenticeship in which I would learn how to make sand-molds and subsequently cast silver objects using these molds. Tonny taught and showed me the intricacies of the processes and after much practice I gained enough skill and confidence to mold and cast independently, meanwhile obtaining relatively satisfying results. With my failures and struggles fresh in mind and still wary of the problems I had to overcome while learning how to cast, I went back to Willem van Laer's early modern rendition of the casting procedure. Furthermore, I had experienced Tonny's repertoire of didactical approaches firsthand, which helped me to look for comparable instances of didactics in the much older Guidebook. Interestingly, the results of this comparison turned out differently than I expected. Contrary to what is suggested by the Guidebook's comprehensiveness, I found that the text provided very little guidance or assistance at the moments I needed it the most. The knowledge that Van Laer treated most extensively in his Guidebook appeared to be circumstantial when it came to the performance of the actual procedure. ${ }^{29}$ For instance, while Van Laer elaborately discussed the preparation of casting sand for the mold, he did not explain how and in what order the actual mold should be assembled. It was only by placing my apprenticeship experience as a negative over the text, that I was able to identify these explanatory gaps.

I must point out that the special relation between RRR and so-called 'documentary gaps' has previously been noticed by several historians as well as conservators. ${ }^{30}$ While it is commonly recognized that RRR is an excellent way to fill these knowledge gaps, the question remains, however, what these gaps can tell us about the text itself. The great advantage of the apprentice-style

28 Hagendijk, "Learning a Craft from Books".

29 Hagendijk and Beentjes, "Vicissitudes in Soldering".

30 Fors et al., "From the Library to the Laboratory", p. 91. Carlyle et al., "The mechanical response". 
mode of RRR is that it allowed me to identify and analyze these gaps from a didactical perspective and from the position of a novice. One of the gaps that I encountered in this context concerned knowledge about manual choreographies: the orderly sequence in which hand movements can be broken down and are performed..$^{31}$ For example, the lack of a proper description on how to assemble a mold can be understood as such. Another explanatory gap concerned sensory indicators - i.e., material cues or subtle signs indicating progress or the need for action. For instance, the appearance of molten silver can help the novice judge whether the material has the right temperature for casting. It should be noted that the aforementioned gaps are felt specifically in educational contexts. For an experienced silversmith like Tonny, the gaps were not immediately apparent as he, mostly unintentionally, filled in the gaps by anticipating the final object which underscores the dependency of the gaps on the reader and the context of text usage. The apprentice approach thus provides a specific context from which these gaps can be understood.

By inversing my role in the staged apprenticeship, we found out that the explanatory gaps were consistent among novices in general. Once I gained ample experience in molding and casting, Tonny and I started teaching others. Various groups at various occasions were presented with the Guidebook's instructions for molding and casting and were put to work. While working through the text and trying to assemble the mold, it turned out that the novices grappled with very similar issues as I had previously encountered. While some problems were overcome by repeated trial-and-error, others proved more persistent, like the choreographies or the order in which the different pieces of the molds should be put together. ${ }^{32}$ Episodes like this one illustrate that the existence of explanatory gaps is not so much anchored in the idiosyncrasy of the apprentice, but is a rather stable outcome of reading texts within a specific context, regardless of their reader.

Another advantage of the apprentice method is that it provides a fuller view of what education entails - even and especially when it concerns things that fall outside the scope of the text. One could think for instance of the makeshift tools that Tonny used. Without Tonny's parallel education, I would have never encountered the 'rammers' that are instrumental in preparing the molds. Usually nothing more than a heavy brass cylinder, the rammers are used to compact sand in the mold, which is essential to ensure the details of the cast (Figure 1). Van Laer must have used similar tools in his workshop. Yet, the makeshift nature of these tools - they often just lay around - and the self-evident nature of this step in preparing molds, might explain why it never made it to the Guidebook. Yet, 
even though the 'rammer' fell outside the scope of the text, it is still part of the making process in which the text is embedded.

\subsection{Working Directly from a Text. Learning How to Solder}

Sometimes the apprentice-style mode of RRR cannot be used, for example when no expert is available to provide training in historical techniques. Instead of relying on a body of experience parallel to a text, one has to work directly from the text instead. This was the case when Tonny and I continued our work with the Guidebook and decided to study a soldering lamp - i.e., a customized oil lamp - which was described by Van Laer.33 This piece of equipment, accompanied by a blowpipe, was commonly found in historical workshops and laboratories of metalworkers, glassworkers, and (al)chemists and was used to locally apply heat to objects and materials. ${ }^{34}$ A great advantage of the tool was, next to its mobility, that it could supply heat proportionally without having to rely on larger furnaces for every single operation. However, the invention of torches in the nineteenthcentury replaced the use of soldering lamps and blow pipes, turning it into a lost art. That is, a lost art in the Western world, because we later learned that this soldering technique is still practiced in parts of Asia. ${ }^{35}$ In any case, using a soldering lamp and blowpipe was as new to me as it was to an experienced silversmith like Tonny.

Even though the better part of soldering usually happened in the forge, Van Laer presents his soldering lamp so that "the maker won't need to put the entire piece back into the fire for a tiny leak or mistake only." ${ }^{6}$ For a silversmith, putting a soldered piece back into the fire was always risky as the soldered joints could melt again and cause more trouble than initially was the case. The preferable method was to repair a soldered piece without having to expose it again to relatively high temperatures, which is where the soldering lamp comes in. Basically, the soldering lamp resembles a modified oil lamp with an extended snout. To reach temperatures high enough to melt the solder, one had to use a small blowpipe to blow additional air through the flame. Skillful blowing would subsequently result in a second tiny yet powerful blue flame hot enough to locally melt silver. That is, at least, what Van Laer seemed to suggest: "when the tip of the flame of such

33 The following paragraphs were previously featured in the following blog post: Hagendijk and Beentjes, "Vicissitudes in Soldering". The text presented in this dissertation contains a few minor changes.

34 Newman, "Alchemy, Assaying, and Experiment"; Abney Salomon, "The Pocket Laboratory"; Kunckel, Ars Vitraria Experimentalis. Pars Secunda, pp. 66-7.

35 Pollen, "Goldsmiths \& Metalworkers".

36 Van Laer, Weg-wyzer (1721), p. 125. 


\section{Chapter 2}

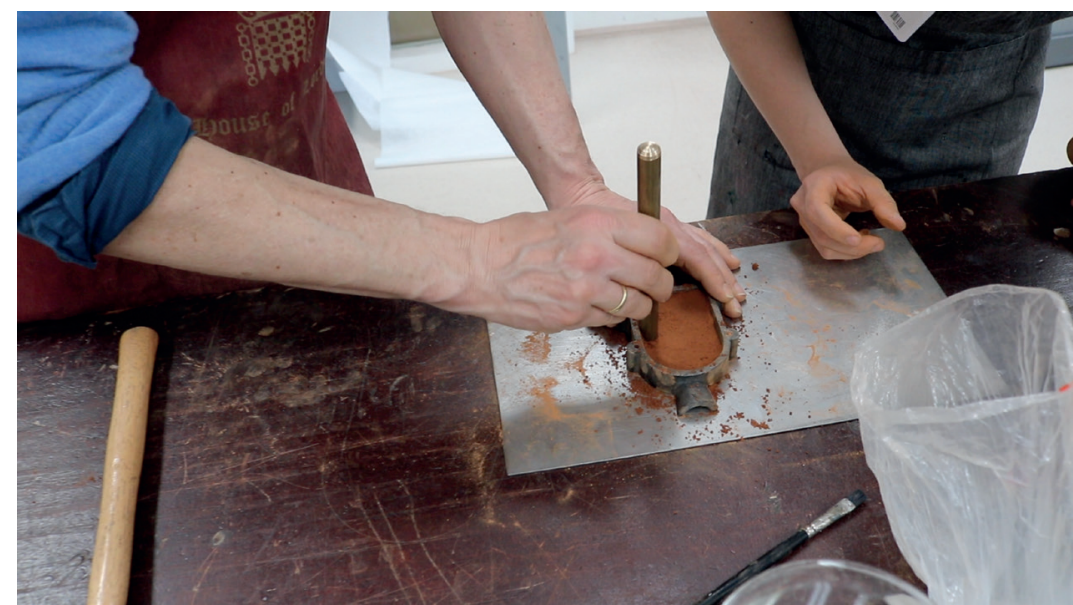

Figure 1: A brass cylinder is used as a rammer to compact the molding sand. This humble tool, despite being essential to ensure fine details in the cast, is not mentioned in Van Laer's Guidebook. Photo: Thijs Hagendijk.

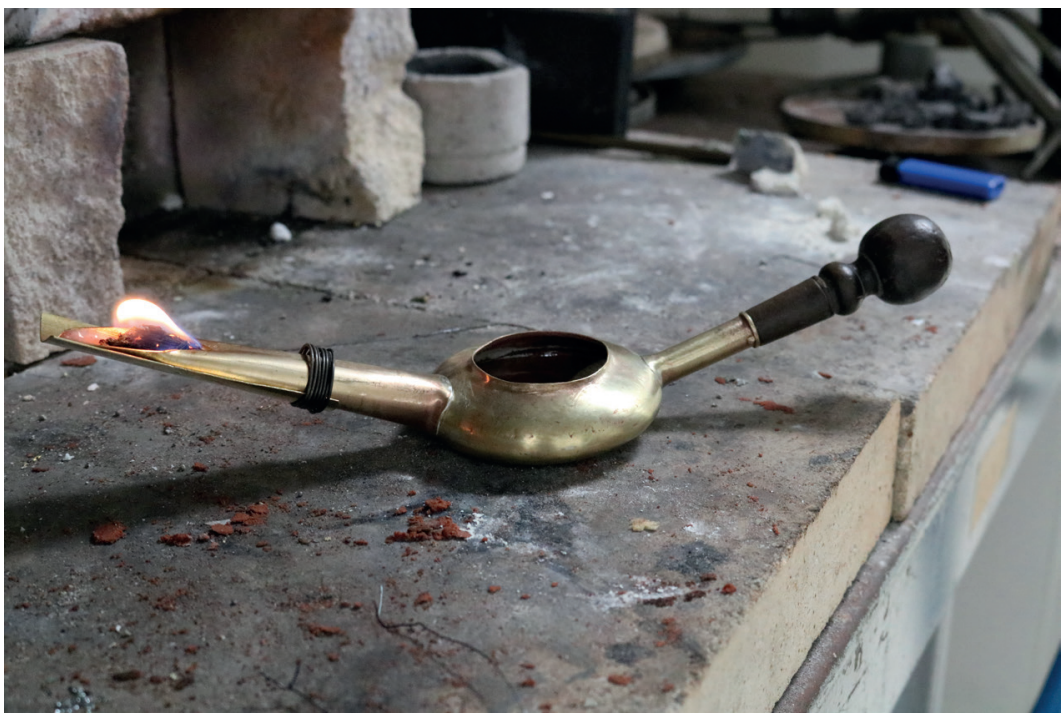

Figure 2: A reproduction of the soldering lamp described in Van Laer's Guidebook. The reservoir in the middle is filled with oil, which subsequently feeds a piece of cotton that runs through its snout. Photo: Thijs Hagendijk. 
a burning Lamp is blown against the spot that needs to be soldered, it makes it hotter over there and the solder will easily run."37

To find out whether we could indeed solder this way, we decided to build a soldering lamp following Van Laer's instructions (Figure 2). Luckily, Van Laer was meticulously detailed with respect to the lamp, discussing its dimensions and the materials needed to produce it. He wrote that the lamp should be made from brass and should measure 3 inches across and 1 inch in height. Additionally, there should be a wooden handle at its back and at the front a snout of about 5 or 6 inches long. To make sure he was well understood, Van Laer also included a schematic engraving of the lamp. We had more than enough information to work with, and based on his drawings and instructions we produced a replica of the lamp. We also laid our hands on a few historical blowpipes. Now that we had the materials, we could learn to handle the tool.

We filled the lamp's reservoir with olive oil and stuffed its snout with a cotton lump. When we finally lit the lamp, the burning oil filled the room with a scent of grilled food. As an initial exercise, we took a small brass strip and tried to heat it until it started to glow (Figure 3). Here is how it proceeded, as recorded in my fieldnotes:

Glowing the metal strip did not happen before we learned our first big lesson. Intuitively, Tonny and I started out by blowing hard through the blowpipe. The more air, the hotter the flame we thought. After trying for quite some time, it seemed as if we weren't making any progress. We could steer the yellow flame, but were not able to get the blue flame where we wanted it. Yet, after I tried some more, it suddenly appeared that I had been blowing way too hard. By blowing rather softly on to the flame, suddenly the little blue flame emerged. In general, the blowing required much exercise. When later that afternoon a visitor dropped by for an interview, we saw the amount of skill that we already acquired. She too tried to produce a blue flame by blowing through the flame, but did not succeed. To my own surprise, I was immediately able to point out what went wrong. The tip of the blowpipe should almost touch the pit of the flame, while one should blow out of the flame, both from beneath and from the inside out. Cheeks filled with air, meanwhile breathing in, breathing out, breathing in, breathing out, filling the cheeks again and keep blowing at the same time. A rhythm occurs in blowing and breathing, which maybe most resembles what happens to your breathing when running. (Fieldnotes Thijs Hagendijk, Amsterdam, April $4^{\text {th }}$, 2017.)

Until this point, then, the story was quite successful. We were able to build the soldering lamp, and, as Van Laer explained, we could reproduce the blue flame. 


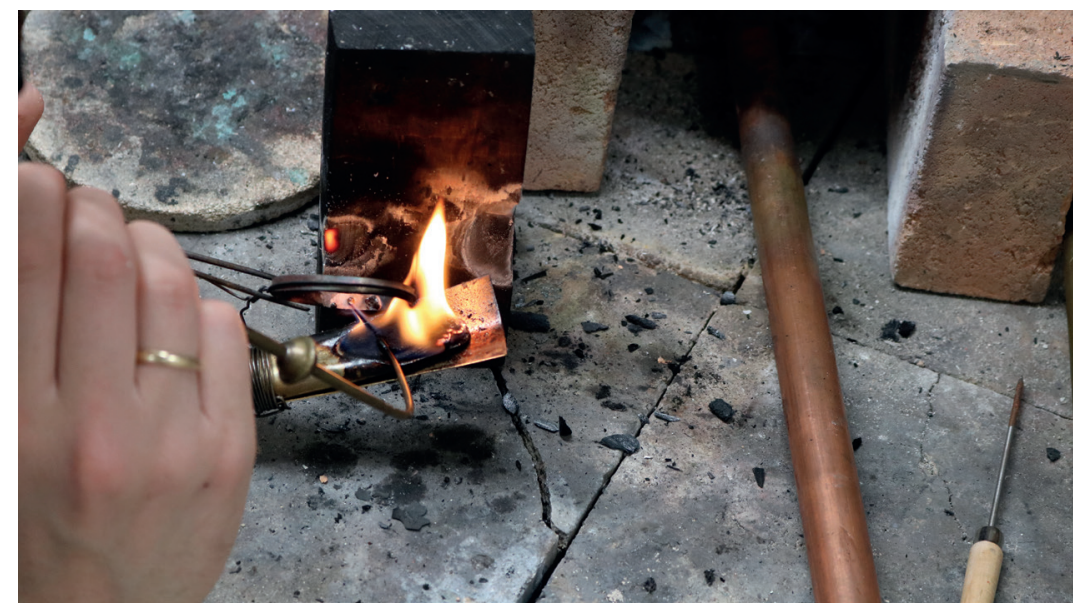

Figure 3: Soldering a brass ring. Note the tiny blue flame. Producing this flame required serious skill and the need to practice circular breathing. Photo: Thijs Hagendijk.

Moreover, the blue flame proved rather hot indeed, as indicated by the different oxidation colors on the brass strip. However, as soon as we tried taking it to the next level, we ran into trouble.

Still happy with the progress we had made, we now wanted to solder a very basic joint. We took another brass strip, hammered it round, and set out to solder its ends together to make a tiny cylinder. We fixed the cylinder in a standing pair of tweezers to free both our hands so we could steer the soldering lamp and hold the blowpipe. A little piece of solder was put on top of the joint, as well as little bit of borax, which is a flux used to facilitate the flow of melted solder. We lit the lamp and started blowing.

One hour later we were so out of breath that we stopped, but the cylinder had not yet been soldered. We had failed. Even though we raised the temperature high enough to make the solder curl up like a drop, we never reached the final state in which it flows out and runs into the joint. Using the soldering lamp appeared less straightforward than we thought it would be. We were curious to know what went wrong, but after several more days of trial-and-error, the list of questions and issues had only grown. We turned to the Guidebook and read and re-read the passages, only to discover that Van Laer was actually quite silent on the matter. Indeed, he carefully described how to assemble the soldering lamp, but spent hardly any time on how to handle it in practice. Should the object be pre-heated, or could the soldering lamp be used on cold objects, too? We blew 
and soldered against a piece of charcoal to create a reverberating heat source, but was this how Van Laer meant the soldering lamp to be used? Moreover, what type of solder should we use? Van Laer listed three distinct recipes for solder with different melting points, but did not indicate which one to use in combination with the soldering lamp. To date, we still have not been able to solder a proper joint using the lamp.

Even though it was difficult to interpret the explanatory gaps that we faced, working with the soldering lamp at least revealed the contours of the skills necessary to successfully operate the soldering lamp. What appeared to be simple blowing when I first read through the procedure in the Guidebook became a skillful art, just by doing. We were able to recognize the importance of this skill because we could significantly vary the amount of the heat by adjusting our blowing. Likewise, we were able to raise a set of very specific questions with respect to the skills and material conditions involved in handling the soldering lamp. These ranged from the melting temperature of different solders, to the types of object and repair that could be managed with the lamp. Even though these questions could not be answered, the act of raising them helped us in reassessing and redistributing the relative priority of passages and remarks in the text. And even without having successfully soldered a simple joint, RRR enabled a provisional overview of the skills, potential issues and workshop practices that were silently carried by the Guidebook.

\subsection{Working in Parallel or Directly from a Text}

The adventure with the soldering lamp illustrates a clear difference between working in parallel or directly from a text. Whereas in molding and casting, Tonny acted as an experienced master craftsman, now we both had to find out how the soldering lamp worked. We started to approach the text by means of trial-and-error; working backwards from the limits and parameters imposed by the book to figure out how the soldering process actually worked. This also meant that the position of a learning novice was no longer tenable. After all, being taught means that you are guided toward good practice, specifically because you do not know how to get there yourself. An instructor is involved who foresees the pitfalls in processes of learning and who tells you right from wrong. Not knowing what to aim for with the soldering lamp meant we felt adrift at times. Working backwards, trying to reconstruct a making process, is not a pedagogical operation and neither could I compare Tonny's didactics with Van Laer's rendition of the same process in the Guidebook.

Whereas both approaches - i.e., the apprentice-style method of inquiry, or working directly from a text - differ in how well they are suited to accessing the pedagogical practices in which a text might have served, both are equally viable means of mapping the skills and techniques that are transmitted, communicated 
and implied by a text. Here too, the way RRR is designed hinges on the questions asked and on how well the resources enable a certain approach. Whereas Van Laer's description of the casting procedure, together with Tonny's expertise, allowed for the perspective of a novice, this was not the case in the other RRR performances I discuss in this dissertation. For instance, reworking glass recipes from Johannes Kunckel's Ars Vitraria Experimentalis (1679) proceeded through a similar investigatory path as was required with the soldering lamp. We had to work our way backwards through the recipes and used trial-and-error to get the recipes to work. The combination of recipes, materials, and tools was new to everyone and there was no expert who could revive the pedagogical context in which these recipes might have functioned. In short, whether one works in parallel or directly from the text, immediately depends on the questions asked, the resources and expertise available, and the nature of the text that is studied through RRR.

\section{Materials and Immaterialism in RRR}

RRR can be employed to bring about a variety of different outcomes or endproducts. These outcomes can be ephemeral or volatile, such as attempts to revive the sound of historical instruments, or material such as the 'model systems' or reconstructions of historical paint layers studied by conservators..$^{38}$ Regardless of the outcome, one always has to go through a process of decision making. What features of historical practices or materials are relevant or irrelevant, crucial or negligible with respect to the question that is being answered through RRR? ${ }^{39}$ The choices vary from materials that are used, to the persons involved, the physical space in which RRR takes place, the scope of the act and the historical sources that are studied - but in principle, this list is endless.

\subsection{Attention to Materials in RRR}

With respect to materials this could mean that scholars go to great lengths to lay their hands on scarcely available natural compounds, which are preferably sourced in ways similar to in the past. The historian of alchemy Lawrence Principe described for example how he undertook an expedition a little south of Bologna, Italy, at the foot of Monte Paderno, to find a specific mineral described in a seventeenth-century alchemical text. ${ }^{\circ}$ Raw materials, rather than processed chemicals, often contain chemical impurities which can play an unexpected

38 Fidom, "Making Musicians Think"; Stols-Witlox, "Imperfect Copies".

39 Hagendijk, "Learning a Craft from Books", p. 215; Stijnman, "Style and Technique are Inseparable", p. 6; Fors et al., "From the Library to the Laboratory", p. 94.

40 Principe, "Chymical Exotica", p. 136. 
yet decisive role when performing an historical experiment. ${ }^{41}$ Similarly, conservators have called for the use of historically appropriate materials in their reconstructions. ${ }^{42}$ For example, lead white, a white pigment, is still commercially available today, but the method by which it is prepared has changed throughout history. White lead produced with nineteenth- and twentieth-century methods has morphological properties that significantly differ from the pigment produced according to the early modern stack processes. To really understand the behavior of lead white in paintings, these differences should be taken into account when performing RRR. ${ }^{43}$ Comparable attention to materials is found in other disciplines as well. Studies in musicology have shown that the constructions of something as volatile as the sound of an organ ultimately rely on very intricate material conditions. For example, an attempt to relearn the skill of organ pipe casting revealed that the sound of the pipe depends on the right proportion of impurities in the metal, the presence of the trace elements and the type of sand used in casting. ${ }^{44}$ In general, there seems to be one rule of thumb with respect to materials that carries validity across disciplines and different approaches of RRR, ranging from experimental archaeology, to history of science. Not every material needs to be authentic, but at least those that are pertinent to the hypothesis under scrutiny should be allowed the opportunity to act during the experiment. ${ }^{45}$ There is no common rule on how materials should be chosen in RRR, instead, these issues should be carefully considered, time and time again, with respect to the question that is under investigation.

\subsection{The Relative Importance of Materials}

Indeed, sometimes the design of RRR is such that the composition or source of materials only plays a minor role or even none at all. For example, when I learned how to cast during my study of the eighteenth-century Guidebook for Gold-and Silversmiths (1721), I practiced with brass instead of silver. Not only is brass cheaper than silver and does it behave similarly when hot, I could substitute silver with brass because I was primarily interested in the skills needed for molding and casting, and these skills would remain the same when switching the two metals. ${ }^{46}$ However, contrary to the unproblematic substitution of metals, the type of casting sand that we used to make the molds, turned out to have a huge impact on the overall success of the casting procedure. Van Laer particularly prescribes the use

41 Principe, “'Chemical Translation'”.

42 Carlyle and Stols-Witlox, "Historically Accurate Reconstructions".

43 Carlyle and Stols-Witlox, "Historically Accurate Reconstructions", pp. 54-5; Stols-Witlox et al., “"To prepare white excellent...”.

44 Kursell and Peters, "Making Sound Present".

45 Outram, "Introduction to Experimental Archaeology", p. 2. Fors et al., "From the Library to the Laboratory", pp. 93-4.

46 In conversation with Tonny Beentjes. 
of so-called ordinary Brussels sand, which needs to undergo a heat-treatment respectively glowing, grinding and washing - before it can be used. We made casts with both treated and untreated Brussels sand and found that the difference between the two was huge. Using untreated sand resulted in an extremely porous object. ${ }^{47}$ In brief, within the confines of one RRR performance different priorities can be assigned to the composition and historicity of each material involved. The decisions to substitute one metal for another and to simultaneously take great care to choose appropriate sand can exist next to each other. Each of these decisions should be made based on the research question that they help to answer and the possible effect that different material integrities have on the outcome of a performance.

\subsection{Modern Chemistry and RRR}

Some attention should also be paid to the role of modern chemistry when working with materials in RRR. Knowledge of chemistry can be of great help, for instance in interpreting a recipe, predicting what might happen, what possible issues could arise along the way, and to take safety measures if necessary. Yet, it also comes with a responsibility. There is the danger of chemical hubris, or what has been called "armchair chemical interpretation", namely, the idea that we are in unique position to tell what historical authors were actually trying to get at, much to their own ignorance. ${ }^{48}$ It is important, therefore, to keep an open mind and to defer chemical reasoning and theorizing in case a RRR-performance takes an unforeseen turn. ${ }^{49}$ For instance, when I, together with two chemists, tried a sixteenth-century recipe as a candidate for classroom reconstructions with chemistry students, we did not expect it to work..$^{50}$ The recipe explained how to silver-plate copper, which ordinarily proceeds through a metal displacement reaction, but instead of prescribing a ready source of necessary silver-ions, the recipe asked for metallic silver and no other ingredients that carried evident silver-dissolving properties. We performed the recipe nonetheless and found out, against our chemical intuition, that it actually worked. This shows that modern chemical theory can get in the way of an open and receptive attitude toward historical instructions and practical texts. However, this does not mean that modern chemistry should be kept away from RRR. On the contrary, once aware of the chemical complexity of an historical procedure, the knowledge and skills of historical actors can be appreciated even more because it readily confronts the performer with possible blind spots in current scientific knowledge..$^{5}$ This

47 Hagendijk, "Learning a Craft from Books”, pp. 234-5.

48 Principe, “Texts and Practices”, p. 160.

49 Principe, "Chymical Exotica”, p. 140.

50 Hagendijk et al. "Reworking Recipes and Experiments"; Piemontese, The Secrets, p. 246.

51 Chang, "How Historical Experiments Can Improve Scientific Knowledge". 
is a point surely missed by those who are less versed in the marvelous world of molecules.

\subsection{In the Absence of Materials}

Other ways to design RRR, this time not involving materials, were explored in workshops I (co)-organized for two different occasions. ${ }^{52}$ The workshops were given in two different contexts - one for Technical Art History students at the University of Amsterdam, the other for a group of international scholars. ${ }^{53}$ Based on early modern recipes for painters' materials, the participants explored "imaginative ethnographies of making processes." They were given recipes found in the manuscript of the Dutch painter Simon Eikelenberg (1663-1738) and asked to draw and visualize the making processes, including the workshop, materials and persons involved, that were implied by these recipes. The sole acts of reading, drawing and thinking through processes of making were already enough to render visible dimensions that had not been articulated in the text, such as choreographies, the itineraries of materials, the availability of tools, the workshop and its spatial organization. Imaginative ethnographies can be insightful because they employ methods of translations, either through drawings or other forms of clarification, which require the performers to actively deepen their awareness and understanding of the topic that is being studied.

Moreover, imagining making processes is often done to prepare for RRR performances that do involve the use of materials at a later stage. Together with glass conservators Márcia Vilarigues and Mario Bandiera from Lisbon, Sven Dupré and I made an attempt to reproduce a seventeenth-century recipe for red-colored rosichiero glass, which was taken from Johann Kunckel's Ars Vitraria Experimentalis (1679). ${ }^{54}$ While the furnace was being stoked to get to the required temperature, we discussed and prepared the samples. I noticed how the entire procedure was already thought through and visualized on paper before the samples came anywhere near the furnace:

While discussing what we are going to do, Márcia is going through the choreographies in advance, already virtually positioning the crucibles in the furnace, thinking about all necessary mixing steps and the time it will take to

52 Another good example of non-material-based RRR is the use $3 \mathrm{D}$ modelling in archaeology. See: Lulof, "Recreating Reconstructions"; Hopkins, The Genesis of Roman Architecture; Fleisher, "Building Medieval Worlds".

53 Workshop "Imaginative Ethnographies of Making (in History)". Learning/Teaching Materials. A Skillshare Workshop. Co-organized with Sven Dupré and Jenny Boulboullé. July 10, 2018. Maastricht, The Netherlands. Workshop "Imaginative Ethnographies" for students of the Technical Art History Program. February 26, 2018. University of Amsterdam, the Netherlands.

54 See chapter "Don't Blame the Text" in this dissertation. 
execute them, meanwhile accounting for the time it will take Mario to get the crucibles out and back into the furnace. (Fieldnotes Thijs Hagendijk, Montemoro-Novo, May 15th, 2019.)

In order to create a choreography, one has to go through and cautiously consider the movements in advance. The dance had to be orchestrated around the furnace - an unforgiving source of heat - which does not allow for big mistakes. Imagining the steps, visualizing them and communicating them with co-workers avoided a lot of trouble once the furnace was opened for real. In brief, thinking through and engaging with historical texts, objects or procedures as if one is working with them in practice helps in freeing up new ideas, to anticipate problems, and to devise crucial strategies, even in the absence of materials.

\section{Ecology in RRR. Materials, Tools and the Environment}

Thinking on materials can also be taken a step further. Another way to approach materials is to understand them as part of a more extensive ecology that embeds an act of making, or, and this is important, the ecology that embeds the performance of RRR. ${ }^{55}$ This ecology is not just a passive witness or a silent decor against which an act of making takes place. Instead, drawing on Tim Ingold's ecological perspective on making, it could be argued that processes of making arise in correspondence with the ecology in which they take place. An act of making could be understood as a "confluence of forces and materials" or a "meshwork"; the coming together of tools, immediate surroundings, materials, persons and all other resources that actively contribute to the becoming of an object. By framing the act of making as a meshwork of acting forces and materials, Ingold does away with a hylomorphic understanding of making, in which the maker or performer is the sole acting entity who forces his/her will onto a passive lump of matter. Indeed, for craftspeople too, it is evident that not only humans act, but that materials respond, that tools afford certain actions and leave traces. When I discussed these issues with Tonny Beentjes, the experienced silversmith with whom I had been casting silver, and asked how he thought about these things, his answer was simple. "Materials are leading." ${ }^{66}$ Take for instance the casting sand, which had to be treated with utmost care and demanded a deep empathy for its properties:

55 Ingold, The Perception of the Environment; Ingold, Being Alive; Ingold, Making. See the introduction of this dissertation for a fuller discussion of the concept of ecology and its application in this dissertation.

56 Hagendijk, "Maken als groeien", p. 6; Auch, "De kennis zit in de handen", p. 25. 
This is really frustrating: that the material does not want to cooperate. It requires precision to moisten the sand. Too moist and it will crumble when you try to press it together. You push the sand on one side, and it will go up on another side. You get some sort offlakes and it will break and tear like a random riverbed in Africa that has been dry for months. Strange?! And then to consider that the sand is actually too moist. Really frustrating, the material seems to have a life of its own and does not obey. You have to surrender yourself. How does that work? Simple: just wait a few hours until the sand has dried a little. But I do not have the time to wait a few hours... (Fieldnotes Thijs Hagendijk, Amsterdam, September 16th, 2016.)

Indeed, not only humans act, but materials respond too, which became painfully evident when the casting sand started to intrude on my schedule. ${ }^{57}$ A master craftsman, but also the historian during an RRR performance, has not always got everything under control and depends on materials, tools, and even the environment, in a great many ways.

The reason for this theoretical detour is that a similar outlook and ecological approach can help to better understand and design performances in RRR, too. One should be aware that the ecology in which the performance is embedded can significantly shape the outcome of a performance. This issue has received little attention in general - laboratories often act as the silent and unquestioned decor against which RRR takes place - but an important exception can be found in the field of experimental archaeology. Alan K. Outram draws a sharp line between laboratory experiments and what he calls 'actualistic' experiments: "One could test many factors about source materials, rendering conditions and end products within the controlled conditions of a laboratory, using sterile glassware and a gas powered heat source [...] However a gulf is left between such laboratory work and how such processes may have been achieved in the past, with a limited range of materials, technologies and a lesser control upon the environment." ${ }^{58}$ It is important to note that Outram does not necessarily favor one type of experiment over another; both laboratory and actualistic experiments can exist next to each other. Instead, his chief issue is to raise awareness of the choices we make when we design and execute an experiment or performance, and to see how these choices impact their outcome. Similar concerns have also been voiced in the field of conservation and restoration..$^{59}$ But what does this mean in practice? The

57 See section "Ecology in RRR" in this chapter.

58 Outram, "Introduction to Experimental Archaeology", p. 2.

59 For example, concerns with respect to downscaling. When reworking historical recipes, conservators often use and prepare samples with significantly less amounts than originally prescribed by the recipe. See: Carlyle, "Practical considerations"; Carlyle, "Historical Accuracy”; Kirby et al., Natural Colorants, p. 87. 
following case study describes what happened when I put this question to the test together with paintings conservator Maartje Stols-Witlox.

\section{Case Study. The Impact of Environment and Tools}

A case study in which we reworked eighteenth-century varnish instructions taught us how a different focus on the ecology significantly influences how a text is interpreted. The varnish recipe of interest came from an eighteenth-century manuscript collection compiled by the Dutch painter Simon Eikelenberg (16631738), which contains notes on his own painting practices as well as those of his colleagues. This particular text on varnish-making - Eikelenberg called it an ervarenis (Dutch for 'experiment' or 'experience') - runs over three pages and narrates how Eikelenberg tried to make varnish on September 30, $1707 .{ }^{60}$ Eikelenberg's vivid descriptions of his varnish-making experience supplied us with ample details to compare with our own experience. We reserved laboratory space for two weeks; bought ingredients; carefully went through Eikelenberg's text and went to work (Figure 4). The photo depicts one of the last steps in the preparation of the varnish. After putting the ingredients (turpentine balsam, turpentine oil and a resin) together, the mixture was heated and finally strained through a cloth. ${ }^{61}$ The photo itself does not only document an event, but harbors a series of methodological issues, too. Let's take a look at some.

(1) I am working in a fume hood. The glass of the fume hood not only acts as a physical barrier that influences the choreography of the work, it also divides the workspace into a safe and unsafe zone. Eikelenberg had no fume hood. (2) The fume hood is connected to a sophisticated ventilation system for practical, health and safety reasons. Although I am glad I did not have to breath the unhealthy varnish fumes, it nonetheless deprived me from fully enjoying sensory experiences, such as smelling the concoction I was brewing. Sensory experiences such as smell were in fact mentioned in the historical texts I worked with. Eikelenberg wrote elsewhere that the "varnishes that smell the least, will also be less sticky". ${ }^{2}$ (3) I worked with two types of gloves. The pair I am wearing was heat resistant, the ones lying on the edge of the fume hood were used to avoid contact with harmful ingredients. In full contrast with current laboratory practices, Eikelenberg mentioned sticking his finger into the mixture

6o See chapter "Unpacking Recipes and Communicating Experience" in this dissertation. Eikelenberg, "Aantekeningen betreffende schilderen", MS 390, fols. $825 \mathrm{ff}$.

61 Turpentine is a balsam obtained from the pine tree. Turpentine oil is the distillation product of this turpentine balsam. Mastic is a resin obtained from the mastic tree. See: Stols-Witlox, "Final Varnishes for Oil Paintings".

62 Eikelenberg, "Aantekeningen betreffende schilderen”, MS. 390, fol. 679. 


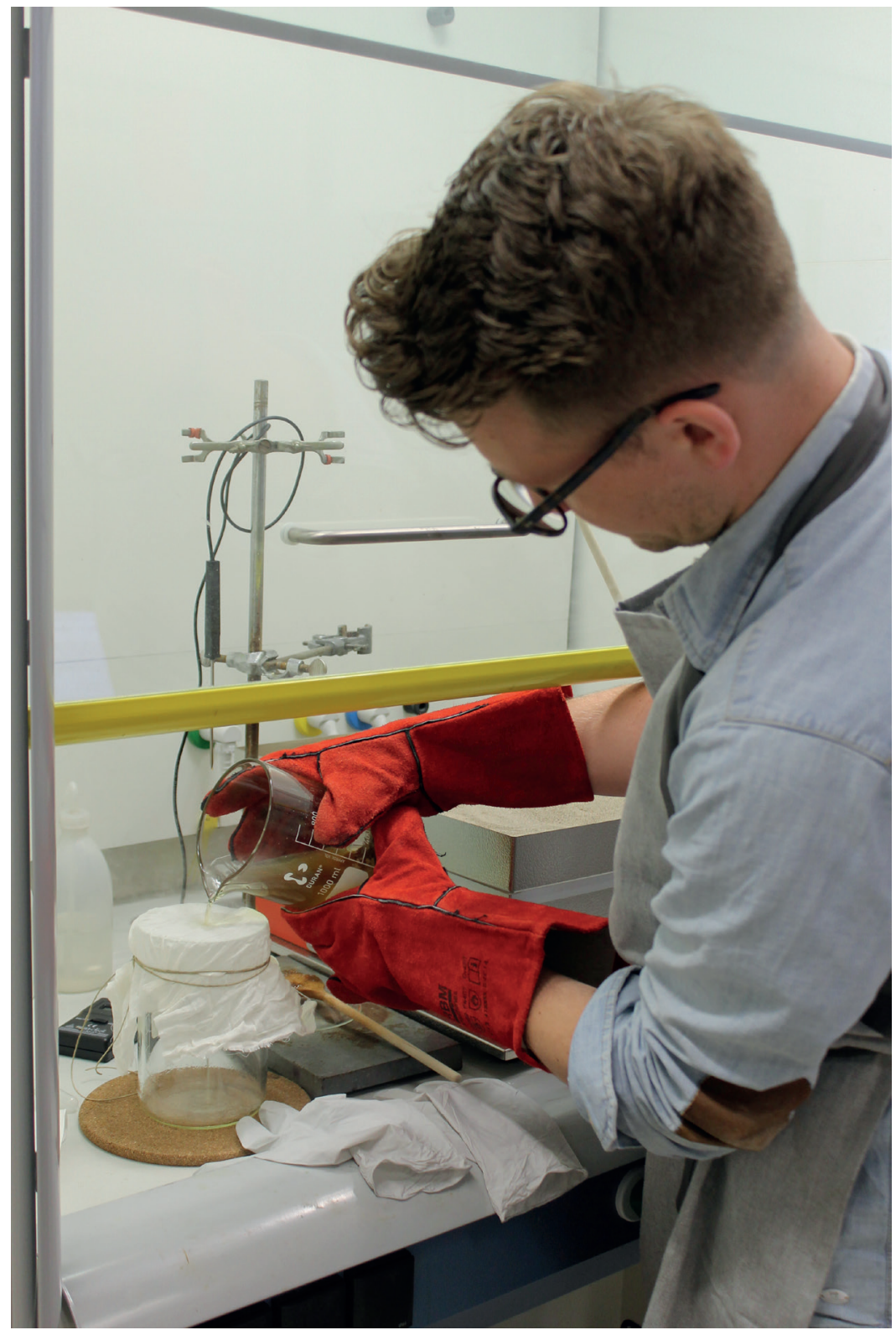

Figure 4: The hot varnish is strained through a cloth. The varnish is prepared in a fume hood, mainly by using modern equipment such as laboratory-grade glassware, a thermometer and an electric sand bath. Photo: Maartje Stols-Witlox. 
to check the temperature of the varnish. ${ }^{63}$ Instead of checking the temperature by sticking fingers into the varnish, we used a temperature probe (the black wire hanging from the retort stand). As a consequence, we did not have to rely on our sensory experience to judge the temperature of the mixture. (4) I am decanting the varnish from one transparent beaker to another. The transparency of the glassware enabled us to closely monitor what goes on in the mixtures and to check for their color, consistency etc. Eikelenberg used earthenware pots, which might give rise to different observations. ${ }^{64}$ (5) Last but not least, in the right corner of the fume hood, just below my right arm, stands an electric sand bath we used to heat the varnish. Eikelenberg, however, prepared his varnishes on a fire. This presented several risks, the most important of which being that the turpentine oil could catch on fire rather easily. (Eikelenberg in fact mentioned this happened once.) Indeed, when browsing through his varnish recipes, his main preoccupation seems to have been how to work safely around the fire, which simultaneously determined much of his choreography.

This list of discrepancies can go on endlessly, and one cannot help but think that historical experimenters are pushing Sisyphus' stone. Indeed, scholars involved with historical experimentation are usually prone to acknowledging that one can 'never walk the streets of the past'. ${ }^{65}$ Still, however much concessions are part of RRR, there might be another reason why sterile laboratories are so persistently present in RRR. Trained respectively as a chemist and a conservator, we have grown accustomed to working in controlled environments to enable successful future reproducibility of the experiments. For a chemist, moreover, whether you use glazed pottery pots, or laboratory-grade glassware usually does not really matter. They are first of all containers, which can be crossedout as a variable. ${ }^{66}$ Let alone that the impact of a fume hood is questioned. We have become so used to working in controllable environments and eliminating variables, that we just might have unlearned to pay proper attention to the ecology of a performance. Yet, even though the environment in a fume hood is less capricious and more predictable than the average backyard, it does remain a valid environment of itself.

What would happen if we repeated the performance, but the second time informed by different choices? What if we not only focused on the materials used by Eikelenberg, but also attended to the tools and the environment in his text? This meant that we replaced the laboratory glassware with earthenware

63 Eikelenberg, "Aantekeningen betreffende schilderen", MS. 39o, fols. 823, 827.

64 Veronesi and Martinón-Torres, "Glass and Alchemy".

65 Fors et al., "From the Library to the Laboratory", p. 92.

66 Questioning the effect of the container can lead to surprising insights. The material of a container could, for instance, influence the boiling temperature of the water that is heated inside. Chang, "How Historical Experiments Can Improve Scientific Knowledge". 


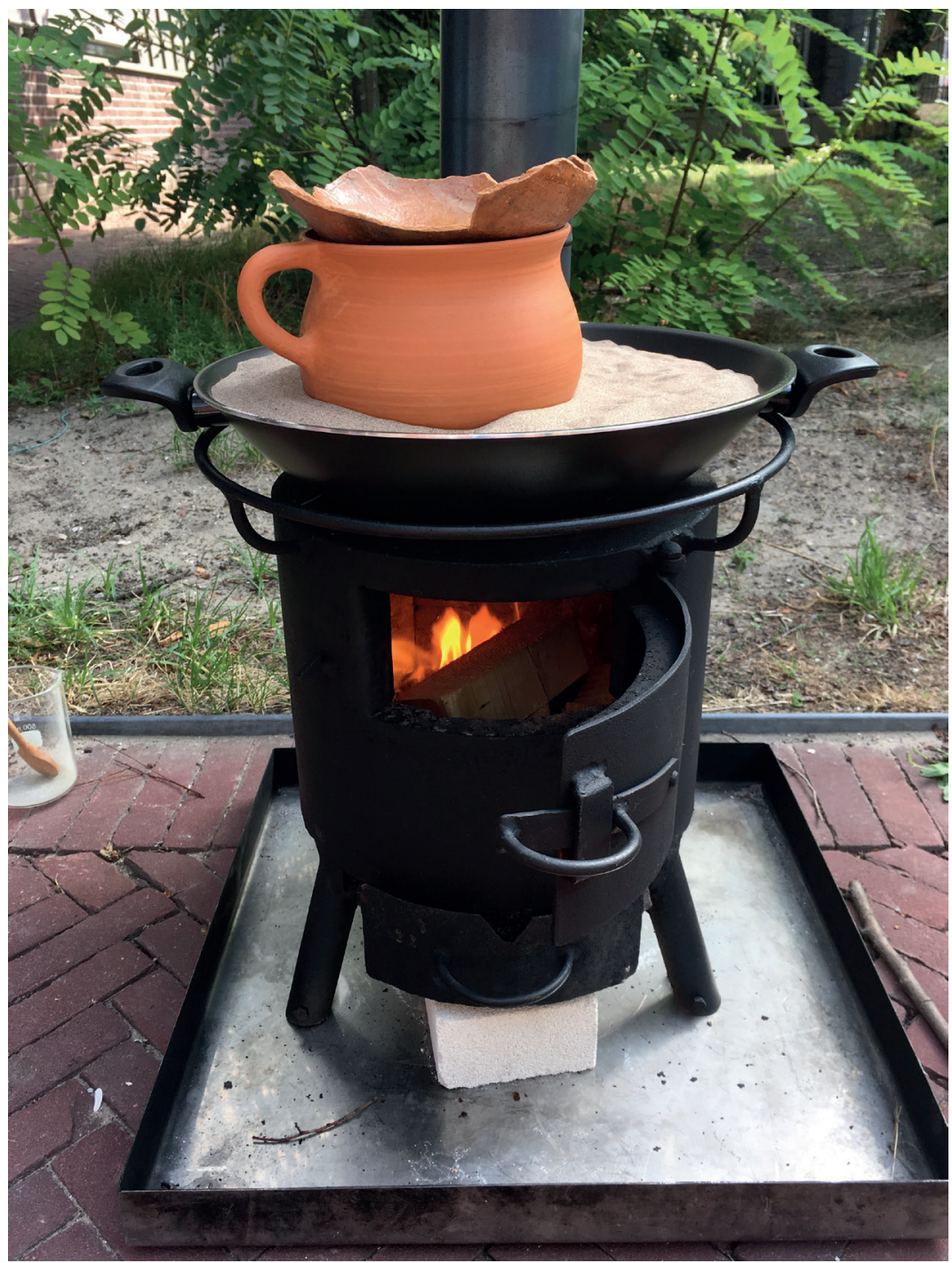

Figure 5: The alternative set-up for the production of varnish, which consists of a wood-fired furnace, a sand bath, and an earthenware pot, all according to Eikelenberg's text. The varnish was produced outside. Photo: Thijs Hagendijk. 
pots like Eikelenberg used in his workshop. We contacted a potter who made replicas of typical early modern pots, which we had covered with the typical lead-glaze of that period. We borrowed a wood-fired furnace, also mentioned by Eikelenberg. And we even went as far as to obtain white sand from the dunes, which Eikelenberg prescribed specifically for a sand-bath on which the pot with varnish had to be placed (Figure 5).

With the second performance, we had a very different experience compared with the first performance in the laboratory. We observed new things that seemed to make more sense in the context of Eikelenberg's text. For instance, whereas we initially assumed that the type of container in which the varnish was prepared would not really matter with respect to the outcomes, we ultimately learned that it did. ${ }^{67}$ While the ingredients were heated on the fire, we saw little cracks appearing on the bottom and the sides of the pot (Figure 6). Meanwhile, a foam emerged that we had not observed during our first performance. As time passed by, the cracks in the pot gradually obtained a darker color, indicating that they were absorbing part of the varnish. Indeed, once the performance was over, we found the pot to be significantly heavier than at the start. Not only might the pot have influenced the composition of the varnish by absorbing part of the liquid - which would not happen in laboratory glassware - at this stage we also began to understand a specific remark that featured twice in Eikelenberg's text. He explicitly described the use of newly glazed pots each time he prepared another varnish. From the perspective of laboratory glassware, Eikelenberg's remarks remained unclear. Only now could we understand that the earthenware pots were only good enough for one cook. ${ }^{68}$

Not only did the second performance elucidate previously unclear remarks, it drastically altered our interpretation, too. Part of Eikelenberg's description concerns a reduction of his varnish. After he tested his concoction, he found it too thin, and decided to heat his varnish again to thicken the mixture. In the end, Eikelenberg claimed that during this process, one fourth of the entire varnish had evaporated, which is a considerable amount. During our first performance in the laboratory, we found that our varnish looked thin too, and so we began heating it again, just as Eikelenberg had done. I remember the process to be painstakingly long. Only gradually did the meniscus seem to come down. I doubted whether we would be able to finish the process before the building would close for the night.

67 Granted, we did consider the possibility that the lead-glaze of the pot might contaminate the varnish. We have not yet done chemical analysis of our varnishes though. (Which speaks to the relative unimportance of the end-products in RRR the way I organized it in this study.)

68 The earthenware pots might also have influenced the consistency of the resulting varnish. If ingredients have been absorbed unequally by the pot, ratios change differently compared to the laboratory glassware. 


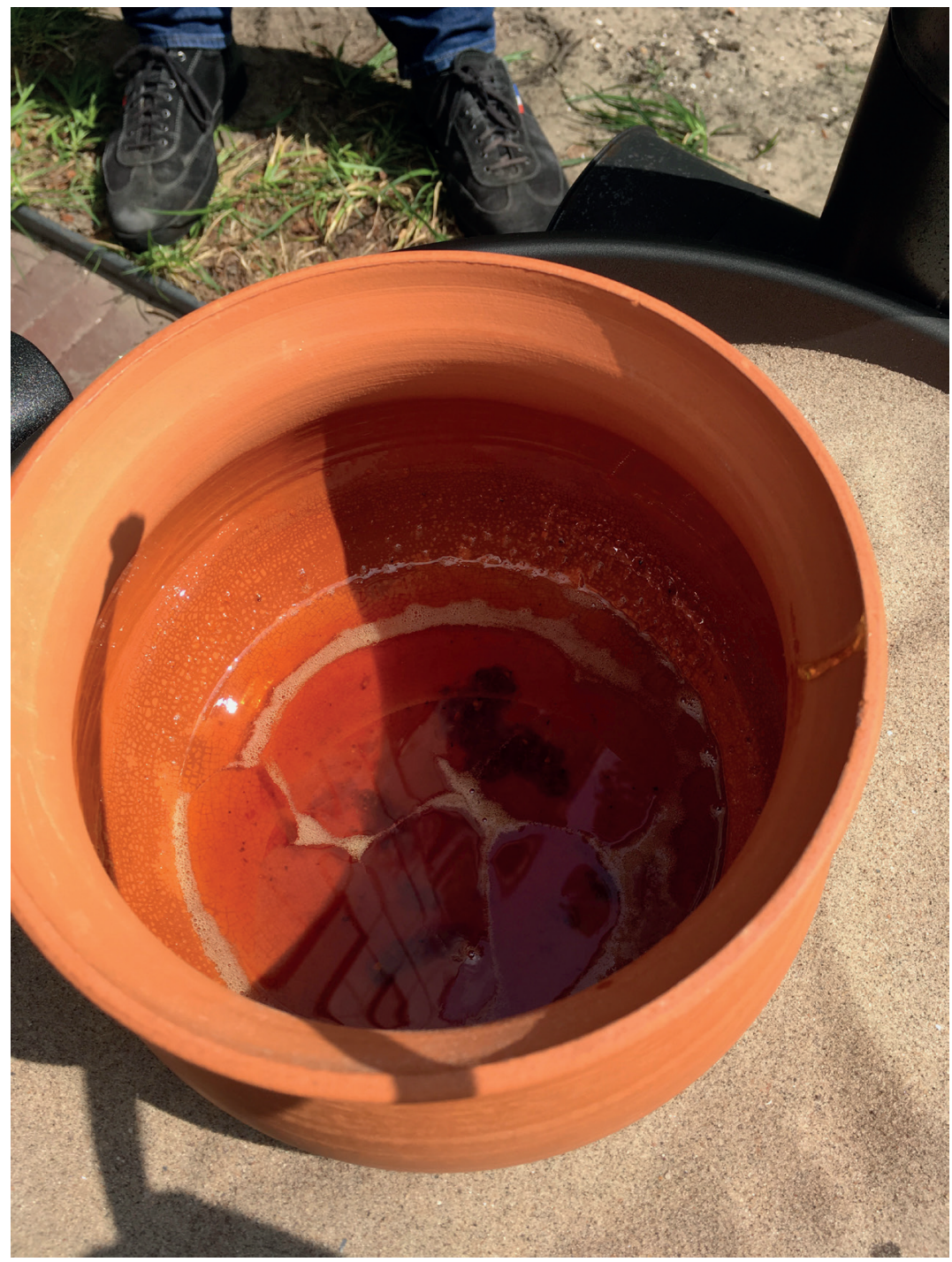

Figure 6: Small cracks appeared in the glaze inside the pot when the varnish was heated. The cracks absorbed part of the varnish. Moreover, a foam appeared on top of the varnish. The cracks and foam were not observed when the experiment was performed using laboratory glassware. Photo: Thijs Hagendijk. 
Meanwhile, I started to think of reasons that might explain how Eikelenberg got to a reduction of one fourth. Maybe a significant part of the varnish would stay behind during the straining step that preceded the reduction? Maybe Eikelenberg had spilled some of the varnish along the way? I even secretly spilled some myself when Maartje was away for a moment. At the end of the afternoon, we had been able to reduce our varnish by a miserable $10 \%$, but meanwhile I was already convinced that Eikelenberg had been stretching his numbers. ${ }^{69}$

The second performance, which we did outside on a wood-fired furnace, proceeded completely differently. ${ }^{70}$ We followed the same procedure as before, and once we started reducing the varnish, I was already mentally preparing for a long afternoon. Wandering off in my mind, and not expecting the varnish to be done within the next couple of hours, I was lucky a third person was involved. Because we worked on an open fire with highly flammable liquids near the Atelier Building, the building's fire inspector had to supervize us. Some 45 minutes after we started with the reduction, the fire inspector suggested that I take a look at the varnish. We were just in time. The very moment I took my first measurement, the varnish had already reduced by a full quarter. Eikelenberg had been right all along.

In retrospect, the difference in time between the two varnish reductions, an entire afternoon compared with 45 minutes, could be explained without much difficulty. First of all, the surface of the liquid exposed to air was significantly larger in the earthenware pot than in the glass beaker we used in the lab. The larger the exposed surface, the faster the evaporation. Moreover, artificial ventilation in the fume-hood would never beat the natural draft we had outside the Atelier Building, which immediately carried away the varnish vapors. Evaporation goes faster when the air is not saturated with the volatile substances emitted by the varnish. Still, even though we now knew how to explain the differences between the two performances, we could have never envisioned what impact the surroundings and tools would actually have on the entire process while we worked on our first performance. The point is that chemistry and physics, and for that matter all preconceived ideas we may have, should not be used to explain and interpret how a performance will work or will probably proceed. Instead, their specific value

69 Moreover, Eikelenberg claimed that he had been stirring the mixture continuously, I think nobody would be able to do that for the entire afternoon. However, 45 minutes would have been less of a problem.

70 I would like to thank Wim Hijdra, the building's fire inspector, for helping us out and for lending us his furnace. 
comes afterwards. Only after the performance has ended can modern theory help in analyzing and explaining the results. ${ }^{71}$

The case study of Eikelenberg's varnish recipe illustrates how surroundings and tools can shape the course of a performance. Even though paying attention to these factors in RRR is still largely in its infancy, there is more evidence suggesting that we should take these factors into account.

\section{A Further Exploration of Tools and Environment in RRR}

\subsection{The Impact of the Environment}

The ability of the environment to shape an RRR performance was also found by Lawrence M. Principe in his study of the historical production of lead white. While reworking an ancient Greek production process for this pigment, Principe found that the environment had a dramatic effect on the success of the outcome. The procedure prescribed the suspension of a piece of lead from a rope above a layer of vinegar in a vessel. With the vessel covered, not sealed, the lead would obtain a white crust - the pigment - over the course of twenty days, which could be scraped off and prepared for painting. When the procedure was tried indoors, in the climate-controlled environment of the laboratory, the reaction would hardly develop and almost no white pigment was formed. Outside, however, the production of the pigment was "rapid and efficient." ${ }^{22}$ The ultimate difference between inside and outside can be ascribed to temperature fluctuations. Outside, as opposed to the laboratory, the vessel was exposed to temperatures that rose during the day and dropped overnight, causing the subsequent evaporation and condensation of vinegar, thus changing the internal pressure in the vessel. This "daily cycle of 'breathing" pushed out the "old" air and sucked in a fresh batch of air, which contained the necessary oxygen and carbon dioxide to feed the reaction. Principe's experience shows how important it is to pay close attention to and to be aware of the surroundings in which a certain historical procedure would have originally taken place. The 'breathing' of the vessel worked best outside, where the pigment was produced in the old days, and not in the artificially controlled laboratory environment. Like the story of Eikelenberg's varnish, the impact of temperature fluctuations was only considered after the process had been performed in two different environments, showing that the effect of the

71 The varnishes that we produced during our experiments were stored and not further used after the experiments had finished. Even though they might serve other investigations or possible future spin-off projects, with respect to our attempt to better understand Eikelenberg's text, their job had already been done.

72 Principe, "Text and Practices", p. 165. 
environment remains difficult to predict. But there is more; similar considerations hold up for historical tools as well.

\subsection{Tools Are Not Inert}

Tools are not always the inert pieces of equipment we take them to be, nor do they necessarily serve a single purpose. ${ }^{73}$ Instead, tools can assume unexpected yet decisive roles in performances of RRR and can be affected by making processes as well. The point can be made with a deceptively simple tool, a mortar and pestle. Of course, the primary purpose of mortars is to grind materials into a powdered state. This, however, does not mean that the tool could be substituted by whatever alternative that gets the job done too. While grinding, mortars give off traces of the material they are composed off. There are several examples in which minute quantities of the material make-up of mortars either prohibit or play a pivotal role in the production of a certain end-product. Using the porcelain laboratory mortars that are common in laboratories can therefore be problematic, precisely because of the absence of certain compounds in their material make-up. ${ }^{74}$ Historical practitioners too were often very aware of these issues and discussed them openly. For example, the author of a sixteenth-century recipe for fake-glass emeralds explicitly prescribed the use of a copper mortar and pestle, and counted on his tools to release small amounts of copper so that the glass obtained a green color. The recipe instructs to pound the ingredients "in a completely copper mortar, \& with a pestle of pure copper, and grind them until they become very fine \& soft powder; this is a sign that they have taken enough of the substance of copper to give them greenness."75 Likewise, as Principe found, when the seventeenth-century chymist Wilhelm Homberg (1652-1715) tried to reproduce a luminous stone (a.k.a. the Bologna Stone) he discovered that it only worked when he prepared the stone using bronze or copper mortars, as opposed to iron mortars. Homberg noted that "the tiny particles of iron that are detached from the mortar ... are undoubtedly the cause of failure." ${ }^{\prime 6}$ The mentioned examples show how mortars and pestles can impact the outcome of a making process beyond the chief purpose they were designed for. They do more than just grinding, which is important to realize, even in cases where historical authors did not mention it.

\subsection{The Case of Furnaces}

Another set of tools which poses potential problems with respect to RRR performances are historical furnaces. Although it might be tempting to mistake

73 Hagendijk, "Rock-paper-scissors".

74 Principe, "Chymical Exotica", pp. 130-2.

75 Making and Knowing Project, "Minimal edition of BnF Ms Fr. 64o", fol. 1oov; Kremnitzer and Shah, "Making Emerald".

76 Wilhelm Homburg in Principe, "Chymical Exotica", pp. 131. 
furnaces for just a random source of heat, uncareful substitution of this tool can have dramatic effects on the making process - not only from a material point of view, but also from the perspective of skill. Furnaces, kilns, forges, and other sources of heat, apart from providing heat, also create atmospheres that can chemically interfere with the objects and materials that are being heated. An important variable with respect to this atmosphere is the amount of oxygen present, which determines how reducing or oxidizing a furnace is. Blast furnaces, for example, which are used to produce metallic iron from its ore, would never get the job done without a reductive atmosphere. Controlling furnace conditions, and deliberately playing with the level of oxidation and reduction is another possibility. When working with wood-fired furnaces, reduction can for instance be achieved by partially blocking the air vents or the chimney so that the draft is limited, or by using green leaves or wet wood which will burn less efficiently. In these cases, oxygen supply is not sufficient to cleanly burn all fuel away, which promotes incomplete combustion of the fuel instead, resulting in black smoke and soot. Doing so, the atmosphere in the furnace is altered and can be exploited to achieve certain effects. For example, archaeometric studies have shown that the typical red and black glosses on ancient Greek Attic pottery were not the result of two different materials - both colors derived from iron-based minerals of a similar chemical make-up - but instead were realized through highly sophisticated fire technologies. ${ }^{77}$ In a first, reductive firing of the vessel, the black gloss was produced. After cooling, the same material was applied for the red gloss, which was brought about under oxidative furnace conditions during a separate and second firing. Another means by which the atmosphere of a furnace can be controlled is by its design. This, for instance, proved to be essential in Principe's study of the luminous Bologna stone. The luminous stone could only be produced with a special furnace, whose vents were deliberately kept small as to limit the supply of oxygen and to promote the formation of carbon monoxide over carbon dioxide. Too much carbon dioxide and the stone would no longer be luminous. ${ }^{78}$ In the following case study, I present more evidence to show how furnaces can shape and steer the reproduction of an historical glass recipe in different directions.

\section{Case Study. Chasing the Impact of Furnaces}

In the course of our attempts to reproduce the red rosichiero glass described in Kunckel's Ars Vitraria Experimentalis, we used two wood-fired furnaces to

77 Walton et al., "Characterization of Coral Red Slips".

78 Principe, "Chymical Exotica". 
replicate a single glass recipe. ${ }^{79}$ The designs of the furnaces differed from one another. The first furnace, in Montemor-o-Novo, rural Portugal, was a vertically built furnace, primarily used to fire ceramics (Figure 7). The second furnace in Villa Borg, Germany, was a reconstructed Roman glass furnace which featured a horizontal layout (Figure 8). The ingredients for the glass, as well as the amounts and the crucibles that we used were kept the same in both situations. When we compared the final results when the experiments were finished, we found differences between the glasses that could only be explained by the furnaces. Both furnaces had produced glass that contained metallic lead and tin. A calcined lead-tin alloy was one of the ingredients for the glass, which, under ideal circumstances, would be fully incorporated into the glass. This obviously did not happen. But rather than being stuck with a failed experiment, the failed glass did tell us something interesting and important about the furnace conditions. Not only had the furnaces been so reductive that the calcined lead and tin were reduced back into their metallic form, the fact that we had more metallic parts in the glass from the Roman furnace at Villa Borg indicated that the atmosphere in this furnace had been more reducing than in the Montemor-o-Novo furnace. When, later on, the glass was replicated ceteris paribus in an electric kiln at the glass studios of the VICARTE research unit at NOVA university, Lisbon, no metallic parts were found at all (Figure 9). Once again, we had stumbled across different furnace conditions, which, in the case of the electric kiln, were far less reducing than in the other furnaces. It would be impossible to know what furnace conditions would best resemble the seventeenth-century circumstances under which Kunckel might have produced the glass. Like the mortar and pestle story, the point is rather that furnaces and kilns do much more than simply heating. Substituting one heat source for another can significantly impact the outcome of a performance, but it remains difficult to predict if and how this happens. Even though in all mentioned examples it has been clarified how certain tools and surroundings shape the outcome of RRR performances, one should realize that these effects have all been clarified in hindsight and cannot be reckoned with in advance, before a performance has actually taken place.

What kind of tools are used in RRR performances also matters when trying to asses, identify and appreciate the skills involved in making processes. To come back to furnaces: working with wood-fired furnaces is very different from flipping the switch of an electric kiln. Using the tools appropriate to a historical recipe and working in an 'actualistic' environment could change the perception on what issues really matter in an historical text and which are of secondary importance. For example, during our attempts to reproduce the rosichiero glass from Kunckel's Ars Vitraria Experimentalis, we learned that making glass was not all about 


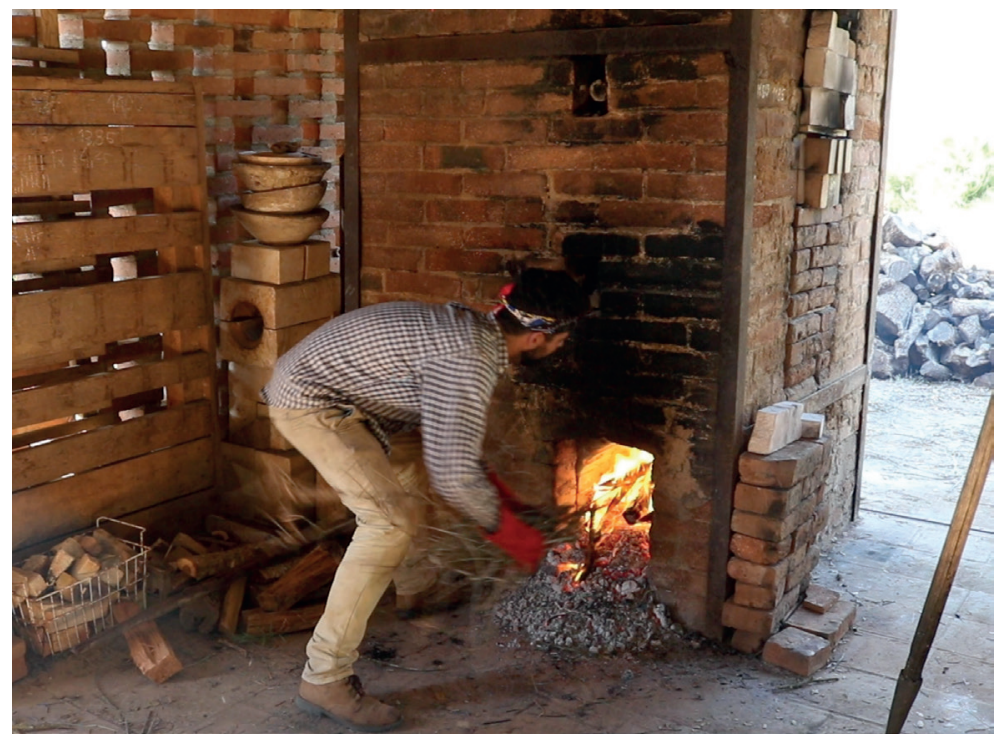

Figure 7: The wood-fired furnace in Montemor-o-Novo, Portugal. This furnace is built vertically, meaning that the fire is stoked below and the flames are led to a second compartment on top, where the glass samples are heated. Note the smoke. Compare with Figure 18. Photo: Thijs Hagendijk

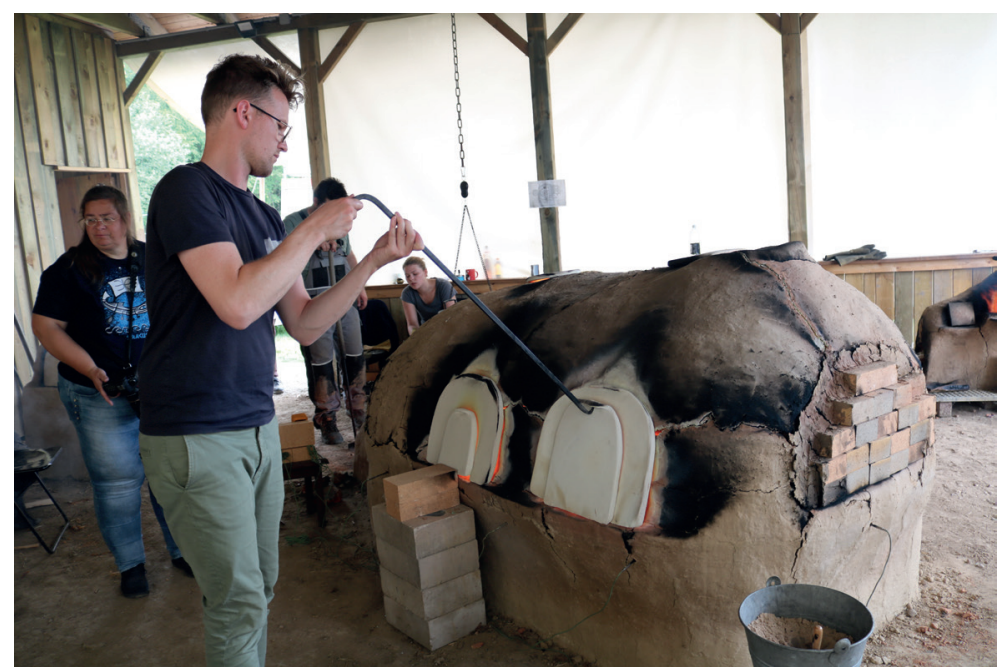

Figure 8: The wood-fired furnace at Villa Borg, Germany. This reconstruction of a Roman glass furnace has a horizontal design. The fire is stoked at the far end (not visible) and the flames are led through the structure, over the crucibles with the molten glass, towards the chimney hole on top, which sits right above the door that I am about to open. All glass samples are positioned directly behind the door openings at both sides of the furnace. Compare with Figure 19. Photo: Sven Dupré. 


\section{Chapter 2}

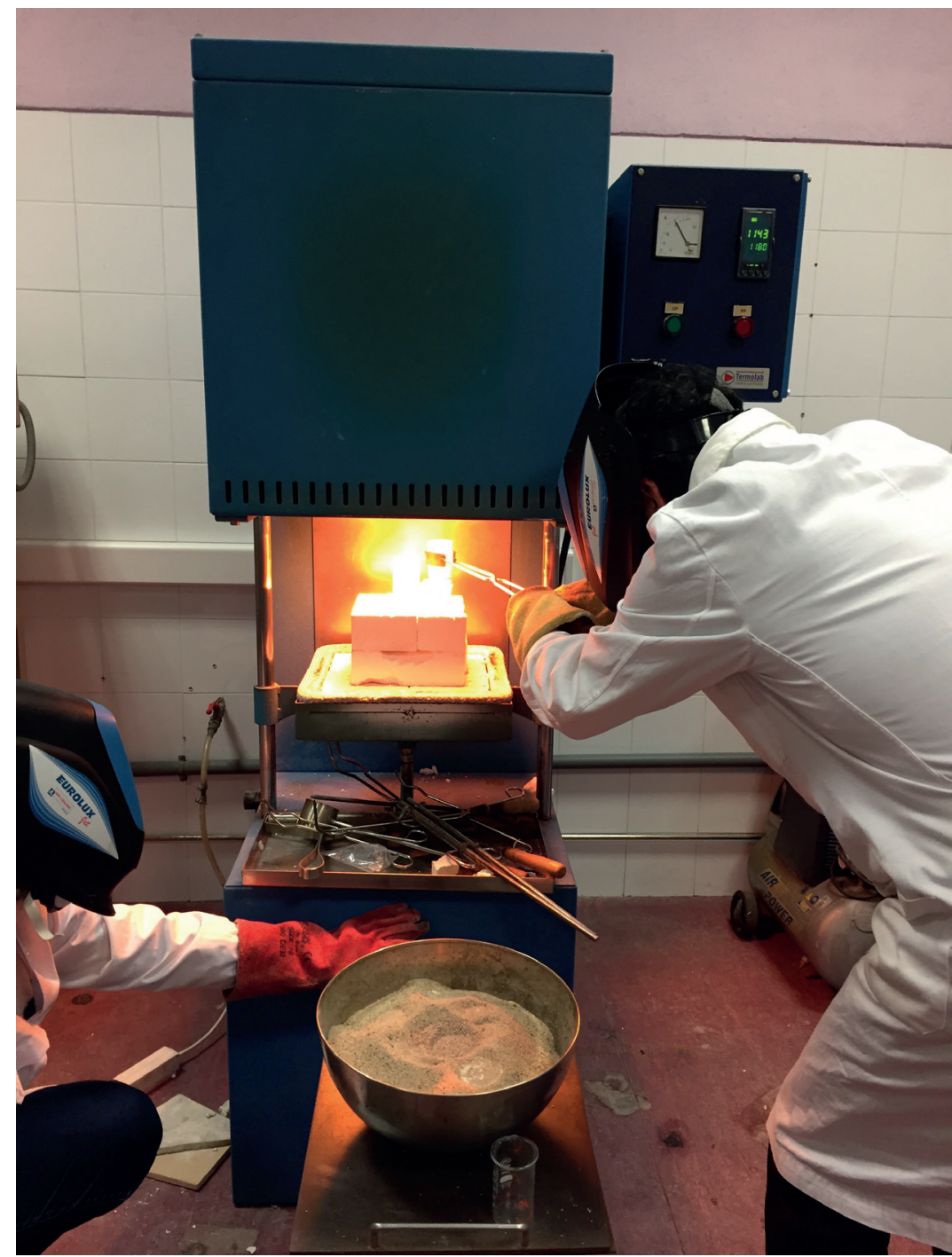

Figure 9: One of the two electric kilns at the VICARTE glass studios in Lisbon. The chemical atmosphere in this kiln was less reducing than the atmospheres in both wood-fired furnaces. Another difference was in the skills necessary to operate the kiln. Attached to its right side is the control panel, which automatically executes a plotted temperature course. The kiln runs at the flick of a switch. Compare with the kiln in Figure 17. Photo: Thijs Hagendijk. 
mixing the right ingredients, but that reworking the recipe and the resulting glass succeeds or fails with the ability to manage the fire in which the glass is made. This also meant that we began to see the fire-related comments in the recipes in a new light by assigning them more priority than we had done initially. Still, we only became aware of the importance of fire-management skills when we switched furnaces between the experiments. Our first attempt at reworking the glass recipe was done in the glass studios of the VICARTE research unit. We had an electric kiln at our disposal, the temperature course of which could be programmed in advance. A consequence of a kiln that requires minimal attention while running is that other issues receive relatively more attention. This meant that at the VICARTE studios most of our attention was paid to the preparation of the materials, understanding their chemistry and finding out what roles the ingredients played in the production of red glass. When a few months later, we moved to the ceramics workshop in Montemor-o-Novo, these questions did not lose their importance, but were no longer the only thing to consider. Next to preparing and measuring the right ingredients, we now had to stoke a fire to heat the furnace, raise the temperature to about 1100 degrees Celsius and keep it steady. Meanwhile, we were learning to 'read' the furnace. Even though we used an infrared thermometer - a pistol-like apparatus that only needs to be pointed in the right direction - we were very aware that historical glassmakers did not have this luxury. Obtaining and maintaining the appropriate temperature of the furnace was achieved by looking inside and judging its color, which ranges from dark orange for the lower temperatures to brighter yellow for the higher temperatures. Operating a furnace, raising the temperature to a certain level and keeping it there, all depart from the ability to discriminate between these different shades of orange. This ability, that was never mentioned in the recipes we worked with, turned out to be an essential skill in the production of glass, nonetheless. It also made us reconsider seemingly casual comments and remarks that we encountered in the historical sources we used. Kunckel, in his commentary on one of the glass recipes, warned for instance that the color of the glass would turn out differently "if the Fire is even a little too Strong". ${ }^{\circ}$ While we worked with the electric kiln at the VICARTE glass studios, this potential problem could simply be avoided by determining and setting the right temperature while the automatic thermoregulator took care of the rest. Yet, when working with wood-fired furnaces, this brief warning suddenly became a source of new problems. How do you minimize temperature fluctuations and avoid sudden increases in heat? Could you even differentiate between the different shades of orange that indicate when a furnace has the right temperature or when the fire becomes too strong? We began to see that Kunckel's comments such as "one should just attend to the fire," or "the

8o Kunckel, Ars Vitraria Experimentalis, p. 194. 
Fire is the Principle thing to observe" were perhaps among the most important instructions provided by the texts. ${ }^{81}$ They described a shift in perspective that we had gradually come to recognize during our experiments. At first, our attention had almost exclusively been devoted to the material components of glassmaking, but as soon as we switched to the wood-fired furnaces, our main occupation became the fire, thereby affecting how we interpreted Kunckel's text. What tools we use and how we use them in RRR, thus not only shapes the final products that they help create, but also carries repercussions for how we read and understand a text.

\section{The Social and Affective Sides of RRR}

One part of RRR that has not been discussed so far concerns its ability to evoke appreciative reactions and emotive responses. Not only do I vividly remember the moments of sheer joy and satisfaction, when, after a day of metal casting, I returned home and realized that I had learned how to make something with my very own hands, less positive, but equally insightful reactions were the moments of uneasiness and awkwardness. Materials run out of control. Others correct you. You feel clumsy or ask the wrong questions - not even knowing how to properly name that tool that you need. Indeed, RRR is pre-eminently subjective and revolves around the sensual experience of the performer, more so than any other historical methodology. Still, even though attention paid to RRR as a methodology has increased over the past decades, less attention has been devoted to its affective side. An important exception is found in educational contexts, specifically in the history of science, where RRR is employed to acquaint students with the material and experimental dimensions of the past. Hasok Chang, for instance, noted that experiments often trigger a 'natural curiosity', 'sense of wonder' and 'excitement' that leads to new questions and follow-up experiments. ${ }^{82}$ The same applies to RRR performances and historical experiments, which in Chang's words "are not immune to this drive of curiosity, and it would be unnatural to restrain our desire to learn." ${ }^{3}$ Similarly, other practitioners of RRR in the classroom have noted the "deep satisfaction" that historical experiments bring about, while the students' learning becomes "joyful and resilient." ${ }^{4}$ Indeed, in pedagogical contexts, it is well known that RRR is an effective way to spice up the classroom. Students become emotionally invested and learning processes become personal,

81 Idem, pp. 193-4.

82 Chang, "How Historical Experiments Can Improve Scientific Knowledge", pp. 320, 337.

83 Idem, p. 321.

84 Crawford, "A critique of curriculum reform", p. 207; Cavicchi, "Faraday and Piaget", p. 91. Both cited in Chang, "How Historical Experiments", p. 321. 
enabling historical topics to attain a sense of urgency that is harder to achieve when merely reading about them. Similar dynamics, however, are less visible in non-pedagogical accounts of RRR. In this section, I want to argue that affective responses during a performance can be surprisingly insightful. They help expose unarticulated assumptions and often lay bare expectations that unknowingly govern a performance.

This idea has most currency in the fields of anthropology and sociology. Indeed, trouble, disruption, unfamiliarity and alienation are often valued as means to access and question the often implicit codes and norms that are inherent to cultures in general, but also to question the perspective through which the investigator perceives the world around. ${ }^{85}$ For example, Stefan Hirschauer has warned that ethnographical studies frequently "suffer from a lack of distortion" and argues that "the most powerful recourse for dealing with things taken for granted ... is the unfamiliarity of the observer." ${ }^{86}$ Indeed, "playing with the familiar and the strange" is an often-seen anthropological technique, which was also employed by the performers of a methodologically-inspiring fingereating experiment. ${ }^{87}$ In this experiment, as reported by Anna Mol et al., four finger-eating experts taught three novices how to eat with their hands over the course of a hot meal. As the finger eating ethnographers noted, exploring the familiar and the strange can take a more extreme form in the way of so-called breaching experiments in which social crises are created by openly displaying disruptive behavior as to expose and study the fabric of social practices and expectancies. ${ }^{88}$ A less disruptive method is the staged experiment, which was preferred by the finger-eating group. Pointing at laboratory experiments, they shared the ideal of carefully organizing an event, in which "reality may be afforded to act." Contrary, however, to laboratory experiments, the ethnographers did little to fix the experiments in terms of a limited set of variables, and neither did they withdraw themselves as subjects from the process. Instead, they allowed themselves to be shaped by the experiment and focused on what emerged. ${ }^{89}$ Doing so, the ethnographers came across a spectrum of appreciative reactions that arose during the shared finger eating experiment, ranging from satisfaction to embarrassment and erotic titillation. Moreover, they found themselves in a situation in which the line between "being a researcher-subject" and "being an object of research" became blurry..$^{\circ}$

85 For an extremely well-written and compelling overview, see Benschop, De eland is een eigenwijs dier.

86 Hirschauer, "Putting things into words", pp. 438, 433.

87 Mann et al., "Mixing methods, tasting fingers", p. 227.

88 See Harold Garfinkel, who developed the notion of breaching experiments: Garfinkel, "Studies of the Routine Grounds of Everyday Activities".

89 Mann et al., "Mixing methods, tasting fingers", p. 226.

90 Idem, p. 224. 
It is worthwhile to highlight the similarities that exist between the fingereating experiments and the RRR performances as discussed in this chapter. An RRR performance, whether it concerns re-enacting historical silver casting procedures or reworking a historical varnish recipe, could be interpreted as a staged experiment too. An RRR performance can be considered a carefully designed event, during which materials, performers and tools are allowed to act without much further restriction. However, whereas the previous sections have mainly addressed RRR performances in relation to the material and historical knowledge they help produce, the performances often have a socially significant side too. A comparison between the finger-eating experiment and RRR performances allows us to further explore and articulate the social and affective sides of RRR performances. I will provide two examples.

First. What does it mean to be an expert? What the finger-eating ethnographers demonstrated is that teaching novices how to eat with their fingers was far from one-way traffic. The experts too were affected by the experiment. Once dinner had finished, finger-eating had fundamentally changed for everyone and "would never be the same again."91 Not only were the experts pushed to articulate hitherto tacit knowledge, it also appeared that the roles of experts and novices were tied up to expectations and assumptions they had about one another, which proved to be wrong at times. For instance, the finger-eating expert who prepared the food refrained from making it as spicy as usual, afraid that the novices who were not accustomed to the same dishes would have little resistance to chilies. The experts had not reckoned with the one novice who, by proudly adding additional spicy pickles to her plate, proved them wrong. A similar play on expectations and the role of expertise happened during our attempt to rework Eikelenberg's varnish. It took a fire inspector, a third party, to point out that the varnish was almost done. Not only was I surprised by this quick turn of events - I had been preparing for a long afternoon, assuming that it would take as long for the varnish to be ready as it had taken when we prepared it the first time - I was also confronted with the fact that I had neglected my duty to keep track of what was happening to the varnish. I had been killing time, apparently not even deigning to check the varnish with the frequency that it required. My curbed expectations had not only gotten the better of me, but also of my interpretation of Eikelenberg's text. Of itself, this was already a painful realization, but the awkwardness of this situation was underlined once more by raising questions about who is considered expert and who is not. At the moment the fire inspector intervened, the social relations were reshuffled. Maartje and I were no longer the sole experts, owners and visionaries of an experiment, but became co-producers in an experiment whose success hinged on the unanticipated but pivotal intervention of the fire inspector. Similar 
to the finger-eating experiment, appreciative reactions signaled when the line between the familiar and the strange was transgressed and expectations no longer held up. Both the proudness of the novice, who contrary to the expectations of the experts was able to withstand spicy food, and the awkwardness I experienced when the fire inspector corrected me on something I considered myself expert, demonstrate that during a performance the distribution of different roles, as well as the expectations that come with it, is not fixed but fluid instead.

The question about expertise can be further specified with a second example that derives from our glassmaking efforts in Montemor-o-Novo:

A big lesson I learned over the past few days was that working the glass furnace was not only fun - as I expected of course - but turned out to be very serious and hard work. Being three days in a row in a shed full of smoke, having stingy eyes, sweating, dragging wood and poking fires is really tiring and not necessarily a good way to contemplate on materials and their transformation. It would take almost 4-5 hours to get to the desired temperature, and the closer we got, the harder we had to work to raise the temperature just a little more - up to a point that we started cursing at the bloody furnace. Again, craft is not necessarily as peaceful as some people tend to think. There is a radical difference between philosophizing with your hands and burning them on a furnace, which I learned the hard way. (Fieldnotes Thijs Hagendijk, Montemor-o-Novo, May 16th, 2019.)

It was during the frustrating and exhausting efforts to raise the temperature in the furnace that once again the distribution of expertise was questioned. Despite our previous work on the glass recipes and the glassmaking experience we obtained while working with the electric kiln at the VICARTE studios in Lisbon, we learned that expertise was highly specific and not as universally applicable as we had hoped. To put it differently, our previous experience in the glass studios did not translate into mastery of similar recipes at a different glass making site. Much like the fire inspector in the previous example, it was the local ceramics expert who assumed a pivotal role during the experiments without which we would have evidently failed. Yes, it was our project that we were pursuing. Moreover, we had already gained experience with the recipes and knew them almost by heart. The local ceramics expert, on the contrary, had never seen our recipes up close. Yet, he singlehandedly overturned the roles and became the prime expert, leaving us in his wake as his novices. He put us to work, not the other way around. He told us to go the extra mile, stoking the furnace a little hotter, regardless of the crazy temperatures outside. The frustration endured while we stoked the furnace was a play on the expectations with which I embarked on the adventure. I expected the glassmaking to be a fun and interesting exercise, but this changed over the course of three days. "Indeed, it's not much fun anymore. Too hot and dizzy from 
the smoke. The smell in the building is actually terrible. No more barbecues for the next months" (Fieldnotes Thijs Hagendijk, Montemor-o-Novo, May 15th, 2019.)

Both examples - the intervention of the fire inspector and the demanding furnace in Portugal - demonstrate how the performance of RRR does not leave the historian untouched. Indeed, to walk onto the stage of your own experiment means that you are affected as well. As the finger-eating ethnographers found, expectations can change, control can be lost, social roles get mixed up and expertise can be overturned. However, while it is clear that RRR performances can be highly social events, the question remains how the social dynamics of a performance might impact the understanding of a text. It is clear that RRR provides a unique opportunity to enact interpretations of texts, to perform them and to bring them to life. But when others are involved - e.g., experts, historians, conservators and fire inspectors - this enactment does not stop at the material world with its responsive materials, tools and surroundings; it extends to the social domain too. The interpretation of a text - with all its inevitable assumptions, unarticulated expectations, and unforeseen problems - is no longer a personal affair, but starts to feed the social relations and interactions during the performance. A collaborative performance means that others can run with an interpretation, interfere with it, and push it in unanticipated directions, which leads to surprising, awkward or frustrating situations. The awkwardness felt when the fire inspector had to remind me of the varnish, was, while emerging in a social context, a direct consequence of my flawed interpretation of Eikelenberg's text. The interpretation of a text thus becomes a social affair and lets itself be felt. This is a great advantage of designing RRR as a collaborative performance. The involvement of multiple individuals indeed puts a lot of knowledge and expertise on the table, but more importantly than that, it means that a text can resonate, not only on the material front, but also in the social sphere. It opens up yet another dimension to the interpretation, while the appreciative reactions that arise during the performance help to detect flaws in interpretations, identify unforeseen problems, and reveal new perspectives. This is not a plea to turn RRR performances into socially awkward events. What I do want to argue, however, is that social dynamics and affective responses during a performance can be surprisingly insightful, even when it comes to how we read a text - and even when the performance is historical, and not anthropological in nature.

\section{Conclusion}

How do you study texts that primarily deal with practical knowledge and instruct readers on how to make something with their hands? The premise of this chapter was to show how RRR can be shaped and employed as a method to 
help in answering this question. I have presented an anthology of choices and decisions that I made while designing my RRR performances. A fundamental design principle is that RRR should create the circumstances under which an historian can fully engage with a text and its instructions without being restricted by a limited set of variables or the need to produce the best possible results. Given that the text itself is the primary object of study, the ultimate aim is to see where the text takes you. This also means that historical practical texts are not read as technical blueprints, nor as the passive documentation of past materials and objects. If anything, these texts are testaments to the authors' struggles to articulate practical experience and know-how, and it is these very struggles that are revived once the text is read and put into practice. Understanding how a text shapes the pedagogical conditions necessary to teach and acquire artisanal practices or techniques means that RRR should create the right circumstances under which these conditions can be explored. RRR can be designed such that it helps to uncover the skills, the surroundings, materials and tools, choreographies, persons and knowledge that all come together in the making process that is communicated in the text. This takes the form of a staged experiment, not one in which all resources, materials, persons, tools and surroundings are broken down into independent and controlled variables, but one in which these resources are allowed to act in correspondence with one another, thus giving rise to new and unforeseen situations. Moreover, the historian enters onto this stage, not as the omniscient director of the performance, but rather as the subject of his own experiment. In this way, RRR creates the circumstances that help us align with our historical actors and train us to see the things and problems that they might have encountered. Seeing a text from the perspective of historical readers, novices or otherwise, and in the light of the resources that would have surrounded them, enables the historian to experience and find explanatory gaps in a text, to struggle with instructions, and to find out how remarks and directions gradually fall into place with the accumulation of practice. It is an attempt at cross-temporal empathy, an attempt to see with the eyes of the historical other, and an attempt to understand those things to which they might have been attentive.

It is worth pointing out that successful reproduction of the RRR performances that are discussed in this dissertation is difficult. This deserves some explanation, especially in the light of the current replication crisis that has been identified as a growing problem in academia. ${ }^{22}$ There are two main reasons why RRR in this dissertation was not designed with an eye to future reproduction. First of all, I chose to investigate instructive texts as part of the ecology in which making processes take place. This meant that, rather than eliminating variables to

92 For a recent and insightful discussion of replicability in the humanities, see: Peels, "Replicability and replication". 
guarantee a controlled experiment and outcome, I deliberately left open the door for possible and hitherto unconsidered factors of importance that could shape the course of a performance. Second, and more importantly, RRR is a tool that creates a higher awareness and helps the historian to adjust his/her eyes to the past. As such, RRR has the ability to counter expectations, to enrich interpretations, and to provide impressions of how texts might have been embedded in practices of making. This, however, hinges on what the historian brings to the performance in the first place. The uncontrolled proliferation of variables, and the historian as his/her own subject, are precisely those things that would hinder successful future reproduction. Yet, in the context of this dissertation, they simultaneously opened up new perspectives that would have remained invisible otherwise.

In the end, the added value of using RRR is determined by how good a job it does in answering a research question. The unpredictable nature of a staged performance not only unlocks new perspectives, it also creates situations in which the outcome of a performance no longer or only partially matches the question that it should have answered in the first place. This happened more than once during the research I undertook as part of the case studies presented in this dissertation. While working on Willem van Laer's Guidebook for Gold and Silversmiths, the re-enactments turned out to do something different from what I initially hoped for. The plan to use re-enactments to lay bare the interaction between text and practice turned out to be a dead end. At the same time, I learned that the re-enactments did a very good job at identifying the explanatory gaps in the text, which, so I realized, could still be used to help answer how and why people would have used the Guidebook on the workshop floor, albeit with a detour. A similar thing happened while reworking the recipes for red rosichiero glass from Johannes Kunckel's Ars Vitraria Experimentalis. Even though RRR was initially undertaken to find out how four closely-related recipes possibly differed from one another, reworking the recipes opened up intriguing new insights into the pyrotechnics behind historical glassmaking in general. While this pyrotechnical exploration was not planned, it turned out to be fruitful nonetheless, and was happily incorporated as the research went along. A more dramatic example, in which the performance and the initial research question indeed went separate ways, concerned the case study of Eikelenberg's varnish-making experience. While the research revolved around the elucidation of Eikelenberg's ervarenissen as a communicative strategy, I eventually realized that reproducing varnishes taught me little in that respect. The reproductions, however, did provide a great opportunity to assess the influence of tools and surroundings on the outcome of a performance, thus becoming a meta-study on RRR as a method, which ended up in this chapter instead of the chapter on Eikelenberg's ervarenissen. This shows that not every study benefits from RRR. Above all, and like all other methods, RRR remains a means to an end, and not an end in itself. 
Learning by Doing 



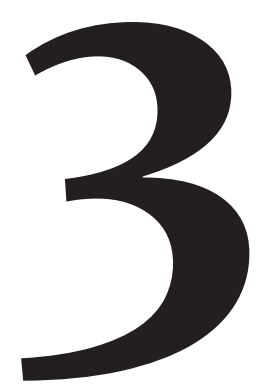

\section{Don't Blame the Text}

Reproducing Rosichiero Glass from Antonio Neri's

Recipes (1612) and Johannes Kunckel's Subsequent Commentary in the Ars Vitraria Experimentalis (1679)

Part of this chapter is the basis of a revised article that will be published as: Thijs Hagendijk, Márcia Vilarigues, Sven Dupré, "Materials, Furnaces, and Texts. How to Write about Making Glass Colours in the Seventeenth Century," Ambix 67, forthcoming fall 2020. 


\section{Introduction}

Glassmaking is a complicated task. One has to reckon with numerous variables that determine what the glass will look like once it comes out of the furnace. Think for instance about adequate timing of the different making steps. Or think of the furnace; its temperature and design. Or the different ways by which ingredients are prepared before they are melted together. Now imagine that you have to communicate this glassmaking process, in all its complexity, by means of written instructions. How could you help readers to productively engage with the instructions and to navigate the myriad of variables? How would you account for diverging conditions on the workshop floor? And what could you do to help readers produce an acceptable piece of glass?

This chapter is about arguably the most important text on glassmaking of the seventeenth century. First published in 1612 by the Italian glassmaker and alchemist Antonio Neri as L'Arte Vetraria, the treatise became an everexpanding project that went through several translations and commentaries. When almost seventy years later, in 1679 , the German chymist and glassmaker Johannes Kunckel finished a German edition of the same treatise, with the title Ars Vitraria Experimentalis, it had grown into a complex and layered text that contained a plethora of recipes, elaborate commentaries and annotations, various appendices dealing with glass technologies, and a variety of descriptions of glassrelated arts. Kunckel also included parts of a previous English edition published by Christopher Merret in 1662. He translated Merret's commentaries on Neri's Italian original and even added his own commentary on Merret's commentary. By 1679, Kunckel had transformed the treatise into a complicated and layered text that had more than quadrupled in size since its first appearance in 1612.

The Ars Vitraria Experimentalis is an ideal source from which to study how material and textual technologies intersect in historical practices of glassmaking. Taking four recipes for rosichiero glass as an example - rosichiero is a transparent red glass used for enameling - this chapter seeks to answer what textual technologies were employed in the Ars Vitraria Experimentalis to help the reader engage with the recipes, to experiment with them and to make them work in the specificity of their own workshop. ${ }^{1}$

Over the past years we have seen a growing interest in textual technologies and the reading and writing practices developed in the arts, including the recognition of the significance of processes of copying, translating, annotating

1 Kunckel, Ars Vitraria Experimentalis. See Appendix I for transcriptions of the recipes and accompanying commentaries that are discussed in this chapter. All translations are mine unless otherwise indicated. All transcriptions of Kunckel's Ars Vitraria Experimentalis were obtained from the Deutches Textarchiv: < http://www.deutschestextarchiv.de/ kunckel_glasmacher_1679>, accessed 3 December 2019. 
and transforming recipes. ${ }^{2}$ The rosichiero recipes, originally included in Neri's first editions, are an instantiation par excellence of these processes, especially as they come with comments and additions by Merret and Kunckel. How should we understand this process of layering and its functions? Even though it might be tempting to interpret commentaries and annotations as the unequivocal corrections and improvements of material practices, I will show that Kunckel's commentary is surprisingly ambivalent, despite its strong empirical rhetoric. On the one hand, his discussion of Neri's recipes is significantly inaccurate at times and it seems unlikely that Kunckel has actually tested Neri's rosichiero recipes. On the other hand, Kunckel used his commentary to share insights and know-how that were unarticulated in Neri's recipes. He shows his readers the mechanisms by which color is achieved, shaped and directed in the rosichiero glass, thus deepening their understanding of the glassmaking process and encouraging them to adapt the recipes to their own needs.

Gaining a thorough understanding of the material technologies behind rosichiero glass is pivotal to assessing the textual technologies by which they are communicated. To this end, the rosichiero recipes were reworked in close collaboration with Márcia Vilarigues and Sven Dupré, and with the help of several conservators, historians and experimental archaeologists. Reproductions of the glass were made at the glass studios of the VICARTE research unit in Lisbon (Portugal). VICARTE is well equipped for the scientific study of glass and has state-of-the-art facilities for the production of glass, such as electric kilns. Materials and ingredients were prepared, specifically with an eye towards their historicity, in Lawrence M. Principe's alchemy-oriented laboratory at Johns Hopkins University, Baltimore (USA). And to understand the role of fire and furnaces, the rosichiero glass was also reproduced in two different wood-fired furnaces, one at a ceramics workshop in Montemor-o-Novo (Portugal) and one at the glass workshop of Roman Villa Borg (Germany).

Concerning the material technologies behind rosichiero glass, I discuss the preparation of one ingredient in particular, crocus martis, and show how different preparations of this ingredient were understood to cause variations in the final color of the glass. Thus, the ability to control and steer the shade of the glass in a satisfactory way not only involved knowing what ingredients to put together, but required a more thorough understanding of how these ingredients were made in the first place. Moreover, I argue that the composition and quality of the glass were shaped by means of fire management and furnace conditions. Furnaces are anything but a simple heating device and require serious skill in operation.

2 Dupré, "Doing It Wrong"; Leong, Recipes and Everyday Knowledge; Boulboullé, "Drawn up by a learned physician from the mouths of artisans"; Smith, "Why Write a Book?"; Neven, "Transmission of Alchemical and Artisanal Knowledge in German Mediaeval and Premodern Recipe Books". 


\section{Rosichiero Glass. Objects, Recipes, and Ingredients}

Rosichiero, or rouge clair in French, is a type of transparent red glass that was mainly used for enameling, specifically on gold. Rosichiero enamels are mentioned in various sources since the beginning of the sixteenth century and an elaborate discussion of their usage and application can be found in the Treatise on Goldsmithing by the acclaimed Italian goldsmith Benvenuto Cellini (1500-1571). ${ }^{3}$ Cellini called this enamel "the loveliest red glass," and "far the most beautiful of all," and relates that rosichiero was "discovered by an alchemist who was a goldsmith as well."4 There are various historical objects that contain this type of enamel. One example is the medieval Royal Gold Cup, or the Cup of St. Agnes, whose red enamel has been identified as rouge clair (Figure 10). ${ }^{5}$ Another example is a pendant cross from the sixteenth century that features a translucent red enamel which has been similarly applied on gold (Figure 11). In this case, the red enamel was not further identified, but analysis confirmed that the glass was colored with copper oxide, a key-characteristic of the rosichiero recipes that are central to this chapter. ${ }^{6}$ Indeed, if anything, the term rosichiero does not appear to be a fixed term, but should be associated with transparent red glass or enamels, as long as they are colored with copper. ${ }^{7}$ It should be distinguished, on the other hand, from various other types of red glass, most notably gold ruby glass (which is colored with gold colloidal particles), sanguine glass (which is a glass paint in which iron-oxides are responsible for the color), or aventurine glass (which contains small crystals of copper that suggest a sparkling gold effect). ${ }^{8}$ In short, there is a history of rosichiero enamels and recipes that predates their inclusion in Neri's L'Arte Vetraria in 1612.

Antonio Neri (1576-1614) was a Florentine glassmaker and alchemist. When he published L'Arte Vetraria in 1612, he could draw on his experiences and the texts he had studied in the glass workshops at the Casino San Marco in Florence. Other resources were his contacts with Emmanuel Ximenez (1564-1632), a Portuguese merchant with a great interest in glass, who invited Neri to Antwerp

3 See specifically the section on "rosechiero, vetro rosso al rame" in Moretti and Toninato, Ricette vetrarie del Rinascimento, pp. 40-2.

4 Cellini, The Treatises, p. 16. For the historical association of alchemy, gold and red colors, see: Von Kerrsenbrock-Krosigk, Rubinglas; Smith, "Vermilion, Mercury, Blood, and Lizards"; Bucklow, "Paradigms and Pigment Recipes".

5 The extensive use of rouge clair on the cup is for instance mentioned in Biron, Émaux sur métal, p. 6o.

6 Wypyski, "Chemical Analyses of Renaissance Enamelled Jewellery".

7 Roschiero has also been identified as red-colored glass, not an enamel, present in a renaissance goblet: Verità and Zecchin, "Scientific Investigations of a Venetian Polychrome Goblet".

8 Von Kerrsenbrock-Krosigk, Rubinglas; Santos and Vilarigues, "Sanguine Paint"; Verità and Zecchin, "Scientific Investigations of a Venetian Polychrome Goblet", pp. 113-4. 


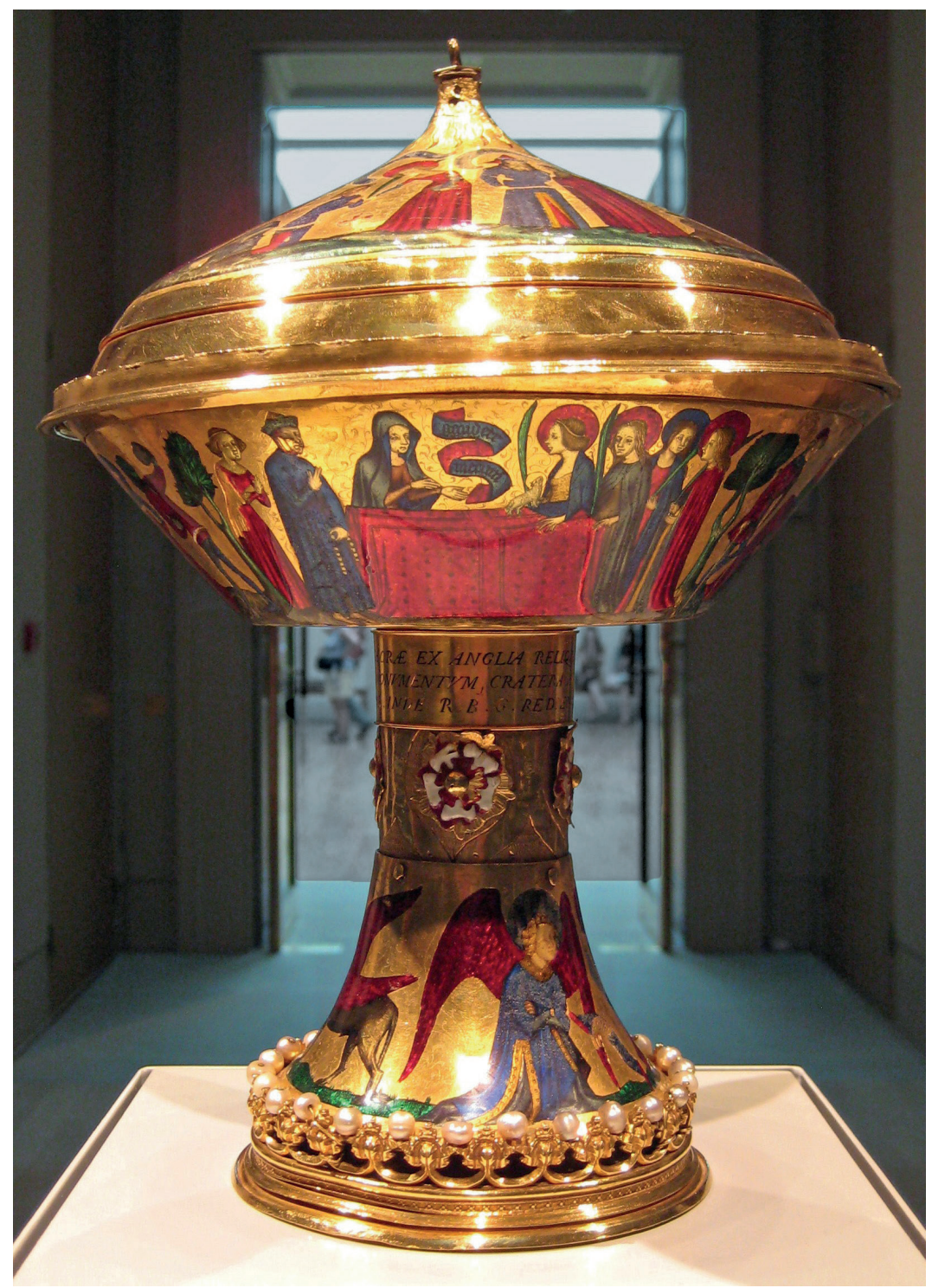

Figure 10: The Royal Gold Cup. Gold, set with pearls, enameled. France, ca. 1370-1380. (The British Museum.) The depictions in red have been enameled with rouge clair (i.e. rosichiero) glass. Photo: Wikimedia Commons. 


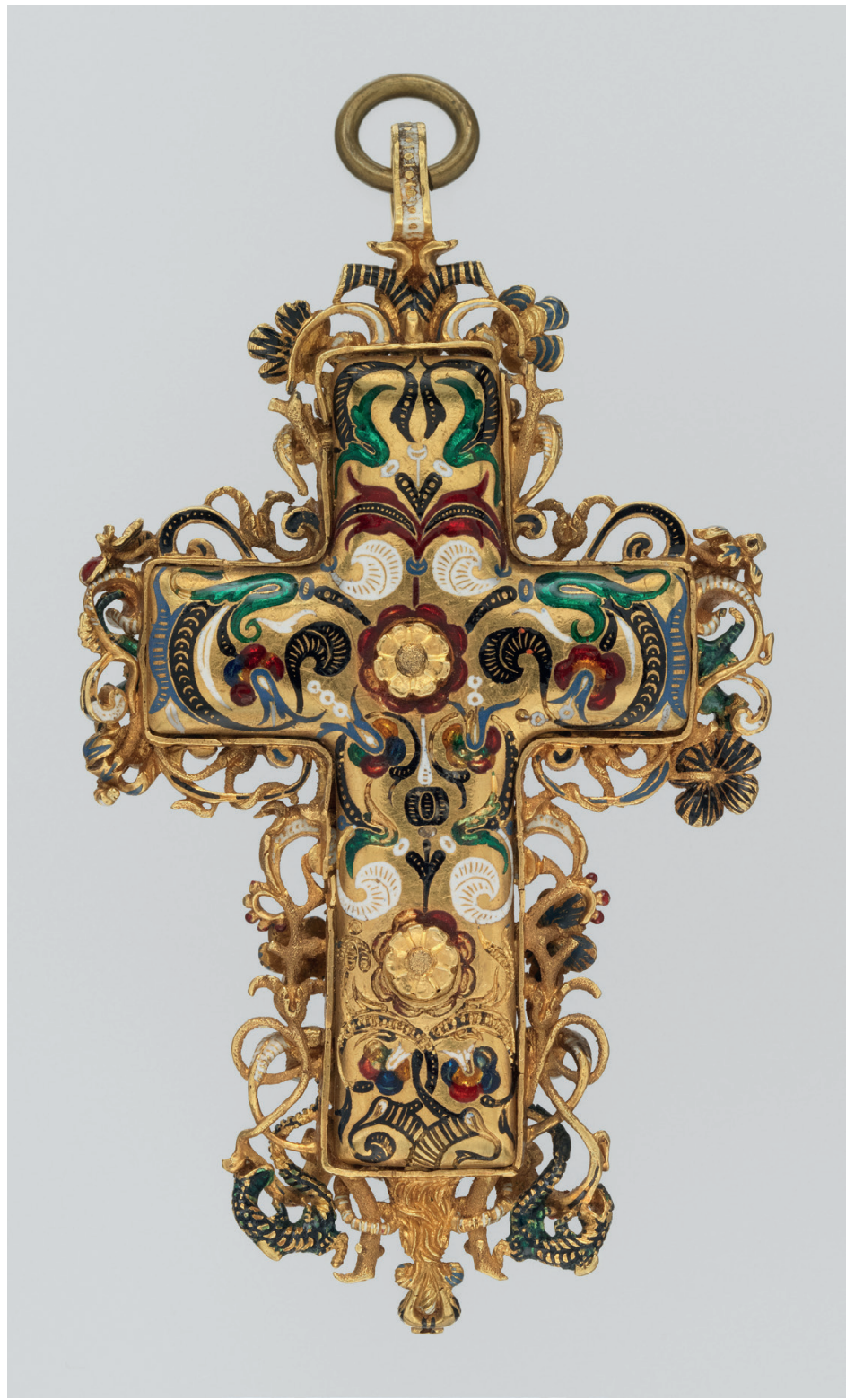

Figure 11: Pendant cross. Gold, partly enameled, set with diamonds. Northern European, 16th Century. (The Metropolitan Museum of Art, New York. Bequest of Michael Friedsam, 1931.) The red enamels bear similar characteristics to the rosichiero glasses described in Kunckel's Ars Vitraria Experimentalis. Photo: The Metropolitan Museum of Art, New York. 
where he could study the glass ovens that were run by the Italian glassmaker Filippo Gridolphi. ${ }^{9}$ The book lists 133 chapters (recipes) that fall into seven parts. Neri opens with a discussion of colorless crystal and continues with recipes for colored glass, chalcedony glass, lead glass, artificial gemstones and enamels. The rosichiero recipes are found in the seventh and final part. The chapter itself is not as systematically organized as the others and presents a miscellaneous collection of things that are "neither vulgar nor common." This also holds for rosichiero enameling, which, according to Neri, is an art "much concealed" and only known to few people. ${ }^{10}$

In total, Neri included four rosichiero recipes (Figure 12). The first (chapter 124), promises "rosichiero to enamel gold" (rosichiero per smaltar l'oro); the second (125) provides "another way" (altra maniera); the third (127) describes a red glass "that can serve as Rosichiero" (che può servire per Rosichiero); and the last (128) reveals a way to make rosichiero that is "proven" (provato). It has repeatedly been suggested that Neri copied the recipes from circulating manuscripts, such as an anonymous Venetian recipe collection from 1560 that contains instructions "to make rosichiero" (per fare rosechiero) or "to make a red enamel for gold (18 or 20 carat), which is called rosichiero" (per fare smalto rosso per oro (da 18 o 20 carati), che si chiama rosechiero). ${ }^{11}$ Another probable source for Neri was a recipe collection close or identical to the Montpellier manuscript Recette per far vetri colorati et smalti d'ogni sort havuto in Murano from 1536, which indeed contains several recipes "to make roschiero" (a fare rosachiero; a far rosso chiaro; and a far rosechier). ${ }^{12}$ The precise relation between Neri's rosichiero recipes and those that circulated in the manuscripts remains an open question, but there are at least two observations that can be made at this point. First, it is doubtful whether Neri fully tested or critically assessed the rosichiero recipes before writing them down. It has been argued that the recipes contained errors similar to those in the manuscript sources, suggesting that they were not noticed or resolved by Neri. ${ }^{13}$ Reworking the recipes indeed confirmed this idea, especially when we encountered serious problems in chapters 124 and 127. A crucial exception was chapter 128, which gave the best results and was indeed the only one that had explicitly been marked "proven" - Neri claimed to have successfully used it in Pisa many times. ${ }^{14}$ While

9 Dupré, "The value of glass"; Grazzini, "Discorso sopra la Chimica”; Beretta, "Glassmaking Goes Public".

10 Neri, L'Arte vetraria, pp. 93-4.

11 Moretti and Toninato, Ricette vetrarie del Rinascimento, pp. 79-8o and the "saggio introduttivo".

12 Zecchin, "Le ricette vetrarie di Montpellier".

13 I would like to thank Jo Wheeler for his insights into this issue. Furthermore, see the comments on rosichiero in: Zecchin, "Le ricette vetrarie di Montpellier", p. 251.

14 See section 6. Detailed results, including scientific analyses of the reproductions, will be published in a sequential paper. 

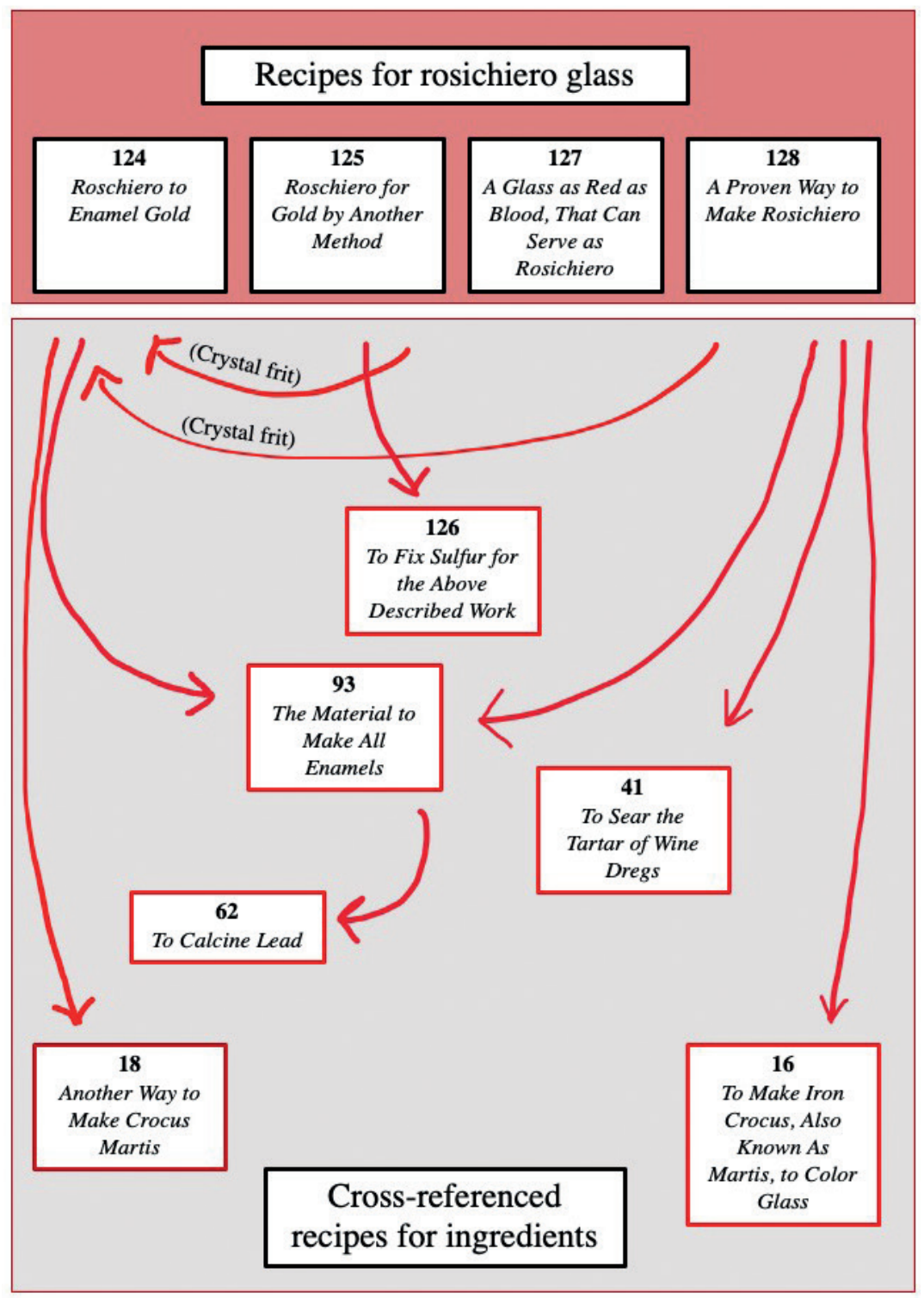

Figure 12: Overview of the four rosichiero recipes (chapters 124, 125, 127 and 128) that were published by Neri and later translated by Kunckel. The red arrows indicate references to other recipes that contain instructions for the preparation of specific ingredients. 
it is no surprise that the textual transmission of know-how was liable to errors and mistakes during processes of copying and translation, the errors in Neri's rosichiero recipes make them an interesting case to evaluate whether Kunckel's annotations and commentaries function as textual technologies that help identify and correct earlier mistakes. ${ }^{15}$ Second, even though Neri probably did not test and revise each rosichiero recipe that he included, he at least edited them to such an extent that they could be integrated into a web of cross-referenced recipes that he carefully wove throughout the book. The instructions in the rosichiero recipes are not complete by themselves, and thus require interaction with other recipes in L'Arte Vetraria, specifically when it comes to the preparation of ingredients. One could say that the recipes function as modular building blocks that can be pieced together according to specific needs and circumstances.

After Neri published L'Arte Vetraria, the rosichiero recipes became subject to commentaries and further annotations, much like the rest of the book. Fifty years later, in 1662, an English edition was published by Christopher Merret (1614-1695). As a physician and founding member of the Royal Society in London, Merret valued Neri's work for its useful knowledge and experimental qualities, and positioned it directly into Francis Bacon's (1561-1626) program of the 'promotion of arts and sciences' as outlined in the latter's Novum Organum. ${ }^{16}$ Not only did Merret publish a translation, he expanded the book by including a new chapter on furnaces, an account of "Prince Rupert's glass drops," and observations on Neri's recipes. The observations present things he "carefully surveid" himself, that he learned from "the workmen," and read in "any good Author concerning whatsoever Neri treats of," most importantly Robert Boyle (1627-1691), Johann Rudolf Glauber (1604-1670) and Giambattista della Porta (1535? -1615). ${ }^{17}$ The harvest with respect to rosichiero was somewhat meagre, nonetheless. Merret's observations were confined to a full quotation of a recipe for "a fair red rosichiero" or "rosa clerum" that he had found in Della Porta. ${ }^{18}$ The recipe from Della Porta differs significantly from the ones provided by Neri. ${ }^{19}$ Whether Merret tested the rosichiero recipes, Neri's or Della Porta's, remains unclear. In general, however, his inclusion of observations was something that Kunckel would adopt and further develop in his German edition. The comments on rosichiero too, were greatly expanded in Kunckel's hands.

15 Dupré, "Doing It Wrong".

16 Merret, The Art of Glass, pp. 205-6; Koinm, "Christopher Merret's Use of Experiment"; Giglioni, "From the woods of experience".

17 Merret, "To the ingenuous Reader" in The Art of Glass, n.p. See also: Dupré, "Doing It Wrong".

18 Merret, The Art of Glass, p. 350.

19 It specifically lacks iron oxide as an ingredient and in addition it introduces the mineral cinnabar (HgS). Compare with the end of this section that deals with ingredients. 
When Kunckel published the Ars Vitraria Experimentalis. Oder Vollkommene Glasmacher-Kunst (1679), the book had more than quadrupled in size compared with Neri's original. Moreover, whereas Merret devoted a significant portion of his observations to an anthology of things read in other sources, the focus in Kunckel's observations was on his personal experience as a glassmaker and chymist - experience that he had gained in the years leading up to the Ars Vitraria Experimentalis. The book consists of two volumes. The first volume presents a German translation of Neri's recipes, with Kunckel's commentary following directly after each of Neri's seven books. Next, Kunckel gives the German translation of Merret's observations, which he subsequently commented upon. The second volume consists of a variety of glass-related practices, recipes, arts, and experiments, that are no longer related to Neri and Merret, but that were gathered and composed by Kunckel himself.

Johann Kunckel (1630-1703) was raised in a family of glassmakers, trained as an apothecary, and employed as a "chymist"; first in the service of the Duke of Sachsen-Lauenburg and later at the Dresden court where he ran "the Secret Chymical Laboratory". ${ }^{20}$ He traveled to Holland where he studied glassmaking practices, taught "Experimentalchemie" at the University of Wittenberg and maintained connections with other chymists, such as Hennig Brand who made the serendipitous discovery of phosphorus during his quest for the Philosopher's Stone. Kunckel began to publish chymical treatises from 1676 onwards (among other things dealing with phosphorus) and moved to Berlin where he was introduced to the Elector of Brandenburg Friedrich Wilhelm (1620-1688). He helped the Elector avoid an alchemists' scam when the latter was offered a "tinctur" for purchase that would turn silver into gold. Kunckel came into good graces and was appointed to oversee the glassworks in Potsdam from 1678 onwards, where he implemented the manufacture of high-quality crystal glass. At the same time, Kunckel wrote and published the Ars Vitraria Experimentalis (1679), possibly urged by the earlier appearance of another German translation in 1678 by a certain Friedrich Geißler, a competitor who Kunckel sought to disqualify wherever he could. ${ }^{21}$ This was also the period that Kunckel experimented with and succeeded in the production of gold ruby glass, a discovery that brought him fame. ${ }^{22}$ In 1685, the Elector offered Kunckel a peninsula, the "Pfaueninsel",

20 For Kunckel's biography, see: Triotzsch, "Kunckel von Löwenstern, Johann”; Kruse, "Johann Kunckel".

21 Geißler, Glaßmacher-Kunst. See Kunckel's remarks on Geißler: Kunckel, Ars Vitraria Experimentalis, pp. 50, 147, 179, 188, 191, 196, 202, 204-5.

22 Von Kerrsenbrock-Krosigk, Rubinglas. 
to build his own glassworks and laboratory. Archaeological excavations have revealed parts of its foundations, including shards of gold ruby glass. ${ }^{23}$

Later in life, Kunckel continued to write books on chymistry, including the comprehensive and posthumously published Laboratorium Chymicum (1716). ${ }^{24}$ In sum, Kunckel was as experienced a glassmaker as he was a chymist, and equally versed in artisanal and scholarly cultures. Following Ursula Klein, he could be characterized as a hybrid expert, someone who connected the artisanal and scholarly world, which perhaps best speaks through the way he organized the Ars Vitraria Experimentalis. For example, the Latin title that Kunckel devised for his book is reminiscent of the Baconian experimental program and the history of trades program at the Royal Society. And just like Merret, Kunckel presented his take on Neri's glass recipes using learned formats. ${ }^{25}$ What Kunckel called "commentario" or "anmerckungen" was in fact a humanist epistemic genre that bears obvious connections with the commentary tradition found in natural philosophy. ${ }^{26}$ Kunckel was familiar with these learned formats and did not hesitate to use them to organize practical knowledge. Additionally, and especially relevant in the context of this chapter, Kunckel used his commentary to identify potential problems and to correct the "Fehler" (errors) that he found in Neri, Merret and Geißler: a strategy that Sven Dupré has described as the "codification of error". ${ }^{27}$ Kunckel is keen on stressing that everything presented in the Ars Vitraria Exerperimentalis has been vetted through experience. The book only contains "infallible Experimenta and Truths," a claim that is dramatically represented on its frontispiece (Figure 13). ${ }^{28}$ The left side is illuminated by the sun - i.e. the "lux veritatis" (the light of truth) - and features ratio and experience. The right side is shrouded in the darkness of incertitude, with all its insanity, errors and vain fantasies. The two sides are separated by a furnace, which is aptly called "tentamen" (test) in which things are tried in the fire. In light of this chapter, this raises the question how Neri's rosichiero recipes would hold up against the scrutiny of Kunckel's furnace.

In terms of ingredients and steps, Neri's rosichiero recipes show significant mutual similarities. Minor differences concern the proportions of the ingredients and variations in the exact order in which they are added to the batch. An exception is the rosichiero glass described in chapter 127. Compared with the

23 Rau, "Das Glaslaboratorium des Johann Kunckel”; Rau, "Johann Kunckel, Geheimer

Kammerdiener"; Schulze, "Kunckels Glaslaboratorium".

24 I use the term 'chymistry' in accordance with Newman and Principe, "Alchemy vs. Chemistry".

25 Dupré, “Doing It Wrong”; Klein, “Introduction. Artisanal-scientific Experts”; Klein, "Chemical Experts".

26 On epistemic genres and observations as a learned format, see Pomata, "Sharing Cases".

27 Dupré, "Doing It Wrong".

28 Kunckel, Ars Vitraria Experimentalis, Vorrede, n.p. 


\section{Chapter 3}

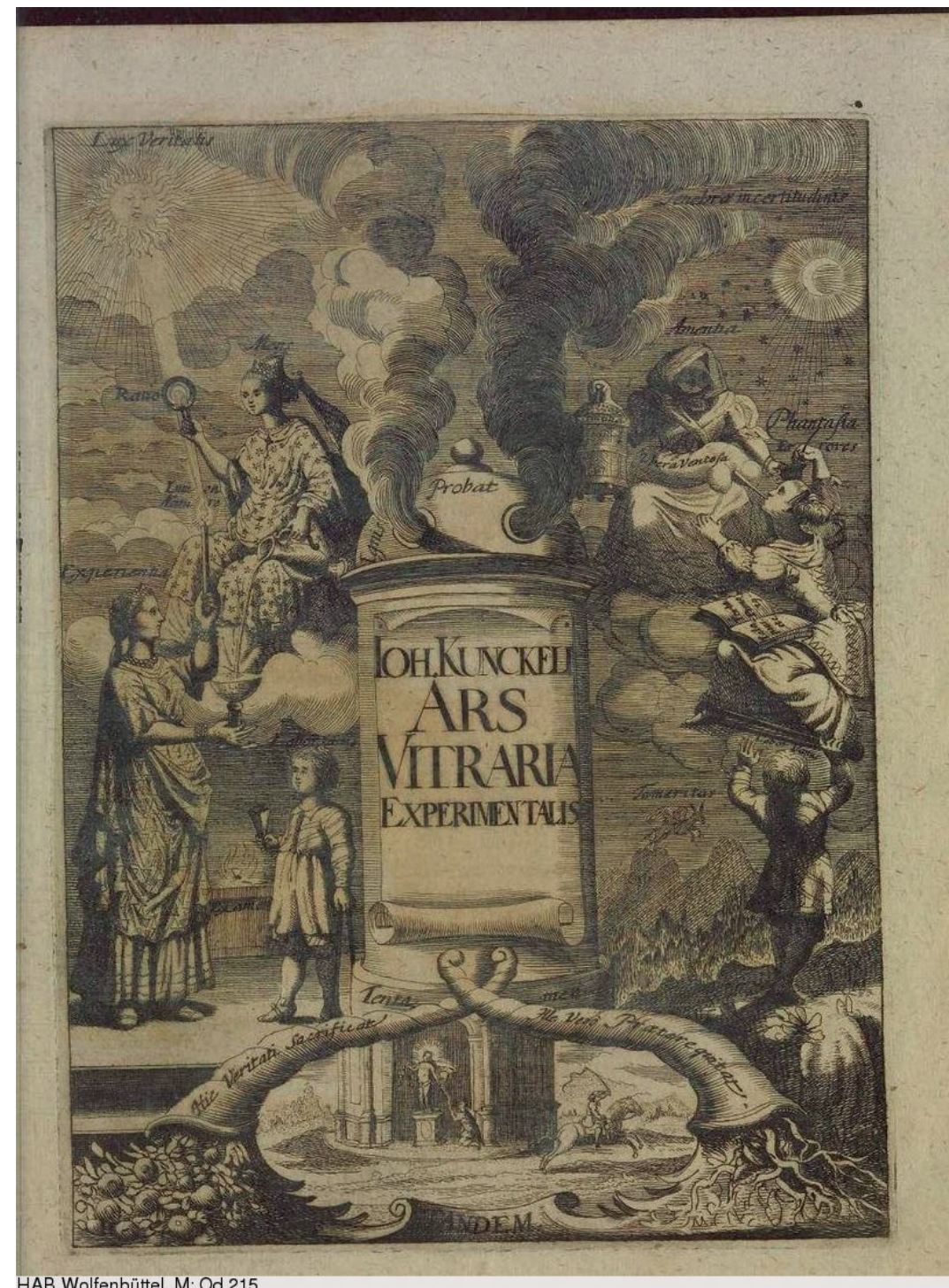

Figure 13: Frontispiece of Kunckel, Ars Vitraria Experimentalis. Photo: Deutsches Textarchiv. 
other recipes, it lacks the addition of iron(III) oxide, an ingredient that turned out to be crucially important during our reproductions. This difference does not come as a surprise - chapter 127 is the only recipe that is explicitly described as a blood-red glass that could pass for rosichiero, which shows how the four recipes also act as a play on different material conditions and color variations that can be associated with rosichiero glass. In what follows, I provide a short overview of the key ingredients in the preparation of rosichiero glass, according to the recipes Kunckel translated from Neri. ${ }^{29}$

1. Crystal frit. The first step in all recipes is to produce a colorless glass that serves as the basis for the final glass composition. Chapter 124 provides the procedure in full, which is omitted in subsequent recipes that refer back to this chapter instead. The crystal frit is made from "white and finely powdered Tarso" (quartz), which is combined with the "salt from the Levantine powder" $\left(\mathrm{Na}_{2} \mathrm{CO}_{3}\right)$ and calcined in a furnace.

2. Calx of lead and tin. The calx functions on two possible levels. It renders the glass opaque, and likely functions as a reducing agent necessary to bring out the final color. $3^{\circ}$ The author refers to another chapter (93) to explain how this ingredient should be prepared. Pieces of lead and tin are melted together to form an alloy and calcined until the alloy oxidizes and a yellow substance is formed.

3. Cream of tartar ("Weinstein"). The role of this ingredient is not fully understood, but it likely contributes to the strong reducing conditions necessary to obtain the red glass. Chapter 128 calls in addition for 'chimney soot' which presumably serves as a reducing agent too..$^{31}$

4. Calcined red copper ("Hammerschlag"). This copper(II) oxide $(\mathrm{CuO})$ is responsible for the red color of the glass. ${ }^{32}$ To bring out the red color, a fundamentally important chemical reaction needs to take place first. The presence of $\mathrm{Cu}^{2+}$ would lead to a turquoise-blue glass instead of the red that is wanted in rosichiero glass. To generate the red glass, strong

29 For general overviews on glass ingredients and compositions, see Davison, Conservation and Restoration of Glass; Henderson, Ancient Glass; Weyl, Coloured Glasses; Vogel, Glass Chemistry.

30 Bandiera et al., "Nanotechnology in Roman Opaque Red Glass"; Davison, Conservation and Restoration of Glass, pp. 77-8; Durán et al., "Study of the colouring process in copper ruby glasses". As the authors indicate, the role of tin(II) oxide in the formation of red copper glass is complex and likely acts as a "redox buffer to regenerate $\mathrm{Cu}^{+}$", instead of reducing all copper oxides to metallic copper. Ishida et al., "Role of $\mathrm{Sn}^{2+}$ in development of red color".

31 Vogel, Glass Chemistry, p. 247.

32 The adjective red refers to copper proper in contrast with yellow copper (brass) and does not refer to the color of the oxide, which is actually black. 
reducing conditions are necessary that lead to the reduction of copper and to its subsequent precipitation in the glass, either as cuprous oxide $\left(\mathrm{Cu}_{2} \mathrm{O}\right.$, composed of $\left.\mathrm{Cu}^{+}\right)$or as metallic copper $\left(\mathrm{Cu}^{\circ}\right)$. When the precipitated particles are of the right size and concentration, a light-scattering effect occurs that gives rise to the red color. ${ }^{33}$ Strong reducing conditions can be achieved by decreasing the amount of oxygen in the furnace atmosphere, or by using specific ingredients that act as reducing agents in the glass, like the mentioned lead-tin calx, but a fourth ingredient, Crocus Martis, is added for this purpose as well.

5. Crocus Martis or bloodstone. Rosichiero glass requires the addition of iron(III) oxide $\left(\mathrm{Fe}_{2} \mathrm{O}_{3}\right)$. While the aforementioned copper particles are directly responsible for the red color of the glass, this color only appears if copper is combined with the iron(III) oxide that acts as the reducing agent for the copper particles. ${ }^{34}$ The chemical mechanism behind this effect is complicated - iron(III) oxide needs to be reduced itself before it can reduce the copper ions - but empirical evidence is nonetheless clear. ${ }^{35}$ We failed to reproduce the only rosichiero recipe (127) that does not involve iron oxide as an ingredient. ${ }^{36}$ In sum: no iron, no red.

Because of the crucial role of iron oxide in the production of rosichiero glass, I will discuss this ingredient more elaborately in the following section.

\section{Crocus Martis and the Quest for Perfect Rust}

This section explores iron(III) oxide $\left(\mathrm{Fe}_{2} \mathrm{O}_{3}\right)$, not only as a crucial ingredient in the production of rosichiero glass, but also as an example that further illustrates the intricate material technologies behind early modern glassmaking and the communication thereof in text.

Even though "iron(III) oxide" is a modern chemical name and not an historical term, it is precisely in the contrast between a modern chemical perspective and a seventeenth-century outlook that interesting questions arise. Early modern understanding of iron(III) oxide was complex and much refined, which is also

33 For an overview and discussion of secondary literature, see Bandiera et al., "Nanotechnology in Roman Opaque Red Glass"; Brill and Cahill, "A Red Opaque Glass"; Weyl, Coloured Glasses, pp. 154ff; Freestone et al., "The production of red glass"; Freestone, "Composition and microstructure".

34 See note 30.

35 I would like to thank Mario Bandiero for pointing out the chemical complexities involved with iron(III) oxide as a reducing agent.

36 Detailed results, including scientific analyses of the reproductions, will be published in a sequential paper. 
reflected in the Ars Vitraria Experimentalis. Indeed, while iron(III) oxide does not differ from ordinary rust, early modern authors show us that we should not be deceived by the humble appearance of this substance. Glassmakers like Neri and Kunckel differentiated between various types of iron(III) oxide, depending on the way it was prepared or obtained as a sourced mineral. In that respect, the early modern attitude toward this substance diverges from a modern outlook, in which distinctions based on the method of preparation might appear redundant rather than useful. ${ }^{37}$ By contrast, each rosichiero recipe in the Ars Vitraria Experimentalis stipulates a different variety of iron(III) oxide. Chapter 125, for instance, prescribes bloodstone (hematite) which is a mineral that can be readily sourced from nature. Chapters 124 and 128 each employ a different type of crocus martis ('saffron of iron'), which is an artificially manufactured iron(III) oxide. A burning question is why these different origins and preparations of iron(III) oxide mattered to Kunckel and Neri. Why do the rosichiero recipes stipulate different varieties of an ingredient that appears to be chemically similar?

In total, the Ars Vitraria Experimentalis differentiates five types of crocus martis. Each of them has its own recipe that explains how to manipulate iron or steel filings to produce the desired crocus martis. For example, the filings can be calcined in the presence of sulfur (chapter 16), or treated with vinegar (17), aqua fortis (18), or aqua regia (19). On top of these four recipes, Kunckel's commentary contains an additional procedure for crocus martis in which the filings are calcined without using any auxiliary substance. The recipes for crocus martis stand by themselves and are only referred to when needed in the production of specific glasses. The recipes for rosichiero glass do so, but also recipes for chalcedony glass, a black glaze and a variety of green glasses refer back to particular crocus martis recipes.

It is specifically in the context of green glass that Kunckel reveals how different croci have the ability to shape, steer and affect its final color and shade. While commenting on the recipes that Neri presented for green glass, Kunckel mentions how struck he was by "all sorts of beautiful and almost uncommon green colors" and continues with a discussion of crocus martis which is worth quoting in full:

Such manifold Variations, however, consist simply and only in the Difference and Preparation of the applied Iron Powders, called Crocus Martis: depending on its preparation and Application, one can have Green as one pleases, because another Art or Color originates when the Iron Powder is prepared with Vinegar, and another when prepared with Sulfur, and yet another when it is prepared by itself. Then - through the Combination of burnt Copper and the Saffron of Iron or

37 Strictly speaking, iron(III) oxide is a polymorph, meaning that it occurs in various crystal structures, most importantly, the alpha, beta and gamma phases. For a detailed physical-chemical overview, see Cornell and Schwertmann, The Iron Oxides. 
prepared Iron Powder - all Distinct green Colors are brought about. Even though the Copper and the similarly applied Hammerschlag all give Green, its manifold Variations depend simply and solely on the Iron Powder, namely, on the way it is prepared and applied. ${ }^{38}$

The quotation helps to clarify two points. First of all, it indisputably states that various preparations and origins of crocus martis should be reckoned with in glassmaking practices. Moreover, and Kunckel is very clear in this respect, he deems crocus martis the key ingredient responsible for shifting the green color in the glass. In his commentary, he continues by pointing out that, contrary to the crocus martis, experimenting with "burnt Copper" (Hammerschlag, or $\mathrm{CuO}$ ) did not result in significant color differences. "I could not find a big variation in the preparation of the Copper" ${ }^{39}$ Kunckel thus establishes a relation between crocus martis and color variations while singling out other factors. It is worth pointing out that glassmaking was not the only field in which different preparatory trajectories of crocus martis were held responsible for different effects. In his posthumously published Laboratorium Chymicum, Kunckel addresses the medicinal context, in which "many different Croci are being made and called by various Names."40 Indeed, open a random contemporary (iatro)chymical textbook and chances are that one finds an assortment of croci that was prescribed and administered to remedy a range of symptoms and diseases. ${ }^{41}$ How the crocus martis was prepared determined the type of illness it could treat. One could for instance distinguish between "crocus martis aperitivius," which is prepared with sulfur and serves to "open up and attenuate", and "crocus martis obstructivus," which is produced in a reverberatory fire and should be administered to relieve someone from dysentery, diarrhea or gonorrhea. ${ }^{42}$ In sum, the idea that crocus martis can be prepared

38 Kunckel, Ars Vitraria Experimentalis, pp. 64-5: "Es befteht aber folche vielfåltige Verånderung bloß und allein in dem Unterfchied und Bereitung des zugerichten Eifen-Pulvers/ Crocus Martis genannt: Nach dem die præparation und Zurichtung deffelben ift/ nach dem kan man auch/ und zwar wie man will/ eine Grůne haben/ weiln fich eine andere Art oder Coleur erzeugt/ wenn das Eifen-Pulver mit Eßig; eine andere/ wenn folches mit Schwefel; eine andere/ wenn es vor fich felbft præpariret worden: denn durch die Zufammenfetzung des gebrannten Kupffers und des Eifen-Saffrans oder bereiteren Eifen-Pulvers werden alle Unterfchiedlichkeitẽ grůner Coleuren zu wege gebracht. Wiewohl das Kupffer und deffelben zugerichtete Hammerfchlag auch allemal eine Grůne gibt/ fo liegt doch die vielfåltige Verånderung derfelben bloß und allein an dem Eifen-Pulver/ nachdem nemlich daffelbe bereitet und zugefetzet wird."

39 Kunckel, Ars Vitraria Experimentalis, p. 65: "Jn der Bereitung des Kupffers habe ich keine groffe Verånderung finden ko̊nnen”.

40 Kunkel, Collegium Physico-Chymicum Expertimentale, p. 366: "Es werden vielerhand Croci gemachet / und mit vielen Namen benennet".

41 Lemery, Cours de Chymie, pp. 146-157; Thibaut, Cours de Chymie, pp. 406-7.

42 Blankaart, Theatrum chimicum, pp. 73-4. 
differently to suit distinct purposes had wider currency. But how exactly are the croci different from each other? Apart from experimentally demonstrable differences, Kunckel also offers some philosophical reflection when he suggests - in otherwise demanding alchemical language - that each crocus martis is a particular reorganization of the different parts that are already present in iron as a metal. Reorganizing these parts is done through a series of "separations and purifications that should not be neglected." 43 Crocus martis prepared with vinegar, for instance, leaves the spiritus tingens of iron intact, a fragile combination of the principle Mercury and a fixed salt, that is lost as soon as one calcines the crocus martis in the presence of sulfur. Even without offering a satisfying interpretation of Kunckel's alchemical thinking, one can see how this reasoning creates the possibility of related but subtly different croci.

In the second place, the way in which Kunckel read and dealt with Neri's recipes for green glass contains an implicit message, one in which Kunckel opens the door for intra-recipe experimentation. Kunckel, as he does in other places, lets go of the individual recipe and starts to look for the one thing that the recipes for green glass have in common as a group. In other words, he hunts for precisely that thing that explains why the variations between these recipes exist in the first place and takes that as his point of departure. A consequence of this approach is that Kunckel's reading is not geared towards the identification of the best recipe out there. Rather, he emancipates his readers and encourages them to find out what works best for them instead. He points his readers towards the one tool they need in order to arrive at the color "as they please", which is found in the preparation of crocus martis.

It is important to realize that both Neri and Kunckel lived and wrote in a non-standardized color-world - the earliest systematic attempts to codify and systematize colors date to the eighteenth century. ${ }^{44}$ Getting the right colors in glassmaking was first of all a matter of experience, training and judgment. ${ }^{45}$ Neri explains for instance a rigorous procedure of repeatedly adding minute quantities of coloring agents to the glass batch while closely monitoring how the color of the glass changes as a result. "This is the way to add all the colors, because this way you will never fail." ${ }^{16}$ Rather than relying on exact measurement, Neri relies on experience: "Be warned in particular to give careful consideration to the colors for which exact and determined amounts cannot be given. Indeed, with experience and due practice learn, and with the eye and judgement know, when a glass

43 Kunkel, Collegium Physico- Chymicum Expertimentale, p. 367: "Solche Scheidung - und Reinigungen sind auch nicht zu verachten".

44 Steinle, "Colour Knowledge in the Eighteenth Century".

45 For a detailed discussion of experience and judgment in historical glassmaking practices, see Dupré, "The Role of Judgment".

46 Neri in Engle, The Art of Glass, vol. 3, p. 25. 
is colored sufficiently and appropriately for the work at hand."47 The required amounts of coloring agents are usually small, thus increasing the likelihood of a mistake, while the final color of the glass also depends on furnace conditions, temperatures and timing. ${ }^{48}$ Neri knew that colors were hard to communicate in text, a problem for which even the quantification in terms of weights and dose did not provide an immediate solution. Instead, he reminds his readers to rely on their own eyes and judgment. But Kunckel takes it one step further. What is good judgement worth if you do not know how to manipulate the color in the first place? In his commentary on green glass, he does not identify his favorite green color, but discloses the means by which the green colors are created, directed and shaped. In a non-standardized color-world, one needs the key that gives access to color enhancement and variation, such that one can optimize it for oneself, based on judgement and experience.

So much for crocus martis in recipes for green glass. But what about the rosichiero recipes? The presence of three differently prepared iron(III) oxides in the rosichiero recipes enticed us to undertake an experiment that was very similar to the one that Kunckel performed on green glass. We wanted to see how different preparation methods of crocus martis would shape the final color of rosichiero glass. To do so, we first of all had to follow the different instructions for crocus martis provided in the Ars Vitrari Experimentalis. For that purpose, I went to Baltimore (USA) and worked together with Lawrence M. Principe to investigate and rework the five recipes presented in the book. What we found were five croci with five very distinct colors (Figure 14).

1. Crocus martis prepared with sulfur. ${ }^{49}$ Chapter 16 describes how alternate layers of steel-filings and sulfur must be placed in a crucible and calcined. We did so accordingly and found a grey-purplish structure that was reminiscent of broccoli. This was followed by reheating. After an observed color change, the product was ground and sieved $(125 \mu \mathrm{m})$. This crocus martis has a deep maroon color.

2. Crocus martis prepared with vinegar. ${ }^{\circ}$ Chapter 17 orders to repeatedly moisten steel filings with "a good and strong vinegar.” Lawrence Principe, having already started the procedure before my arrival, observed how the color of the filings changed during the process, starting as purplish but soon turning into a brown slurry upon remoistening. As described by the recipe, the filings pulled together "in lumps". After grinding and sieving,

47 Neri in Engle, The Art of Glass, vol. 1, p. 7 .

48 Henderson, Ancient Glass, pp. 66-7; Dupré, "The Role of Judgment". See also sections 4 and 5 that deal with furnaces.

49 Kunckel, Ars Vitraria Experimentalis, pp. 27-8.

50 Idem, p. 28. 
we obtained a crocus martis with a rusty brown color, or a color like "brick dust", as mentioned by the recipe.

3. Crocus martis prepared with aqua fortis..$^{51}$ Chapter 18 involves nitric acid, which must be sprinkled on a batch of steel filings. We proceeded carefully, each drop of aqua fortis reacted vehemently with the filings, releasing brown clouds of nitrogen dioxide. Having repeated the procedure twice, the product was ground and sieved. This crocus martis had a dark brown color.

4. Crcocus martis prepared with aqua regia..$^{52}$ Chapter 19 presents perhaps the most intriguing way to prepare crocus martis - it involves aqua regia, an acid known for its ability to dissolve gold. 53 It should not come as a surprise that Neri earmarks it as "perhaps the best Art of all," even though he immediately assures that the other preparations should not be dismissed. The aqua regia was prepared and the steel filings were added to the liquid, which immediately dissolved while releasing brown fumes, similar to the aqua fortis procedure. After the reaction stopped, the solution was heated to promote evaporation. During heating the remaining product turned from brown to black and finally to a red color. The crocus martis was ground and sieved, and revealed an intensely deep red color, unlike the other croci.

5. Crocus martis without additions. ${ }^{54}$ Next to Neri's four recipes, Kunckel gave one too in his commentary on crocus martis and argues that this variety is "even more perfect". It is prepared by calcining steel filings without any additions, after which "the Iron will swell on high as an extraordinary beautiful red and black powder". When trying the procedure in Baltimore, nothing of the sort happened. The filings simply turned black in the crucible. We did not observe a red color, nor did the filings swell as Kunckel described. Indeed, some of the clarity or transparency that features Neri's recipes - our reworkings matched the descriptions in the text - seems to be missing in Kunckel's commentary, which comes across as a little cryptic at times. He appears to withhold information, which he admits in the very last passage of his commentary, suggesting, for instance, that his crocus martis "surely serves for more than I care to mention here." 55

51 Idem, pp. 28-9.

52 Idem, p. 29.

53 The aqua regia was prepared by dissolving 4 grams of sal ammoniac $\left(\mathrm{NH}_{4} \mathrm{Cl}\right)$ in 32 grams of nitric acid $\left(\mathrm{HNO}_{3}\right)$.

54 Kunckel, Ars Vitraria Experimentalis, p. 60.

55 Idem, p. 61. 


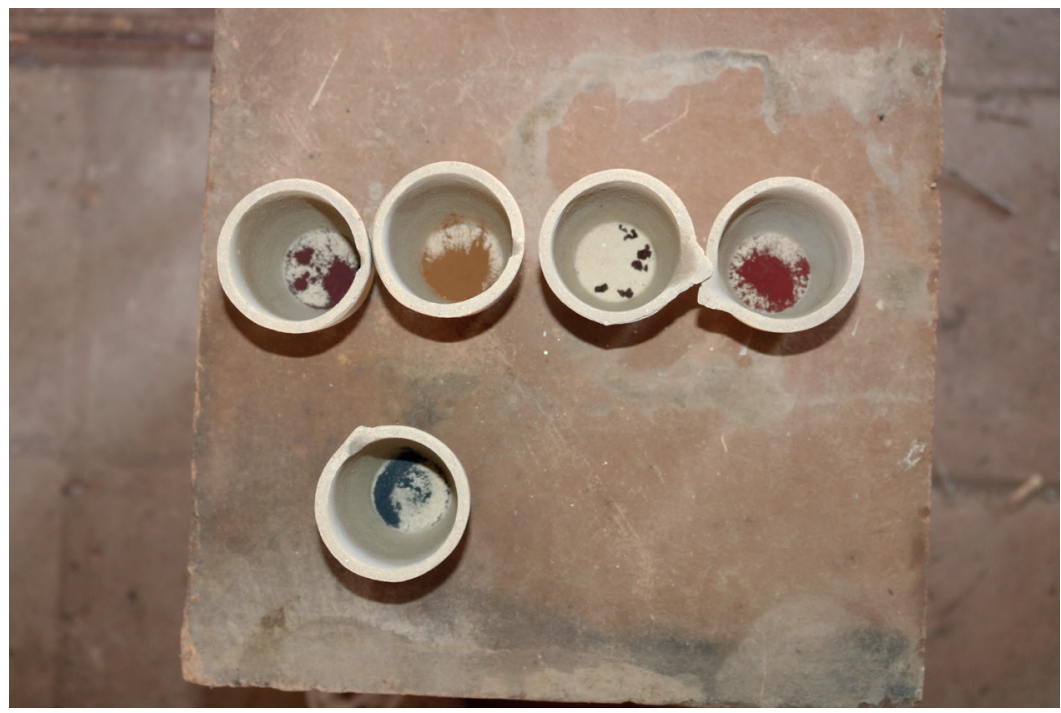

Figure 14: An overview of the five different crocus martis. Note the color differences. Top row, from left to right: crocus martis prepared with sulfur (chapter 16); crocus martis prepared with vinegar (chapter 17); crocus martis prepared with aqua fortis (chapter 18), and crocus martis prepared with aqua regia (chapter 19). Below: the crocus martis prepared without additives, as described by Kunckel in his commentary. Photo: ARTECHNE/VICARTE.

Five different procedures, five different croci. We were struck not only by the wide range of colors that the final croci possessed, but also by the deep red color that some of them exhibited. Rust can be unexpectedly beautiful! To continue with part two of the experiment, the crocus martis was shipped to Portugal where we used it to reproduce rosichiero recipe 128. The experiment was set up in a way that allowed us to compare the relative influence of each crocus martis on the color of the glass. For that purpose, we prepared five samples of recipe 128. One sample contained the crocus martis that was originally prescribed by the recipe (prepared with sulfur). In the other four samples, the originally prescribed variety of crocus martis was substituted for the other varieties (prepared with vinegar, aqua fortis, aqua regia and without additives). All the other ingredients were kept the same, and all samples were collectively melted in the same wood-fired furnace, thus ensuring similar conditions (We used the wood-fired furnace in Montemor-oNovo - see section 5). Having manufactured the rosichiero glass with the different croci, we found that each variety was responsible for a different shade of red in the glass (Figure 15). How these color differences arise as a result of differently 


\begin{tabular}{llllll}
\hline Furnace & Crocus Martis & $\mathbf{L}^{*}$ & $\mathbf{a}^{*}$ & $\mathbf{b}^{*}$ & Color \\
\hline \multirow{3}{*}{$\begin{array}{l}\text { Montemor-o- } \\
\text { Novo }\end{array}$} & 16 (sulfur) & 27.30 & 8.87 & 7.99 & \\
\cline { 2 - 5 } & 17 (vinegar) & 30.43 & 12.70 & 6.88 & \\
\cline { 2 - 5 } & 18 (aqua fortis) & 29.08 & 4.90 & 4.31 & \\
VICARTE & 19 (aqua regia) & 25.75 & 2.64 & 2.14 \\
glass studios & 17 (vinegar) & 31.21 & 13.30 & 8.87 & \\
\cline { 2 - 5 } & 18 (aqua fortis) & 29.70 & 12.07 & 6.11 & \\
\cline { 2 - 5 } & 19 (aqua regia) & 28.71 & 8.67 & 5.19 & \\
\hline
\end{tabular}

Table 1: Colorimetric measurements of the rosischiero samples produced with four different crocus martis and in two different furnaces - a wood-fired furnace (Montemoro-Novo) and an electric kiln (VICARTE glass studios). The color values were determined following the CIELAB standardization system. $L^{*}$ represents lightness from black (zero) to white (hundred), $\mathrm{a}^{*}$ from green (negative values) to red (positive values), and $\mathrm{b}^{*}$ from blue (negative values) to yellow (positive values). The shown colors are digitally rendered representations of the measured colors. Compare with Figures 15 and 21. CIE standard illuminant D65/2ㅇ.

prepared crocus martis is still unknown. It is possible that chemical impurities, diverging particle sizes or subtle morphological differences of the crocus martis play a role in these processes..$^{56}$ Be that as it may, our results do underscore the practical relevance of describing different preparation methods for crocus martis.

The entire experiment was repeated in two other furnaces as well: another wood-fired furnace and an electric kiln (Villa Borg and VICARTE respectively, see section 5). These replications taught us two things. First, the trials confirmed that differently prepared crocus martis result in different shades of color in the glass, just like our first experiment. Second, while different croci would generally yield different shades of color, we were unable to trace individual varieties of crocus martis to corresponding shades of color (See Table 1). One variety of crocus martis would thus produce a different shade in a different furnace. This, however, did not come as a surprise. As will become clear below, the color of the glass depends on many more variables than those of its ingredients alone. For example, different furnace conditions too are responsible for different coloring effects, thus prohibiting a simple comparison between trials using different furnaces.

56 Cornell and Schwertmann, The Iron Oxides. A more elaborate discussion of the experimental results will be published in a sequential paper. 


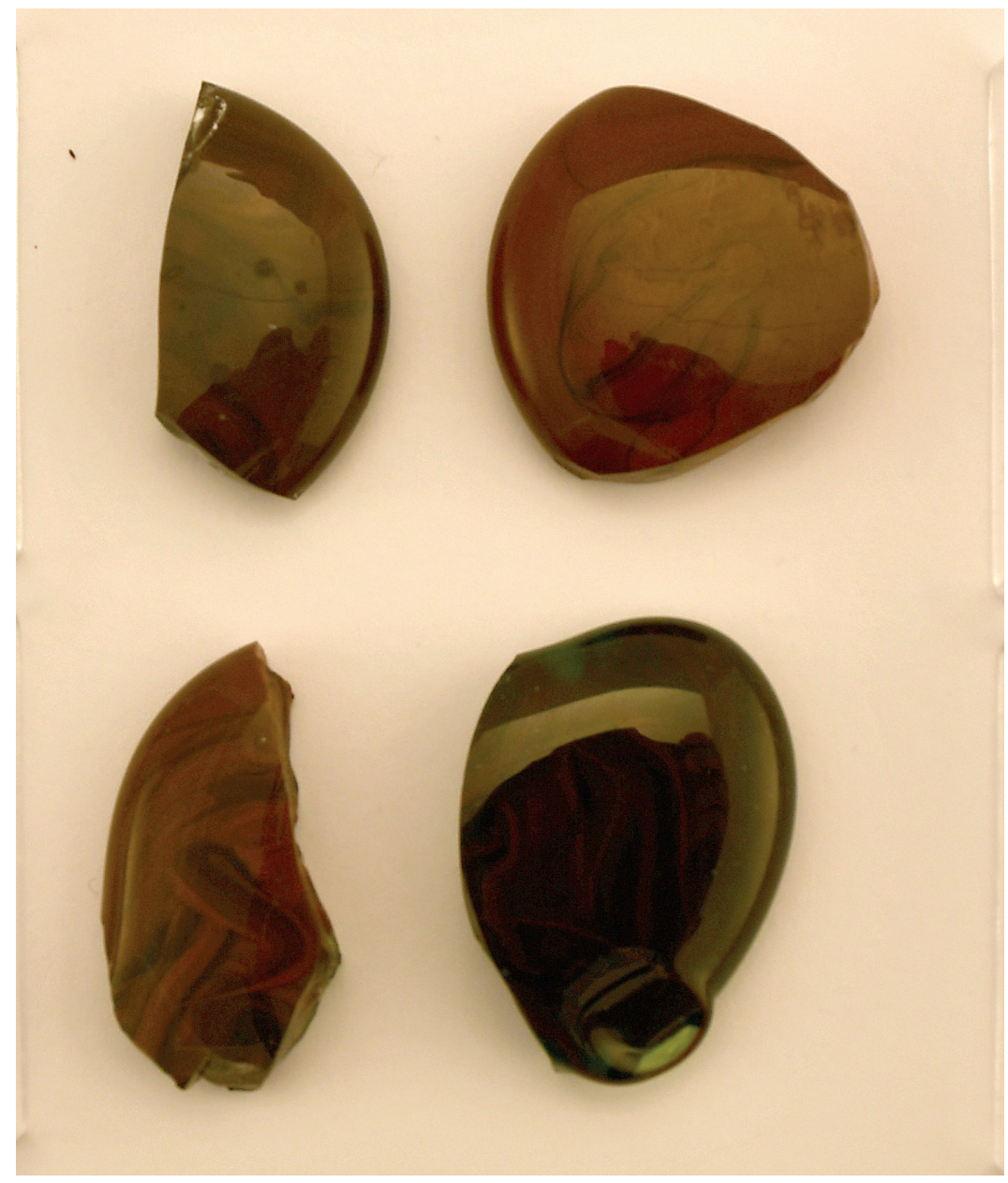

Figure 15: Reproductions of rosichiero recipe 128 using four different crocus martis. Upper left: rosichiero glass produced using crocus martis prepared with sulfur (chapter 16). Upper right: rosichiero glass produced using crocus martis prepared with vinegar (chapter 17). Lower left: rosichiero glass produced using crocus martis prepared with aqua fortis (chapter 18). Lower right: rosichiero glass produced using crocus martis prepared with aqua regia (chapter 19). The rosichiero glass with Kunckel's crocus martis is not shown here. The reproductions were performed in a wood-fired furnace in Montemor-o-Novo. Compare with Figure 21 that displays the same samples but under different lighting conditions. Photos: Élia Roldão. 
Yet, establishing a clear connection between different croci and their respective coloring effects is not what this experiment was about. Kunckel too did not make these connections in his commentary on green glass. He was not trying to find the best crocus martis, nor did he try to determine which crocus martis was responsible for a particular shade of color. After all, chances were that these correlations would be shuffled in a different situation, similar to what happened during our trials. Rather, Kunckel made an argument about the different croci as a group: as long as differences exist in the preparation of crocus martis, differences will arise in the color of the glass. That is the lens through which the material conditions and color variations that are inherent to rosichiero glass can be explored. In the eye of the glassmaker, it matters what sorts of rust are used.

\section{Furnace Histories}

Before I analyze the reproduction of rosichiero glass using wood-fired furnaces, it is sensible to take a step back and look at the history and historiography of furnaces in general. Furnaces might seem uncomplicated tools, but the reality behind stoking and managing fire, heat, draft and combustion is complex and furnace stoking requires serious skill and continuous attention. Some of these complexities have been described in the secondary literature, which also informed how we understood and approached the role of furnaces in our rosichiero reproductions. Even though the scholarship on the history of furnaces and furnace design is fragmented, to say the very least, there are a few interesting points that can be made.

Throughout history, furnaces have connected different groups of people, different arts and activities, and served multiple interests. ${ }^{57}$ Ancient Greek alchemical recipes, for instance, frequently mention that furnaces used in glassmaking and pottery are also suitable for alchemical procedures. Even bread ovens are mentioned as viable candidates..$^{58}$ Similar patterns are discernable in the early modern period. The ubiquity of fire, furnaces and corresponding tools such as distilling hardware, tongs and bellows, do not distinguish laboratories from artisanal workshops, and arts such as glassmaking, dyeing and goldsmithing from alchemy. ${ }^{59}$ Renaissance examples of artisanal trading zones, such as the Florentine Uffizi Gallery and the Casino de San Marco, even contained specially

57 Even though this not the place to develop it into a full-blown argument, furnaces share the characteristics of boundary objects - an intriguing perspective from which their history can be explored. See Star and Griesemer, "Institutional Ecology”; Star, “This is Not a Boundary Object".

58 Martelli, "Greek Alchemists at Work", p. 309.

59 Dupré, "Introduction" in Laboraties of Art, pp. vii-xix. 
allocated workshops, the fonderia, in which fire-related activities and arts were concentrated. ${ }^{60}$ In the eighteenth century, an organized group of artisans existed in Paris who were specialized in furnace building: the fournalistes. ${ }^{61}$ They are described as the artisans "who make the earthen furnaces that are used by the mints for refining and melting of metals, for distillations, and finally for all the works of golds- and silversmiths, the foundry and for chymical operations." ${ }^{2}$ Another example is found in the Royal Prussian Porcelain Manufactory at the end of the eighteenth century, which brought in outside experts to experiment with and improve their furnaces. The interesting thing is not only that the Manufactory collaborated with chemists to this end - e.g. Alexander von Humboldt (1769 - 1859) and Martin Heinrich Klaproth (1643-1817) - but also that the Prussian government actively promoted improvement and study of furnaces in anticipation of a growing shortage of wood as a fuel. ${ }^{63}$ A similar story can be told about Scotland, where the chemist Joseph Black (1728-1799) was consulted by the Secretary of the Board of Trustees for Manufactures in Scotland to assess a new type of furnace for iron production. ${ }^{6}$ These examples suggest that pyrotechnical skill and knowledge such as furnace design brought together different groups of people with diverging interests. Indeed, it has been shown that ideas on furnace design travelled back and forth between Europe and the New World. ${ }^{65}$ However, much about where and how these interactions occurred and whether these collaborations took place on a regular basis remains largely unexplored.

Furnaces can also be considered in terms of technical innovation and operational properties. ${ }^{66}$ One of these innovations concerns the development of portable or mobile furnaces in eighteenth-century chemistry. ${ }^{67}$ Interest in these convenient furnaces increased with the recognition of their versatility; they could facilitate almost all chemical operations. Different designs began to circulate, but one design in particular by Joseph Black appears to have caught on, which among other things contained eight different brass plugs that could be removed to regulate the temperature. ${ }^{68}$ Temperature control in general was a major fornacic concern, which pushed the Dutch engineer Cornelis Drebbel (1572-1633) to

6o Kieffer, "The Laboraties of Art and Alchemy"; Beretta, "Material and Temporal Powers".

61 I would like to thank Marco Beretta for pointing this out to me. As he argued earlier, the fournalistes also supplied the furnaces and crucibles to French chemists such as Antoine Baumé and Antoine Lavoisier: Beretta, "Between the Workshop and the Laboratory", p. 201.

62 Jaubert, Dictionnaire Raisonné Universel, pp. $306 f f$.

63 Klein, "Chemical Experts", p. 117.

64 See: Anderson, "Joseph Black and His Chemical Furnace".

65 White and Woodward, "'A Most Exquisite Fellow"'.

66 For a comprehensive and technical overview of pyrotechnics and furnaces, see Rehder, The Mastery and Uses of Fire.

67 Werrett, Thrifty Science, pp. 105-7.

68 Anderson, "Joseph Black and His Chemical Furnace". 
develop a thermostatic or self-regulating oven that employed two instruments: a thermometer-like device and a feedback mechanism that could open and close a lever to adjust the airflow into the oven. As Vera Keller points out, Drebbel's furnace emerged from intersecting concerns and interests in alchemy, philosophy, engineering, and natural magic. ${ }^{69}$ Other furnace-related issues that required continuous attention were their efficiency and the temperatures they could reach. ${ }^{70}$ So much so, that William Newman compared the pursuit of a reliable furnace with "a quest for the Holy Grail." ${ }^{71}$ Indeed, seventeenth-century figures like the chemist Johann Rudolf Glauber (1604-1670) and William White (ca. 16oo1673), a colonial technologist and expert furnace-maker, worked simultaneously on a new design for air furnaces that employed smokestacks, which, thanks to a chimney draft, provided more control while demanding less attention, consumed less fuel and reached higher temperatures..$^{72}$ Fuel too was an issue that helped shape furnace design. The substitution of coal for wood in response to increasing deforestation co-determined new pyrotechnical innovations from the sixteenth century onwards. ${ }^{73}$ What immediately stands out are the introduction of iron grills to support the coals and an ash-chamber to gather the unburned remains, while in glassmaking the use of covered glass pots was promoted to prevent the coal fumes from damaging the glass. ${ }^{74}$ Christopher Merret, for instance, in his English translation of Neri's L'Arte Vetraria, offers an overview of such coal-fueled furnaces in English glassmaking, whereas Neri and Kunckel resorted to wood to fire their Italian and German furnaces. ${ }^{75}$

Especially important with respect to the reproduction of rosichiero glass is the question of how furnaces interfere with the glass beyond supplying heat. Or, as the archaeologists Martinón-Torres and Rheren asked, what differentiates a furnace "from the common bonfire or cooking oven" ${ }^{76}$ In the historiography of science, this issue has received almost no attention, but an important exception is found in Lawrence M. Principe's study of the luminous Bologna Stone, an early modern chemical curiosity. Successful production of this stone depended on the design of the furnace. ${ }^{77}$ Luminosity, as Principe demonstrates, is enabled by a

69 Keller, "Re-entangling the Thermometer".

70 The following two blog posts explore furnaces and temperature control from a practical perspective, involving reconstructions: Hendriksen and Verwaal, "The 'Gentle Heat' of Boerhaave's Little Furnace"; Hendriksen and Verwaal, "A Cool Oven".

71 Newman, Gehennical Fire, p. 53.

72 White and Woodward, "A Most Exquisite Fellow".

73 Clow and Clow, The Chemical Revolution, pp. 27-9, 271. Peat too, has been used for glassmaking, albeit to a significantly lesser extent. Schlüter, "The Use of Peat in Danish Glassworks".

74 Charleston, "Glass Furnaces through the Ages".

75 "Of the furnaces," in Merret, The Art of Glass, pp. 239-249.

76 Martinón-Torres and Rehren, "Technical Ceramics”, p. 110.

77 Principe, "Chymical Exotica”. 
strong reducing atmosphere in the furnace, which is achieved through incomplete combustion. Key to the production of this luminous stone is building a specific furnace whose vents are so small that the supply of oxygen remains limited and the formation of carbon monoxide is promoted over that of carbon dioxide. Indeed, reproductions of the specific furnace and the Bologna stone revealed that luminosity could not be achieved when the stone was calcined outside this special furnace, for example on an open charcoal fire. Perhaps even more important is that the effects of different furnace atmospheres were also known to the historical figures who operated the furnaces. For example, Wilhelm Homburg (1653-1715) - one of the early modern chymists who worked on the Bologna stone - was very aware of the need for a specifically designed furnace for this purpose, which underscores that furnaces were perceived as complicated tools that do much more than just heating. Another example is found about a century later at the Royal Prussian Porcelain Manufactory, where Alexander von Humboldt performed tests on the firing of colored enamels by injecting additional "vital air" (oxygen) into the furnace. Humboldt explained that he expected to change the particular shade of color by altering the level of oxygen in the furnace. ${ }^{78}$

The question of furnace atmospheres has received more attention in archaeology and conservation and restoration, specifically concerning historical metallurgy, ceramics and glass. ${ }^{79}$ It has been argued, for example, that the typical black and red gloss on ancient Greek pottery was not produced using two different coloring agents, but simply by manipulating firing conditions. ${ }^{80}$ The ingredient for both colors was the same iron-based mineral. The black color was produced by putting the vessel in a furnace with a reducing atmosphere. Reduction was achieved in a number of ways, for example by using wet wood or by blocking the air vents to limit the draft. The red color was achieved in a second round of firing, for which the oxygen supply in the furnace was restored. Closer to home are various studies in which the effect of furnace atmospheres on glass have been experimentally investigated. Reproductions of medieval forest glass have shown that a range of colors can be achieved by using just one single recipe. ${ }^{81}$ One example is a medieval recipe for glass found in Theophilus' De Diversis Artibus (On Diverse Arts), a twelfth-century Latin text dealing with medieval arts, that prescribed one part sand and two parts of beechwood ash. ${ }^{82}$ The ashes and sand contain oxides of manganese iron that serve as natural colorants, and

78 Klein, “Chemical Experts", pp. 116-7.

79 For a technical discussion and various examples, see Rehder, The Mastery and Uses of Fire.

8o Walton et al., "Characterization of Coral Red Slips on Greek Attic Pottery".

81 Davison, Conservation and Restoration of Glass, pp. 6-8; Royce-Roll, "The Colors of Romanesque Stained Glass"; Henderson, Ancient Glass, pp. 65-8.

82 Hawthorne and Smith, Theophilus on Diverse Arts, pp. 52-7. 
adjusting the furnace conditions is enough to alter the color. Oxidizing conditions culminate in a purple color, intermediate conditions in a flesh or pink color, and reducing conditions in a yellow color. Adding copper as another colorant changes the spectrum of colors that could be created, but here too, the atmosphere remains a significant factor: an oxidizing atmosphere creates a blue glass and a reducing atmosphere produces a red colored glass. ${ }^{83}$ These examples show that furnaces not only provide heat, but also feature as a chemically significant environment that, whether controlled or not, affects the products that are being fired.

While most elements in furnace design can be explained by material motives, sometimes an evolution in furnace design is best explained as a form of geographical differentiation. A comprehensive overview of glass furnaces, both based on archaeological remains and textual sources, shows how it is possible to distinguish between a southern and northern tradition in glass furnace building. The southern tradition, which can be dated back to manuscript sources from about 9 A.D., comprises furnaces that are circular and feature an annealing chamber on top of the structure. This southern tradition culminated in the typical 'beehive' furnaces that are described and depicted in Renaissance sources such as Agricola's De Re Metallica (1556) (Figure 16). The Northern tradition, on the other hand, featured rectangular designs in which the annealing furnace was built separately from the main furnace in which the glass was melted. In these cases, the annealing furnaces were heated through a fire-channel connected to the main furnace. ${ }^{84} \mathrm{~A}$ similar fire-channel can actually be found in Kunckel's description of his experimental furnace, to which I will later return. Even though it has been suggested that the geographical differences in furnaces might be related to the availability of one particular ingredient for glass - sodium-based ashes in the south and potassium-based ashes (potash) in the northern regions - there is no further evidence to back this claim. ${ }^{85}$

This overview is far from exhaustive. If anything, it testifies to the complexity of fornacic history, while suggesting some angles from which this history might be pursued. It is only by collecting and mapping instances of furnace design, furnace building and furnace operation that that we can begin to understand the great variety of furnaces that were once used, as well as the scrutiny and sensitivity that historical actors displayed in these matters. In case of the rosichiero glass, two factors caught our attention in particular. How would the furnace atmosphere affect the composition of the glass? And what does it take to operate a furnace at a steady temperature, especially in a seventeenth-century workshop where autoregulating devices such as Drebbel's invention and thermometers were lacking?

83 Royce-Roll, “The Colors of Romanesque Stained Glass”, p. 78.

84 Charleston, "Glass Furnaces through the Ages".

85 Charleston, "Glass Furnaces through the Ages", p. 10. 


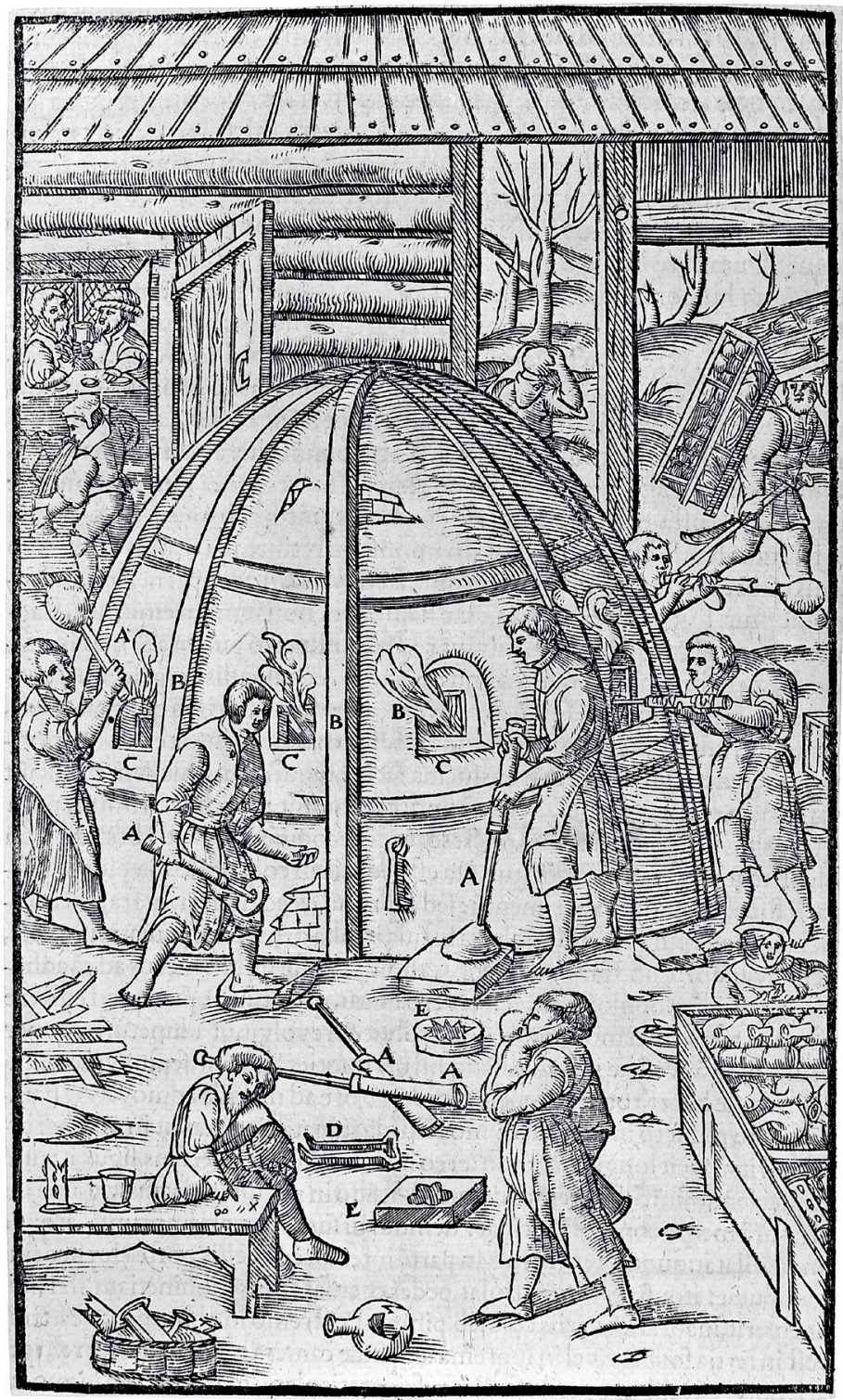

Figure 16: A typical 'beehive glass' furnace as depicted in Agricola, De re metallica (1556). The furnace is divided into three sections. The fire is stoked near the ground. The crucibles with molten glass sit on the next level. The upper level is the leer, the cool oven, where glass objects are annealed and gradually cool down. Photo: Wellcome Collection. 


\section{The Fire and the Furnace}

With all ingredients prepared, from the crocus martis to the crystal frit, we were ready to study the role of fire and furnace conditions in glassmaking. We explored this topic from a material point of view - asking how different furnaces and furnace conditions would shape the consistency and composition of the glass - and from a perspective of skill. In total we used four different furnaces to reproduce the rosichiero glass. The first two were electric kilns at the VICARTE glass studios in Lisbon (Figure 17). The other two were wood-fired furnaces in Montemor-o-Novo (Portugal) and the Roman Villa Borg (Germany). The furnace in Montemor-o-Novo is designed vertically and is used to fire ceramics (Figure 18). It has two holes near the ground in which fire is made. The two fire holes are on opposite sides and end up in the main chamber on top that contains the crucibles. The oven is built as such to create a down-draft. The heat and flames are reflected back by the ceiling and go down again, touching the crucibles, and leaving the chamber through the chimney-opening at the bottom in the back. During our reproductions, we had to adjust the furnace to reach higher temperatures, to which end the chimney was extended by approximately two meters. It is worth

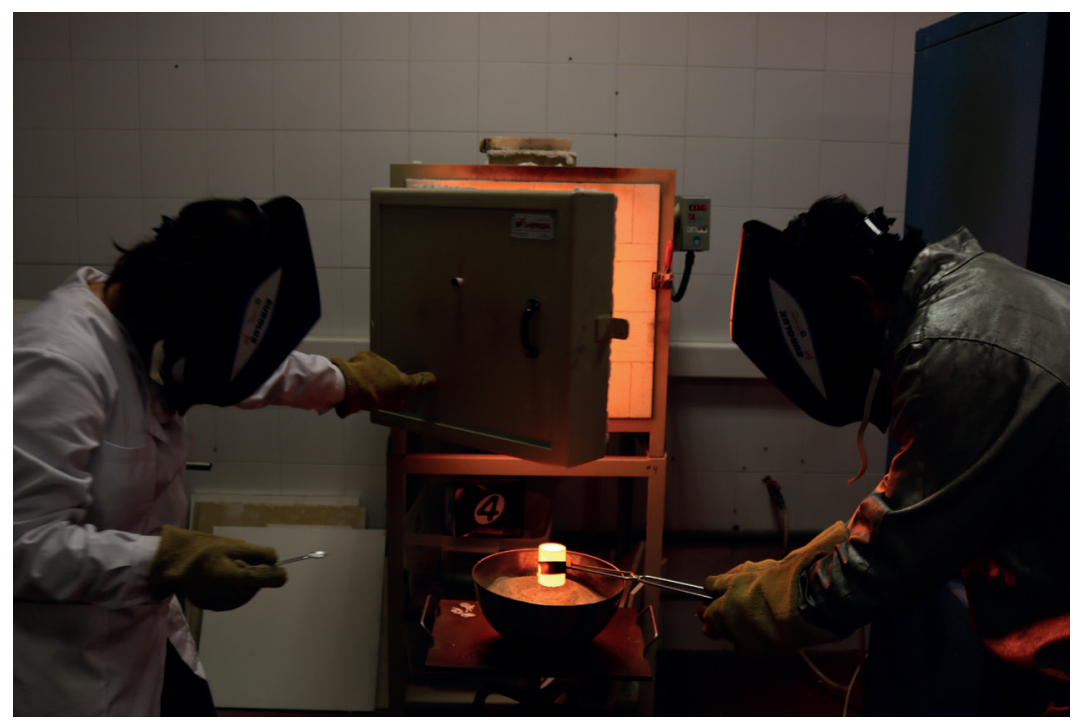

Figure 17: One of the two electric kilns we used at the VICARTE glass studios in Lisbon (Portugal). Note the thermoregulating device attached to its right side. The other electric kiln is depicted in Figure 9. Photo: ARTECHNE/ VICARTE. 


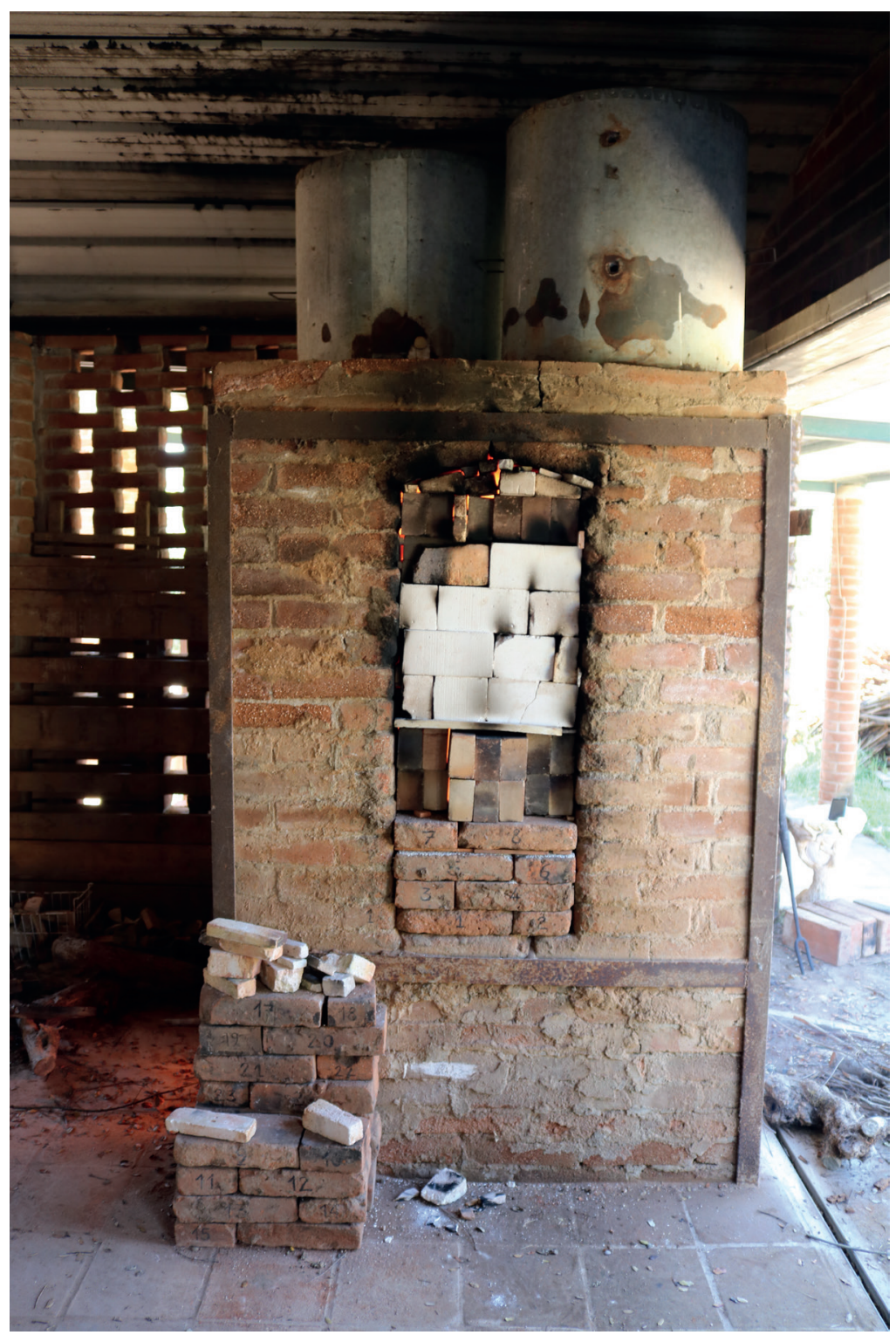

Figure 18: The wood-fired furnace in Montemor-O-Novo (Portugal). The fire is stoked at both sides near the bottom (invisible in this photo, but compare with Figures $7 \& 20$ ). The entrance to the main chamber is provisionally blocked to retain the heat. To put the samples inside the furnace, or to get them out, various bricks had to be temporarily removed. The practice of blocking entrances and holes of glass furnaces is mentioned too in historical sources, such as Agricola's De re metallica. (Royce-Roll, 1994). Photo: ARTECHNE/VICARTE. 
mentioning that the Montemor-o-Novo furnace resembles the experimental furnace that Kunckel described in his book and that he used for glass tests. I will return to this topic below. The furnace at Villa Borg is distinctly different from the one at Montemor-o-Novo (Figure 19). It was a reconstructed Roman glass furnace, a horizontal model, that was fully raised from cob, a combination of clay and straw. ${ }^{86}$ It follows the archetypical design of a reverberatory furnace, in which the low ceiling radiates the heat back onto the crucibles. ${ }^{87}$ The fire is stoked at one end and the flames are guided toward the other, such that they extend over the crucibles along the way. The crucibles are positioned behind four shielded openings, two openings at each side of the furnace. The smoke leaves from a chimney-hole rather than an actual chimney. There is sufficient draft, however, which can be adjusted by partially covering the hole.

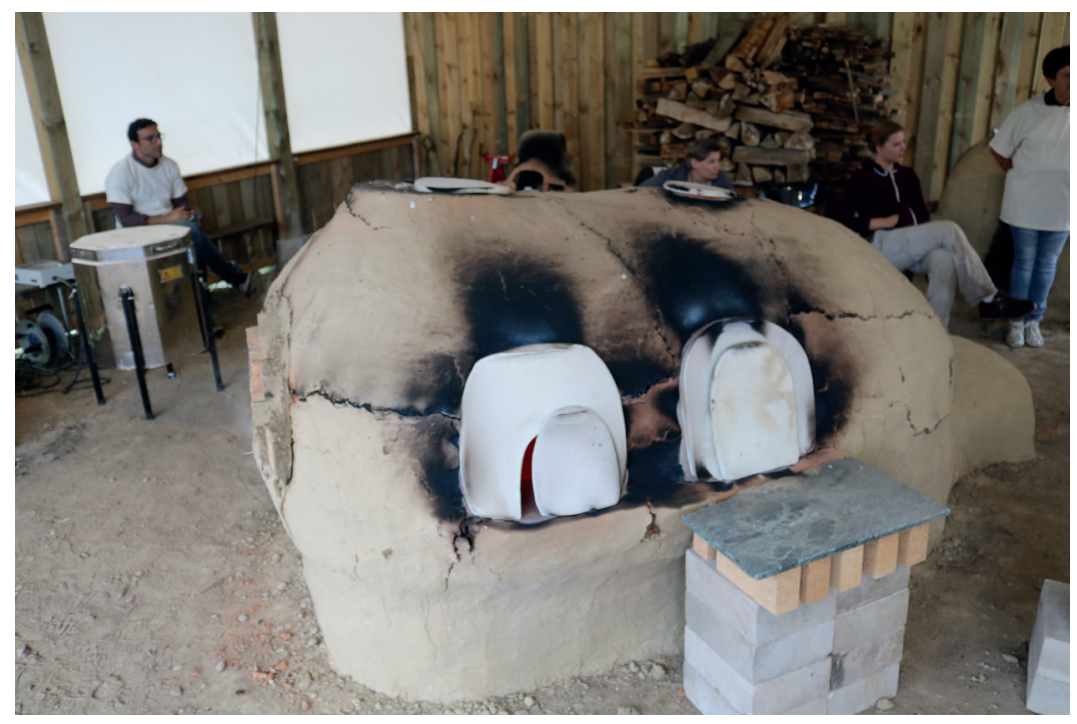

Figure 19: The wood-fired furnace at Villa Borg (Germany). The furnace is a reconstructed Roman glass furnace and is very similar to a reverberatory furnace. The fire is stoked at the far end to the right. The crucibles with molten glass sit behind two doors at each side, which can be opened and closed by removing the white slabs. The slabs at the top can be removed and adjusted to control the draft inside the furnace. Compare with Figure 8. Photo: ARTECHNE/VICARTE.

86 Birkenhagen and Wiesenberg, "Der experimentalarchäologische Werkstattbereich".

87 Rehder, The Mastery and Uses of Fire, p. 42. 
Each glass recipe was scaled down to fit small ceramic crucibles of volumes of approximately 8occ. This meant that we brought down the amount of glass base mentioned in the recipes (in the range of $1.9-7,5 \mathrm{~kg}$ ) to 30 grams each, while keeping the ratios with respect to the other ingredients. It has been argued that downscaling might introduce new and unforeseen issues when reproducing recipes. ${ }^{88}$ While it might indeed be argued that bigger batches would enable better mixing, thus allowing for more homogeneity in the glass, there are indications that Kunckel too, downscaled the glass recipes to perform glass tests in his experimental furnace. This means that the potential problems introduced by downscaling would resemble Kunckel's workshop practices even more closely than would be the case if we followed the original amounts prescribed by the recipes. I will return to this issue below.

Each time a new ingredient had to be stirred into the glass, one person took the crucible out of the furnace, another stirred the ingredient(s) into the molten batch, and the crucible was returned to the furnace. A typical procedure, like our reproduction of rosichiero recipe (128), consisted of the following steps: 1) heating and melting the crystal frit in the furnace, 2) mixing in the calx of leadtin, followed by reheating, 3) mixing in the copper-oxides, followed by reheating, 4) mixing in cream-of-tartar, soot, and additional crocus martis, followed by reheating, and 5) pouring the glass and letting it cool. Mixing had to be done within a relatively short time span to ensure the glass would not cool down too much. With the wood-fired furnaces, a third person had to be involved to open and close the furnace, sometimes even having to extinguish the wooden handles of the tongs when they caught fire. Being a multi-person endeavor, reproducing the rosichiero glass became a choreographical exercise that required careful consideration and advance planning (Figure 20). ${ }^{89}$

The wood-fired furnaces could be stoked such that incomplete combustion takes place, thus contributing to reducing conditions in the presence of soot and carbon monoxide. There are even a few sensory indicators that help in recognizing a reducing atmosphere in the furnace..$^{\circ}$ For example, at Montemor-o-Novo we were told to pay attention to the smell. An oxidizing environment smells "clean," as if one is baking bread. When the smell turns unpleasant, it indicates incomplete combustion. Another way to recognize a reductive environment is to watch the openings and cracks in a furnace. If soot appears on the outside, the atmosphere in the furnace is reducing, and as soon as the black disappears, the furnace is oxidizing, meaning that the fire is able to clean away all unburned carbon. Considering all these variables, we expected that all furnaces would affect

88 See for instance: Carlyle, "Practical considerations"; Kirby et al., Natural Colorants, p. 87.

89 Vilarigues, "Choreographies of Glassmaking".

90 Fieldnotes Thijs Hagendijk, Tuesday 11 June, 2019. For sensory indicators: Hagendijk,

"Learning a Craft from Books". 


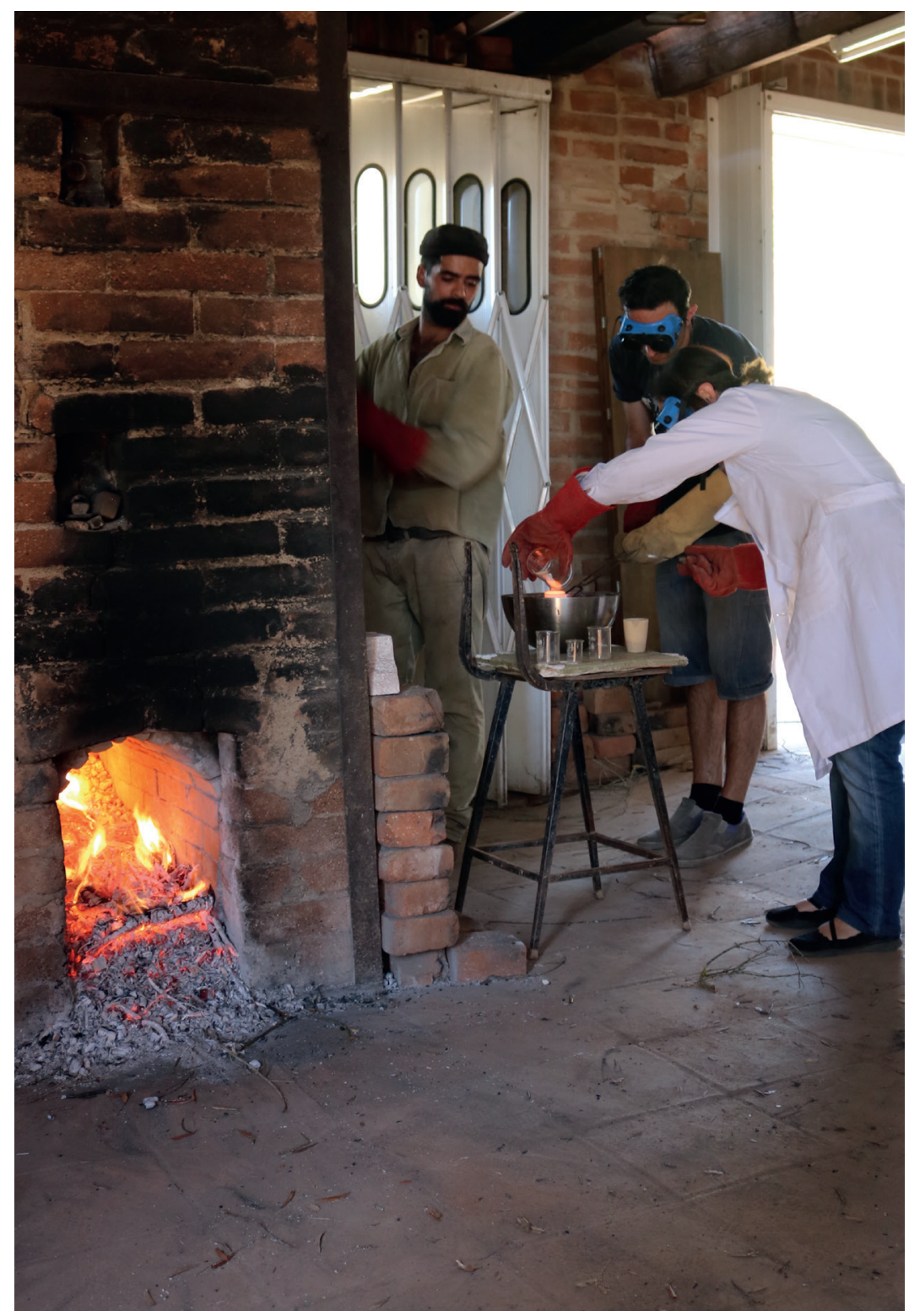

Figure 2o: Operating furnaces and producing glass are choreographical exercises. This photo was taken while working with the furnace in Montemor-o-Novo. One person has to remove the bricks from the furnace entrance (left), another picks up the crucible using tongs (middle), while a third person mixes the ingredient(s) into the molten glass (right). Photo: ARTECHNE/VICARTE. 
the glass differently. The electric kilns, in the absence of fire and combustion products, were expected to be more oxidizing than the wood-fired furnaces, which would presumably result in different compositions of the glass. But we were also curious to see whether differences would arise between the wood-fired furnaces themselves, which might perhaps be caused by differences in design.

When we reproduced the rosichiero glass from chapter 128, we found that different furnaces indeed produced different results (Figure 21). But it was not so much the color, but rather the composition of the glass that changed with the furnaces. The wood-fired furnaces in particular were so strongly reducing that, throughout the glass, elemental metal was visible to the naked eye. Not only was the copper successfully reduced to produce the red color, the lead and tin oxides too were reduced to such an extent that they had precipitated out of the glass. The furnace at Villa Borg was especially reductive; the glass we made there was the least homogenous of all and contained a high number of metallic parts (Figure 22). The glass produced in Montemor-o-Novo contained only minute bits of metal. Contrary to the wood-fired furnaces, the glass produced with the electric kilns was completely homogenous. All in all, our reproductions clearly show that furnace conditions strongly affect the glass that is produced in the furnace. To guarantee the production of a good quality rosichiero glass, these conditions need to be anticipated, controlled and adjusted, which demands serious skill and practice from the glassmaker. But there is more.

Working with wood-fired furnaces acquainted us with the pyrotechnical skills that were fundamental to historical glassmaking practices more generally. Stoking a fire, raising the temperature and keeping the temperature steady at a certain level, requires the ability to read and respond to a furnace and its needs. Consider how this was done in the seventeenth century, without the availability of thermometers and automatic thermo-regulating devices. It is true that some efforts were being made to develop temperature-controlled furnaces, for instance by the previously mentioned Cornelis Drebbel (1572-1633), but in general, gauging the temperature of a furnace was done by peeking inside and judging the color of the fire and the insides of the furnace, which ranges from dark orange for the lower temperatures to brighter yellow for the higher temperatures. This is an skill that can be trained. For instance, the people who worked with the furnace in Montemor-o-Novo had turned it into a competitive game. There are a few spyholes through which the insides of the furnace can be observed without having to open the furnace entirely. Taking turns, regularly estimating the temperature by checking the color, and verifying it with a thermometer, is how they learned quickly enough..$^{91}$ The experienced glassblowers at Villa Borg had a similar approach and challenged the novices to stare into the furnace as 


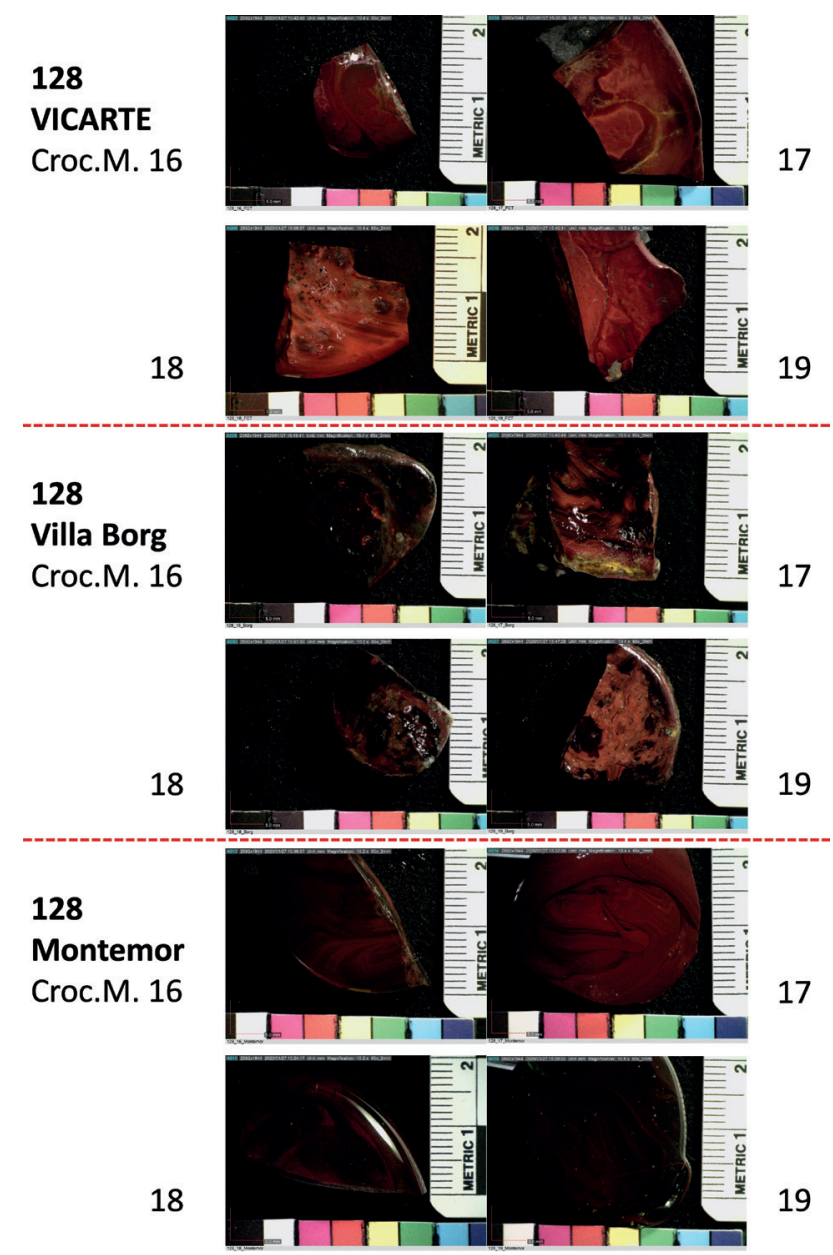

Figure 21: Overview of reproductions of rosichiero glass based on recipe 128 using three different furnaces and four different crocus martis (chapters 16-19). The samples show how each furnace impacts the glass differently. The top four samples were produced with the electric kiln at the VICARTE glass studios. The four samples in the middle with the wood-fired furnace at Villa Borg. The four samples below with the wood-fired furnace at Montemor-o-Novo. Note the difference in composition. The glass from Villa Borg (middle four) contained a high number of metallic parts, indicating significant reducing conditions in the furnace. Compare with Figure 22. The glass from Montemor-o-Novo was considerably more homogeneous, but still contained small metallic clusters, indicating a slightly reducing furnacic atmosphere. The glass produced using the electric kiln was homogenous. Photos: Élia Roldão. 


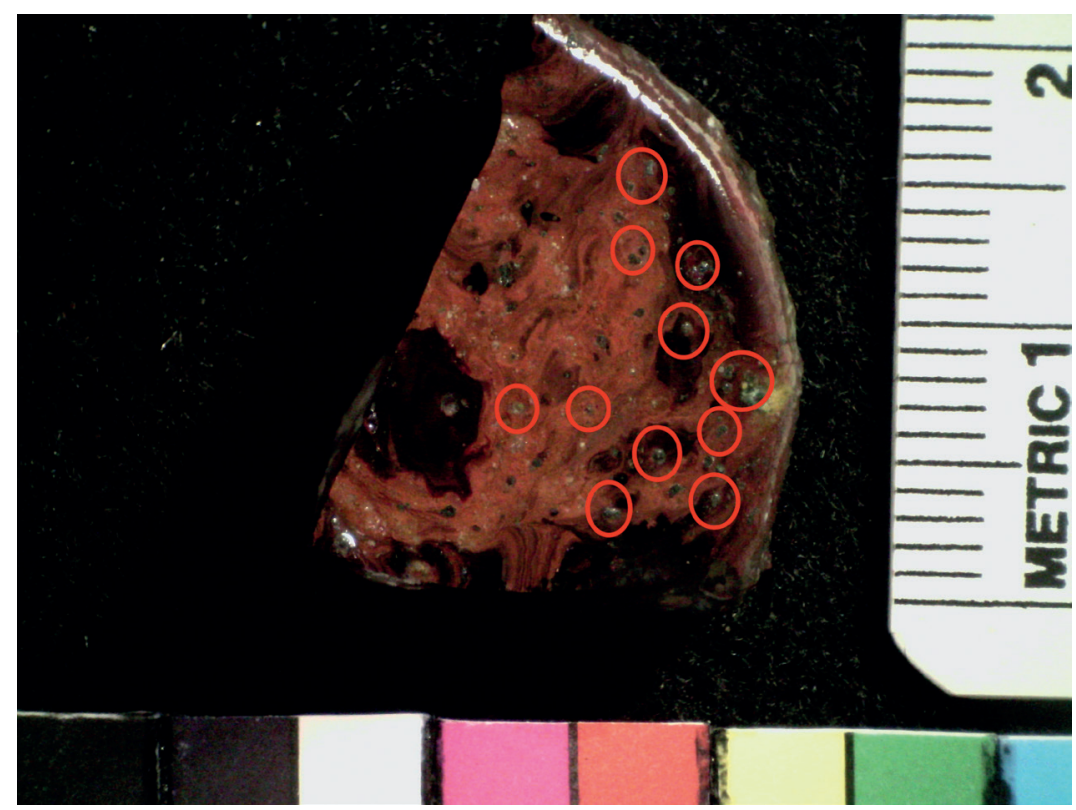

Figure 22: The glass produced with the furnace from Villa Borg contained a significant number of metallic parts. This is a close-up of a reproduction of rosichiero glass based on chapter 128 made with crocus martis from chapter 19. The red circles indicate examples of reduced metal in the glass. Photo: Élia Roldão.

soon as there was nothing else to do, and to check their estimations with the measurement of the thermocouple. However, being able to adequately read the temperature of a furnace does not mean much if you are not able to further control it. Indeed, while reworking the recipes, we had to deal with an exhausting number of variables. Variations in temperature were for instance caused by wind and weather conditions and the types of fuel used. Moreover, the temperature of the crucibles also depended on their respective positions in the furnace, and the temperature would drop significantly each time a new log of wood was thrown on the fire. ${ }^{92}$ Managing temperatures also depended on the design of the furnaces themselves. Stoking the furnace at villa Borg, for instance, was much easier

92 Royce-Roll, "The Colors of Romanesque Stained Glass". Royce-Roll came previously to similar conclusions. During glass reconstructions in a wood-fired furnace, they "discovered that only certain 'hot spots' on the melt chamber's siege platform (the inside ledge on which crucibles rest) reached the temperature necessary to melt medieval glass types", p. 78. 
than stoking the Montemor-o-Novo furnace. The biggest challenge in terms of temperature control turned out to have a social component. We had to share the furnace in Germany with glassblowers, whose priorities did not overlap with ours. While we were desperate to maintain a steady temperature, the glassblowers would leave the doors open to gather glass and to reheat their objects, which resulted in significant temperature drops. It happened several times that we had to wait before executing the next step in the recipe, because the glass had lost part of its malleability and needed to become a little hotter first. A furnace is a tool that draws together a plurality of people, activities and interests at one and the same time. Things like stoking, glass blowing, glass gathering, reheating and performing experiments can exist next to each other, but are as likely to invite conflicting situations, thus requiring continuous renegotiation.

Some related variables in furnace management are also explicitly mentioned by Kunckel, Neri and Merret. Kunckel points out, for instance, that German furnaces are generally stoked hotter than those in Italy, because of a relative abundance of wood. ${ }^{33}$ This has consequences for how Neri's Italian recipes should be executed in Germany. For example, a recipe for milk-colored glass, lattimo, only needs to stay in the furnace for three days according to Kunckel, instead of the 18 days required by Neri. ${ }^{94}$ Neri in turn, warns that one must be careful when using hard dry wood, because the smoke it generates is harmful to the glass that is placed inside the furnace. ${ }^{95}$ Merret, in response to Neri's preference for oak, gives an overview of other types of wood that can be used. For example, ash wood creates a "pleasant fire," but it burns quickly. And wood from the juniper tree provides a "lasting and strong, and sweet fire" ${ }^{96}$

Moreover, Kunckel describes a specific and versatile furnace that he used for glass tests and experiments "with various useful things" (Figure 23). ${ }^{97}$ Its performance is more than satisfying according to Kunckel: "Once it is truly hot," he explains, "it could melt everything that is meltable." It is also fuel efficient, because "once it is hot, it consumes not too much wood." On top of that, the furnace contains a fire channel by which its residual heat can be used to feed a smaller furnace for various smaller operations, for instance to calcine or "digest" (dissolve) substances. Kunckel's discussion of the furnace is relevant for two reasons. First, it shows that Kunckel was in the habit of testing glass, for which

93 Kunckel, Ars Vitraria Experimentalis, Vorrede, n.p.

94 Kunckel, Ars Vitraria Experimentalis, p. 100; Dupré, "Doing It Wrong", p. 184.

95 Neri in Engle, The Art of Glass, vol. 1, p. 8.

96 Merret, The Art of Glass, pp. 274-5.

97 Kunckel, Ars Vitraria Experimentalis, Pars Secunda, pp. 138-9: “[...] in welchen man auch auff einmahl fehr viel Glasproben einfetzen/ und allerhand nuitzliche Dinge experimentiren kan [...] in diefen Ofen/ wann er einmahl recht heiß/ kan man alles/ was nur zu fchmeltzen ift/ fchmeltzen/ [...] Es ift mir diefer Ofen fehr beqvem/nimmt auch/ wann er einmahl in der Hitze/ fo viel Holtz nicht weg [...]". 


\section{Chapter 3}

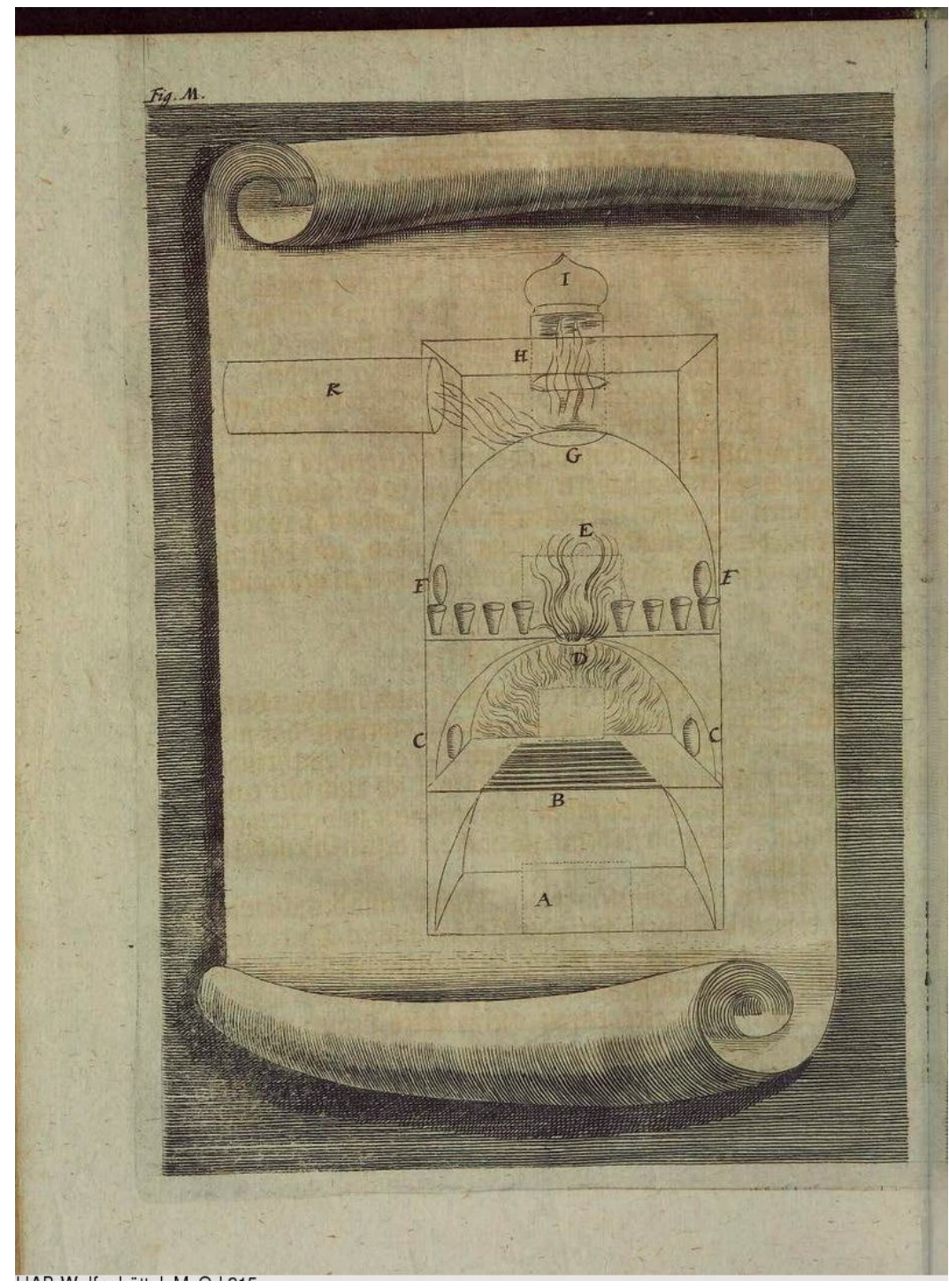

Figure 23: A sketch of Kunckel's compendious furnace that contains several small crucibles used for testing (F). Especially noteworthy is the fire channel $(\mathrm{K})$ that could be used to hook up another and smaller furnace. Photo: Deutsches Textarchiv. 
he purposefully scaled down the original formulas. He explains that his furnace has the capacity to conduct "twenty tests on a small scale" [ins kleine]. ${ }^{8}$ Indeed, making small tests is a sensible way to limit material costs - e.g. expensive colorants, costly wood for stoking - and to save someone from having to discard big batches of failed and otherwise useless glass. ${ }^{99}$ More evidence for Kunckel's use of glass tests was found in archaeological excavations of the remains of his glass laboratory on the Pfaueninsel, which were carried out in the 1970s. Many small crucibles were discovered that contained glass of various colors, ranging from green to red-brown, including shards of what appears to be gold ruby glass, Kunckel's most famous production. ${ }^{100}$

A surprising coincidence is that the size of the excavated crucibles (approx. $6.5 \mathrm{~cm}$ high and $3.5 \mathrm{~cm}$ in diameter) matches the size of the alumina crucibles that we used for our reproductions $(6.5 \mathrm{~cm}$ high and $4.7 \mathrm{~cm}$ in diameter). The excavations thus not only show that downscaling was a common historical operation, but also give an impression of the general size of Kunckel's tests. Second, Kunckel's description of his "remarkably adequate and compendious furnace" illustrates that different glass-related practices were distributed over different furnaces. Smaller work, such as glass tests or recipe testing, was preferably done in a separate and smaller furnace, without having to resort to the bigger founding furnaces that Kunckel also describes in his book (Figure 24). During our reproductions of the rosichiero glass, we personally experienced why a separate furnace would be convenient. Some glasses require a high and stable temperature, which is incompatible with the temperature drainages that occur during glass gathering, blowing and reheating. In addition, a separate furnace also allows the glassmaker to actively steer and optimize furnace conditions for one specific type of glass.

In sum, reworking the rosichiero recipes taught us that glassmaking is not only about mixing the right ingredients, but also about managing fires and furnace conditions. Hard as it is to adequately operate a furnace, one needs to consider that a furnace shapes the final composition of the glass. There is, however, nothing new in this. Neri already warned his readers in the preface of his L'Arte Vetraria not to underestimate the role of fire in glassmaking: "The fire in this art is of notable importance, indeed this is what perfects everything, and without which nothing can be done, therefore give it proportionate consideration." ${ }^{101}$ In the light of the textual transmission of know-how, one might wonder how the complexities involving furnaces were translated into text. How did Kunckel communicate

98 Kunckel, Ars Vitraria Experimentalis, Vorrede, n.p.

99 For a general exploration of the historical relations between economy and experiment, see Werrett, Thrifty Science.

100 Rau, "Johann Kunckel, Geheimer Kammerdiener", p. 135; Schulze, "Kunckels Glaslaboratorium"; Rau, "Das Glaslaboratorium des Johann Kunckel".

101 Neri in Engle, The Art of Glass, vol. 1, p. 8. 


\section{Chapter 3}

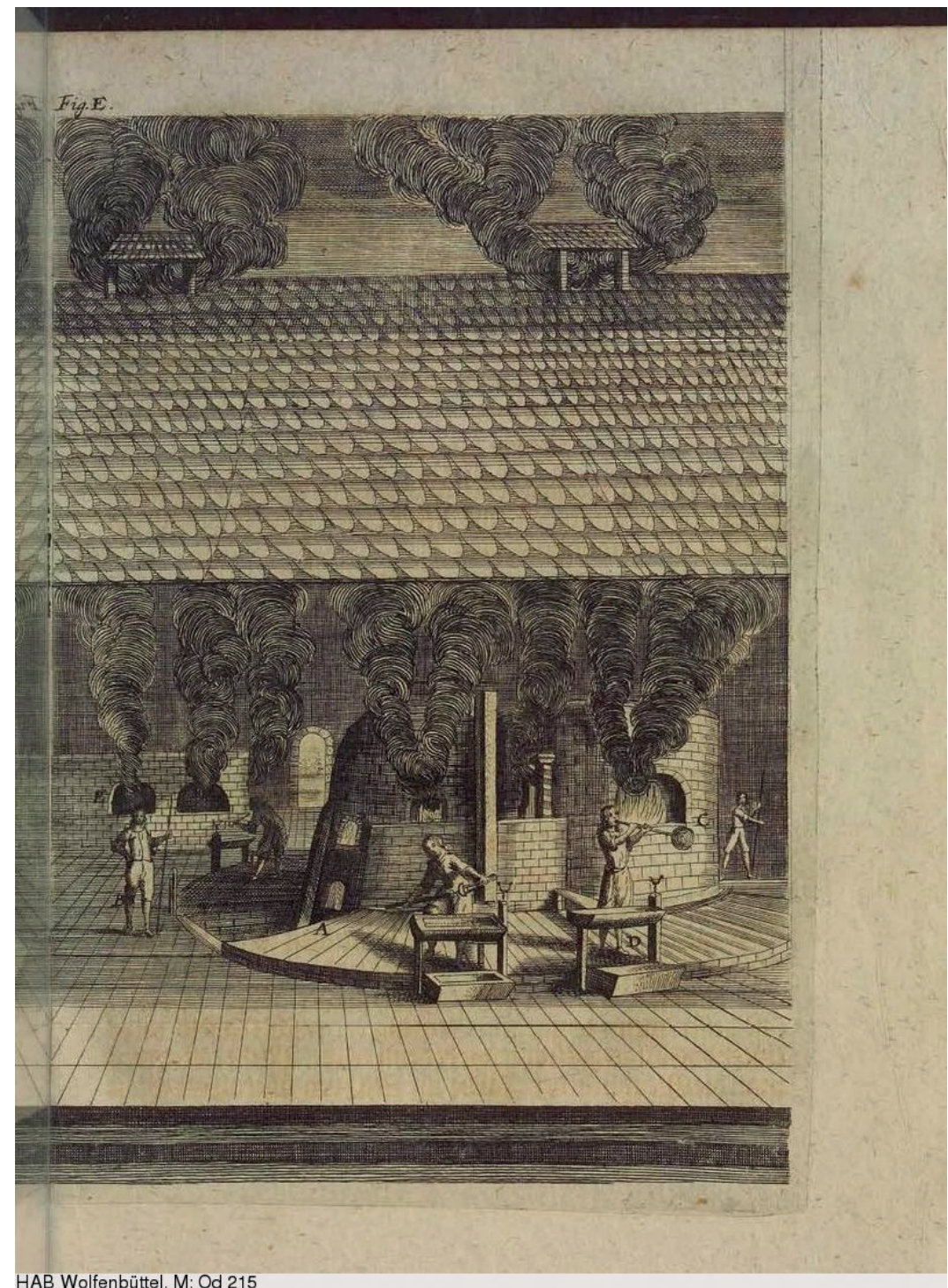

Figure 24: A sketch of a larger glass furnace that shows several glassblowers at work. Photo: Deutsches Textarchiv. 
the fornacic intricacies that one inevitably runs into when executing the glass recipes from the Ars Vitraria Experimentalis? The next section argues, among other things, that these pyrotechnical concerns have a specially allocated place in Kunckel's commentary.

\section{Ambivalence in Kunckel's Commentary}

Reworking recipes and reproducing the rosichiero glass gave insight into the material technologies, but also into the textual technologies present in Kunckel's Ars Vitraria Experimentalis. First, I will discuss Kunckel's commentary on the rosichiero recipes. Given Kunckel's strong empirical rhetoric, his emphasis on testing, and his stated ambition to correct the failures he detected in Neri's recipes, it comes naturally to wonder how his comments hold up against our experiences during our reproductions of rosichiero glass. It appears that Kunckel's commentary is ambivalent at times. While his comments are not always the improvements and corrections Kunckel claimed them to be, they are however particularly strong in conveying how furnaces influence the production of rosichiero glass. Second, Kunckel's commentary is but one out of various strategies found in the Ars Vitraria Experimentalis that motivates readers not to slavishly and unthinkingly follow recipes, but to engage with them, become independent of them, and to take matters into their own hands.

The fact that Kunckel's comments should not be interpreted as straightforward corrections of Neri's recipes became obvious during the reproduction of two different recipes for rosichiero glass. First, Kunckel's commentary remained suspiciously silent where we identified a substantial error during our reworking of chapter 124. Reproduction of the rosichiero glass using the ratios mentioned in this recipe resulted in a almost black color. The only way to resolve this issue was by 'diluting' the ingredients against the amount of crystal frit, the glass base. This meant that all ingredients, except the crystal frit, were substantially reduced, i.e. half of the original amounts that we were using in the first place. Only then, while keeping the rest of the procedure the same, did the glass become a red, albeit opaque, color. While our findings fully agree with previous assertions that Neri's rosichiero recipes are erroneous in nature, the question remains whether Kunckel spotted this issue too, and if so, why he did not make the effort to set the record straight in his commentary. ${ }^{102}$

Another issue arose during the reproduction of rosichiero chapter 125, which involved a special ingredient. According to Neri's recipe, "fixed sulfur" should be added to the glass in addition to the other ingredients. Neri subsequently refers to

102 Zecchin, "Le ricette vetrarie di Montpellier". 
another chapter (126), "how one should fix the sulfur for aforementioned use," that contains further instructions on how the sulfur should be processed such that it can be used for rosichiero. Kunckel, however, counters Neri's recommendation in his commentary and argues that the "fixed Sulphur does not serve any purpose here. It can as easily be left out as well as being added." ${ }^{103}$ As a result, the reader is left with two contradictory statements. Should Neri's instructions be followed to the letter? Or should we take Kunckel's advice seriously and ignore the additional sulfur? To validate Kunckel's comment we devised a simple experiment in which we reproduced chapter 125 with and without the sulfur. We were surprised to learn that the sulfur was actually an essential ingredient whose addition proved essential for the color of the glass. Without the sulfur, the glass turned green. With the sulfur however, and contrary to Kunckel's assertion, the glass turned red (Figure 25).

Both issues - i.e. Kunckel's apparent unawareness concerning the ratios in chapter 124 and his ill-advised characterization of the sulfur in chapter 125 render it unlikely that he actually tried these rosichiero recipes before writing his commentary. This also throws new light on the codification of error as a textual strategy, of which Kunckel's commentary has been put forward as a prime example. Indeed, Kunckel, like many other seventeenth-century authors and readers of practical and instructive texts, was well aware of the errors that were commonly made during processes of copying, transmission and translation of know-how. ${ }^{104}$ As it turned out however, his stated ambition to correct the failures with respect to Neri in the Ars Vitraria Experimentalis did not necessarily correspond to what he actually pulled off in his commentary. The idea behind it, or so it seems, was more important than its meticulous execution. The codification of error might therefore be partially interpreted as a rhetorical strategy, thus allowing Kunckel to promote himself as a credible expert at the Brandenburg court. After all, only an expert is able to spot the errors and correct the mistakes that others have made.

There is however another side to Kunckel's commentary. Despite the incongruences between his commentary and our reproductions of rosichiero glass, Kunckel does in fact provide valuable advice on fire management and adequate timing in glassmaking. Interestingly, and very similar to his commentary on crocus martis and green glass, his pyrotechnical comments are less concerned with individual recipes, but rather apply to all glazes and not just rosichiero:

It should be known that, like all Glazes, one should just attend to the Fire. Because when the Fire is much too Strong, the Color that one obtains will perish and another will appear that one does not desire nor wants to have. ${ }^{105}$ 


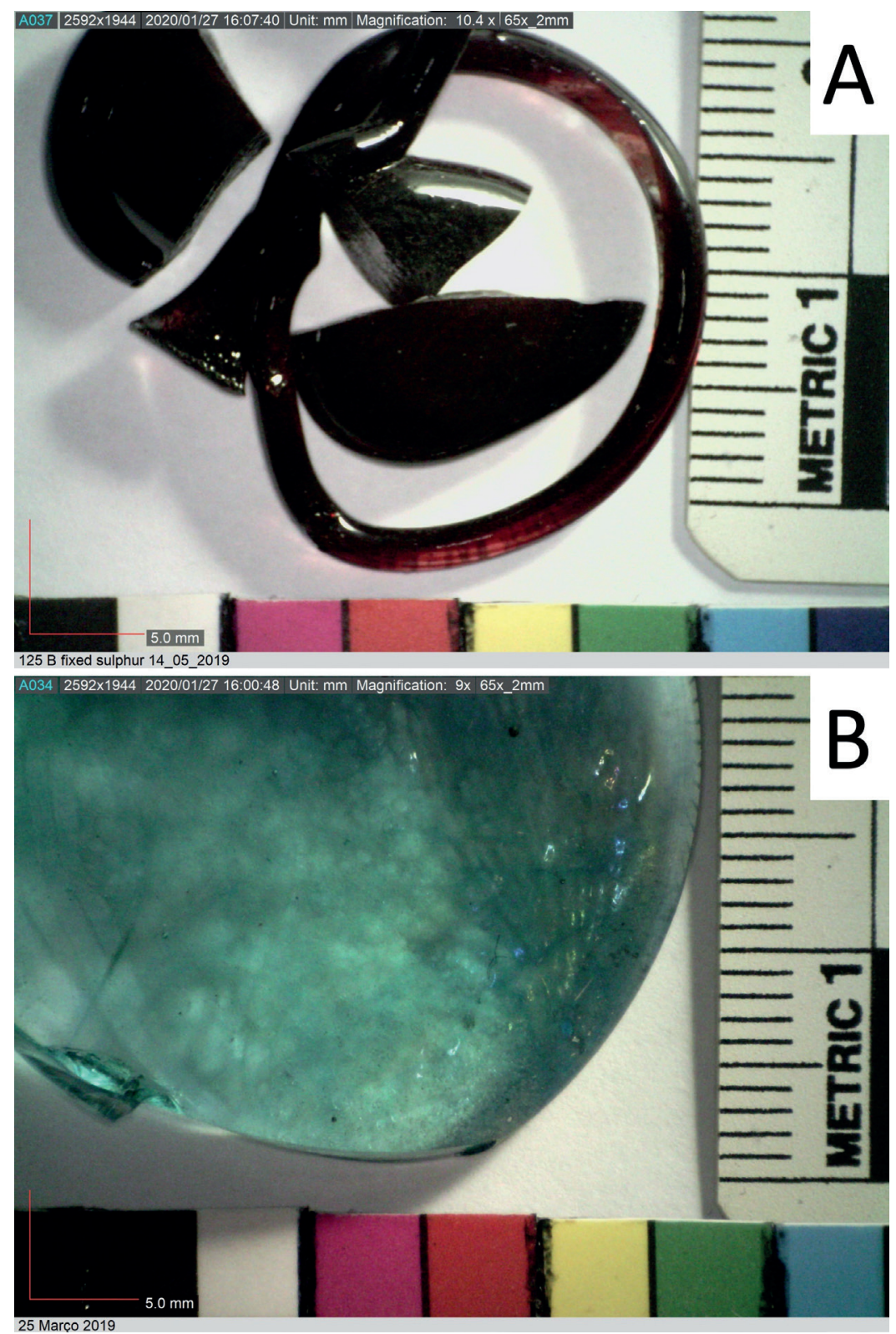

Figure 25: Experiments with rosichiero recipe 125 show that sulfur is an essential ingredient to obtain a red colored glass. The red glass (A) was prepared with sulfur. The green glass (B) is the sample that did not contain sulfur, thus disproving Kunckel's assertion that the sulfur "does not serve any purpose here." Photos: Élia Roldão. 
Indeed, Kunckel is keen on stressing that "the Fire is the principle thing to observe" and states more than once that colors will fade "when the Fire is even a little too strong" ${ }^{106}$ This advice might appear a little too general to be actually helpful, but what Kunckel does is quite radical in the end. He adds an entirely new and previously non-existent pyrotechnical layer to Neri's rosichiero recipes, which indeed did not contain any fornacic directions with respect to the glass. Kunckel thus verbalizes the relation between furnaces and rosichiero glass that is left unarticulated by Neri. ${ }^{107}$ By opening up the furnace perspective, Kunckel makes an epistemic move and urges his readers to consider how furnace conditions influence the quality of the rosichiero glass. It is a powerful move too. He does not tell the readers how exactly to handle the furnace, but by revealing the fire as "the principle thing" he shows the readers the underlying mechanism by which they could optimize the glass themselves. He thus makes them understand, rather than follow.

But Kunckel is not quite done. Another topic that he addresses in his commentary concerns adequate timing and pacing of the different steps in the rosichiero recipes. Indeed, there is a specific order in which the ingredients should be added to the batch, while the time between the different steps further influences the composition and color of the glass. For example, Kunckel writes about chapter 128:

When the Kupffer-Schlacken [TH: copper(II) oxide] is added here, one should not let it stay for long, otherwise is becomes Radiant Green. While initially it gives a beautiful Red, it only lasts a very short Time. ${ }^{108}$

Kunckel mentions moreover that there is a "right tempo" that must be "observed." Especially concerning the red rosichiero color, there is only a small window of opportunity since the color "changes in half a quarter of an hour." ${ }^{109}$ Here too, Kunckel complements Neri's rosichiero recipes. Even though Neri indicates a clear order and provides some indications with respect to timing during different steps, he does not further specify time as a color-changing factor. Kunckel however, sheds light on the very mechanism behind rosichiero glass, just as he did by introducing the furnace perspective, and establishes that timing and tempo directly affect the color of the glass, which prepares his readers to reckon with this factor and to put it to good use.

106 Idem. p. 194.

107 The closest Neri comes to articulating a relation between furnace and color is by describing heat as a factor that "intensifies" the color at the end of chapter 127. It is part of the problem-solving advice he offers. See: Neri in Engle, The Art of Glass, vol. 3, p. 57. 108 Kunckel, Ars Vitraria Experimentalis, p. 194.

109 Idem, pp. 193-4. 
Kunckel's advice can be verified from two different angles. First, during the reproductions of rosichiero glass, we were able to confirm the importance of timing. We performed a very simple experiment, in which we reproduced chapter 128 in an electric kiln by putting in all the ingredients at once. We thus ignored time. As a result, we obtained a dark blue, black-inclining glass (Figure 26). Yet, using the same ingredients, we obtained a red glass as soon as we started to follow the order that was prescribed by the recipe. Tempo, being the spreading of different steps through time, thus seems crucial in achieving rosichiero glass. Second, Kunckel's Ars Vitraria Experimentalis is not the only historical source to address the relation between time and color-change in glassmaking. Returning to the pseudonymous medieval monk Theophilus and the variety of glass colors that could be obtained from one single glass formula, timing appears to be the essential means by which to arrive at these very colors. This is what Theophilus writes:

If you see [the glass in] the pot changing to a saffron yellow color, heat it until the third hour and you will get a light saffron yellow. Work up as much as you want of it in the same way as above. And if you wish, let it heat until the sixth hour and you will get a reddish saffron yellow. Make from it what you choose. ${ }^{110}$

It has been suggested that time reflects how furnace atmosphere and glass composition are not static but in motion during glassmaking. For example, the initial atmosphere in the furnace tends to be reducing but gradually develops towards an oxidizing one, while the ashes used for the glass likely contain carbonaceous material that would contribute to reducing conditions in the glass at the beginning. ${ }^{111}$ Both affect the color of the glass over time, such that the glassmaker only needs to wait for the right color to appear, after which the glass can be taken out of the furnace. To what extent these considerations apply to rosichiero glass (which among others things uses copper(II) oxide as an additional colorant) is unknown to this date, but it is clear that the color of the glass depends on the final oxidization state of its ingredients, and those need time to develop.

In sum, Kunckel's commentary is ambivalent. His discussion of the rosichiero recipes contains errors and there is no reason to assume that Kunckel actually tested Neri's rosichiero recipes. But there is another side to his commentary in which he uncovers and articulates two layers that are absent from Neri's instructions. He shows his readers that making rosichiero is not only a matter of mixing the right ingredients and melting them together, but asks them to take

110 Theophilus in Hawthorne and Smith, Theophilus on Diverse Arts, p. 55.

111 Henderson, Ancient Glass, pp. 66-7; Hawthorne and Smith, Theophilus on Diverse Arts, p. 56. 


\section{Chapter 3}

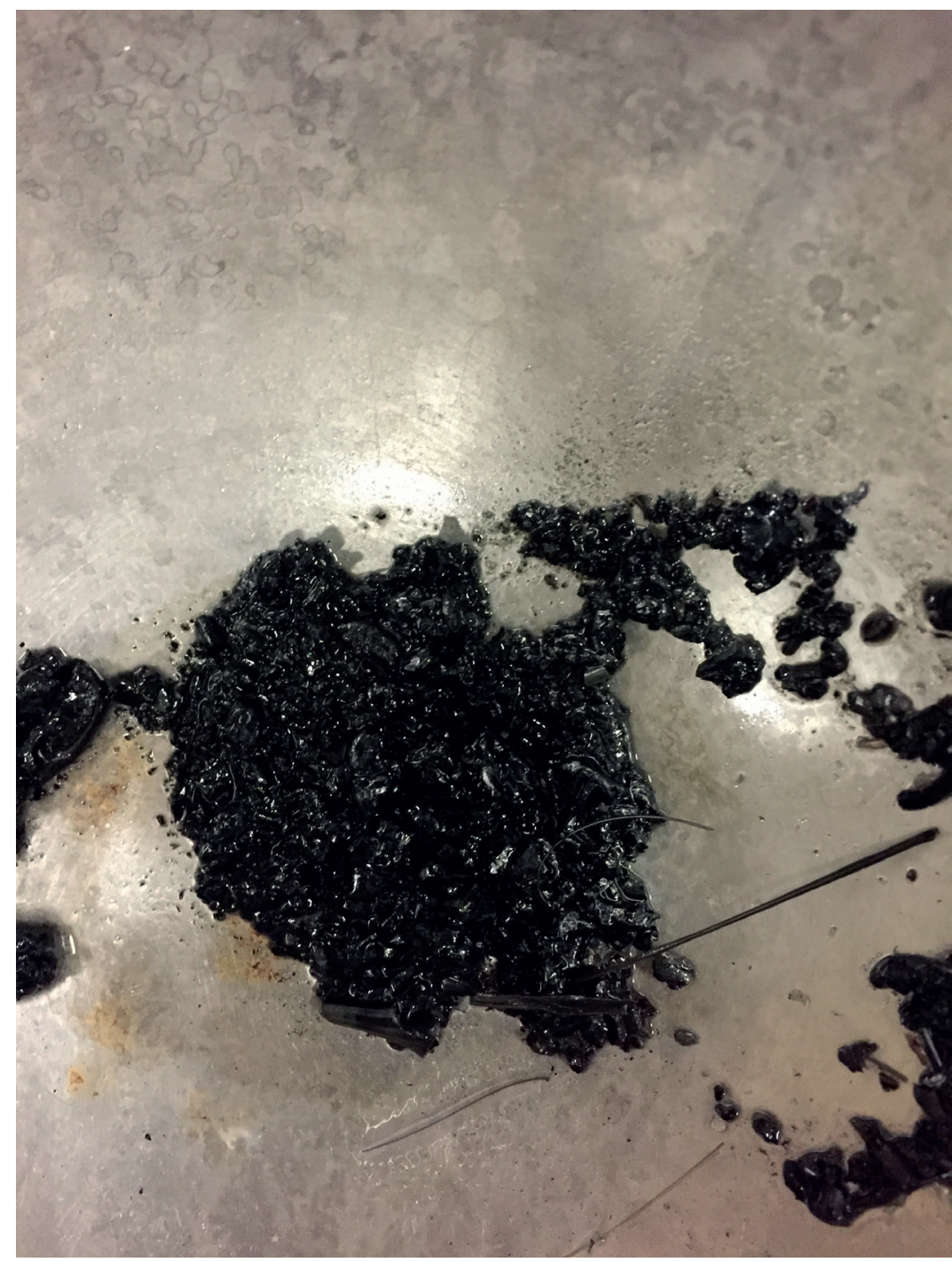

Figure 26: Reproducing recipe 128 by putting in all ingredients at once, while ignoring order and timing, resulted in a black-colored glass. Compare with other reproductions of recipe 128 (e.g. Figure 21) in which the proper order was observed. Photo: ARTECHNE/VICARTE. 
fire and timing into consideration as color-effecting factors. Kunckel shows his readers how something works, rather than telling them precisely what to do.

\section{Don't Blame the Text}

One should keep in mind that writing down and textually communicating how to make a certain type of glass, such that the readers are able to reproduce this very glass from the instructions, is an almost impossible task - or literally a recipe for disaster. As we saw in the previous sections, the color and composition of glass are affected by several variables at the same time. Add to this that ingredients, furnaces, fuel, temperature and colors were not standardized in the seventeenth century, and it almost seems a miracle if an acceptable piece of glass is reproduced from text. Indeed, in his commentary on rosichiero glass, Kunckel mentions that "reproducing this glaze requires as much Art as inventing it". ${ }^{112}$ If that is the case, how then, should we understand the role of glass recipes in the communication of glassmaking knowledge and in the reproduction of specific glasses?

The only way in which the textual transmission of this type of knowledge can be successful is if one can rely on the reader to do the right thing. Both Neri and Kunckel had strategies to make sure the reader is able to steer the glassmaking process in the right direction and to amend the recipes to remedy possible failure. Neri, for example, turns to the reader in his preface and makes an urgent appeal:

If anyone trying my recipes and methods to make the colors, pastes, and tinctures, does not succeed in making what I have described, do not reject my work or think I have written lies, but reflect upon where you may have erred. Especially those who have never before handled such things, because it is impossible on the first try to have the ability to be a master. That being the case, repeat the work, so that it will continuously improve, and ultimately be perfect, as I describe it. ${ }^{113}$

Neri points out to his readers that the burden is on them to make the recipes work. Possible failure cannot be blamed on the text but should be remedied through repetition, practice, and trial-and-error. What Neri has written is as far as he can go, the rest should come from the reader.

There is however one more thing that Neri has to offer. He includes problemsolving advice in his recipes and tells his readers what to do when, for example, the color of the rosichiero glass is not satisfactory: "If it is over-colored, give it

112 Kunckel, Ars Vitraria Experimentalis, p. 193.

113 Neri in Engle, The Art of Glass, vol. 1, p. 7. 
a little manganese to dilute it. If it is clear of color, add more of the fixed sulfur, hematite, a little red copper, and a little white wine tartar at your discretion so it becomes the desired color."114 Neri offers the beginning of a solution, but there is little more he can do. Ultimately, it is up to the reader to identify the problem and to determine to what extent it needs to be solved. Neri thus puts the ball in the readers' court and urges them to keep on trying to compensate for the things he could not communicate in text.

Kunckel's strategy is somewhat different. Considering that some experimentation and trial-and-error is inevitable when trying to make recipes work, Kunckel helps his readers in the process by guiding their attention. He educates his readers on the mechanisms that constitute the recipes and shows them where exactly to intervene in the process to shape the color of the glass and to gain further control over the making process. He argues that the color of glass is sensitive tothe manner in which crocus martis is prepared, that it responds to furnace conditions and that it gradually changes over time. What this means for individual readers and workshops is something that Kunckel could not tell. But by simply connecting the dots, he shows the readers the mechanisms behind the glass-coloring process and provides them with the necessary means by which to figure it out by themselves.

In sum, Neri's plea for trial-and-error, his problem-solving advice, and Kunckel's identification of key factors in the glassmaking process, all help readers to engage with the recipes and to make them their own. In addition, there is another and more implicit textual strategy present that silently promotes a similar effect: the alternative recipes. A recurring phenomenon in early modern practical texts is the existence of groups and series of alternative recipes, commonly meant for one practice, substance or object. Due to their serial and repetitive format, it has been argued that such alternative recipes, often simply listed as "another way," promote trial-and-error and the necessity of repeated practice. ${ }^{115}$ Indeed, the presence of not one, but several alternative recipes for crocus martis and rosichiero glass might be interpreted along similar lines. One should realize however, that these recipes are not just alternative paths that lead to one identical outcome. Rather, they spell out subtle differences and allow readers to explore a wealth of material conditions and color variations that can be associated with one particular product. The four recipes for rosichiero, together with Kunckel's commentary, cover a spectrum of possibilities and set the boundaries between which experimentation and trial-and-error could take place. Growing and cultivating practical experience and judgment within these boundaries, is the way by which readers could successfully reproduce the glass that is communicated

114 Neri in Engle, The Art of Glass, vol. 3, p. 55. Neri provides similar advice in all four rosichiero recipes, pp. 54-58.

115 Smith and The Making and Knowing Project, "Historians in the Laboratory", p. 219. 
in the Ars Vitraria Experimentalis. But then again, success cannot be measured by the book, but is ultimately determined beyond the book, based on the experience and judgment of the glassmaker.

\section{Conclusion}

This chapter explored the interaction between textual and material technologies in Kunckel's Ars Vitraria Experimentalis. This was done through reworking four recipes for rosichiero glass, which opened up fresh insights that not only applied to the recipes, but also extended to early modern glassmaking practices and the textual transmission of know-how in general. Concerning the material technologies, this chapter argued that successful reproduction of rosichiero glass involves a sensitivity towards material preparation, which was exemplified by the case of crocus martis. Neri and Kunckel had a refined understanding of how materials like crocus martis behaved and interacted in the glass and how different preparations of ingredients would shape its final composition. Furnaces and adequate fire management, were important means by which the quality of glass was controlled. Even though it is clear that Neri, Kunckel, and glassmakers in general, understood that furnaces were more than just a simple source of heat, a similar awareness can hardly be detected in the current historiography of science and must instead by sought in neighboring fields, such as archaeology and conservation and restoration. Indeed, there would be much to gain from a general and more systematic history of furnaces. Furnaces were sophisticated tools that not only required serious skill, but also connected the arts, chymistry, oeconomy and industry on a profound level. I expect that a history of pyrotechnical innovation, taking into account contemporary understandings of fire, and the historical exchange of furnace design and operating skill, would provide a fresh and fruitful perspective from which to study the interaction between these fields.

In this chapter, the discussion of material technologies in glassmaking did not stand on its own, but primarily served to establish the proper context from which the textual communication of glassmaking knowledge should be understood. Glass is the result of a myriad of variables - crocus martis and furnace conditions are but two examples - whose intricacies and interactions can never be fully reflected in text. Indeed, the situation in which a recipe is written differs from the situation in which it is read. In the end, readers will always be thrown upon their own resources, which becomes even more pressing in the absence of standardized colors, materials, conditions, tools and temperature measurement, etc. Still, to help readers bridge the divide, Neri and Kunckel employed strategies that encourage readers to engage with the recipes, to experiment with them and to make them work in the specificity of their own workshop. The merit of Kunckel's 
commentary lies in his attempts to educate his readers on how Neri's recipes work. He shows them the very mechanisms by which color in the glass is achieved and adjusted. Producing rosichiero glass, therefore, is not a matter of rigidly following a recipe, but of gaining an experimental understanding of the making process and of knowing where and when to intervene; a process Kunckel tried to support in his commentary. But Kunckel's commentary was not helpful in every aspect. His discussion of Neri's recipes was inadequate at times, especially considering the empirical standards he imposed on himself.

Not only contemporaneous readers of the Ars Vitraria Experimentalis were dependent on their own resources - this is also true for experimenting historians. Reproducing the rosichiero glass was a vast collaborative project that involved glass conservators and experienced glassmakers, experimental archaeologists, and historians of various specialisms. Rather than a simple acknowledgment, this is a methodological point that should be taken into account when reworking recipes, performing reconstructions, reproductions and re-enactments. Usually, a historian does not have advanced furnaces at his/her disposal and the same applies to the practical and chemical knowledge necessary to produce the glass and to follow and understand what exactly is going on during the reproductions. Seeking outside council is inevitable, but even more fruitful is the dialogue that follows, during which recipes are continuously read and re-read with different eyes. Recipes can be studied from different angles and contain many layers that can be analyzed. Take for instance the chemical stance, in which making processes can be dissected into amounts, chemical formulas and reaction mechanisms. Or the perspective of skill that views recipes from an angle of practical experience, judgement and dexterity. On another level, recipes resonate with historical writing technologies or with the history of scientific and chymical practice. Collaboration is not only a fruitful way to get all these different angles out into the open, it also allows these different perspectives to complement and inform each other, thus turning every single recipe into a trove of new insights. 
Don't Blame the Text 



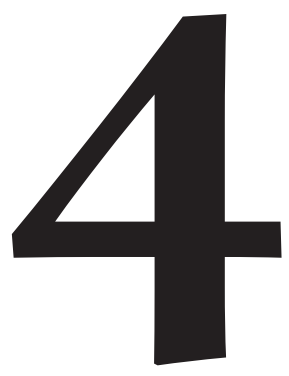

\section{Unpacking Recipes and Communicating Experience}

The Ervarenissen of Simon Eikelenberg (1663-1738) and the Art of Painting

This chapter was previously published as: Thijs Hagendijk,

"Unpacking Recipes and Communicating Experience The Ervarenissen of Simon Eikelenberg (1663-1738) and the Art of Painting," Early Science and Medicine 24 (2019), 248-282, doi: $10.1163 / 15733823-00243$ Po2. 


\section{Introduction}

How do you effectively communicate know-how in a text? This question troubles not only today's writers of technical manuals and cookbooks, but can in fact be argued to be an age-old question. While the early modern period saw a great increase in artisanal handbooks, manuals and recipes, the authors of these texts often warned that know-how was easier shown than written down. The complexity of writing down know-how pushed writers to experiment with style and to devise alternative communicative strategies.

One of these strategies is found in the work of Dutch polymath and painter Simon Eikelenberg (1663-1738). Eikelenberg was a diligent collector of artisanal recipes, but whenever he wrote down know-how himself, he steered away from recipes and adopted another literary format instead, which he called ervarenissen. The central question in this article is what these ervarnissen were and how they differed from recipes as a communicative strategy. In order to answer this question, I will follow Eikelenberg through a particular event in which the two textual formats converge.

On 30 September 1707, Simon Eikelenberg stood in his workshop in Alkmaar, a Dutch provincial town, stirring a hot batch of freshly prepared varnish. We know this because he troubled himself with meticulously writing down his experiences of making this varnish. He called his experiences ervarenissen and entered them as such in his notes. Meanwhile, he worked from a specific recipe previously described by Samuel van Hoogstraten (1627-1678). One of Rembrandt's most celebrated pupils, Van Hoogstraten was a Dutch painter and theorist known for his Introduction to the Academy of Painting, or the Visible World (1678), which provided the instructions for this varnish preparation on this late September day. "Our varnish of turpentine, turpentine oil and crushed mastic, melted, serves our works well enough."

Eikelenberg gathered the ingredients mentioned in the recipe and started to make the varnish. The ensuing ervarenissen vividly describe his procedure and the outcome. He had to guess the amounts of Van Hoogstraten's ingredients and apparently had trouble arriving at a satisfying result, because the varnish curdled and was initially too thin.

There we have two different texts: a recipe and an ervarenis, which nevertheless serve a similar interest. One is rule-like, only providing succinct directions to secure a certain outcome. The other narrates an event and reveals the intricacies of a process. One is short, only fifteen words long. The other is long

1 Eikelenberg, "Aantekeningen betreffende schilderen”, MS 390, fol. 677: "Onzen vernis van terpentijn, terpentijnoly en gestooten mastix, gesmolten, is dienstig genoeg tot onze werken." Van Hoogstraten, Inleyding tot de hooge schoole der schilderkonst, p. 223. All translations are the author's except where otherwise noted. 
and runs over three folio pages. Despite their differences, both texts are part of a comprehensive manuscript Eikelenberg began compiling around the turn of the eighteenth century (Figure 27). The manuscript revolved around contemporary painting practices, even though Eikelenberg did not eschew branching out into 'chymistry,' natural history, philosophy and optics. ${ }^{2}$ Amidst all the recipes he gathered, the excerpts he took, and the notes that were passed on by fellow painters, Eikelenberg's ervarenissen stand out. Within the manuscript they are generally distinguishable by a specified date, the first-person voice and the use of the past tense. They reflect Eikelenberg's experiences as a painter and provide a glimpse into his own practice. Eikelenberg himself thought the ervarenissen deserved special attention as he drew up a special category for them in the index, something he did not do for the other contents of the manuscript, which he indexed thematically rather than according to format (Figure 28).

Even though recipes have been identified as the ubiquitous vehicles for written know-how in the early-modern period, I argue that the ervarenissen represent an ongoing search for new ways to unpack the ineffable dimensions of know-how in

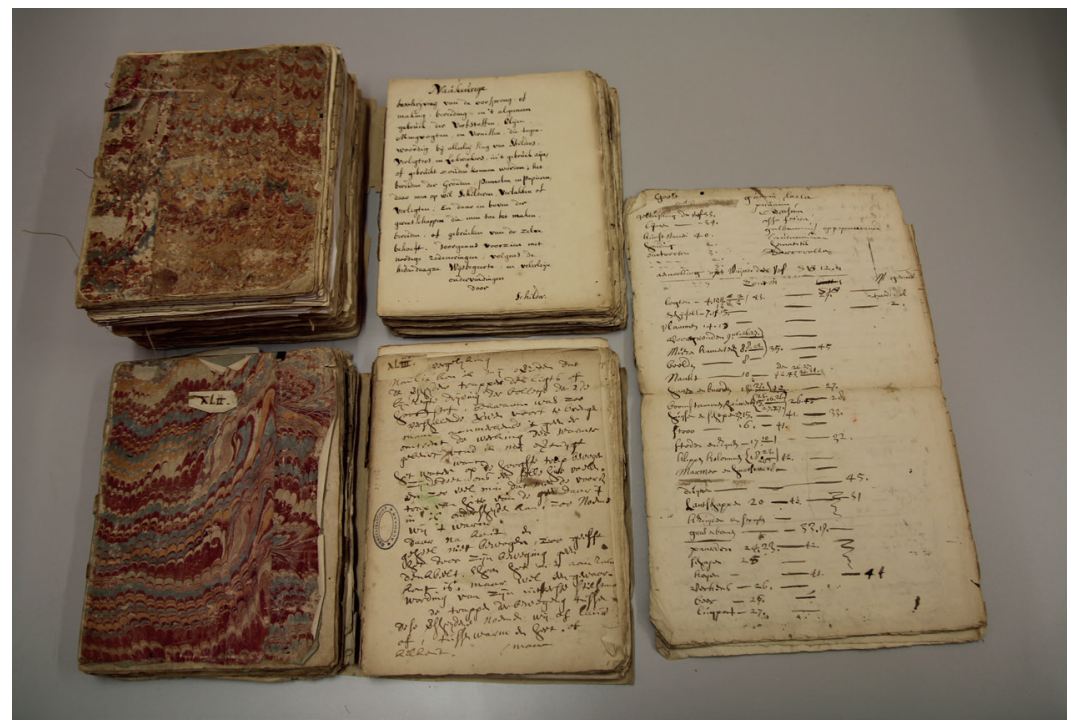

Figure 27: Eikelenberg's notes on the art of painting, comprising five different manuscripts. Photo: Regionaal Archief Alkmaar.

2 I use the term 'chymistry' in accordance with Newman and Principe, "Alchemy vs. Chemistry". 


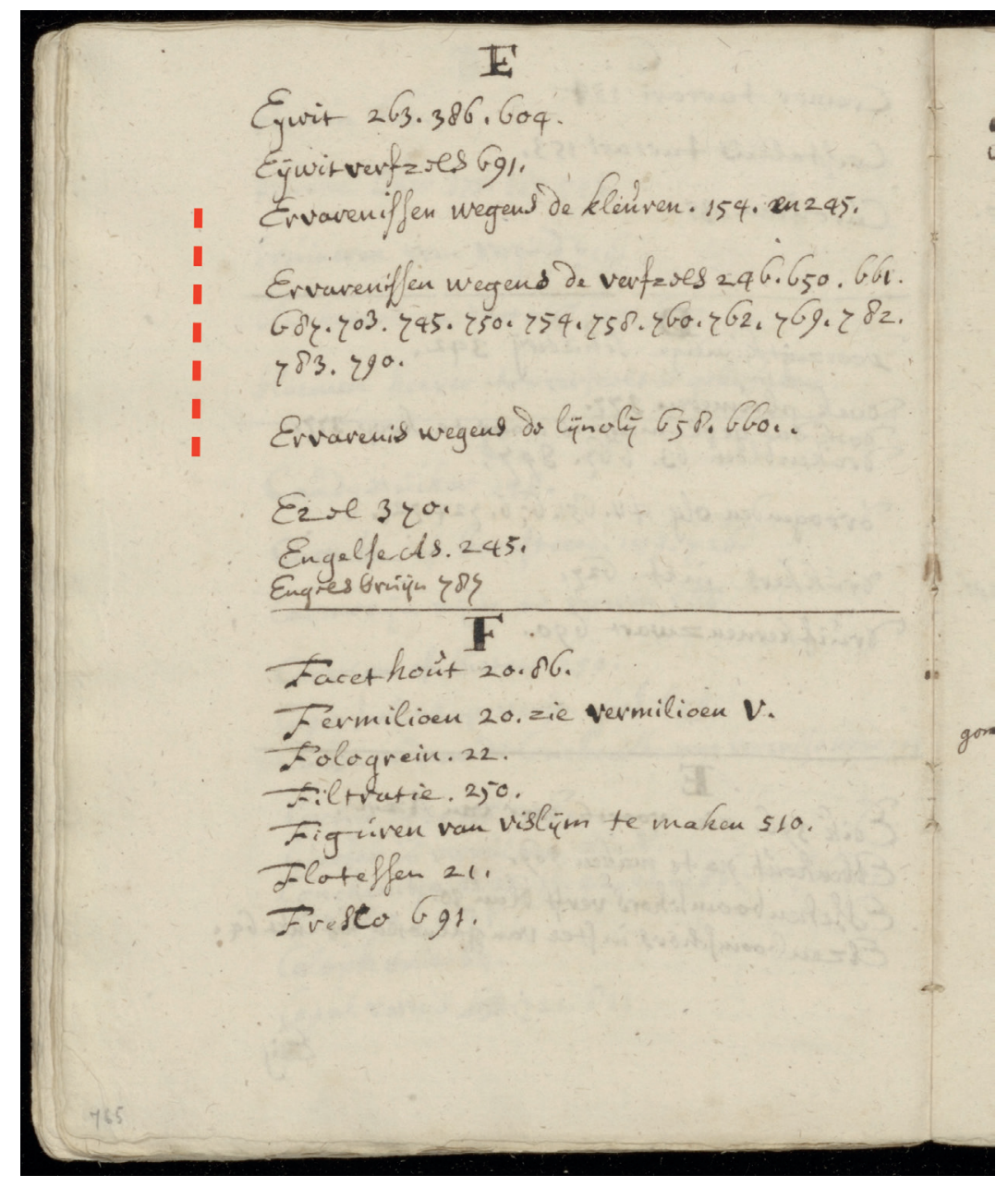

Figure 28: Page from the index of Eikelenberg's notes. The third, fourth and fifth entry concern the ervarenissen as indicated by the dotted line. Photo: Regionaal Archief Alkmaar. 
text. The ervarenissen not only embody this struggle for effective communication, they also place it in a broader context by showing how Eikelenberg responded to changing notions of experience during the seventeenth century and to new methods of communication used by proponents of the new sciences by means of the experimental essay. I argue that Eikelenberg appropriated the experimental essay as a literary form that allowed him to describe the intricacies of the processes involved in making, that would otherwise be lost in a recipe format. Particularly, the ervarenissen appeal to the practitioner's vulnerability during the making processes and try to put readers in the right frame of mind, both of which can be understood as strategies to create what Richard Sennett has called "expressive instructions."3

Before I continue, there are two issues that need some attention. The first is that Eikelenberg's notes on the art of painting were never published. Nor is there any evidence of eighteenth-century readers engaging with his notes, which makes it impossible to say anything certain about their reception. What can be said however, is that Eikelenberg intended his notes to be published. Throughout his notes, three different prefaces can be found, one of which promised that Eikelenberg's descriptions would be "comprehensible and of service to all sorts of readers."4 In another preface, Eikelenberg explicitly addressed his readers with respect to the 'lessons' he provided in his notes: "thou reader, if you have had the patience to properly study my lessons, you will already have sufficiently experienced how necessary it is to know the nature of the composition of materials and paints. ${ }^{5}$ Moreover, Eikelenberg compiled an exhaustive index and drew up a provisional title, which promised an "accurate description of the origin or making, preparation and general use of paint materials, oils, mix-fluids and varnishes." In brief, there is ample reason to assume that Eikelenberg wrote for others and did not plan on keeping the notes to himself.

The second issue is the question of what readership Eikelenberg envisioned for his notes, as this is not something the notes address. Still, his close involvement with the local "College for the Lovers of the Art of Painting" suggests at the very

4 Eikelenberg, "Aantekeningen betreffende schilderen”, MS 391, fols. 3-4: "De beschrijving zal volgens 't opschrift naukeurig zijn, de taal zuiver duits de stijl en redenering klaar en gemaklijk, beknopt of wijtloopiger na vereisch der zaken: en 't werk doorgaans geschikt en voorgedragen even of den schrijver maar alleen beoogt had aan allerleij lezers verstaanbaar en dienstig te zijn."

5 Eikelenberg, “Aantekeningen betreffende schilderen”, MS 392, fol. 32: “[H]ebt gij leser 't gedult gehad mijner lessen te doorsien na behoren, zoo hebt gij reets genoeg bevonden hoe nodig het is dat men den aart in 't zamenstel der stoffen en verfsels kenne."

6 Eikelenberg, "Aantekeningen betreffende schilderen", MS 391, fol. 1: "Naukeurige beschrijving van de oorsprong of making, bereiding en 't algemeen gebruik der verfstoffen, olijen, mengvogten en vernissen.” 
least that his readership would be found in such circles. Eikelenberg drew up the statutes of this college, occasionally taught its members, and actively inquired after a similar institute in Leiden, to learn how the Alkmaar college could be improved. 7

Why the manuscript was never printed is unknown. Still, the mere fact that Eikelenberg experimented with style signifies a critical development in early modern practices of writing down know-how. Likewise, his repeated mentions of potential readers indicates that the ervarenissen can and should be taken seriously as a communicative strategy.

\section{Simon Eikelenberg and his Notes on the Art of Painting}

To really understand what the ervarenissen are about, it is essential to get an overview of Eikelenberg's life and the contents of his notes - which reveal that Eikelenberg was a man of many interests. As I will argue, the ervarenissen are the result of the intersection of these interests.

In 1663, Simon Eikelenberg was born in Alkmaar, a Dutch town near Amsterdam, where he lived until his death in $1738 .^{8}$ He ran a brush-shop, an occupation he inherited from his father, but it kept him from doing the things he really wanted to do in life. Painting was one of those things: "I painted diligently, but I had to watch the shop two days a week and could not paint then [...]. So great was my desire for this work [...] that it saddened me that time was passing by so quickly."9 He picked up painting somewhere around the turn of the century and tells of how he had lessons from the Amsterdam painter Nicolaas de Vree (16451702), who taught him "about the preparation and use of oil paints." ${ }^{\circ}$ Eikelenberg typically painted landscapes and improved over the years (Figure 29). In 1699, he sold his brush-shop, dabbled a while in the flower business and eventually tried to live entirely off his art. ${ }^{11}$ He succeeded for a few years, entered the painters' guild and was able to get by, but in 1704 he hit rock-bottom. Unable to secure an income,

7 Eikelenberg, "Ontwerp”, MS 396; Eikelenberg, "Wetten en Ordonnantys", MS 396; Eikelenberg, "Aantekeningen betreffende het leven", MS 557, fol. [46]; Van Schendel, "Een briefwisseling". For the history of art lovers, see: Skogh, "The Varied Role of the Amateur".

8 Van Schendel, "Simon Eikelenberg's Experiments; Goedings, "De 'vrijerijboeken' en 'pareltjes' van Simon Eikelenberg”; Goedings, “'Deurslepe vryers en beminnelyke meysjes".

9 Eikelenberg, "Aantekeningen betreffende het leven", MS 557, fol. [37]: "[I]k schilderde wel naarstig maar 2 dagen in de week moest ik op de winkel passen en kon dan niet schilderen. [...] Zoo groot was mijn lust tot dit werk, [...] dat ik verdrietig was dat de tijt zoo ras voortschoot."

10 Idem, fol. [40]: "[W] egens het prepareeren bereijden en gebruyken der olijverf."

11 Eikelenberg, "Aantekeningen betreffende de financiële toestand", MS 558, fols. [10-11]. 


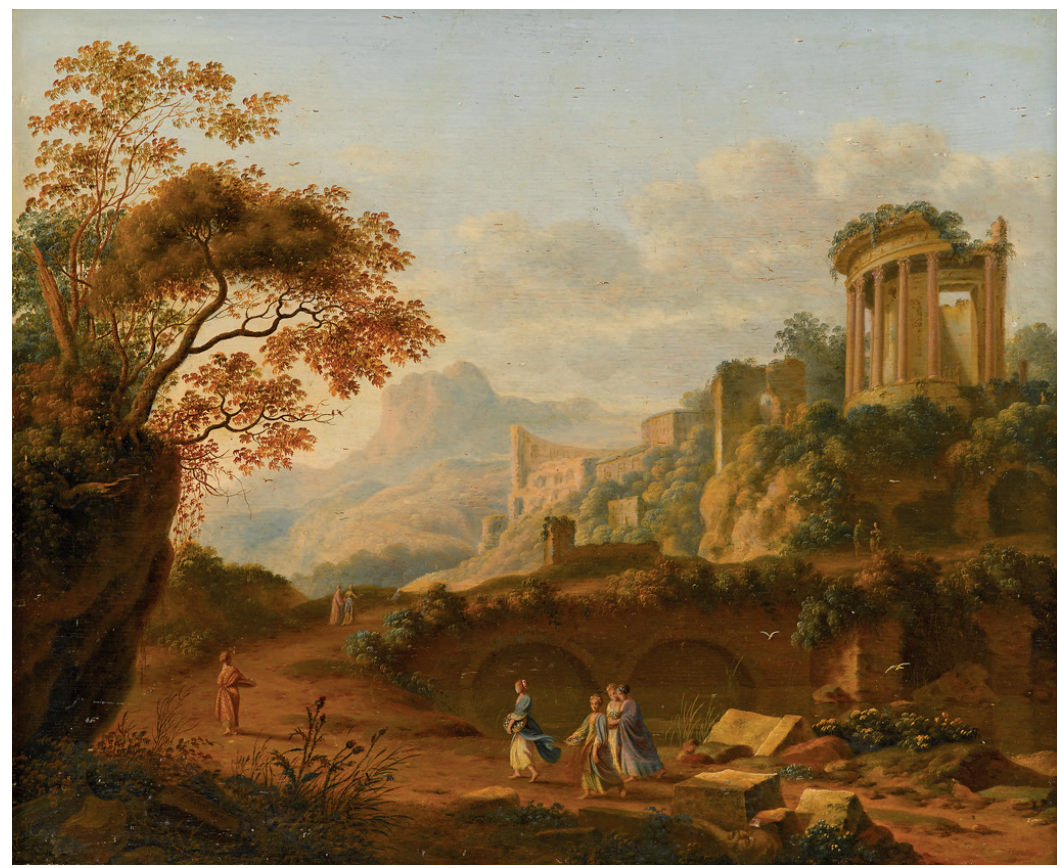

Figure 29: Simon Eikelenberg, Capriccio with maidens, c. 170o. Oil painting, $34.1 \times 41.4$ cm. Photo: Freeman's Auction House.

he found there was no honor in art: "Art is delightful, because it adds joy to our lives. But how much more delightful are Life and Honor? Esteem languishes, yes, and dies, when life can no longer be supported." ${ }^{\prime 2}$ Around that time an offer came from his home town to take him on as a public servant. He could make a living again while carrying on painting.

Eikelenberg left behind an abundance of rich and relatively unexplored materials, such as correspondence, autobiographical sketches, genealogical records, financial records, poems, moral notes, historical notes and survey records on his home town of Alkmaar. ${ }^{13}$ Altogether, these materials provide a comprehensive overview of his life, and situate him at the crossroads of arts,

12 Correspondence from Simon Eikelenberg to [unidentified], 23 April 1704. Eikelenberg, "Brieven van en aan Simon Eikelenberg," MS 556: "[D]e konst is beminlijk, om dat ze ons leven vermaak geeft. maar hoeveel beminnelijker is nog 't Leven en d' Eer? De Agting kwijnt, ja sterft, zo dra 't leven zijn onderhoud mist."

13 Manuscripts of Simon Eikelenberg, MS 12-28, 376, 390-396, 439, 556-558, Collectie Aanwinsten, Regionaal Archief Alkmaar. 
commerce and science. ${ }^{14}$ While he had only enjoyed a primary education, he worked his way up through disciplined self-study, rigorous reading and correspondence with knowledgeable people. He learned Latin and French, made mathematical exercises and wrote poems for various occasions. He developed a keen interest in history and was the first to debunk a prevailing legend about a mythical town called Vroone, earning him a lasting reputation amongst Dutch historians. ${ }^{15}$ He read books on natural and experimental philosophy - Descartes' Principia was a great source of inspiration - and acquainted himself with key works in natural history, botany and theology. He read about experimental medicine and kept up with the latest fashions in chymistry. ${ }^{16}$ For example, he fondly agreed with the French chemist Nicolas Lémery (1645-1715) in his belittling attitude towards alchemy as "an art without art." ${ }^{17}$ Finally, he read theoretical art treatises and delved through stacks of practical texts and recipes, such as books of secrets.

Not only did Eikelenberg read, he was also a diligent compiler of notes. Significant parts of these notes were later reworked into thoroughly researched books, such as the aforementioned history of the mythical town Vroone (1716), or a posthumously published history of Alkmaar (1739). ${ }^{18}$ Our main focus here, however, is Eikelenberg's notes on the art of painting, which comprise five separate manuscripts currently held by the Alkmaar Municipal Archives, and running to more than a thousand folios of written material. The five manuscripts are likely the result of a nineteenth-century disintegration of what was once a single bound collection of notes; the original numbering is occasionally shuffled and the index cross-references to notes that are scattered over multiple manuscripts. ${ }^{19}$ Judging by the dates in the manuscript, Eikelenberg began compiling his notes in the late 1680s; it became a rather serious pursuit around 1700, and faded again towards the 1730 . Most of the material was written by Eikelenberg in Dutch vernacular, with the exception of a few notes written by different hands, which he incorporated into the manuscripts as well. Occasionally, he included figures "to

14 Cook, Matters of Exchange; Margócsy, Commercial Visions.

15 Eikelenberg, Gedaante en Gesteldheid van Westvriesland.

16 Blankaart, De Kartesiaanse Academie; Lemery, Het Philosoophische Laboratorium; Lancilot, De Brandende Salamander.

17 Eikelenberg, "Aantekeningen betreffende schilderen", MS 390, fol. 141 [83]: "De alchimia is een konst sonder konst, welker begin is liegen, het midden werken en het eynd bedelen (Lemmerij)."

18 Eikelenberg, Alkmaar en zyne geschiedenissen.

19 The Alkmaar archivist Cornelis W. Bruinvis (1829-1922) might have reorganized Eikelenberg's manuscripts. 
make everything even more comprehensible." ${ }^{\circ o}$ Some notes were cut and glued to other folio pages, suggesting that he occasionally edited his notes too.

Eikelenberg's notes reflect the diversity of his bookshelf, but it would be wrong to see them as a collection of loose interests. On the contrary, he had different fields of interest and tried to harmoninze them to establish a comprehensive picture of the art of painting, with his notes "generally accompanied by the necessary reasonings in accordance with contemporary philosophy and many experiences." ${ }^{21}$ On the whole, his notes can be roughly divided in two categories: those that reflect on the art of painting, mostly from a philosophical and historical stance, and those that deal with the practice of the art of painting.

Eikelenberg's interest in color theory, optics and perspective helped him to navigate what he called the "theory of this art" - a phrase he presumably borrowed from Van Hoogstraten. ${ }^{22}$ He documented for instance how he produced an "optical painting," which "showed long and misshapen figures, from which no one could infer what it was, when it was hanging on the wall, but when it was laid on a table and watched through a peephole [...] one saw the castle of Egmont raising itself vertically with its towers from the panel's plane." ${ }^{23}$ When he co-founded a local art academy in 1698, he expressed his ambition to speak about art like "mathematicians do when they speak of an issue: they first define it." ${ }^{24}$ He sometimes resorted to geometrical drawings, for instance to prove "why the luster and paints of bodies fade in the distance." ${ }^{25}$ Eikelenberg also valued contemporary chymistry as a way to gain deeper insights into his craft. He quoted Nicolas Lémery, Carlo Lancilotti, Athanasius Kircher and the Dutch experimental physicians Steven Blankaart and Cornelis Bontekoe, and was well informed about contemporary theories, such as that concerning the interaction between acids and

20 Eikelenberg, "Aantekeningen betreffende schilderen", MS 391, fol. 5: "En om alles nog te beter te doen begrijpen."

21 Idem, fol. 1: "Naukeurige beschrijving van de oorsprong of making, bereiding en 't algemeen gebruik der verfstoffen, olijen, mengvogten en vernissen [...] Doorgaans voorzien met noodige redeneringen volgens de hedendaagze wijsbegeerte en vererleije ondervindingen."

22 Eikelenberg, "Aantekeningen betreffende het leven", MS 557, fol. [39]: "[T] heori dezer konst." See also: Weststeijn, The Visible World; Blanc, "Van Hoogstraten's Theory".

23 Eikelenberg, "Aantekeningen betreffende het leven", MS 557, fol. [39]: "[E]en optisch gezigt-kundig schilderij [...]. Het verbeelde lange en zeer wanschape figuuren, daar men niet wist wat af te maken, als 't aan de wand hing, maar op een tafel leggende en door een zeker gaatje [...] zag men het kasteel van Egmont, heffende zig lootregt met zijn torens uit het vlak van 't panneel."

24 Idem, fol. [27]: "De wiskonstenaars als zij van een saak sullen spreken, maken eerst een bepaling. Wij moeten dit ook doen, etc. anders zullen wij niet behoorlyk weten wat de konst is." Eikelenberg, "Ontwerp", MS 396.

25 Eikelenberg, "Aantekeningen betreffende schilderen", MS 391, fol. 31: "De reden waarom de glansen en verfen der lichamen in 't verschiet verflauwen." 
alkalis, which came into fashion at the time. ${ }^{26}$ He also borrowed from chymical reasoning to explain the behavior of the painter's materials. For instance, he analyzed the problematic discoloration of indigo in terms of potential and harmful volatile parts which, he theorized, could possibly be separated from the dyestuff as a preventative measure. ${ }^{27}$

Natural history, botany and travel accounts were also unmistakable parts of his painting notes. The reason was as pragmatic as it was simple. For things involving the art of painting that Eikelenberg could not explain from his own expertise, he had to rely on other sources:

Concerning the origin and the making of things of which one can have no personal experience, such as foreign gums and paint materials - these matters will be diligently investigated and followed only by reliable messages. ${ }^{28}$

Eikelenberg, for example, scrutinized Dodonaeus's herbal Cruydt-Boeck (1554) for information on dye-plants, inks and colors ranging from blue, yellow and red to black. ${ }^{29}$ Merchants were another source of information. One of them claimed, for example, that the best indigo comes from Guatemala and not Jamaica. ${ }^{30}$ Native preparations of painter's materials were closely studied by Eikelenberg as well. He copied excerpts from natural history books and travel accounts from authors like Jean-Baptiste Tavernier, Johannes de Laet, Nicolas Sanson, José de Acosta and Jean de Thévenot, and quoted them on how, for example, the Indians harvested cochenille, or on the preparation of indigo in the Indies. ${ }^{31}$ It seems that local know-how from overseas not only satisfied his curiosity, but that it helped him determine how to process the materials in his own practice.

Even though contemporaneous philosophy and natural history are present throughout the manuscript, most of Eikelenberg's notes deal primarily with practical issues. Most of these notes concern recipes and instructions for preparing artist's materials, such as pigments, dyes, varnishes and oils. Some of these recipes were shared by colleagues and friends, but most were copied from books of secrets, such as Dutch editions of Alessio Piemontese's De' Secreti (1555), or other published compilations of practical instructions like Simon Witgeest's Toover-

26 Ragland, "Chymistry and Taste".

27 Eikelenberg, "Aantekeningen betreffende schilderen", MS 390, fol. 784.

28 Idem, MS 391, fol. 5: "Omtrent den oorsprong en de making der dingen daar af men zelf geen ondervinding kan hebben, als daar zijn de buitenlantze gommen en verfstoffen, zal men een naarstige navorzing en alleen geloofwaardige berigten gevolgt zien."

29 Eikelenberg, "Aantekeningen betreffende schilderen", MS 390, fol. 705. The pages mentioned by Eikelenberg correspond to editions of Dodonaeus's Cruydt-Boeck published in 1618 (Leiden) and 1644 (Antwerp).

30 Idem, fol. 788.

31 Idem, fols. 686, 813. 
boek (1698). A few recipes came from Dutch translations of Athanasius Kircher's Mundus subterraneus (1665) or chymical textbooks from the aforementioned authors Lémery and Lancilotti. Roughly 80 percent of Eikelenberg's notes can be traced back to other sources, with possibly higher percentages for recipes.

The ervarenissen, however, are an important exception to Eikelenberg's anthological efforts. As lenghty accounts of his experiences, they also disclose his workshop practices and reveal how he tried to make sense of recipes, how he dealt with whimsical materials, and how he worked through new procedures. In general, there are about thirty different ervarenissen that describe a variety of painting materials and their preparation, including varnishes, linseed oil, and pigments like verdigris, smalt, massicot, indigo, and minium (Appendix II). At times, Eikelenberg devoted multiple ervarenissen to one material, as he did for the varnishes. With seven in total, the varnish ervarenissen constitute a comprehensive and cross-referenced group of connected texts. As the most detailed of Eikelenberg's ervarenissen, they provide the focal point for this article. An English translation of the varnish ervarenissen was published by Arthur van Schendel in the 1950s, and serves as valuable resource in support of this article. ${ }^{32}$

\section{The Recipe and the Ervarenis}

To understand Eikelenberg's writing practices, it helps to have a good sense of his reading practices. One of the ervarenissen records in great detail how Eikelenberg read and unpacked Van Hoogstraten's varnish recipe. Years went by between the recipe's initial appearance in the notes and Eikelenberg's retrieval and commentary upon it (Figure 30). Its first occurrence in the manuscript (fol. 677 ) is located near two notes that were jotted down in 1700 and $1704 .{ }^{33}$ This is widely separated from the ervarenis (fol. 825) by which the recipe is revisited in the notes. The recipe itself is a paraphrase. It contains no instructions, but merely lists the ingredients (turpentine, turpentine oil, mastic), and contains only two participial adjectives that are suggestive of a process (crushed, melted). ${ }^{34}$ That said, the recipe appealed sufficiently to Eikelenberg for him to finally attempt to put it into practice in September 1707 (Figure 31). The attempt was not without problems. Before he even began, Eikelenberg was challenged by Van Hoogstraten's instructions.

32 Van Schendel, "Simon Eikelenberg's Experiments".

33 Eikelenberg, "Aantekeningen betreffende schilderen", MS 390, fols. 673, 696.

34 Turpentine is a balsam obtained from the pine tree. Turpentine oil is the distillation product of this turpentine balsam. Mastic is a resin obtained from the mastic tree. See also: Stols-Witlox, "Final Varnishes for Oil Paintings". 


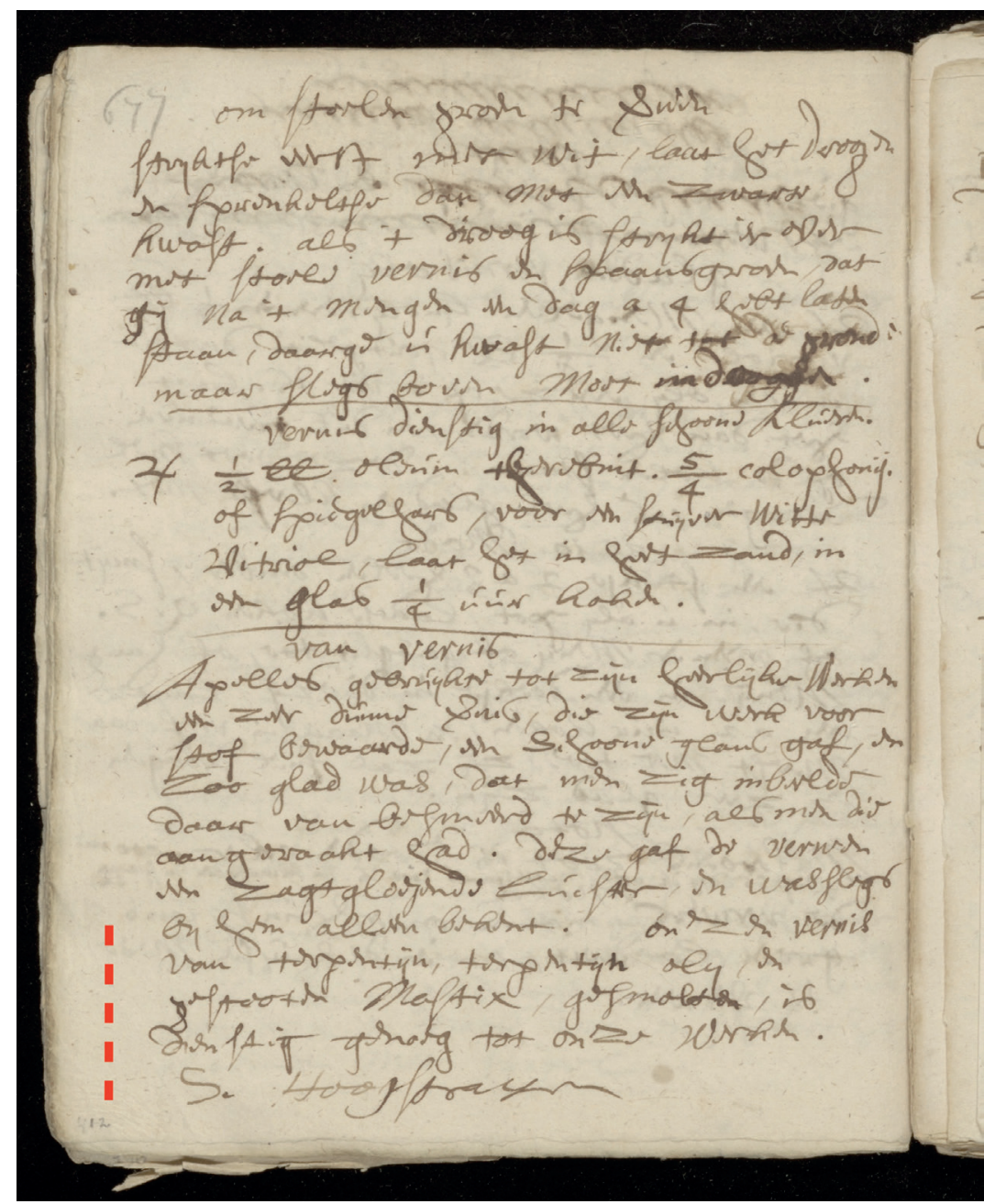

Figure 30: Van Hoogstraten's comments on varnish as copied by Eikelenberg in his notes. The recipe is indicated by the dotted line. Photo: Regionaal Archief Alkmaar. 


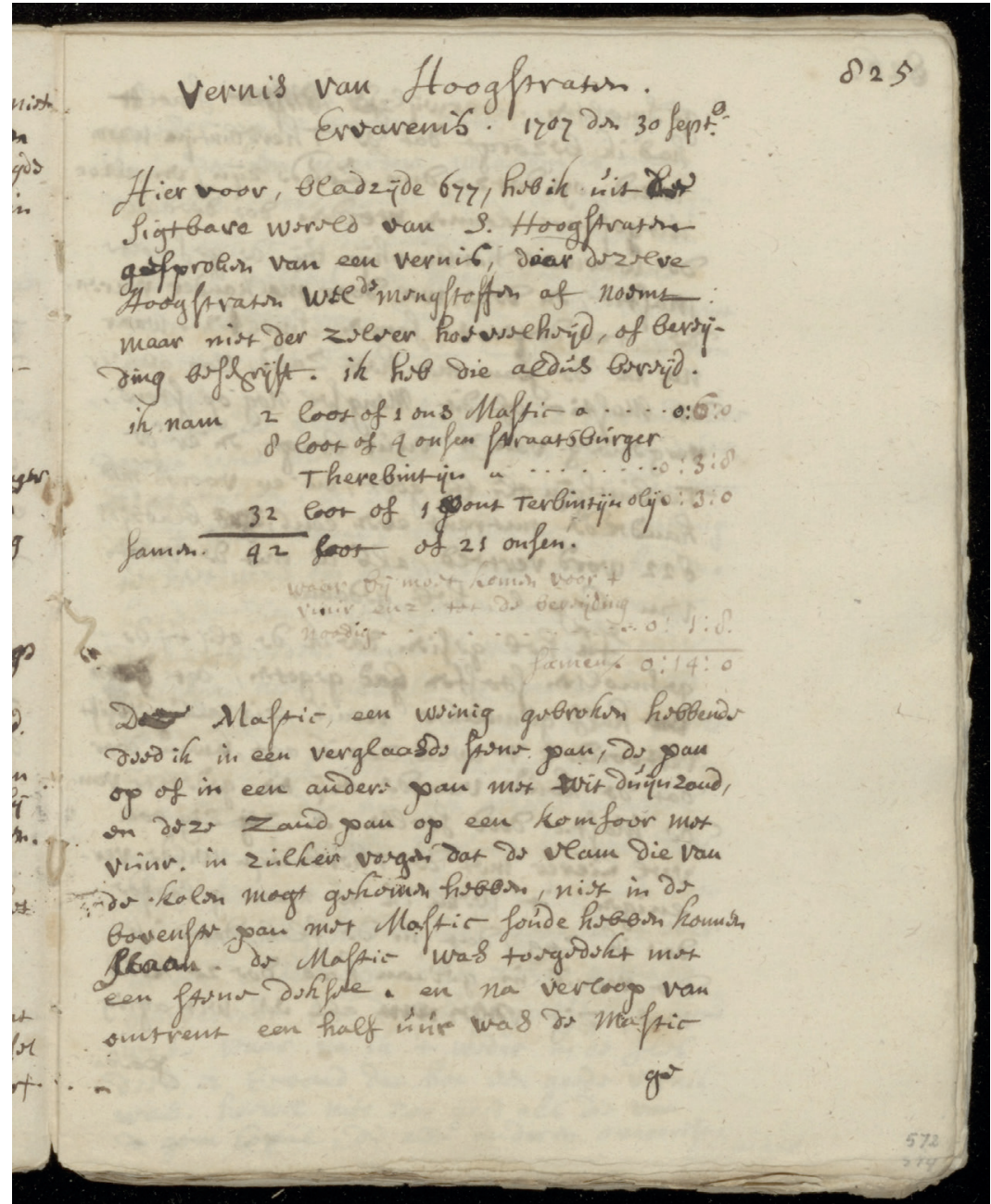

Figure 31: The first page of Eikelenberg's ervarenis on Van Hoogstraten's varnish recipe. Photo: Regionaal Archief Alkmaar. 
Before, page 677, I spoke of a varnish from the visible world of S. Hoogstraten, of which Hoogstraten mentions the substances but not their quantities or preparation. I prepared it as follows.

\begin{tabular}{|c|c|c|}
\hline I took & 2 lot or 1 ounce Mastica at & $0: 6: 0$ \\
\hline & 8 lots or 4 ounces Strasbourg turpentine at & $0: 3: 8$ \\
\hline & 32 lots or 1 pound turpentine oil at & $0: 3: 0$ \\
\hline together & 42 lots or 21 ounces & \\
\hline & to which should be added for the fire etc. & \\
\hline & necessary for the preparation & :1: \\
\hline
\end{tabular}

Eikelenberg filled in the blanks of Van Hoogstraten's recipe, but it is unclear on what precisely he based his quantities. The manuscript contains nothing to indicate these numbers, apart from other varnish recipes that only roughly maintain similar ratios for the ingredients (turpentine oil > turpentine balsam $>$ resin). It is likely that Eikelenberg made an educated guess, based on the experience he gained while working on two other varnishes earlier that year..$^{36}$ The passage also shows that Eikelenberg took the recipe's financial implications seriously. He tried to determine its costs from the outset, including materials, expenses for the fire and his wage. A few years later, when the ingredients "were a bit more expensive," Eikelenberg took care to update his calculations, scribbling a "nota" in the margins that indicated that the preparation costs were now "a stiver for a lot."37 Similar calculations were made for other recipes, while scattered throughout the manuscript additional references to the availability and costs of painter's materials can be found. After establishing quantities and costs, Eikelenberg continued:

Eikelenberg, "Aantekeningen betreffende schilderen”, MS 390, fol. 825: "Vernis van Hoogstraten Ervarenis 1707 den 30 sept. Hiervoor bladzijde 677 heb ik uit het sigtbare wereld van S. Hoogstraten gesproken van een vernis daar dezelve Hoogstraten wel de mengstoffen af noemt maar niet der zelver hoeveelheijd of berijding beschrijft. Ik heb die aldus berijd.

\begin{tabular}{|c|c|c|}
\hline \multirow[t]{3}{*}{ Ik nam } & 2 loot of 1 ons Mastica a & o:6:0 \\
\hline & 8 loot of 4 onsen straatsburger therebintijn a & $0: 3: 8$ \\
\hline & 32 loot of 1 pont terbintijn olij & o:3:0 \\
\hline \multirow[t]{3}{*}{ Samen } & 42 Loot of 21 onsen & \\
\hline & $\begin{array}{l}\text { Waarbij moet komen voor 't vuur enz. tot de } \\
\text { berijding nodig }\end{array}$ & o:1:8 \\
\hline & Samen & \\
\hline
\end{tabular}

36 Idem, fols. 8oo, 821 .

37 Idem, fol. 828: "Nota. Maar den 23 September 1711 dese selve vernis makende, en de mengstoffen wat dierder zijnde, bevont dat de kosten met maakloon daarbij 't loot een stuijver." 
Having slightly broken the Mastic, I put it in a glazed stone pan. This pan I placed on or in another pan filled with white dune sand and this sandpan on a stove with fire, in such a way that any flame that might have come from the coals could not have reached the upper pan with Mastic. ${ }^{38}$

Flowing from Van Hoogstraten's concise qualification melted, Eikelenberg established a rigorous procedure to heat his substances, including precautionary measures to nip potential fire hazards in the bud. He had been using similar procedures previously, when working on other varnishes, and his notes clarified the importance of his precautions. In an earlier ervarenis, Eikelenberg recalled that when he once worked "near the fire, something splashed out of the pan into the fire, the flame of which immediately set fire to the vapor that came from the mixture, after which everything caught fire and spoiled." 39 With the risks fresh in his mind, Eikelenberg introduced an additional safety measure and decided to keep the turpentine oil, the most volatile substance, as far away from the fire as possible.

The Mastic was covered with a stone lid and after about half an hour the Mastic had melted. While it was melting I had taken care to heat the turpentine so as to have it thin and easy-flowing. Then I added the warm turpentine to the melted Mastic and, stirring these well, I melted them thoroughly together, whereupon I took the hot sandpan with the Mastic or mixture far away enough from the fire and poured the turpentine oil upon it and dealt with it next as is told on page 822 like I also did with the copal varnish. $4^{\circ}$

At this point, the ervarenis shows itself to be part of a greater web of experience and know-how that Eikelenberg had started to weave around his notes. Not only did the ervarenis respond to Van Hoogstraten's recipe and draw upon similar

38 Idem, fol. 825. Translation from Van Schendel, “Simon Eikelenberg's Experiments”, pp. 129-13o. I changed Schendel's translation "brazier" into "stove" and kept the original capitalization. "Deze Mastic een weinig gebroken hebbende deed ik in een verglaasde stene pan, de pan op of in een andere pan met wit duijnzand en deze zandpan op een komfoor met vuur. in zulken voegen dat de vlam die van de kolen mogt gekomen hebben niet in de bovenste pan met Mastic soude hebben konnen slaan."

39 Idem, fol. 824: "[H]et is mij gebeurt dat ik de vermenging bij 't vuur doende ietwes uijt de pan in 't vuur spatte waarvan de vlam terstont vattende in de waasem die van 't mengsel uijtging alles in de brand stak en bederf."

40 Idem fols. 825-826. Translation based on Van Schendel, "Simon Eikelenberg's Experiments", p. 13o. I changed Schendel's translation "cover" into "lid," kept the original capitalization and revised his translation of the last sentence. "De Mastic was toegedekt met een stene deksel en na verloop van omtrent een half uur was de Mastic gesmolten. Terwijl zij smolt had ik bezorgt dat de therbintijn warm wierd opdat ze dun zoude zijn en alzoo uitgestort konnen worden. Doe deed ik de warme therbinthijn bij de gesmolten Mastic en deze wel door malkander roerende ter degen te samen smelten waarna ik de pan met heet zand zoo als er de Mastic of dit mengsel nog op stond ver genoeg van 't vuur bragt en er de terbinthijn olij bij goot en er voorst mee handelde omtrent even eens bladzijde 822 word verteld als ik met de vernis van Copal heb gedaan." 
earlier experiences, Eikelenberg brought in another ervarenis to substitute for part of its protocol. Specifically, he refered to the work he had done on a varnish of gum copal on April 29th of that year. There too, he had to mix in the highly flammable turpentine oil and described how he first took the mixture from the fire and out of the sand bath. He then poured in the turpentine oil with one hand while swiftly stirring with the other. At that point, Eikelenberg observed how "the coldness of the poured oil firstly caused the gum to coagulate and to stick somewhat firmly to the ladle."41 He solved the problem by placing the pan back on the warm sand while he kept on stirring. The benefit of this approach was likely something he wanted to bring to Van Hoogstraten's recipe too.

When I added the oil to the melted ingredients I noticed that the half-prepared varnish appeared to curdle. This I believe was due to the coldness of the oil solidifying part of the mastic; while also the oil mixed better with the turpentine. I was still more convinced of this when I saw that in the bottle, in which I had put the varnish when cold, a whitish sediment had formed on the bottom and increased slowly. For this reason I believe that it would be wiser to add the oil to the melted mixture by small amounts and the second half of it not before the first has become rightly heated and mixed with the turpentine and Mastic. ${ }^{42}$

In the hands of Eikelenberg, Van Hoogstraten's casual reference to melted, became a rather complicated affair. The mixture did not behave as Eikelenberg expected, and he started thinking about improvements. Indeed, two years later Eikelenberg made another attempt at Van Hoogstraten's varnish, which he recorded in a different ink. "On May 28, 1709, I made this varnish in that way, putting the oil and the Mastic at the same time on the hot sand. I also heated the turpentine separately on the sand and made it become fluid and added it later."33 Even though

41 Idem, fol. 822: "De koude van de ingegoten olij veroorsaakte ten eersten een stolling der gom die enigsins stijfagtig om de spatel daar ik ze met roerde bleef hangen."

42 Idem, fol. 826. Translation from Van Schendel, "Simon Eikelenberg's Experiments", p. 13o. I kept the original capitalization. "Ik heb gesien doe ik de olij bij de gesmolten stoffen had gegoten dat half gemaakte vernis zig als geschift vertoonde, 't welck zoo ik agt kwam door dat de koude van de olij een gedeelte van de mastic deed stollen en zij zig ook veel liever met de therbintijn wilde verenigen 't welck ik te meer geloofde doe ik zag dat in de fles daar ik de vernis in gedaan had doe ze koud was zig als een wit agtig poeder op de bodem zette en allengs meerder meerder. Waarom ik meen dat het beter zoude zijn de terbinthijn olij bij 't gesmoltene te doen bij een weijnig teffens en het tweede gedeelte niet voordat het eerste verwarmt en met de terbintijn en Mastic vermengd."

43 Idem, fols. 826-7. Translation from Van Schendel, "Simon Eikelenberg's Experiments", p. 130. "Ik heb den $28^{\mathrm{e}}$ meij 1709 deze vernis alsoo gemaakt, stellende de olij en de Mastic te gelijk op't hete zant, ook deed ik de terpentijn a part op zand heet of dun worden en deed er die naderhand bij." 
the solution differed from his initial plan, the rationale remained the same as he tried to overcome the troubling cold of the turpentine oil. In 1707 however, he had to work with the concoction he had already created and he continued by trying its consistency first: "When the varnish was cold I found that it was rather thin and that it did not cover well." 44

Description of failure is part of the ervarenis too. The varnish did not have the particular properties Eikelenberg was looking for. But rather than discarding the varnish, he embarked on a journey of improvement and adjustment.

Therefore I put it again in the pan on the hot sand and let it become slightly too hot to keep my finger in. I made it evaporate and become thicker, but I did not omit to stir often and I noticed that the white powder sediment gradually mixed itself with the rest. When the whole mixture had lost about $1 / 4$ of the weight of the components before the melting, I poured it into another pan, stirring steadily until all was cold. Then I put it again in the bottle and found that it was a good varnish, though not as good as the varnish of gum Copal which surpasses all others, but yet better than if sandarac is added, as I have described on p. 802, and very clear and shiny. ${ }^{45}$

Working with what he had, Eikelenberg tried to improve the varnish by this process of heating and thickening. Yet even though he seemed to have arrived at a satisfactory result, his journey of improvement was hardly finished. Eikelenberg would return many times to Van Hoogstraten's recipe, finding new ways for further improvement. For example, it occurred to him later that it would be better to reduce the initial quantity of turpentine oil by a fourth to avoid squandering it in another arduous evaporation exercise. ${ }^{46}$

Reading the ervarenissen about varnishes reveals the situatedness of Eikelenberg's practices. They disclose the meshwork of materials, recipes and experiences, and show how all these different histories intersected in the local

44 Idem, fol. 827. Translation from Van Schendel, "Simon Eikelenberg's Experiments", p. 130. "Doe de vernis koud was bevond ik ze wat dun en datze niet genoeg dekte."

45 Idem, fol. 827. Translation from Van Schendel, "Simon Eikelenberg's Experiments", p. 130. I kept the original capitalization. "Derhalven ik zette die weer in de pan op 't heete zand totdat ze een weijnig te heet was om er de vinger in te houden. Latende die uitwasemen en bijgevolg dikker worden. Maar ik versuijmde ondertusschen niet dikwijls te roeren en bemerkte dat het geschifte witte poeder zig allengs met de andere stoffen vermengde. Dat nu het geheele mengsel omtrent $1 / 4$ verloren had van de swaarte die de stoffen tesamen voor de smelting hadden, doe goot ik over in een andere pan het zelve gestadig omroerende tot dat het gantschelijk koud was. Waarna ik 't weder in de fles deed en bevond dat het een goede vernis was. Hoewel niet zoo goed als die van gom Copal die alle anderen overtreft, maar evenwel beter als dan wanneer men er sandarac bij deed van welcken ik bladz. 802 heb geschreven en zeer klaar en blinkende."

46 Idem, fol. 828. 
environment of his workshop. ${ }^{47}$ Unpacking Van Hoogstraten's recipe took place in this unique environment. The sand for the sand bath came from the dunes, which were in close proximity to his home town, Alkmaar. Eikelenberg fueled his furnace with coals and used flasks for his varnishes that weighed " 8 1 12 lot without the cork." ${ }^{48}$ Moreover, his workshop was furnished with new glazed stone pans, stone lids, flat bottom pans, cauldrons, cloths he used for straining, a balance, a mortar, a fine sieve, spatulas, paintings for testing, and last but not least, pen, paper and ink to write down his ervarenissen. Yet, when another varnish recipe specifically called for a Cologne pot, Eikelenberg resorted to a glass flask, which highlights the finite possibilities of his inventory. ${ }^{49}$ Moreover, the ervarenissen occasionally show how Eikelenberg depended on his environment for recipes, good practices and materials, which were not always of superior quality. For example, he obtained an elaborate recipe for a sandarac-based varnish from his former teacher Nicolaas de Vree. When he put it to the test, someone else told him to powder the gums before using them, which he initially forgot to do..$^{5^{\circ}}$ In yet another ervarenis, he recalled how he received two ounces of gum copal, which he found "very bad, crumbly, opaque, contaminated with filth," and yet, he did not discard the gum, but tried to make the most of it..$^{11}$

It is in the specificity of this environment that Eikelenberg's own practices and standards were shaped, which he further organized through the ervarenissen. Initially improvised procedures gradually turned into standard practice through repetition. For example, built around earlier experiences, the ervarenis on Van Hoogstraten's varnish soon became protocol itself, soliciting references like "I dealt with it as I had done with the varnish of Van Hoogstraten as described on page $827 .{ }^{52}$ Moreover, in judging the quality of his varnishes, Eikelenberg barely referred to standards other than those that emerged within the confines of his workshop. As such, Van Hoogstraten's varnish was worse than the copal varnishes, but better than those containing sandarac, which were all described in separate ervarenissen. A recipe for a Chinese varnish can be found crossed out on its folio page, accompanied by a short nota relating it to one of the copal ervarenissen: "found it no good, but see 821 etc." 53

47 I borrowed the term "meshwork" from Tim Ingold, who advocates an ecological approach to the act of making. See Ingold, Being Alive.

48 Eikelenberg, "Aantekeningen betreffende schilderen", MS 390, fol. 820: "De vernisfles weegt ledig behalven 't kurk 8 1/2 loot."

49 Idem, fols. 8oo-1.

50 Idem, fol. 8 oo.

51 Idem, fol. 829: "[Z]eer slegt, bros, ondoorschijnig met vuijl vermengdt."

52 Idem, fol. 822. Translation from Van Schendel, "Simon Eikelenberg's Experiments", p. 129. "[I]k deed [...] daar mede als ik bladzijde 827 van de vernis van hoogstraten had gedaan."

53 Idem, fol. 721: "[N]iet goet bevonden; maar zie 821 enz." 
The ervarenissen demonstrate clearly how a recipe, upon execution, and much in contrast with its generalized and rule-like character, is adapted to a very specific environment. To make Van Hoogstraten's varnish recipe operational, it had to be introduced into this intricate meshwork of materials, texts, experiences and people that intersect at the locality of Eikelenberg's workshop. A recipe cannot be imposed onto reality; it needs to become part of it instead.

\section{Unpacking Recipes}

It remains difficult to pin down what exactly a recipe is, and in Eikelenberg's case, it is true that the term was not even mentioned in his work. Yet, the recipe as such carries significant and distinguishable features that sets it apart from other texts. Not only can these features be found in Eikelenberg's notes, a better understanding of them helps to see how this literary format differs in function and style from the ervarenissen. During the early modern period, the recipe was one of the main vehicles for technical know-how. ${ }^{54}$ What immediately stands out when compared with other literary formats, is that the recipe calls for action. With a stated purpose and listed ingredients, the recipe promises the reader that something can be done and lays down the manner in which to proceed. These are the features that generally distinguish recipes from other texts. Texts that do not exhibit all of these features, but nevertheless sought a similar effect, have previously been called recipe paraphrases..$^{55}$ Van Hoogstraten's recipe is such a paraphrase: even though it lacks a proper imperative, it nevertheless called Eikelenberg into action.

Recent historiography has dissected the recipe further. As William Eamon wrote in his seminal work on early modern books of secrets, the recipe should be distinguished from other ways of conveying know-how. Technical processes could also be narrated in a descriptive-historical style, as was done for example in Renaissance texts like Biringuccio's Pirotechnia (1540) or Agricola's De re metallica (1556). Unlike historical descriptions, the recipe does not describe technical processes as past events, but instead provides rules to follow. Recipes can thus be thought of as "formulas for making," or "sets of short matter-of-fact instructions." 56

Nevertheless, to define recipes in terms of rules, formulas, and instructions, can be a deceptively simple portrayal of the dynamics in which they were embedded. Rules, as iron-cast and rigid as they appear to the modern mind, often leave

54 Eamon, Science and the Secrets of Nature; Leong and Rankin, Secrets and Knowledge.

55 Mäkinen, "Efficacy Phrases".

56 Eamon, Science and the Secrets, pp. 9, 131; Leong and Rankin, "Introduction: Secrets and Knowledge", p. 8; Eamon, "How to Read a Book of Secrets", p. 30. 
wriggle-room and space for interpretation. Indeed, even to arrive at these rules from practice was perceived to be quite problematic by early modern authors. ${ }^{57}$ Know-how can be difficult to put into words, involving much that is tacit, gestural or embodied in the nature of making practices..$^{58}$ To write down a recipe implies the inevitable loss of those things that resist articulation. In competition with hands-on instruction, recipes can therefore appear to be suboptimal vehicles for know-how. Yet, it is precisely by surpassing the specificity of the workshop that recipes were able to impart know-how. ${ }^{59}$ The depersonalized and generalized character of recipes allowed them to travel across social, cultural, and linguistic barriers, but this came at a price: the burden was on the reader to make the recipe operational. ${ }^{60}$

Plenty of recipe collections have survived that document, in the margins or between the lines, the experiences of readers who navigated the ambiguities, difficulties and errors contained, thereby adapting the recipes to their own needs and practices. ${ }^{61}$ Two lines of argument have been developed in recent historiography to explain why readers had to make their recipes work. Firstly, Elaine Leong has called attention to the so-called "thinness" of recipes. Their flexibility or ambiguity allowed them to fit different frames and be mapped onto "different systems of explanation." ${ }_{22}$ The fact that recipes could harbor multiple readings was not directly problematic - it also helps to explain their longevity - but their very thinness might have led readers astray too. The chemist Robert Boyle (1627-1691), for example, was afraid that the established recipe style would allow for too much miscommunication. Chances were that the recipe, due to its peculiar style, was not able to keep its message under control. When he published a collection of medicinal recipes, he freely admitted that he frequently altered the "Style of the Formulary's of Receipts," because he was "more concern'd that the Meaning should be close kept to, than the Style rectify'd." ${ }_{3}$ This goes directly against the notion that recipes, as rule-like as they are, constrained the realm of possibilities for the reader. ${ }^{64}$

Secondly, recipes not only left wriggle-room with respect to the action they called for; sometimes they had to be actively altered in order to work. For example, translating recipes from one language to another, or from one workshop

Eamon, Science and the Secrets, p. 9. See also: Smith, The Body of the Artisan, pp. 8o-2; Smith and the Making and Knowing Project, "Historians in the Laboratory"; Hagendijk, "Learning a Craft from Books.

58 Polanyi, Personal Knowledge. For further references and a discussion of tacit, gestural and embodied knowledge in the context of written know-how, see Hagendijk, "Learning a Craft from Books", pp. 203-5.

59 Dupré, "Doing It Wrong".

60 Goody, The Domestication of the Savage Mind, p. 136

61 Pennell, "Perfecting Practice?”; Leong, “Collecting Knowledge for the Family”; Pugliano, "Pharmacy, Testing".

62 Leong, "Brewing Ale", p. 72.

63 Boyle, The Works, vol. 10, pp. 176-7; DiMeo, "Communicating Medical Recipes".

64 Goody, The Domestication of the Savage Mind, p. 141. 
to another, often invited error with respect to locally specific terms, materials and practices. As Sven Dupré argues, the identification of these errors and their codification in recipes became common practice in the seventeenth century. ${ }^{65}$ Eikelenberg too was aware of the potential for written know-how to produce error. Considering why contemporaneous art treatises, such as Gerard ter Brugghen's Verlichtery kunst-boeck (1616), did so little to describe the "the making of paints," he blamed the overall quality of the available written material. No wonder authors like Ter Brugghen shied away from practicalities,

because the descriptions of which they had to avail themselves, were so full of errors and yokes of alchemists, that the lover would become an alchemist rather than an illuminator would he have followed them. ${ }^{66}$

In brief, reading a recipe and subsequently putting it into practice was not as straightforward as one might expect. Pamela Smith reminds us, therefore, that recipes, besides delivering know-how, also promoted trial-and-error by the reader. Early modern recipe collections, either published or written, often presented a variety of alternative recipes for one end-product, which positively encouraged experimentation and comparison of procedures. ${ }^{67} \mathrm{~A}$ recipe never readily transmitted what it promised. Instead, the written word needed to be brought back to life by infusing it with one's own experience. A recipe had to be made operational.

Eikelenberg was an avid collector of recipes and his attitude towards them is clear in one of his prefaces in which he gave the following "Warning to the reader":

Reader, the notes you find in this book have been gathered over the years by me, my pen and those of others, and concern many great and sure things with respect to all kinds of paints. Yet, they are unrefined and I have not tried them all. Yes, there are many from it [the manuscript] that I have not yet found the time to make [...] and they are merely put together so that I can avail myself of them at a later time. ${ }^{68}$

65 Dupré, "Doing It Wrong”.

66 Eikelenberg, "Aantekeningen betreffende schilderen”, MS 392, fol. 32: "[O]m dat de beschrijvingen waarse zig daar van mosten bedienen zoo vol dolingen en grollen der stofscheiders [in the margin: 'alchimisten'] waren dat de liefhebber eer een stofscheider dan een verligter zoú worden indien hij hen gevolgt had."

67 Smith, "Why Write a Book?".

68 Eikelenberg, "Aantekeningen betreffende schilderen”, MS 39o, fol. 3: "Waarschuwing aan de lezer. Lezer, de aantekeningen die gij in dit boek vind zijn sederd verscheijde jaren door mij, zoo door mijn pen als die van anderen bijeenvergaderd, en behelzen wel vele goede en zekere dingen ten opzigt van allerley slag van verfzels, maar zijn onbeschaaft en niet alle van mij beproeft. Ja, ook vele, die ik nog geen tijt heb gehad daar uit te doen, [...] en zij zijn slegs bijeen gesteld op-dat ik mij daar naderhand af zou konnen bedeene." 
This passage reveals Eikelenberg's recipe collection as a temporary repository to store and collect know-how. It reflects the transitionary state of the manuscript and illustrates its open character with notes and recipes moving in and out of his collection. Eikelenberg's manuscript thus carries none of the definitive and fixed properties that were sometimes claimed by authors of other recipe collections, most famously by those of books of secrets. ${ }^{69}$ More importantly however, the provisional nature of the manuscript spills over to the recipes themselves. Eikelenberg did not regard recipes as formalized knowledge, or polished textual renditions of established practices, but rather as source material that could be mined for know-how, the value of which could not be judged with certainty by only glancing over its words. Recipes needed to be tested, or beproeft, to establish their usefulness. This attitude extended also to the recipes he retrieved from his former educator Nicolaas de Vree, showing that Eikelenberg did not exempt those recipes for which credibility had already been established. ${ }^{70}$ Recipes, he seems to have suggested, could never be taken at face-value, regardless of where they came from.

\section{Communicating Experience}

Whereas recipes are characterized by their thinness, Eikelenberg's ervarenissen, by contrast, provide a dense and detailed overview of his experiences with respect to a variety of materials, recipes and procedures tried in his workshop. This section is concerned with the ervarenis as such, and how Eikelenberg came to use this specific literary format in his notes. Addressing this question is complicated, because contemporaneous thinking on experience was in flux; the associated terminology had not fully crystallized and its epistemological validity was yet not well established. Learned discourse offered two Latin terms for experience, experimentum and experientia, and both were occasionally translated as ervarenis in Dutch..$^{71}$ At the same time, ervarenis was interchangeably connected to other Dutch terms like bevinding and ondervinding - echoed in the English noun 'finding' - which carries a similar meaning. To make things even more complicated, these vernacular terms were part of ordinary and everyday discourse and could hardly be singled out as philosophical talk.

69 Eamon, "How to Read a Book of Secrets".

70 Eikelenberg, "Aantekeningen betreffende schilderen", MS 390, fol. 3; Leong and Pennell, "Recipe Collections".

71 "Experientia” was translated as 'ervarenis' in Descartes, Brieven. Derde Deel, p. 225.

"Experimentum" was translated as "ervarenis" in Kircherus, d'Onder-Aardse Weereld.

Compare with Kircherus, Mundus subterraneus. 
The unsettled nature of experience and its susceptibility to different interpretations are evident in Eikelenberg's notes. Apart from the ervarenissen, Eikelenberg used an extensive repertoire of experiential statements that followed recipes or that were simply scribbled between the lines. In that sense, his notes fit a larger historiographical picture. Adding practical annotations to a text was common practice in the early modern period. Over the past decade, scholars have identified several annotation practices and found traces of experiences in different practical texts, ranging from those concerned with domestic cooking, through pharmacy and medicine, to the arts. ${ }^{72}$ Eikelenberg too added simple remarks to recipes, saying "I made this thus," or "as I experienced myself." On other occasions he signaled his experimental findings more clearly, for instance: "nota, I have found the grinding with vinegar to be very good," or, "nota: the one below is not good for paintings." Another experiential qualifier was the occasional "probatum," asserting that Eikelenberg had tried the recipe in question. ${ }^{73}$ To a certain extent, the ervarenissen are in line with these experiential statements. Both convey specific validations, directions, improvements or revisions that flowed from the enactment of recipes or tried procedures and practices. But there are differences too. Firstly, Eikelenberg's experiential statements are rather succinct compared to the elaborate ervarenissen. Secondly, the ervarenissen display a fixed literary format contrary to the more varying style of his experiential statements. Finally, the ervarenissen do not always depend on existing recipes. Whereas some might be read as extensive annotations, for example on Van Hoogstraten's varnish recipe, others stand on their own and appear to have had no basis in recipes at all, such as two ervarenissen on gum copal. Unlike the experiential statements, the ervarenissen should therefore be seen as full-blown reports that were worth communicating in their own right. But what motivated Eikelenberg to write his ervarenissen?

Besides Eikelenberg's notes, there are two contemporaneous examples of designated use of the term ervarenis. One of them concerns a Dutch translation of Athanasius Kircher's Mundus subterraneus [d'Onder-aardse weereld], 1682. This book, chiefly dealing with the Earth's geology but with a broader scope, announced on its frontispiece that it was a "first-time translation from Latin,

72 Leong, Recipes and Everyday Knowledge; Wall, Recipes for Thought, pp. 209-250; Pennell and DiMeo, Reading and Writing Recipe Books; Leong and Rankin, "Testing Drugs and Trying Cures. Experiment and Medicine"; Pugliano, "Pharmacy, Testing”; Leong and Pennell, "Recipe Collections"; Mäkinen, "Efficacy Phrases".

73 Eikelenberg, "Aantekeningen betreffende schilderen”, MS 390, fols. 22, 455 (alternative numbering), 651, 662, 663, 705, 708, 713, 720, 724, 727, 736, 748, 769, 811, 835. "[H] eb ik aldus gemaakt" (727); "zoo ik zelf heb bevonden" (835); "Nota het wrijven met azijn heb ik zelf zeer goed bevonden" (748); "nota: deze onderste is niet goet tot schilderij" (713). 
and embellished with many ervarenissen and copper plates."74 Eikelenberg was well aware of this source and copied several excerpts from the Dutch translation. Ervarenis in this case was a translation of the Latin experimentum. Upon close inspection, there is little resemblance between Kircher's ervarenissen and those of Eikelenberg. The ervarenissen in Kircher's book look like recipes, complete with imperatives, stated purposes and listed ingredients. Moreover, Kircher's ervarenissen were primarily intended to help the reader conduct a certain experiment, not produce an end-product.75 This approach to recipes is consistent with what Peter Dear and William Eamon noticed with respect to the Royal Society; to communicate experimental findings, the Fellows of the Royal Society regularly used a "recipe-like format" - i.e., a set of instructions that enabled readers to replicate an experiment on their own. ${ }^{76}$ In addition, the term experimentum, and by extension Kircher's ervarenis, was historically associated with medical and alchemical recipes. ${ }^{77}$ Yet, even though Kircher's ervarenissen deviate significantly from Eikelenberg's ervarenissen, they illustrate an important point nonetheless; terms like experiment(um), experientia, and ervarenis did not warrant a specific literary style during the seventeenth century and could find their way into both prescriptive and descriptive texts.

More akin to Eikelenberg's use of ervarenissen is how they were employed by the Dutch experimental physician Anthonius de Heide (1646-169o/1696)..$^{8}$ Chances were that Eikelenberg was familiar with De Heide's books - he cited experimental physicians from the same circle, like Cornelis Bontekoe and Steven Blankaart - even though he never made explicit references to De Heide himself. For De Heide, ervarenissen had a clear epistemological goal: "the Art of Medicine and Surgery is to build, [...] not by decorating it with uncertain presumptions, but by the performance of many ervarenissen." 79 De Heide practiced what he preached, for example when he clarified various uncertainties regarding "callus," a healing tissue formed at the site of bone fractures; various ervarenissen helped him to study how and from what material this callus grew. One of them is recounted as follows: "In the year 1674, I smashed a bone of a dog into pieces, and left it without bandages." Eighteen days later he killed the dog, and, having repeated the experiment on another dog and some frogs, he was ready to admit that callus

74 Kircherus, d'Onder-Aardse Weereld, frontispiece: "Nu eerst uit het Latijn vertaalt, en met veel Ervarenissen en Kopere Platen vercierd."

75 Asmussen, Scientia Kircheriana, p. 117.

76 Dear, "Totius in Verba”; Eamon, "How to Read”, p. 41.

77 Park, "Observation in the Margins"; Pomata, "The Recipe and the Case".

78 Zuidervaart, "Het in 1658 opgerichte 'Theatrum Anatomicum'”.

79 De Heyde in Vande Voorde, Nieuw Lichtende Fakkel der Chirurgie, p. [5]: "[T]ot op-bouwing der Genees-en Heel-Konst [...] niet met onwisse onderstellingen te versieren, maar door het doen van veelerlei ervarenissen." See also De Heide, Ontledinge des Mossels. 
presumably originates from blood. ${ }^{80}$ Gruesome details aside, the literary format is reminiscent of Eikelenberg's ervarenissen. It contains a specified date, is written in the past tense and features a first person voice.

The story of De Heide's ervarenissen is one which seamlessly fits with the greater narrative of the rise of the New Sciences over the course of the seventeenth century. Eikelenberg's ervarenissen too should be understood against this background. His correspondence contains a specific mention of ervarenissen that leads to the heart of the New Sciences. In 1691, the young Eikelenberg wrote a letter to a friend who was studying at Leiden University. After some pleasantries, he got down to the business of what motivated him to write the letter:

When you were here the other day, you recounted that one of your Professors forced the mercury, if I am not mistaken, to climb to a height of 30 inches in an airpump. [...] If you get the chance, I sincerely hope you will let me know more about the tube or glass, the amount of mercury and the way he proceeded, as well as the other Ervarenissen you might obtain concerning mercury. ${ }^{81}$

Without doubt, Eikelenberg was referring to a replication of one of Boyle's airpump experiments. ${ }^{82}$ Leiden University was in possession of a replica of this pump and the then professor of physics, Burchardus de Volder (1643-1709), had established a rigorous curriculum in experimental philosophy. De Volder's pedagogy revolved largely around the demonstration of experiments, many of which were taken from Boyle's New Experiments Phyisco-Mechanical Touching the Spring of the Air and its Effects (1660). ${ }^{83}$ With his reference to the airpump, Eikelenberg not only appears to have been fully up-to-speed with developments in the 'New Philosophy,' his letter also draws an explicit connection between ervarenissen and what Boyle called "experiments." For Boyle, and more generally for the Royal Society, experiments were historically unique events and in order to gain epistemological weight, they had to be communicated and shared. For experiments which were notoriously difficult to replicate, vivid accounts were

8o De Heyde in Vande Voorde, Nieuw Lichtende Fakkel der Chirurgie, p. 570: "In het Jaar 1674. heb ik een Hond sijn been in stukken geslagen, en sonder eenigh Verband laten blijven."

81 Correspondence from Simon Eikelenberg to Cornelis Hildernis, 4 October 1691. Eikelenberg, "Brieven van en aan Simon Eikelenberg", MS 556: "Doe gij lest hier waart, hebt gij mij verhaald dat een uwer Professooren de merkurius door een lugtpomp, zoo ik Mij Nooit bedrieg, tot de hoogte van 30 duijmen, wist te doen opklimmen [...] van de buijs of 't glas en de hoeveelheijd der Mercurius met welke dat geschiede, nog ook op welk een wijs hij te werk ging dit alles zou ik gaarne willen, dat gij mij bij gelegendheijd eens doe weten, beneffens d'andere Ervarenissen die gij van de kwik moogt krijgen."

82 Van Helden, "The Age of the Air-pump"; Nyden, "De Volder's Cartesian Physics".

83 Nyden, "Living Force at Leiden". 
written that allowed others to virtually witness what happened instead. ${ }^{84}$ The resulting literary format - i.e., the experimental essay - described experiments as discrete events linked to a particular time and place, was a conscientious recounting of the facts, reserved a central role for the observer, and used a first person and active voice. ${ }^{85}$ All of these features are found in Eikelenberg's ervarenissen, but there is a difference too.

Since Peter Dear's seminal work on the seventeenth-century advancement of experience in the mathematical sciences, the notion of experience has sparked new scholarly interest. As Dear showed, thinking about experience evolved from a largely Aristotelian notion, understood as cumulative experience or the collective memory of universal regularities, towards experiments as highly specific and historical events. ${ }^{86}$ Meanwhile, similar developments have been mapped for the history of medicine, alchemy and chemistry, tracing the roots of a similar appreciation of experience, trials and experimentation as ways to know and investigate nature. ${ }^{87}$ At the same time however, experience has largely been understood and analyzed as an epistemic category, and it is precisely in this respect that Eikelenberg is different. Producing varnishes was not so much an epistemic operation. So, what was communicated through the ervarenissen?

By employing the literary format of the experimental essay, Eikelenberg emphasized the highly specific and eventful character of his ervarenissen. Contrary to what Dear, Shapin and Schaffer have argued with respect to the origins of experimental methodology, the literary format of the ervarenissen was not meant to warrant authority, nor was its purpose to turn the experience of an individual into the experience of many. Instead, the ervarenis became an end in itself; a way to communicate the very situatedness and specificity of each and every act of making. The ervarenissen showed something that recipes, the ubiquitous vehicles of written know-how, could never show; their specificity stands at odds with the recipe's generalized character and reveals intricacies of making that would otherwise never speak through text. This amounts to a peculiar trade-off. Whereas adherents to the New Philosophy were striving to turn the individual experience into the experience of many, Eikelenberg turned this around; he juxtaposed recipes, which were intrinsically reproducible and potentially the experience of many, with ervarenissen, and illustrated how each

84 Shapin and Shaffer, Leviathan and the Air-pump.

85 Dear, "Totius in Verba", pp. 152-3. The origins of this literary format can be traced back to contemporary French fictional prose, see: Principe, "Virtuous Romance and Romantic Virtuoso".

86 Dear, Discipline E Experience; Dear, "Totius in Verba".

87 Ragland, “Making Trials"; Leong and Rankin, Testing Drugs and Trying Cures; Newman, Atoms and Alchemy; Pomata, "Observation Rising". 
and every act of making is ultimately individual, unique and idiosyncratic, anchored within the confines of the workshop and the experience of the maker.

\section{Expressive Instructions}

When it comes to written instructions, style matters. By writing ervarenissen instead of recipes, Eikelenberg sought an alternative literary format to communicate know-how, and this touches on an issue that has recently been brought to light by Richard Sennett in The Craftsman. Given the difficulty with which know-how and all its tacit dimensions can be put into words, it is important to question how "to make written instructions communicate." 88 Following Sennett's suggestion, Eikelenberg's ervarenissen can be read as a communicative strategy, or as Sennett puts it, an attempt to "create expressive instructions."

Sennett argues that there are a number of ways to create expressive instructions and presents a variety of "imaginative tools," such as metaphors, similes, narratives, loose analogies, sympathetic illustrations and adverbial color that culinary authors employ to effictively communicate with their readers. ${ }^{89}$ Even though know-how remains difficult to put into words, imaginative tools help significantly to bring its tacit dimensions to the surface and to evoke a feeling for them in the readers. Yet, as powerful as these tools are, exacting language can be restricting. While some recipes offer instruction in exactly what to do, they can be paralyzing in their precision, while sterile language causes them to remain largely ineffective. ${ }^{90}$ By contrast, Henry Perowne, the brilliant neurosurgeon in Ian McEwan's novel Saturday, prefers a lack of expressed exactitude: "From recipes he draws only the broadest principles. The cookery writers he admires speak of 'handfuls' and 'a sprinkling,' of 'chucking in' this or that. They list alternative ingredients and encourage experimentation." ${ }^{11}$ In conclusion, it matters how instructions are written down. They can be appreciated differently from reader to reader, but one thing is clear: to achieve effective communication, it is worth experimenting with style.

The literary format of the ervarenissen displays characteristics that Sennett identifies as expressive instructions. Firstly, the ervarenissen can be read as sympathetic illustrations. Sennett argues that sympathetic illustrations draw attention to the interaction between practitioner and material, rather than focussing on material transformation alone. They do not employ an authoritative tone, but anticipate the insecurity an inexperienced practitioner might feel when

88 Sennett, The Craftsman, p. 179.

89 Idem, pp. 179-193.

90 Idem, pp. 182-4.

91 McEwan, Saturday, p. 177. 
encountering the material for the first time. ${ }^{92}$ Likewise, the personal style of the ervarenissen allows readers to imagine themselves in Eikelenberg's position and to see through his eyes. They show how Eikelenberg navigated his way through the procedure and responded to unanticipated contingencies. They portray him in a vulnerable position. His ervarenissen recount how he scorched his gum copal because he "became aware of it too late"; how he subsequently "decided to add oil to prevent everything from going to waste"; how he initially "forgot to powder the gums"; how he "feared" his varnish would congeal like it did the previous time. ${ }^{93}$ Readers can sympathize with this vulnerability. Eikelenberg's mistakes are likely the mistakes that any first-timer would encounter. Yet, by writing them down, Eikelenberg helped his readers to avoid them. More generally, the ervarenissen prepared readers not to be daunted by failure. Instead they demonstrated how people can improvise their way out of failure, revisit procedures and continually refine them.

Secondly, the ervarenissen can be read as scene narratives. The scene narrative embeds know-how in time and place, and contextualizes it from beginning to end. As Sennett puts it: “'where' sets the stage for 'how'." By describing the conditions of recipes, procedures, and materials, the scene narrative puts readers in the right frame of mind. It omits detailed and precise instructions, but once the scene is sketched and the orienting landmarks are in place, readers have enough information to figure out its moral on their own, much like a parable. ${ }^{94}$ Similarly, Tim Ingold advocates for stories and telling as a modality to convey know-how. ${ }^{95}$ Drawing on his experience as an anthropologist in the field, Ingold noticed that stories played an important role in the education of novices when they learnt how to hunt like their predecessors. Telling stories is an "education of attention" - through stories, novices learn to attend to their environment and to respond to subtle cues. Much in contrast with articulation or specification - i.e., what Sennett calls dead denotation - stories guide novices in discovering know-how on their own.

Not surprisingly, telling is precisely what Eikelenberg did in the ervarenissen: "like is told [on] page 822," or "like was told [on page] 821 in the first ervarenis." 96 And here too, the 'how' is embedded in the 'where'. Specified with a date and

92 Sennett, The Craftsman, p. 186.

93 Eikelenberg, "Aantekeningen betreffende schilderen", MS 39o, fols. 80o, 821, 822, 823:

"[I]k versuymt had de gommen te poederen" (8oo); "t welk ik te laat gewaar wierd" (821);

"Om nu voor te komen dat niet alles verloren ging besloot ik de olij daar in te doen" (821822); "en vreesende datse 't enemaal zoude schiften" (823).

94 Sennett, The Craftsman, pp. 187-9.

95 Ingold, Making, pp. 109-111.

96 Eikelenberg, "Aantekeningen betreffende schilderen", MS 39o, fols. 826, 830: "[E]ven eens bladzijde 822 word verteld" (826); "even eens als 821 in de eerste ervarenis is vertelt" (830). 
staged in Alkmaar, Eikelenberg took his readers on a journey in his ervarenissen. In the case of Van Hoogstraten's varnish, Eikelenberg set the stage by touching on his first encounter with the recipe: "Before, page 677, I spoke of a varnish from the visible world of S. Hoogstraten." We are provided with an orienting problem: "Hoogstraten mentions the substances but not their quantities". ${ }^{97}$ Eikelenberg also presented a financial perspective: "on Sept. 23, 1711, the ingredients were somewhat more expensive and I found the cost to be 1 penny the lot, manufacture included. ${ }^{98}$ He introduced the reader to a jumble of continuously attracting and retracting materials, shifting viscosities and the phase transitions that took place in the earthenware pot: "When I added the oil [...] I noticed that the halfprepared varnish appeared to curdle. This I believe was due to the coldness of the oil solidifying part of the mastic; while also the oil mixed better with the turpentine." He put the varnish in a glass bottle, looked at it anew and made further observations: "I saw that in the bottle, in which I had put the varnish when cold, a whitish sediment had formed." He considered the varnish in connection to other varnishes: "not as good as the varnish of gum copal [...] but better than if sandarac is added." He framed it in terms of spillage: using less turpentine oil yields a varnish that "would cost less." 99 And he framed it in terms of fire hazards, emphasizing how he prevented "any flame" from reaching the "pan with mastic". Central to the ervarenis however, are the continuous transformations of the varnish. It is this storyline that ties together all the different material outlooks. Meanwhile, Eikelenberg stayed away from imperatives. Not standing opposite but next to the reader, he points things out, allowing the reader to see the things he sees. The story follows a path and tags the reader along, indicating alternative paths and drawing attention to holes, pitfalls, shortcuts, steep slopes and viewpoints. Gradually, an extensive ecology unfolds in the ervarenis, enabling readers to enter and experience foreign territory.

\section{Conclusion}

Communicative strategies like the ervarenissen underlie the history of written know-how. By writing ervarenissen to communicate know-how, Eikelenberg chose a literary format that significantly differed from recipes. Whereas a recipe strived

97 Unless stated otherwise, the quotes in this paragraph were previously introduced in Section 3 .

98 Eikelenberg, "Aantekeningen betreffende schilderen”, MS 390, fol. 828. Translation from Van Schendel, "Simon Eikelenberg's Experiments," 130. I changed Schendel's translation "loot" into "lot." "[D]en 23 September 1711 [...] de mengstoffen wat dierder zijnde, bevont dat de kosten met maakloon daarbij 't loot een stuijver."

99 Idem., fol. 828: "[E]n nog minder kosten." 
to emancipate know-how from the locality of the workshop, Eikelenberg sought to bring it back in. To this end, he appropriated the experimental essay form used by proponents of the New Sciences, which seemed particularly suited to reflecting the local meshwork of materials, experiences and workshop practices that constituted an act of making. By showing the specificity and idiosyncrasy of the act of making, he tried to establish a sympathetic relationship with his readers, to put them in the right frame of mind, and to show that failure and improvisation belong in the workshop.

Eikelenberg's efforts show how the authors of practical texts kept searching for new strategies to cope with the difficulties of articulating their know-how. Doing so, they often steered away from recipes as the default literary format. This can also be seen in the popular contemporaneous Guidebook for Gold-and Silversmiths published in 1721. Written in the first-person voice, the book utilizes recipes merely as quick fixes for non-essential know-how. ${ }^{100}$ Moreover, communicative strategies did not develop in isolation, but were frequently modelled after learned textual formats. Authors resorted to 'epistemic genres' such as observationes to communicate and organize artisanal experience. ${ }^{101}$ An example of this has recently been elucidated by Sven Dupré, who identified these observationes in English and German translations of the first published book on glassmaking by Antoni Neri (1576-1614). ${ }^{102}$ Eikelenberg too, turned to an epistemic genre, yet his appropriation of the experimental essay was not aimed at communicating new knowledge, but to show how to get something done. When it comes to written instructions, style matters.

100 Hagendijk, "Learning a Craft from Books"; Van Laer, Weg-wyzer (1721).

101 Pomata, "Sharing Cases"; Pomata, "The Recipe and the Case".

102 Dupré, "Doing It Wrong". 
Unpacking Recipes and Communicating Experience 



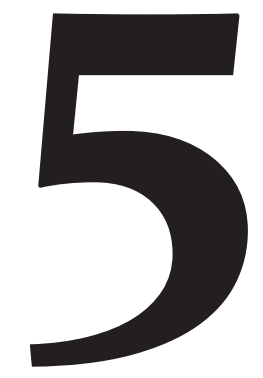

\section{Learning a Craft from Books}

Historical Re-enactment of Functional Reading in Goldand Silversmithing

This chapter was previously published as: Thijs Hagendijk, "Learning a Craft from Books. Historical Re-enactment of Functional Reading in Gold- and Silversmithing," Nuncius 33 (2018), 198-235, doi: 10.1163/18253911-03302002. 


\section{Introduction}

In 1721, the Dutch silversmith Willem van Laer (1674-1722) wrote that up till then "nobody has depicted with letters on Paper, the essence of a good Gold or Silversmith." For that reason, he took it upon himself to write a didactic manual of his craft, entitled Guidebook for upcoming gold- and silversmiths (Weg-wyzer voor aankoomende goud en zilversmeeden). In just over two hundred pages, the author explains the ins and outs of his craft. The book touches upon several assaying techniques to assess the quality of gold and silver; it explains how to build furnaces; it elaborates on basic techniques like casting, soldering and embossing; it provides several recipes and even presents an invention: a machine that can be used for soldering. That Van Laer knew what he was writing about, is evidenced by a surviving set of communion-beakers (1709) that until today serve their original purpose in a church in Heino, The Netherlands (Figure 32). ${ }^{2}$

The description of skill and technique displayed in Van Laer's work is unparalleled in other early modern sources on gold- and silversmithing. Writing on gold- and silversmithing from the preceding centuries is generally restricted to assaying techniques, mining and metallurgy, while circulating recipes and instructive texts touched upon a limited selection of techniques, such as gilding, medal making and life casting. ${ }^{3}$ The Guidebook breaks away from this tradition and its didactic voice suggests it can be considered as an early manual or textbook for the craft. Van Laer reassures his readers in the preface that "through this Sketch, the Reader will be put on his way, not only to thoroughly comprehend the many Mechanical Arts, but also to surely do them."4 In general, the book was quite successful. In less than fifty years, four editions were published, including a pirated edition in Mechelen. ${ }^{5}$ A bookseller in Middelburg suggested that the Guidebook was specifically "valuable to novices" and was both "scarce and used a lot on a daily basis." The same bookseller indicated that the book was sold in the cities of Zeeland, "as well as the cities of Holland." In addition, the anonymous writer of the Mechelen preface, tells us that "the art lover's favorable reception of the first edition of this little work, which already became very uncommon, moved us to publish a second edition." ${ }^{\prime 7}$ Furthermore, the Guidebook could be obtained

Van Laer, Weg-wyzer (1721), p. 1. All translations mine, unless otherwise indicated.

Dubbe, Zwols zilver, p. 113.

3 Smith and Beentjes, "Nature and Art"; Beentjes and Smith, "Sixteenth-Century Life-Casting Techniques".

4 Van Laer, Weg-wyzer (1721), p. 1.

5 The first edition of the Guidebook was published in Amsterdam (1721). Exact reprints appeared in Middelburg (1730) and Amsterdam (1768). A slightly altered edition was published in Mechelen (1750?).

6 Middelburgse Courant, July 5, 1759.

7 Van Laer, Weg-wyzer (1750?), p. i. 
in "de Gekroonde Smit" a hardware store for gold- and silversmiths, run by Jan Stand in Amsterdam, who sold a variety of tools and materials, ranging from English and German files to saltpetre. ${ }^{8}$ Jan Stand also served as the clerk of the Amsterdam guild for gold- and silversmiths. ${ }^{9}$ This shows that the book was not perceived as a threat to established routes to craft learning and supports the idea that craft secrecy was relatively insignificant in the Low Countries. ${ }^{10}$ Finally, a copy signed by the early nineteenth-century silversmith W. van Calker speaks of the Guidebook's circulation among professional silversmiths (Figure 33). ${ }^{11}$

Van Laer's objective of writing a guidebook for his craft, as well as its favorable reception, gives rise to an important question concerning the role of 'how-to' texts in practices of learning. What role did the Guidebook play in the acquisition of practical skills in the eighteenth century? Unfortunately, annotated copies and archival material that could answer this question are scarce. To assess the

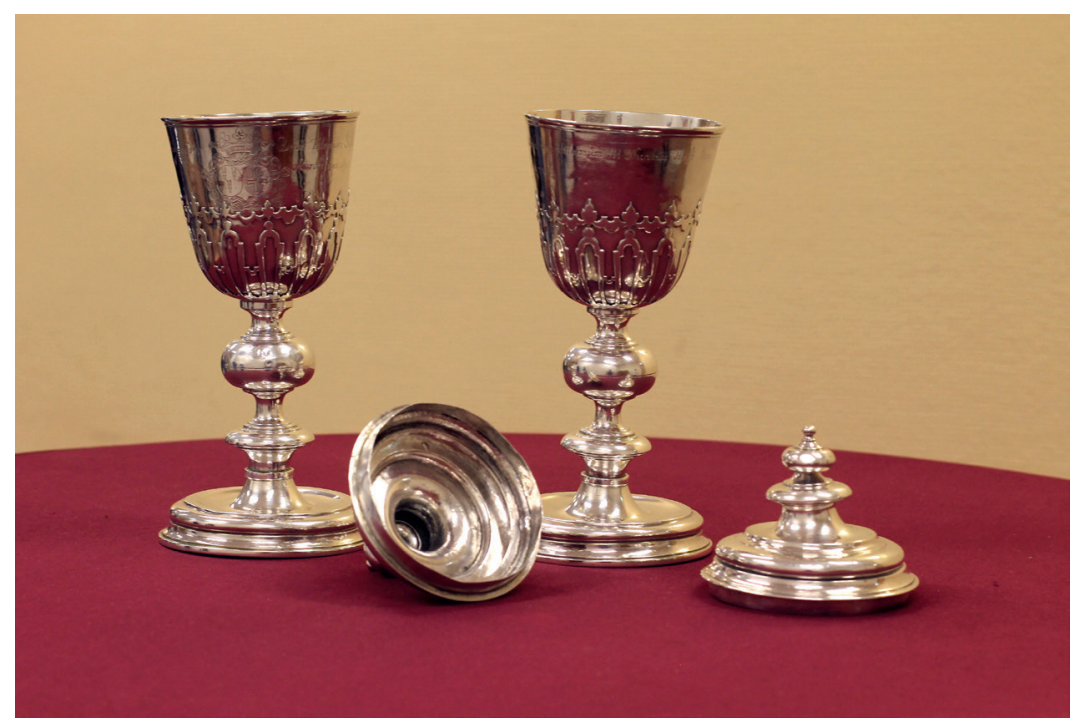

Figure 32: Communion-beakers (1709) by Willem van Laer. Photo: Thijs Hagendijk.

8 Amsterdamse Courant, May 3, 1731.

9 Amsterdamse Courant, July 1, 1721.

10 Davids, "Craft Secrecy".

11 Van Laer, Weg-wyzer (1768) in the collection of the Othmer Library, Philadelphia, Pennsylvania. For W. van Calker, see: http://www.geheugenvanzeist.nl/wiki/Zilverindustrie in_Zeist (accessed 22 Jun. 2017). 


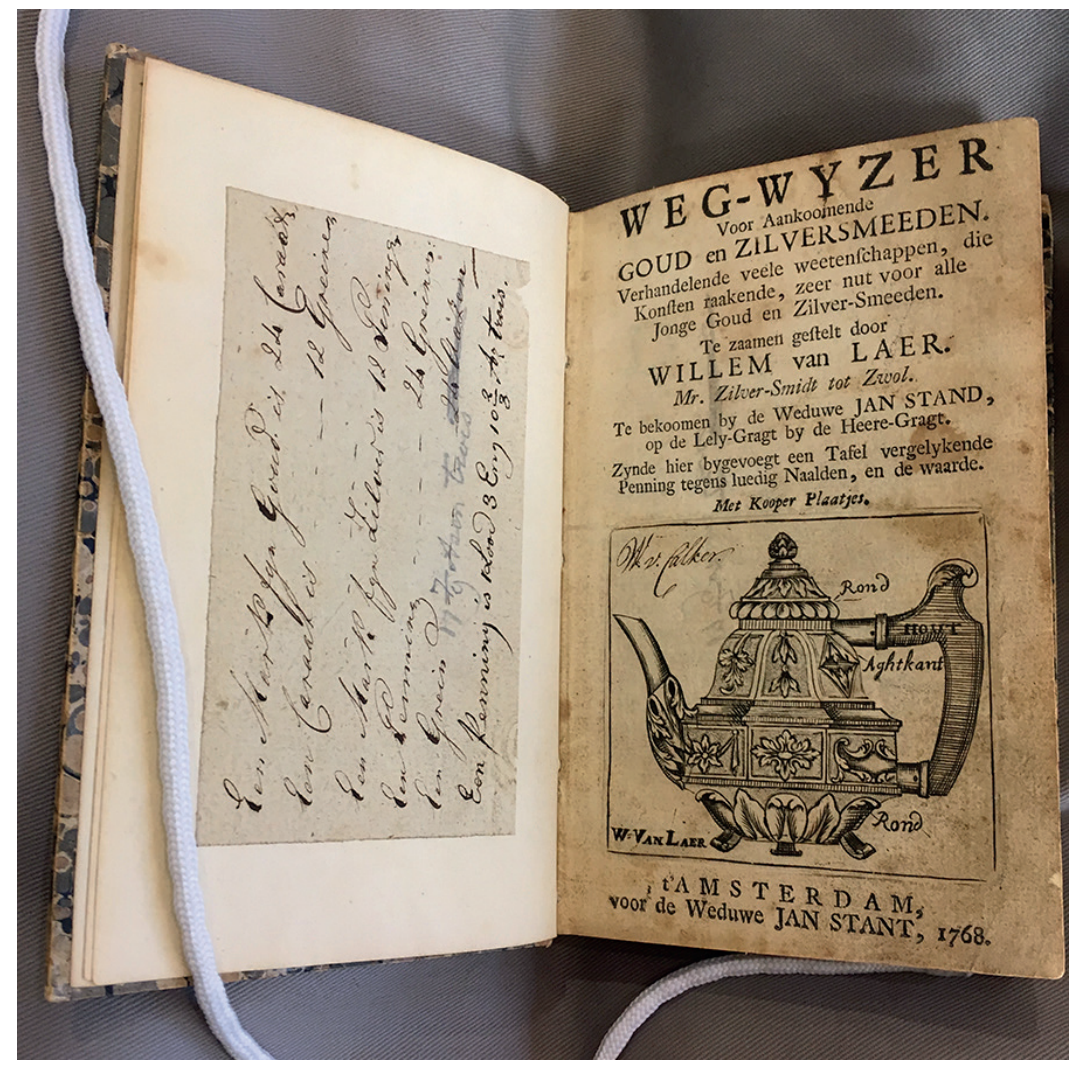

Figure 33: Signed copy of Willem van Laer, Weg-wyzer voor Aankoomende Goud en Zilversmeeden (Amsterdam: Weduwe Jan Stant, 1768). Photo: Thijs Hagendijk.

historical role of the Guidebook in education processes, this study employs a multi-angle approach, including re-enactments. I argue that effective use of the Guidebook depended on complementary hands-on teaching by craftsmen who could make up for knowledge not provided by Van Laer. Yet its dependence on complementary hands-on education does not mean that the book was useless. The Guidebook brought benefits to the workshop as well, specifically because it helped to overcome some of the limits and challenges posed by hands-on education. 


\section{Text and Practice}

The early modern period witnessed an explosion of artisanal 'how-to' treatises, both in print and manuscript, that dealt with a variety of practices, ranging from smithing to mining, and from glassmaking to painting. ${ }^{12}$ While it might be tempting to read these sources as unequivocal accounts of early modern artisanal cultures of making, recent scholarship has pointed out that the relationship between these texts and actual artisanal practices was in fact more complex. Over the past few years, many scholars have therefore stressed the need to study these texts with particular attention to historical usage and their embeddedness in contemporaneous artisanal or craft practices. ${ }^{13}$ There are at least two reasons to re-address the interplay between text and practice. First, early modern artisanal writing constitutes a very complicated and versatile body of texts. Authors had different motives for writing, and readers engaged with these texts for various reasons. Historians have identified several of these motives, arguing that artisanal treatises were used to show off skill and know-how in writing, to elevate the status of craft work, to convey didactics of making, to instruct in the ability to improvise,' as aide memoires, to codify errors, and to preserve knowledge that was going out of practice. ${ }^{14}$ Although limited, this list shows that the interaction between text and artisanal practices differed from case to case and illustrates the need to study artisanal texts on an individual basis.

A second complicating factor in the relation between text and practice is the fact that text, as a medium for the transmission of artisanal knowledge, is often constrained. Willem van Laer wrote, for instance, that "it is not possible to put everything on paper with such clarity, that one would be able to understand it fully without hands-on instruction." ${ }^{15}$ Other early modern authors wrestled with similar issues.$^{16}$ For example, the sixteenth-century mining official Lazarus Ercker (ca. 1530-ca.1594), who wrote a book on metallurgy, stated that "these things refuse to be depicted on paper, such that one can grasp it by reading alone. Instead, reading provides the direction, and the work of the hand provides the

Eamon, Science and the Secrets of Nature; Leong and Rankin, Secrets and Knowledge;

Smith, "Why Write a Book?"; Long, Openness, Secrecy, Authorship, pp. 102-4.

13 Long, "Trading Zones in Early Modern Europe", p. 846; Martinón-Torres, review of Laboratories of Art, p. 387; Eamon, "How to Read a Book of Secrets", p. 41.

14 Smith, "Why Write a Book?"; Long, Openness, Secrecy, Authorship, pp. 102-4; Goody, The Domestication of the Savage Mind, pp. 140-2; Sennett, The Craftsman, pp. 179-193; Pennell and Dimeo, "Introduction," in Reading and Writing Recipe Books, p. 7; Yeo, Notebooks; Dupré, "Doing it Wrong"; Hendriksen, "Necessary, Not Sufficient".

15 Van Laer, Weg-wyzer (1721), p. *3r.

16 Smith, The Body of the Artisan, pp. 8o-2. See also: Smith and The Making and Knowing Project, "Historians in the Laboratory", pp. 211-2. 
experience." ${ }^{17}$ Likewise, the alchemist and glassworker Antonio Neri (1576-1614) remarked in his famous treatise on L'arte vetraria that "experience teaches much more than long studying." 18

Scholars have often pointed to tacit knowledge to explain why texts are suboptimal vehicles for the transmission of craft knowledge. ${ }^{19}$ Indeed, craft knowledge is best transmitted, taught and learned through apprenticeships, in which there is plenty of room for intimate observation, imitation, trial-and-error and repeated exercise. Text on the other hand, requires the articulation of craft knowledge, which, due to its sensory and physical character, is easier shown than explained. Tacit knowledge, in this respect, accounts for the fact that "we can know more than we can tell." ${ }^{20}$ Even though there is little reason to doubt this line of reasoning, this study regards tacit knowledge as conspicuous and in need of questioning in relation to artisanal texts, rather than as an analytical category. First of all, the term "tacit knowledge" is semantically obscure. For example, it remains difficult to find a clear-cut definition of what tacit knowledge precisely entails, whereas "the term 'tacit' has many shades of meaning, ranging from the silent through the unspoken to the implicit." ${ }^{21}$ More importantly however, parallel to tacit knowledge, other concepts have been developed and used, which despite semantical differences seem to serve similar goals. For instance, to denote the "tacit dimensions" of historical experimental practices, historian H. Otto Sibum uses the term "gestural knowledge" to refer to the "complex of skills and mastery." 22 In a similar manner, the term "embodied knowledge" is frequently used by others but is often left undefined. ${ }^{23}$

Second, the fact that knowledge is not always articulated is not necessarily the result of the impossibility to put it into words. For example, it could deliberately be kept a secret, or it could be presupposed by the author. Moreover, certain knowledge did not surpass the domain of common understanding and was therefore not deemed worthy of putting into words. ${ }^{24}$ Knowledge could also be obtained by working with materials and tools, either through trial-and-error or by exploring their affordances. ${ }^{25}$ Furthermore, even though some knowledge might indeed appear to be impossible to express, to understand tacit knowledge

19 Sennett, The Craftsman, p. 94; Smith, "What is a Secret?", p. 50; Epstein, "Craft Guilds in the Pre-Modern Economy”; Marchand, "Muscles, Morals and Mind”; Smith, "The London Apprentices"; Wallis, "Between Apprenticeship and Skill” (2015).

20 Polanyi, The Tacit Dimension, p. 4. See also Polanyi, Personal Knowledge.

21 Ingold, Making, p. 109.

22 Sibum, "Reworking the Mechanical Value of Heat", p. 76.

23 O'Connor, "Embodied Knowledge".

24 Collins, Tacit and Explicit Knowledge, pp. 91-8; DiMeo, “Openness vs. Secrecy”.

25 Gibson, The Ecological Approach to Visual Perception, pp. 127-143. 
as being opposed to articulated or explicit knowledge can be misleading as well. Tacit knowledge can be "unpacked" using narratives, metaphors or sympathetic illustrations. ${ }^{26}$ Through these means, tacit knowledge can still find expression and evoke an understanding. Rather than being opposed to explicit or articulated knowledge, tacit knowledge appears to be consonant with it, which makes it more fluid and difficult to grasp. ${ }^{27}$ Finally, the importance of tacit knowledge for craft knowledge can also be downplayed, as was done by Melvyn Usselman et al.; after replicating a nineteenth-century chemical experiment of Justus von Liebig based on the latter's publications, they indeed recognized the important role played by tacit or gestural knowledge and the difficulties it posed through its ineffability. Nonetheless, in their opinion the absence of certain tacit knowledge in Liebig's text only made replicating more complex but did not prevent them from succeeding. ${ }^{28}$

In short, the versatility of the early-modern body of artisanal writing, as well as the problematic articulation of craft knowledge in text, has led to the awareness that the relation between text and practice should not be understand in a "hierarchical" or "binary" way. ${ }^{29}$ By taking this premise as a point of departure, this study investigates the relation between textual and artisanal practices closely by looking at how early-modern people used texts to learn how to do things. ${ }^{30}$ In this context, the Guidebook provides a valuable case study, primarily because Van Laer unambiguously stated that he wrote this book while having in mind the education of young and upcoming gold- and silversmiths. This study takes this claim seriously and investigates the ways in which novices and apprentices could have been effectively using this book. In addition, the Guidebook marks, as a craft manual, the early beginnings of a development in which texts gradually played a more visible role in vocational training of gold- and silversmiths. ${ }^{31}$ Although beyond the scope of this article, the interplay between textual and artisanal practices can thus be historicized and followed through time.

26 Sennett, The Craftsman, pp. 179-193; Ingold, Making, p. 109.

27 Nonaka and Von Krogh, "Tacit Knowledge and Knowledge Conversion”; Polanyi, "The Logic of Tacit Interference", p. 7.

28 Usselman et al., "Restaging Liebig"; Chang, "How Historical Experiments Can Improve Scientific Knowledge", p. 321.

29 Smith, "Why Write a Book?", p. 48.

30 Glaisyer and Pennell, "Introduction" in Didactic Literature in England.

31 The Dutch vocational school for gold- and silversmiths (Vakschool Schoonhoven) had developed its own textual resources and workbooks. 


\section{The Guidebook in Context}

Willem van Laer was born in 1674, the son of the silversmith Pieter van Laer. His father had an established reputation in Zwolle, a Dutch provincial town, and trained his son in his profession. Willem appears to have been quite unfortunate in financial matters. He was troubled by debt and after a forced auction of his home in 1718, he suddenly turned up in Amsterdam. In the preface to the Guidebook he explained his situation: "The Vicissitude of this World has put me in an unfortunate position regarding my temporary goods, such that I have retained nothing more (due to certain people), than my Wife, and Child, and the use of my limbs, as long as the almighty will please." ${ }^{22}$ To make things worse, Willem van Laer was not admitted to the Amsterdam guild for gold- and silversmiths, meaning that he had no access to its professional and educational infrastructure. Consequently, he was unable to practice his craft and therefore decided to write down his twenty-five years of experience, which eventually resulted in the Guidebook. ${ }^{33}$ From the preface, it becomes clear that Van Laer hoped that by writing this book he could turn things around and generate more income. He offered his services at a "decent price" to those who want to receive the complementary and necessary manual education needed to understand everything that is explained in the book. Van Laer also claimed that he "has not found anyone yet, who has sketched the essence of a good Gold or Silversmith with letters on paper." 34 He was convinced that through his writing many people would start to see the complexities of his craft. Even though these reasons resonate with those typical for technical authorship from the fifteenth century onwards, i.e. to fish for patrons or commissions, or to elevate the status of the craft, Van Laer also genuinely believed that his book would actually enable people to "do" the "Mechanical Arts" themselves:35

The reason I call it a Guidebook is that there will be few young Gold-and Silversmiths who, while reading, will not be able to find anything to their use and taste, and taken by the hand, will be lead to knowledge of many things. ${ }^{36}$

The Guidebook is unmistakably endowed with an educational purpose. Furthermore, Van Laer frequently referred to "young" and "upcoming goldand silversmiths" as his target audience, which likely encompassed future professionals such as apprentices and novices. Apart from these youngsters

32 Van Laer, Weg-wyzer (1721), p. *2r.

33 Bert Dubbe in Van Laer, Weg-wyzer (1967), p. xxix; Van Laer, Weg-wyzer (1721), p. 1.

34 Van Laer, Weg-wyzer (1721), p. 1.

35 Idem. For reasons for writing, see Smith, "Why write a book"; Long, "Power, Patronage".

36 Van Laer, Weg-wyzer (1721), p. *2v. 
however, the book might also have been of appreciable interest to a specific class of non-professionals, such as art lovers, amateurs, connoisseurs and virtuosi. ${ }^{37}$ Indeed, Van Laer mentioned them too. Interestingly, in his view the lovers are anything but passive consumers, collectors and appreciators of art. Rather, it is the lover who produces the actual objects. Moreover, the late seventeenth-century, and rather negative, identification of lovers as people who held inferior knowledge of art, does not seem to have applied to gold- and silversmithing. ${ }^{8}$

How neatly the Figures and tiny Amsterdam Landscapes were shaped by a Lover is sufficiently witnessed by the Golden watchcases, snuffboxes and other Gold and Silver Works. ${ }^{39}$

Nonetheless, to ask whether both non-professionals and young gold- and silversmiths alike might have bought and read the Guidebook seems beside the point. When it comes to actual and effective usage, I will argue that understanding the book often required prior knowledge and basic acquaintance with techniques and tools, which is more likely to be found in professional circles.

The Guidebook can be divided into two parts. After some general remarks about the importance of the art of drawing, "which cannot be praised enough," Van Laer introduced the first half of the book, which dealt with quality assays, methods for separating metals and ways of purification. He explained that a "Gold- or Silversmith, and all negotiators in these beloved metals, need to know well their inner grade, or value. If not, it will cause (the buyer, or seller) great damage."40 This knowledge was already widely available through several treatises published prior to the Guidebook. One of these treatises was the aforementioned Beschreibung aller fürnemsten mineralischen Erzt unnd Berckwercksarten, first published in 1574 by the Bohemian-Saxon mining official Lazarus Ercker. This treatise likely served as an example for Van Laer, specifically because several of the processes described in the Guidebook can be found in here as well, such as a closely related description of the cupellation process. ${ }^{41}$ More compelling evidence of Van Laer's interest in Ercker is found in an engraving that displays a composition of distilling furnaces and retorts. Interestingly, the inverse composition is identical to one found in Ercker's Beschreibung, which makes it likely that it was traced and copied by Van Laer. Even though it is clear that Van

37 Skogh, "The Varied Role of the Amateur"; Guichard, “Taste Communities”; Honig, Jan Brueghel.

38 Taylor, "The Birth of the Amateur".

39 Van Laer, Weg-wyzer (1721), pp. 147-8. See also pp. 38, 84, 176.

40 Idem, p. 4.

41 Compare Van Laer, "Om goede klaar te maaken," in Weg-wyzer (1721), pp. 50-2, with Ercker, "Wie man guete Clär machen soll," in Beschreibung aller fürnemsten mineralischen Erzt, p. 11. 
Laer's descriptions of quality assays and procedures are far from original, the Guidebook is nonetheless the first known published book on this topic in Dutch. The only predating Dutch source is a manuscript from 1639 that was written by Peter Geerts, a Dutch goldsmith from the city of Groningen. Called Assays on gold and silver coins, this manuscript specifically contains knowledge for mint masters, but whether it was actually published is unknown. ${ }^{42}$

The second part of the Guidebook is devoted to techniques, processes, and knowledge immediately concerned with the fashioning of silver and/or gold objects. Unlike the first half of the book, this part cannot be traced back to previous artisanal writings and presents a near complete and structured account of the craft of gold- and silversmithing. Almost every chapter is concerned with a different "art," such as soldering, casting, chasing, gilding and polishing. In many cases, Van Laer explained why these arts are of importance to the reader. For example, he introduced soldering by stating that "many have learned, through harmful experience, that a master Silver- or Goldsmith is in great need to know how to solder well. That is why I want to share with the student all I know, hoping it will safeguard him from disasters in due course."43 In almost each of his chapters, Van Laer led with his personal experience. He explained what worked best in his opinion, and yet, he left no stone unturned when it came to alternative procedures used by his colleagues. Throughout his chapters, he alternated between extreme detail and summarizing descriptions. For instance, in his discussion of chasing, he explained in great detail how to transfer a design to silver but provided almost no guidance on how to perform the actual chasing. ${ }^{44}$ This selective eye for detail suggests that Van Laer addressed an audience that was already acquainted with some of the craft tools and procedures, which is why he could skip these parts in his explanations.

Because Van Laer singled out future professionals as his audience, and because he presupposed familiarity with some of the craft procedures, the Guidebook could most effectively be employed when incorporated in apprenticeship learning. Indeed, high percentages of book possession amongst Dutch gold- and silversmiths, i.e. up to $79 \%$ between $1672-1720$, illustrate their literacy and secure them as a potential audience. ${ }^{45}$ In the early modern period, apprenticeship was a compulsory step for those wanting to become masters. ${ }^{46}$ Craft guilds were the main institutions through which this educational system was organized,

42 Tump, Ambachtelijk geschoold, pp. 208-9.

43 Van Laer, Weg-wyzer (1721), pp. 117-8.

44 Idem, pp. 147-151.

45 Tump, Ambachtelijk geschoold, p. 202.

46 Davids, "Apprenticeship and Guild Control"; De Munck, Technologies of Learning; De Munck, "Corpses, Live Models, and Nature"; Smith, "The London Apprentices", p. 151; Wallis, "Between Apprenticeship and Skill" (2015); Wallis, "Apprenticeship and Training in Premodern England", p. 848. 
although in the Northern Netherlands apprenticeships could also be organized independent from guilds. Before entering an apprenticeship, a contract was signed in which finances and expected outcomes were negotiated. Even though minimal information about the actual learning process has survived, it is unlikely that a formalized educational program was in place. Instead, learning was often more spontaneous than structured. This idea is also supported by Joan Lane in her study of apprenticeships in England. Even though she draws on early nineteenthcentury accounts, she argues that in general the apprentice would move through different stages. The first stage concerned unskilled and routine tasks, such as tidying the shop and running errands. Subsequently, apprentices would move onto low-level tasks, which would provide them with practical experience and knowledge of materials. Gradually, the apprentice would take on more complex and responsible tasks. ${ }^{47}$ Even though not much is known about the course of the apprenticeship, it is clear that preferably no material or time was wasted for practice and educational purposes only; learning happened on the job.

In the Dutch Republic, the duration of the apprenticeship for gold- and silversmiths varied widely, but seemed to have fluctuated around four years. ${ }^{48}$ Frequently, apprentices switched masters because they wished to expand their knowledge and skill. Master craftsmen were often specialized in a selection of products or areas, meaning that they were not able to provide a complete overview of the craft. The most obvious case of specialization was that of gold- or silversmithing. Van Laer too, differentiated between these two areas and described them as "two Arts, each of which require a complete human being." 49 There are however examples of more specialized areas of expertise. Some apprenticeship contracts from the seventeenth and eighteenth century stipulated a selection of different areas in which the apprentice had to be trained, such as gold- or silverplating, gold- or silverbeating, embossing or wiredrawing. Other contracts merely mentioned the objects, such as the fashioning of gold- or silver buttons or thimbles, for which the apprentice would receive training. In addition to selective expertise of the craftsmen, specialization could also occur in the course of the apprenticeship, due to a lack of talent or particular skillfulness exhibited by the apprentice..$^{\circ}$ Finally, it needs to be emphasized that transmission and education of craft knowledge was not the sole purpose of the apprenticeship. Apprentices usually enrolled as adolescents and were consequently trained and raised by the master, not only professionally, but also to prepare them for adulthood.

47 Lane, Apprenticeship in England, pp. 57-69.

48 Schoen, Tussen hamer en aambeeld, p. 182; Hesselink, "Goud- en zilversmeden", p. 130;

Tump, Ambachtelijk geschoold, p. 89.

49 Van Laer, Weg-wyzer (1721), p. 3.

50 De Munck, Technologies of Learning, pp. 47-88; Schoen, Tussen hamer en aambeeld, pp. 188-9. 
Several scholars have pointed out that the apprenticeship was, and in fact still is, important for character formation of young people..$^{51}$

All in all, there was no such thing as a standardized apprenticeship, even though some attempts were made to complement or streamline apprenticeship learning..$^{22}$ For example, from the sixteenth century onwards, schools were founded for drawing, which freed masters from the often mandatory drawing lessons during the apprenticeship. Van Laer too emphasized the indispensability of drawing for gold- and silversmiths, but did not explain this skill in his book. ${ }^{53}$ Additionally, in England attempts were made to introduce textual resources to apprenticeships, such as Richard Dafforne's The Apprentices Time-Entertainer Accomptantly (1640). Similar examples have however not been found in the Low Countries.

\section{Re-enactment as a Method to Assess Historical Usage}

Even though it is known that the Guidebook was read and used, no historical sources have been found that adequately describe its specific role in the historical workshop and in practices of learning. To better understand how exactly the Guidebook may have been embedded in these practices, I used the method of historical re-enactment. Well-known in the fields of archaeology and conservation and restoration, experimental methods have become part of the historian's toolkit too. ${ }^{44}$ Specifically in cases where the interpretation of texts, the primary source material for historians, is difficult, experimental history can significantly enhance more traditional humanistic methods such as closereading and archival research. Many terms have been employed to describe the act of historical experimenting. Historians have written about their experimental research as replication, restaging, reconstruction, and re-enactment, with each term denoting slight methodological differences. ${ }^{55}$ Indeed, terminology, methodology, and application of experimental historical research differ from case to case. For example, historical experimentation can be used to lay bare the experiences, skills and tacit knowledge underlying a historical text. Along

51 Marchand, "Muscles, Morals and Mind"; Smith, "The London Apprentices".

52 Wallis, "Between Apprenticeship and Skill”; De Munck and Soly, "Learning on the Shop Floor”; De Munck, “Corpses, Live Models"; De Munck., Technologies of Learning, p. 53; Smith, "The London Apprentices", p. 151.

53 Van Laer, Weg-wyzer (1721), p. 2.

54 For reconstructions in archeology, see Ingersoll et al., Experimental Archeology. For reconstructions in conservation and restoration see Carlyle and Witlox, "Historically Accurate Reconstructions".

55 Fors et al., "From the Library to the Laboratory"; Chang, "How Historical Experiments Can Improve Scientific Knowledge". 
this line, H. Otto Sibum demonstrated that the success of the canonical heatexperiment of the nineteenth-century scientist James Joule depended on the latter's artisanal experience as a brewer. ${ }^{56}$ Alternatively, experimental history can be used as a tool to significantly enhance understanding of a text. As such, Lawrence Principe found that the reproduction of alchemical recipes can be a valuable tool in falsifying prevailing interpretations, which resulted in a drastic re-evaluation of alchemical knowledge and the awareness that alchemical texts, although allegorically, were based on actual experimental practices in alchemy.57 Similarly, historical reconstructions have recently been explored in the Making and Knowing project as a method for close-reading and as a heuristic device in translating artisanal texts..$^{8}$

Closest perhaps, to the envisioned approach of this article, are a series of reconstructions the Making and Knowing project made of life-casting techniques described in BnF. Ms. Fr. 640, a sixteenth-century French manuscript. Together with an expert-maker, Tonny Beentjes, who is a practicing silversmith and Amsterdam-based conservator and who returns later in this article, they reconstructed this fashionable Renaissance technique and found that it enhanced a better understanding of the materials and techniques mentioned in the manuscript. ${ }^{59}$ Reconstruction taught them, for example, that metal casting is not so much about the metals, but rather about "experimentation on mold materials." It also helped them identify details on museum objects that would have otherwise escaped their attention, such as the little holes left by the pins that kept the dead animals in place while building the mold. ${ }^{60}$ Above all, they found that reconstructions had the potential to reveal "systems of belief and knowledge, as well as testify to the material, physical, and philosophical engagement of craft with the generative and transformative power of nature."61

This study shares some important characteristics with the aforementioned approaches. It recognizes the importance of historical experimentation as a way to access and understand the material and tacit dimensions that lay behind an artisanal text such as the Guidebook. Indeed, as the Making and Knowing project found, only after carefully following Van Laer's instructions on casting, did the value of good quality casting sand become apparent, as well as its relative importance compared to other variables in the casting procedure. However, although a thorough understanding of early modern materials and techniques

56 Sibum, "Reworking the Mechanical Value of Heat".

57 Principe, The Secrets of Alchemy, pp. 137-171.

58 Bilak et al., "The Making and Knowing Project", p. 46. See also Moureau and Thomas,

"Understanding Texts with the Help of Experimentation".

59 Smith, "Historians in the Laboratory", p. 215.

60 Smith, "In the Workshop of History", pp. 21, 23.

61 Smith, "Historians in the Laboratory", p. 228. 
remains indispensable, re-enactment based on the Guidebook was not primarily aimed at the elucidation of materials, techniques and worldviews behind it, but rather at exploring the processes of learning and the role of books therein.

For this study, I chose to re-enact the educational context for which the Guidebook was initially designed. Consequently, drawing from my field notes and ethnographies of the re-enactments, I could enhance my understanding of the specific role and contributions of the Guidebook in the educational process as a whole. This method was not only inspired by the aforementioned historical approaches, but also indebted to the fields of anthropology and sociology in which the "apprentice-style method of inquiry" has become a much-appreciated method to study craft knowledge and craft education. By becoming corporeally and sensually involved in learning a craft, the ethnographer gets a better grip on what precisely is going on, especially because "most on-site communication is nonpropositional, and relies more immediately on an intercourse of visual, auditory and somatic information." ${ }^{2}$ The apprentice-style method thus allowed me to keep track of the non-propositional communication and knowledge involved in learning the craft of silversmithing.

The Guidebook provides two basic conditions for the re-enactments. First, Van Laer explicitly addressed novices who want to pursue a career as a gold- or silversmith. More specifically, his target audience consisted of "upcoming gold and silversmiths," whereas the book was supposedly of "great use to all young gold- and silversmiths." ${ }^{3}$ Having no prior gold- and silversmithing experience, I took up the role of the learning novice. Second, Van Laer reminds his readers that the textual instructions had to be complemented with hands-on education and that is why Tonny Beentjes joined the project. Although learning would initially happen through the Guidebook, Beentjes would oversee the education process as a master craftsman and complement the Guidebook with hands-on instruction where necessary. This collaboration proved rather fruitful in the end, not only for me, but for Beentjes too. Although Beentjes' expertise and familiarity with historical gold- and silversmithing practices proved indispensable in interpreting the Guidebook, his role was not solely advisory. Teaching me as a silversmith enabled him to reflect on his own pedagogy. ${ }^{64}$ Additionally, my unexperienced position forced us to keep an open mind and to question procedures that otherwise would have been taken for granted.

It is important to note that even though the re-enactments were aimed at a better understanding of historical practices, they were themselves an ahistorical

62 Marchand, "Muscles, Morals and Mind", p. 249. See also O'Connor, "Embodied knowledge"; Atkinson, "Blowing Hot; Grasseni, "Skilled Vision”; Pink, Doing Sensory Ethnography; Ingold, The Perception of the Environment.

63 Van Laer, Weg-wyzer (1721), title page.

64 Dupré, "Re-working with Makers (Part 2)". 
staging of an educational context. ${ }^{65}$ This means that historical research took place before and after the re-enactment was performed. Preceding the re-enactment, the experimenting historian needs to make choices, deciding what features of historical practices are essential or irrelevant with respect to the topic and question under investigation. ${ }^{66}$ These choices vary from materials, persons and expertise involved, through the physical space of the workshop, to the scope of the re-enactment. Based on these historically informed decisions, a scenario is drawn up and the stage is set. It is only then that the historian enters the scene as a participant-observer and starts to perform ethnographical research. Subsequently, the ethnographies, insights, and questions that arise during the re-enactment serve to further inform and interpret the historical topic under investigation. Historical research and re-enactments thus complement each other. As a methodological consequence, one should keep in mind that next to informing new historical insights, re-enactments can as easily function as a gimmick that reinforces existing interpretations while obscuring the alternatives. It is therefore imperative to continuously keep going back and forth between historical decision-making and re-enactment, while reflecting on the double role of historian and participant-observer. ${ }^{67}$

\section{Historical Conditions and Limits of Re-enacting}

In the summer of 2016, re-enactments started in the Atelier Building in Amsterdam, a state-of-the-art facility for conservation and restoration practices of the Rijksmuseum, the Cultural Heritage Agency of the Netherlands and the University of Amsterdam. It is important to note that the re-enactments took place in a workshop that was distinctly different from what a historical workshop would have looked like. In an engraving from 1576, goldsmith Étienne Delaune (1518/1519-1583) offers a great impression of the set-up of a historical goldsmith's workshop (Figure 34). Immediately striking is the central place of fire. The forge would be employed to melt metals and was fueled by a charcoal fire. Even though the Atelier Building has a fire place, melting would be done by hand using gas-fueled torches, with the smoke immediately carried off by a sophisticated ventilation system for practical, health, and safety reasons.

65 Mann et al., "Mixing Methods, Tasting Fingers"; Dupré, "Re-working with Makers (Part 2)".

66 Stijnman, "Style and Technique", p. 6; Fors et al., "From the Library to the Laboratory", p. 94 .

67 Höttecke, "How and What Can We Learn From Replicating Historical Experiments?", pp. 345-6. 


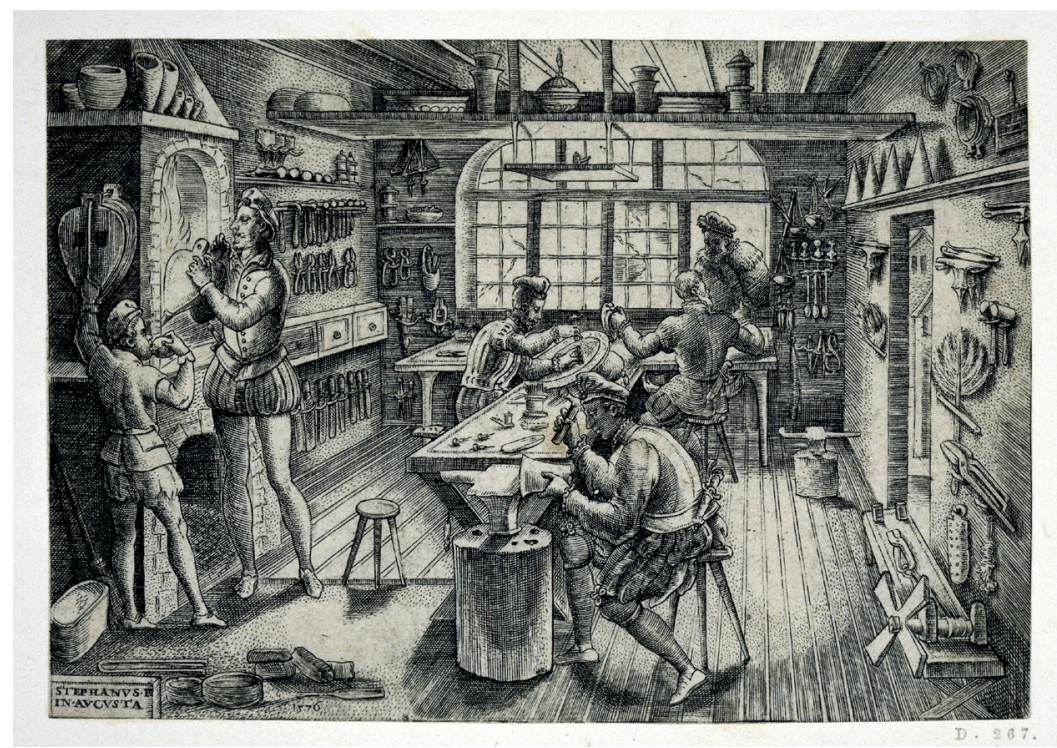

Figure 34: Étienne Delaune, A Goldsmith's Workshop, 1576. Engraving, 83 x $120 \mathrm{~mm}$. (C) Trustees of the British Museum.

Another difference concerned the people in and around the workshop. A historical workshop would have ordinarily harbored multiple individuals, such as apprentices, journeymen and the master himself. The average size of gold- and silversmithing workshops was found to be small in the Low Countries, but in some cases limits had to be imposed on the number of employees. ${ }^{68}$ Likewise, Delaune's engraving depicts several people at work. This meant that the apprentice had ample opportunity to observe, watch and learn how others worked, moved and behaved around the workshop. According to sociologist Paul Atkinson, the workshop could be thought of as a "site of choreography." In his ethnography of glassblowing, Atkinson argues that understanding the workshop, also means to understand "posture, the angles of the body, the rhythms of the body, the co-ordination of different workers' bodies in the confined space of the studio." ${ }^{\prime 69}$ Similarly, the gold- and silversmiths' workshop was a site of choreography. In Delaune's engraving, the forge clearly effects co-ordination and collaboration

68 Tump, Ambachtelijk geschoold, pp. 92-3; Schoen, Tussen hamer en aambeeld, p. 183; De Munck, Technologies of Learning, pp. 131-153.

69 Atkinson, "Ethnography and Craft Knowledge", p. 59; Atkinson, "Blowing Hot". For a historical perspective on movement and rhythm, see Wellman, "Hand und Leib". 
between two people. One of the figures, likely the apprentice, is working the bellows, while the other, presumably the master, is minding the silver in the crucible. Meanwhile, other workers are busy chasing a large basin or hammering out, 'raising,' a bowl against the anvil. At the Atelier Building however, similar choreographies rarely occurred. Learning simply by absorbing the dynamics of the workshop and by witnessing peers was impossible.

But maybe one of the largest differences was that the re-enactments, compared to historical practices, were not restricted by time, money or commissions, nor influenced by a need to shape a young person's life. Whereas from a historical perspective, learning came virtually down to working, we took a different approach and explored the Guidebook topic by topic, not hindered by any deadlines or the need to secure income. $7^{\circ}$ Topics were selected based on their feasibility and potential interest for the research question. Consequently, procedures like mercury-gilding were off-limits due to safety concerns. While our selective approach allowed for much freedom, as a downside, we never finished an entire object. Normally, a craftsman foresees the trajectory of an object from beginning to end and is trained to think ahead accordingly..$^{71}$ For example, when making a mold, a silversmith efficiently positions the runners towards the replica as to minimize the loss of detail during finishing, which prevents a half day's work of compensatory chasing in the end. Similar anticipatory decisions keep a lid on expenses and make processes more efficient. As Beentjes explained during one of the re-enactments, "sometimes a silversmith needs to think even up to ten steps ahead." The re-enactments however, due to their selective nature, did not leave much room to experience how different stages of work affected one another as an object comes into being. As a result, the urgency of certain techniques and the 'why' of certain procedures did not always become apparent because they were never performed in full connection to each other.

\section{6. "On the casting of both silver and gold"}

Re-enactment began with a ten-page chapter on casting silver. This decision was grounded in Beentjes' experience that casting serves as an accessible introduction to the craft. Interestingly, Van Laer does not distinguish between entry-level and advanced techniques in the Guidebook, nor does he stipulate a curriculum. So already at this stage, Beentjes became immediately didactically involved by deciding what chapter to start with, a decision that seemed random to me at

70 De Munck, Technologies of Learning, p. 56.

71 Tim Ingold deliberately employs the term "foreseeing" instead of "overseeing" to account for the "inclinations of alternatively pliable and recalcitrant materials." Ingold, Making, p. 70. 
best, since the chapter is positioned in the middle of the book between soldering and chasing. In brief, casting as described by Van Laer concerns a procedure that today is understood as founding. Founding comprises both mold-making and the subsequent casting of the mold with molten metal. Although historical and current practices overlap in many respects, terminology differed in two important ways: Van Laer did not speak of founding, nor did he speak of molds.

To optimally prepare for the re-enactment, I started close-reading Van Laer's instructions and tried to reconstruct the casting process on paper. Van Laer introduced the chapter on casting by saying that "every Gold and Silversmith knows the great convenience and advantage of learning to master the Art of casting in Gold and Silver from their Master craftsman. Doing it well depends on a lot of things." ${ }^{72}$ He discussed a wide array of materials and tools, ranging from silver alloys to crucibles, fluxes, and casting flasks. Subsequently, he provided a detailed account on the type of sand needed for casting. The instructions continue with remarks on dusting sand, the preparation of casting flasks, and finally the cutting of sprues and runners.

Initial close-reading of the chapter emphasized two important things. First, as an inexperienced layman, I was able to follow the casting procedure as explained in the Guidebook and make some sense of it. Yet many of the terms and tools were new to me and many of the instructions seemed less comprehensible at second glance than they initially appeared to be. For example, I did not understand why certain parts of the process received more attention from Van Laer than others. Why would he bother so much with different types of casting sand while the actual casting process was virtually neglected? Reading the instructions with the intention of carrying them out made me aware of problems that would have otherwise escaped my attention.

Second, I hoped to find an explanation that would eventually lead me to cast an object from scratch. I nevertheless searched in vain. A step-by-step explanation, such as in twenty-first-century cookbooks, manuals for remote controls and IKEA-instructions, was not presented in the Guidebook. On the contrary, I had to gather information from a selection of rather randomly distributed remarks. The procedure had to be reconstructed by piecing together seemingly casual references for which I had to browse back and forth through the chapter (Appendix III). ${ }^{73}$

How hard it is to get a complete picture of the casting procedure just by reading the Guidebook became clear when I tried to understand the role and function of one very specific tool: the casting flask. Not having seen or handled this tool before, a combination of reading and deductive reasoning taught me the

72 Van Laer, Weg-wyzer (1721), p. 130.

73 Pamela H. Smith observed a similar lack of linearity when reading and working with the sixteenth-century recipe collection BnF Ms. Fr. 640. Smith, "Historians in the Laboratory", p. 218. 
following things. It has a mouth and consists of two halves which can be fixed onto each other. The flask itself is filled with moist sand and somewhere in the middle sits the so-called pattern or model which is being cast. Moreover, Van Laer prescribed the use of special dusting sand to ensure that the pattern and both halves of the flask come loose easily. After the flask has been filled with sand, runners are cut out through which the molten silver or gold will eventually flow, but casting can only happen once the flask has properly dried.

Unfortunately, for an inexperienced layman, this rather cryptic compilation of flask-related remarks is difficult to understand. This seems to suggest, once again, that Van Laer addressed those readers who already knew their way around the workshop. Young gold- and silversmiths, for example, would better understand the order and place of Van Laer's remarks in the entire casting process, because they would have frequently witnessed the casting process on the shop floor.

\section{Choreographies, Temporality and Tools}

Because I was interested in the practicability of Van Laer's instructions, I first tried to prepare a casting flask without Beentjes' supervision. On the workbench waited a small flask approximately ten centimeters high, together with a bucket of the required Brussels sand that had already been moistened according to Van Laer's instructions. Beentjes also provided me with the pattern: a replica of the object that I was about to reproduce. It was a four-centimeter brass disc, at the front of which a lion's face had been raised, while being flat at the back.

I quickly ran through the procedure in my head. It made sense to first take the flask apart and to fill both halves separately. Once one half had been filled with sand, I could insert the pattern and start filling the other half on top. This way, I reasoned, the pattern would always end up in the middle of the flask. Upon closer inspection, I saw that one half of the casting flask had four iron pins mounted on its frame that fitted into four related slots on the other half. Later I would learn that these halves are called cope and drag respectively, although Van Laer never spoke of them that way. Because the Guidebook did not prescribe with which half to start, I randomly decided to take the half with the slots, and placed it slotsdown on the bench (Figure 35A).

A little uncomfortable, I filled the frame with some moistened sand and gently started to push the sand into the frame with my fingers. To my surprise, it was possible to significantly compact the sand, just by pressing it a little. Although Van Laer did not mention how much pressure to apply, it followed quite naturally from the material itself. I kept adding sand little by little and continued pressing until it was pressed so tightly into the flask that it could be lifted from the bench without falling apart (Figure 35B). 

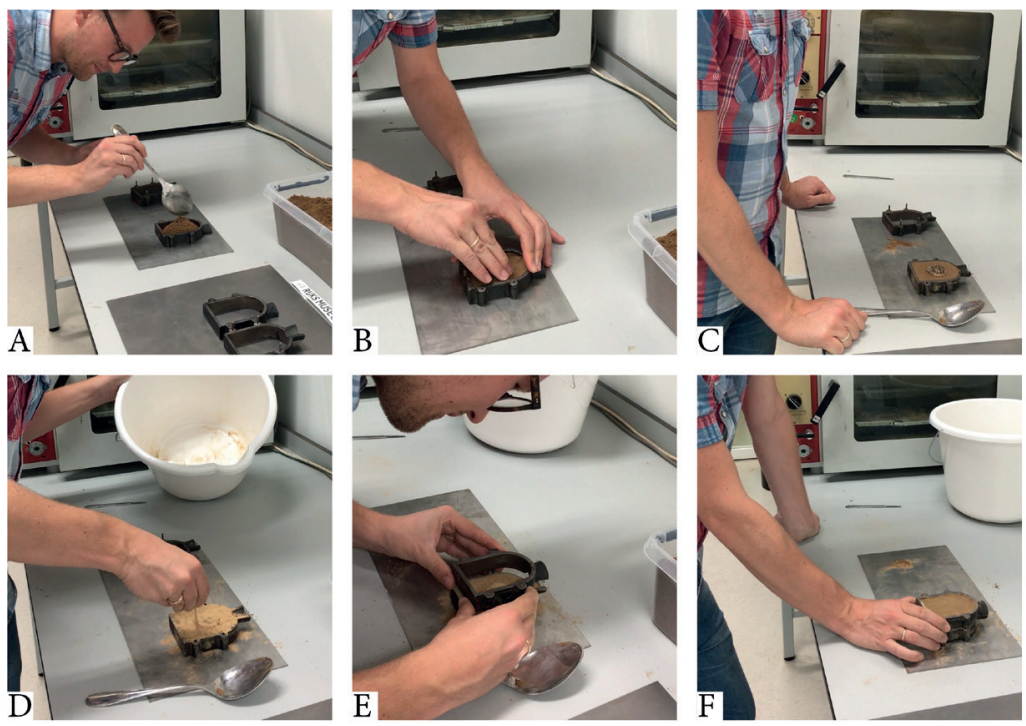

Figure 35: First attempt to prepare the casting flask. A: Filling the first half of the flask with sand. B: Pressing the sand. C: Placing the pattern on top of the first half of the flask. D: Scattering dusting sand over the pattern and flask. E: Placing the second half of the flask on top of the first. F: Filling the second half of the flask with sand. Photos: Thijs Hagendijk.

I turned the flask upside-down, which revealed a smooth surface of tightly compacted sand. Now the pattern had to be placed on top of the first half of the casting flask. This could be done in two different ways, either with the lion facing downwards into the pressed sand, or with the lion facing upwards. Since the Guidebook did not explain how to proceed, I decided to position the pattern with the lion facing upwards, such that the newly pressed sand could be pushed into the cavities of its face (Figure $35 \mathrm{C}$ ).

Next, I needed to apply dusting sand. Van Laer explained that "dusting sand is of great importance when pressing. The sand is scattered on one half of the pressed flask, before the other half is pressed upon it. For this reason: otherwise the sand that has been pressed together cannot be separated anymore." Even though he presented a variety of materials that will do the job, he "uses finely ground pressing sand the most."74 Accordingly, I took some of the dry Brussels sand, similar to the sand I previously used to fill the flask. I judged it to be fine enough - its consistency reminded me of flour - and sprinkled it over the filled 
half of the casting flask together with the pattern (Figure $35 \mathrm{D}$ ). Next, I mounted the casting flask together and gently started to fill the empty space with sand on top of the pattern, just like I had done before (Figure $35 \mathrm{E}, \mathrm{F}$ ). The flask was ready. I cautiously opened it and once Beentjes returned, we took a look at the result.

I was glad to recognize the lion's face in the imprint, even though the result proved to be generally disappointing (Figure 36). Beentjes saw immediately that too much dusting sand had been used. It came off in flakes, while two smooth surfaces should appear once the flask is opened. Next, he told me that many details of the imprint were lost, because at several points, sand remained in the cavities of the pattern. Moreover, the pattern could not be removed without losing detail due to undercuts. Finally, the pattern had not been positioned in a practical way. Preferably the runner should be connected to the thickest part of the imprint to minimize loss of detail, which in my case would be the lion's beard and not the top of its head. After we had reflected on the initial result, Beentjes prepared a second casting flask.

Beentjes took a brush and started to dust the pattern, using talcum powder as a separating agent (Figure $37 \mathrm{~A}) .{ }^{75} \mathrm{Next}$, Beentjes placed the pattern, face-up, on the table and took the half of the casting flask with the slots and positioned it slots-down over the pattern. The pattern was oriented with the lion's beard facing the flask's mouth (Figure 37B). Beentjes grabbed a handful of sand, threw it on the pattern and started pressing the sand, first along the edges of the flask while cautiously avoiding the area above the pattern. He explained that by starting with the edges, the sand would provisionally fasten the pattern to ensure no latitude was left before applying the remaining sand. After the edges were sufficiently compacted with his fingers, Beentjes pressed the sand on top of the pattern as well. Next, he grabbed another handful of sand and threw it into the flask. This time, after he had fastened it first by pressing it a little, he took a solid brass cylinder, a rammer, and started pounding on the sand to compact it even more. He repeated this step two or three times until the first half of the casting flask was completely filled with sand. Next, he took a squared metal sheet and used it to scrape off the surplus sand in order to meticulously level out the sand with the frame of the flask. He then turned the flask, flipped it and placed it back on the table, re-revealing the pattern (Figure $37 \mathrm{C}$ ). I looked at the pattern's back, while the rest of it was already firmly buried in the sand. With his nail, Beentjes carefully removed the bits of sand that clasped around the pattern's edges. Next, he scattered some talcum powder on the prepared half of the flask, such that it covered the sand as well as the pattern. With his finger, he softly rubbed it over the flask, blowing any excess of dusting sand away. We were halfway through the

75 This was an anachronistic choice, but later we would switch to pumice powder, which Van Laer offered as an alternative to the fine Brussels sand we used in the initial attempt. 


\section{Chapter 5}

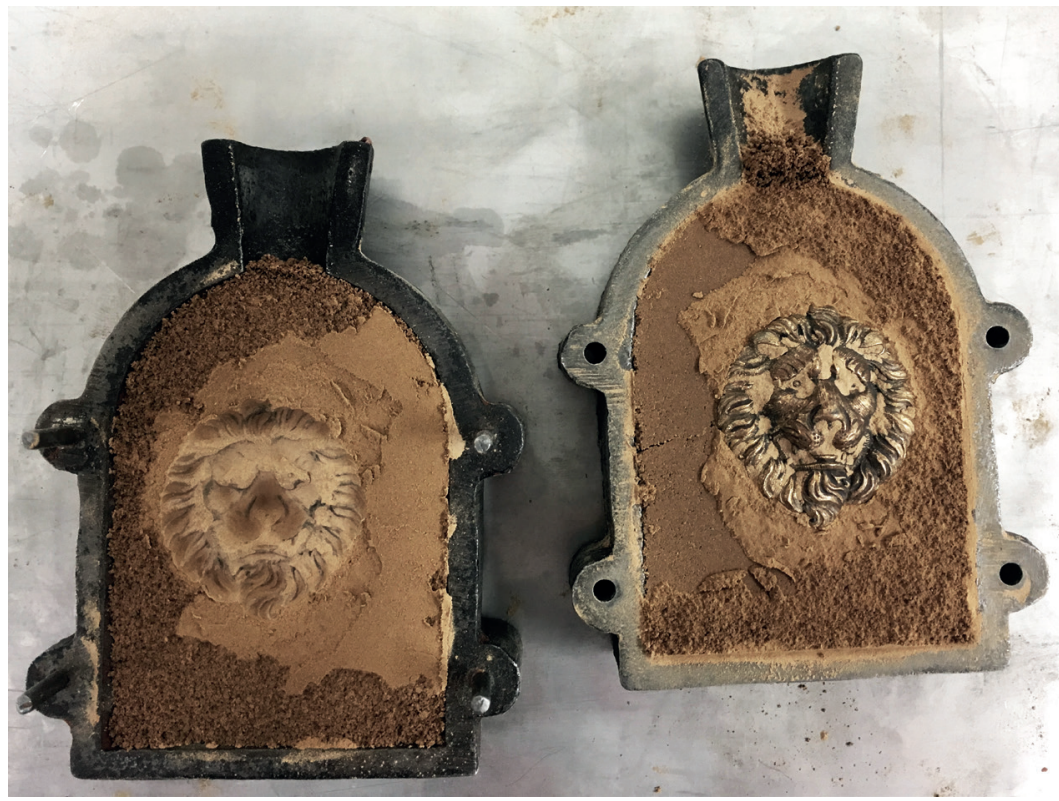

Figure 36: The first but failed preparation of the casting flask. Photo: Thijs Hagendijk.
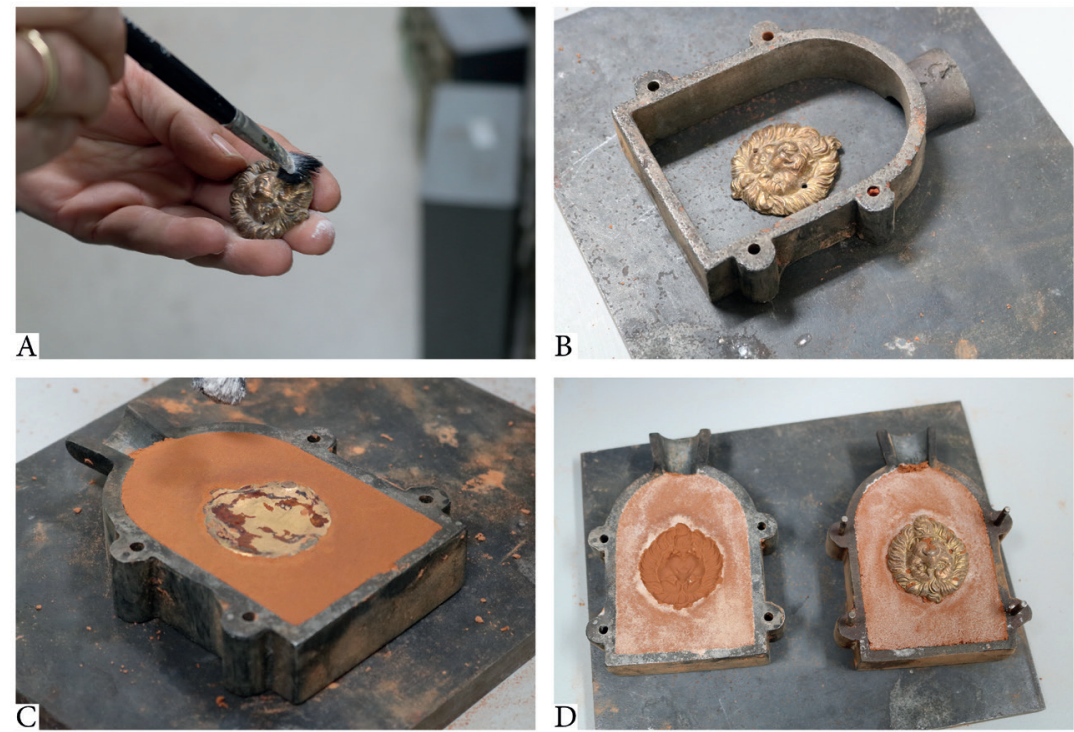

Figure 37: The second preparation of the casting flask with Tonny Beentjes. A: Dusting the pattern with talcum powder. B: The first half of the flask is placed slots-down on the table and the pattern is positioned towards its mouth. C: The first half of the flask is ready. D: Opening the flask revealed a satisfying imprint. Photos: Thijs Hagendijk. 
process. Beentjes mounted the other half of the flask onto the half he had just prepared. As before, he alternately filled the flask with sand and compacted it using the brass cylinder, finally scraping off excess sand. Now, the flask could be opened. Using a small spatula, Beentjes loosened the pattern from the first half by lifting it a little. With a sudden movement, he quickly flipped the flask upsidedown. The pattern fell out, leaving a satisfying imprint behind (Figure 37D).

Major differences between our approaches were apparent. First of all, there was a difference in what can best be described as manual choreography. By this term, I mean the orderly sequence of hand movements in which a procedure can be broken down and is performed. With no prior experience, I derived my choreography from Van Laer's description of the casting flask. This meant that I simply inserted the pattern halfway through the procedure, because it needed to end up in the middle of the two halves. Beentjes on the other hand, deliberately started with the pattern in anticipation of the final result. Later on, when I asked him about the reason behind this order, he explained to me that experienced craftsmen usually start by positioning the pattern on a flat surface, because it allows for the sand to be compacted even further into the cavities, which enhances the detail of the imprint in the end. While the novice does not yet fully understand how every step affects the end result, the master has learned to reason back from the desired outcome. This anticipation, this sense of temporality, could not be grasped from Van Laer's instructions and neither does he describe the flask-making choreography. Secondly, Beentjes introduced new tools to the process, which I would never have considered using. Indeed, the rammer to compact the sand, as well as the squared metal plate used to level out the sand were not mentioned by Van Laer. However, they were important means to achieve the best possible result. The simple pressing that I encountered in the book suddenly became a sophisticated technique in the hand of Beentjes. Similarly, the importance of levelling the sand - an irregular surface would deform the imprint when the flask was flipped and pushed upon from the other side - escaped me as well.

Gradually, I began to understand what Van Laer meant when he emphasized the necessity of hands-on education in learning to cast well. ${ }^{6}$ At first, I read this as an idle truism and obligatory remark mentioned with respect to all kinds of craft knowledge. Yet during the re-enactment, this remark took on a different meaning. I began to see the choreographies, the temporality and the tools that were not explicated in the Guidebook and which had to be passed on by Beentjes instead. Nonetheless, that these elements were not explicated, did not mean that they were simply absent in the text. The Guidebook proved fully compatible with

76 Van Laer, Weg-wyzer (1721), p. 134. 
Beentjes' instructions. His extensions did not violate Van Laer's instructions but laid bare knowledge and practices that had been silently present all along.

On a methodological level, the re-enactment forced us to rethink the purpose of our approach. Whereas I initially hoped to retrieve information on the mechanisms through which the Guidebook would inform my material practices and my education as a silversmith, I gradually began to see that our approach effected the opposite instead. Comparison between the Guidebook and Beentjes' instruction helped to identify in particular those types of knowledge that remained unarticulated in text, but that simultaneously proved indispensable in learning the craft. Instead of immediately laying bare the interaction between text and practice, re-enactment thus proved first and foremost a valuable tool to investigate the explanatory gaps in text and helped us to sort out and narrow down what goes by the names of tacit, embodied and gestural knowledge. In other words, it has the potential to provide a typology of unarticulated knowledge.

\section{Sensory Indicators}

Apart from knowledge concerning choreographies, temporality and tool-use, another category of largely unarticulated knowledge emerged during the reenactments. This type of knowledge is best described as sensory indicators. By this term I mean knowledge that enables craftsmen to develop "skilled vision," or rather a skilled sensory apparatus in general, and the ability to "read" the materials they work with. Sensory indicators guide both perception and action and help the craftsman to look for material signs or subtle cues that indicate progress or the necessity to take action. ${ }^{77}$

A good example of a sensory indicator was found when Beentjes and I finished the aforementioned flask and continued by casting it. Once dry, the two halves of the flask were clamped together and conveniently positioned at the fire place. A few scraps of silver were placed in a crucible, we put on gloves and protective goggles, and together we started to heat the silver with a blowtorch (Figure 38). I was excited to see what would happen, as I had never melted metal before. It was an intriguing process. Within a few minutes, the silver had already gone through several stages. Some silver scraps were covered by a thick layer of corrosion, tarnish, which would break open under the local heat of the torch and reveal a reflecting surface of shiny silver. Other scraps exhibited colorful states of oxidation, much like the iridescence of an oil film on water, which were gone as quickly as they appeared. After a while however, the smallest scraps began to

77 Grasseni, "Skilled vision”; Ingold, "From the Transmission of Representations"; Ingold, Making, p. 110. 
melt and the bigger pieces gradually followed like chunks of melting chocolate. At this stage, different patches of dirt floated on the surface and the molten silver moved rather stiffly. To get rid of the dirt, Beentjes threw in a small teaspoon of borax; a mineral that works as a flux and cleaning agent. Continued heating eventually caused the floating film of dirt to gradually break away towards the sides, and finally a red, gleaming surface was revealed that much reminded me of mercury. But then, all of a sudden, I wondered when the silver would actually be hot enough for casting. I had been so caught up in the heating process, that I completely forgot to think about the next step. Quickly, I tried to rethink all of Van Laer's instructions, only to realize that the Guidebook did not touch on this issue. When I asked Beentjes about it, he mentioned a very useful rule of thumb: as soon as the silver in the crucible starts to behave and ripple like water, it is ready to be poured into the flask. We did so accordingly and finally got ourselves a much-desired silver replica of the lion's head (Figure 39).

Later on, Beentjes told me that successful casting really depends on the silver having the right temperature. The water metaphor functions as a sensory indicator that tells the silversmith, quite accurately, what to look out for. Beentjes was not the first to resort to this metaphor. In fact, this sensory indicator is and was commonly shared among silversmiths and can even be traced back as far as the sixteenth-century Italian gold- and silversmith Benvenuto Cellini (15001571). In his treatises on goldsmithing and sculpture, he describes the process of melting silver and explains that "after a while you will see the silver beginning to float like water." This was his cue to throw in some flux and to start casting..$^{8}$ The commonality of this metaphor, as well as its long history, makes its absence in the Guidebook even more noticeable. Why would Van Laer leave out this type of information?

Even though the water metaphor is valuable knowledge cherished by every silversmith, this sensory indicator is no guarantee for perfect casts. It is not an unequivocal formula that can be readily transmitted and understood. Rather, it provides novices with a sense of direction and helps them by guiding their perception. This too, was the case when I eventually started to cast independently from Beentjes. Even though I knew what to look out for, once I found myself in the middle of the casting process, it proved very difficult to decide what behavior of the silver was actually water-like and what not. In other words, the watermetaphor did not signify a binary state. Instead, the silver rippled a little at first, which gradually increased until it was suddenly too hot. So even if the sensory indicator is transmitted in text, it still needs to be rediscovered in practice by the novice. ${ }^{79}$ 


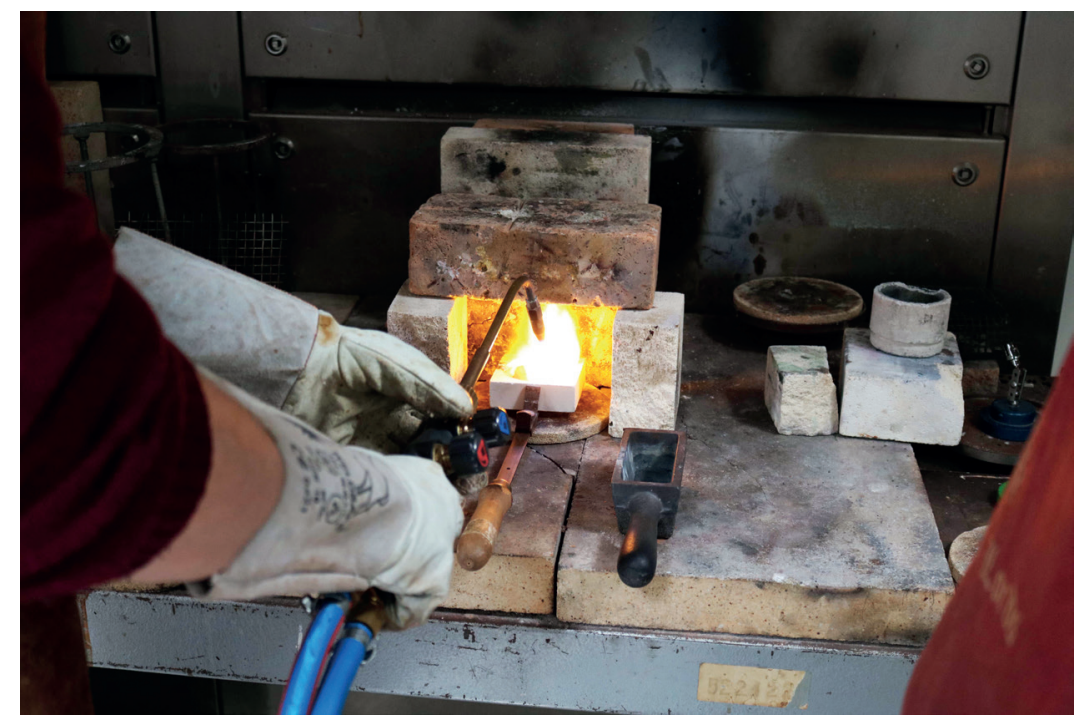

Figure 38: Melting the silver with a blowtorch. Photo: Tonny Beentjes.

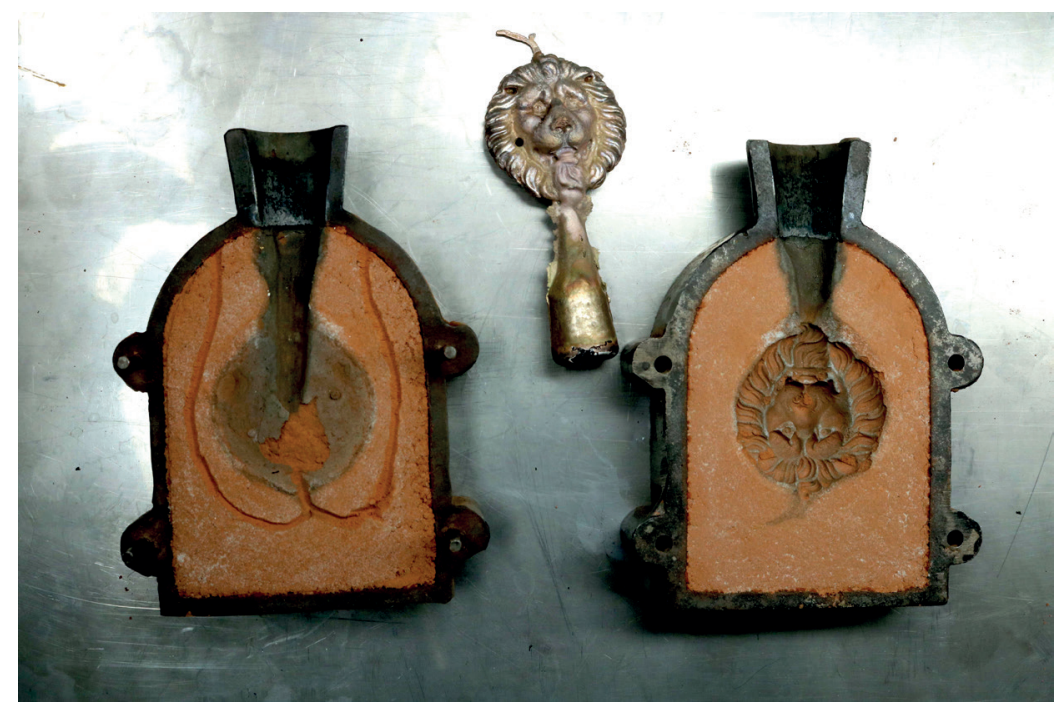

Figure 39: Casting resulted in the much-desired silver replica of the lion's head. Photo: Thijs Hagendijk. 


\section{Learning Through Trial and Error}

A few months later we confirmed that trial-and-error is a powerful way to, at least partially, overcome the difficulties posed by the gaps in the text. Beentjes and I set up a small workshop in which we offered participants the opportunity to try out Van Laer's instructions for themselves. The group consisted of participants of a workshop on Re-enactment, Replication, Reconstruction that took place in June 2017. ${ }^{80}$ No participant had prior gold- or silversmithing experience and the workshop was designed in a similar way to the re-enactment described above. ${ }^{81} \mathrm{At}$ first, participants were handed a selection of casting-related remarks (Appendix III). Tools and sand waited on the benches and with no further explanation, the participants were put to work. A few started by meticulously dusting an empty casting flask with dusting sand. Others first filled one half of the flask with sand and subsequently tried to firmly press the pattern with its detailed side into the already compacted sand. When they did not succeed because of the sand not giving in, they removed the pattern, carved out a pattern-sized cavity and tried again. Even though these actions would be illogical from a craftsman's point of view, the Guidebook nevertheless allowed for these different readings and procedures. However, after several trials, the participants began to approach procedures that indeed yielded recognizable imprints of the patterns. Without any textual or professional indications, they also started to introduce new tools to the process, using squared metal sheets to level off the sand and brass cylinders to compact the sand. One team, upon observing a loss of detail in the imprint, analyzed this problem and rightly decided to use more dusting sand next time. Even though none of the procedures figured out by the participants would yield a perfect cast in the end, it was impressive to witness the power of trial and error and the resourcefulness of the participants. In fact, several issues appeared to be self-resolving, simply by exploring the limits of materials and the affordances of tools. ${ }^{82}$ The lack of certain steps and knowledge in the text did not hinder the participants from discovering them on their own. This indicates the necessity to rethink the importance of tacit knowledge in relation to crafts and indeed confirms the aforementioned argument of Melvyn Usselman et al. that tacit, gestural or embodied knowledge makes the transmission of craft knowledge a complex, but not impossible affair. Materials and tools provide

8o For more information, see http://www.rrr-network.com (accessed 4 Apr. 2018).

81 I would like to thank the participants who enabled these observations: Ruth Benschop, John Hopkins, Annie Jamieson, Roeland Paardekooper, Peter Peters, Lawrence Principe, and Rebecca Wolf.

82 Gibson, The Ecological Approach, pp. 127-143. 
guidance too in situations where text remains silent. ${ }^{83}$ For example, even though unarticulated in the Guidebook, it followed quite naturally from the sand how much pressure it needed for compacting. Furthermore, the amount of dusting sand was easily determined and adjusted after a single failed attempt during the workshop. In brief, the existence of tacit, embodied or gestural knowledge does not necessarily arrest each and every non-verbal attempt to transmit craft knowledge. Unarticulated knowledge is not necessarily lost in text but can be recovered in a material context.

Nonetheless, additional hands-on instruction by Beentjes was needed to significantly improve the quality of the prepared casting flasks. For example, none of the participants arrived at the idea to start preparing the mold with the pattern and instead introduced it only halfway through the process. Likewise, the patterns were not ideally positioned towards the mouth of the casting flask. When Beentjes walked them through the entire process, one participant exclaimed that, all of a sudden, he began to understand how Van Laer's instructions fit together; reading and struggling with the text enabled him to understand the logic behind Beentjes' process, while it was only with this experience that he started to discern a similar logic that had been silently present in the Guidebook all along.

\section{1o. Learning a Craft from Books}

The re-enactments resulted in a typology of unarticulated knowledge and, consequently, did not immediately reveal the mechanisms through which a craft could be learned from text. However, the explanatory gaps, such as choreographies and sensory indicators, relate something important too. This knowledge is essential in learning to master techniques and silversmithing practices, especially if someone wishes to do it well. Advanced apprentices and trained craftsmen would have benefited the most from the Guidebook, because they could either rely on others to fill in the explanatory gaps or rely on their experience as an interpretive scheme. Learning to master the techniques and procedures without this experience would otherwise become a complicated affair very quickly. The Guidebook was thus far from a DIY crash course, which is also confirmed by Van Laer, who more than once pointed out the indispensability of complementary hands-on education. This raises a very important question however. Would it not be easier to just learn everything the old-fashioned way? If the Guidebook indeed depended on complementary training, or on prior experience, why bother with a book at all?

83 Usselman et al., "Restaging Liebig"; Chang, "How Historical Experiments Can Improve Scientific Knowledge", p. 321; Ingold, "The Textility of Making". 
One might argue that the interdependence of text and hands-on instruction was above all a strategic attempt by Van Laer to carve out a livelihood. Since the Guidebook could not be used on its own, the principle purpose of this book was to force serious readers to become paying customers; the Guidebook indeed makes a clever invitation to his workshop. Van Laer explicitly reminded his readers that he could teach them how to make silverwork in the "old-fashioned" or "newfashioned" way and how to create the associated models, patterns and drawings. ${ }^{84}$ The idea of books needing aftercare for which readers could subsequently be charged in the workshop had more currency in the early modern period. With respect to so-called "usus et fabrica" books, i.e. books that explained to readers how to build and use mathematical instruments, historian of science Mario Biagioli made the suggestion that they could be seen as "cheap bait" to draw readers into the "labor-intensive economy of artisanal and pedagogical services." ${ }^{85}$ Still, to view the Guidebook from this perspective only would be somewhat one-sided. Certainly, the existence of gaps in the text might be interpreted as a strategic decision to carve out a livelihood, yet the better part of these gaps concern craft knowledge that, one way or another, remains rather difficult to put into words. Besides, Van Laer's promotional remarks are much less explicit than would be expected on the basis of the "usus et fabrica" books; even directions to his workshop are missing. More importantly however, this line of argument addresses the Guidebook merely from a writer-perspective. Whether or not the Guidebook was intentionally written as advertising material still does not explain how the book could have been used by the people who ended up reading it. Put differently, the important question is not so much how the complementarity of text and hands-on instruction came about in the first place, but rather how the Guidebook's end-users ultimately dealt with this issue. This leads to an alternative explanation.

To understand why people would indeed bother to use the Guidebook to learn the craft of gold- and silversmithing in spite of its dependence on handson instruction, it is helpful to look at a similar Dutch text that was published over two centuries later. In 1936, a new handbook for jewelers and gold- and silversmiths came onto the market, which was specifically meant to educate upcoming craftsmen. This handbook was not very original in content and rested heavily on its eighteenth-century predecessor. In fact, it even presented an appendix in which significant parts of the Guidebook were summarized and reproduced, including Van Laer's instructions on casting. However, apart from implicitly demonstrating the durability and comprehensiveness of Van Laer's account, this handbook also provides some clues as to why functional reading in 
craft education might actually be helpful. In the introduction, the author explains that several colleagues asked him to write a handbook and subsequently recounts his own training.

For myself, I was indeed convinced of the need for Dutch professional literature for gold-and silversmiths. I often experienced the lack thereof during my own training. There had always been many technical questions that remained unanswered, because we neither could or ought bother the teaching assistants from whom we had to learn everything. Besides, many times they did not manage to formulate their answers well, however competent and skillful they were though. ${ }^{86}$

The author's plea for texts in vocational training is interesting because it redirects the attention from the limitations of the text to the limitations of the educator. Indeed, it can be very difficult to write craft knowledge down and to learn practical things from a text, but the oral transmission of knowledge is not perfect either. As in the twentieth century, apprenticeship learning in the early modern period was limited too. As argued earlier, many craftsmen were specialized in one or other area. What they could teach was often limited, meaning that apprentices had to switch masters to extend their knowledge. Historian De Munck, based on several examples of apprenticeship learning in early modern Antwerp, even argues that specializations were the "most serious impediments to the transfer of technical knowledge." ${ }^{87}$ Moreover, there are several known cases in which apprenticeships were not successful for less noble reasons than specializations. Some Dutch apprentices in gold- and silversmithing complained about mediocre education in the seventeenth century. They were busier running errands than learning or complained about the rather selective and one-sided education they received. ${ }^{88}$ The limitations of text and the limitations of apprenticeship learning thus seem to start balancing the scale with respect to the transmission of craft knowledge. In this light, functional reading of Van Laer's Guidebook as a way to support apprenticeship learning starts to make sense. Whereas the master craftsman was essential in complementing the explanatory gaps in the Guidebook, the gaps left open by the craftsman could be complemented by the Guidebook in return. The Guidebook thus seems to be a clever solution to overcoming the challenges posed by hands-on education, such as divided attention from the master and limitations brought about by specializations, prioritized work or plain didactic clumsiness. Of course, master craftsmen too could refer to the Guidebook as a way to free their hands of needy apprentices.

86 Hendriks, Vakboek voor den Juwelier, p. 5.

87 De Munck, Technologies of Learning, p. 51.

88 Schoen, Tussen Hamer en Aambeeld, pp. 183-9. 
The re-enactments not only clarified what knowledge was missing from the Guidebook, but also proved that the Guidebook was particularly helpful when it came to advanced knowledge in terms of tips, tricks and best practices. For example, even though Van Laer did not describe how to assemble the casting flask, he did go to great lengths to explain how the casting sand should be prepared. He explained that "ordinary Brussels sand is used in this country, which is good by nature, but could be improved a lot through art." Subsequently he gave the instructions. "I have considered it useful to moisten the sand and to form it into balls before it is used for casting. The balls should be glowed in a bright coal fire, so that all of the sand's combustibles are taken away that would otherwise inflict porosity." ${ }^{89}$ Beentjes and I went with and against his advice and soon established that his instructions made a vital difference to the cast object. Untreated sand indeed amounted to extreme porosity, while the use of glowed sand resulted in a smooth surface. In addition, Van Laer discussed different types of material throughout the Guidebook, such as dusting sand and fluxes for melting, and explained their properties and preparation..$^{\circ}$ He provided measurements and instructions to build forges, reminded the readers of the ratios in which the silver alloys should be prepared for soldering, listed several recipes to prepare wax for lost-wax casting and demonstrated how to produce charcoal to polish silver. ${ }^{91}$ Moreover, for most of these explanations, Van Laer not only disclosed his best practices, but those of his colleagues too, which enabled his readers to make their own informed decisions. To understand these instructions and to put them to good use, indeed required a basic level of experience and understanding of the craft. But once arrived at this level, the Guidebook could free the apprentice from the limitations of hands-on education and provide them with an opportunity to extend their knowledge independently from their masters.

My work shows that more research needs to be done to close the gap between the Guidebook and its twentieth-century successor, and more generally between early modern craft manuals and the current use of texts in vocational training. In other words, there is a need to historicize functional reading in craft education. The Guidebook is only an early example of this phenomenon and points at an emerging interest in the eighteenth century in introducing textbooks to craft learning. As others have already suggested, this development is in all probability connected to the waning influence of the guilds in the eighteenth century. ${ }^{92}$ Yet evidence that convincingly demonstrates this connection is still meagre and not well established. However, with respect to textual and traditional methods of knowledge transmission, the Guidebook elucidates at least one important point:

89 Van Laer, Weg-wyzer (1721), p. 133.

9o Idem, pp. 135-6, 141.

91 Idem, pp. 28-30, 127-130, 207-8, 173-5.

92 Glaisyer and Pennell, "Introduction" in Didactic Literature in England, p. 9. 


\section{Chapter 5}

guilds, the traditional organizers of craft education, and texts like the Guidebook, did not so much compete with each other, but rather benefited from each other in a symbiotic manner. To Van Laer however, this was already a foregone conclusion. 
Learning a Craft from Books 



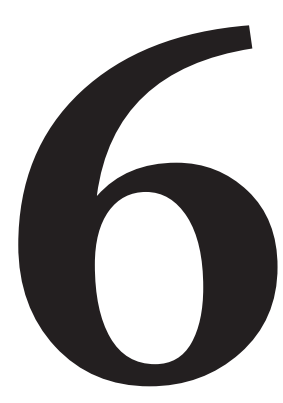

Conclusion 
In this dissertation, I examined how artisans and craftspeople in the early modern period engaged with texts, both through reading and writing. Putting practical knowledge into written words was by no means a simple and straightforward task, but writers were not the only ones that faced the challenges of textual communication. Looking at practical texts from a readers' perspective, I have argued that unpacking written instructions was a complicated task too. The central question in this dissertation was: which reading and writing strategies were used and developed in the early modern arts to mediate the challenges that came with the communication of practical knowledge in text? In addition, I asked how practices of reading and writing can be investigated through performative approaches such as reconstructions, reproductions and re-enactments? I will answer these questions by comparing my explorations of the three case studies: Johan Kunckel's Ars Vitraria Experimentalis (1679), Simon Eikelenberg's Notes on the Art of Painting (ca. 170o), and Willem van Laer's Guidebook for Upcoming Gold- and Silversmiths (1721).

\section{The Challenges of Text}

What particular challenges do texts, as a medium, pose for the communication of practical knowledge? What could and could not be written down, what could and could not be read, and how could these challenges be historicized? A preliminary answer to these questions might be given in terms of the tacit, embodied or gestural character of practical knowledge. Skills, experience, judgement and dexterity - precisely those things that are so fundamental to the arts - are also among the things that can hardly be articulated. But as the different case studies illustrate, even when authors were able to find the right words, new issues arise for the reader who needs to put these words into practice. Another challenge concerns the unpredictable and elusive nature of materials that render written words pointless. Moreover, text puts distance between author and reader, which manifests itself in the lack of shared frames of reference, or as different physical circumstances under which instructions are executed. Indeed, whereas a master craftsman and a novice inhabit a similar world within the confines of a workshop, authors and readers do not. Authors and readers do not share experiences, nor do they have the ability to gauge experiences against each other. Each is grounded in his own environment, an environment that constitutes a unique meshwork of materials, forces, and resources.

To begin with, clear formulas, written rules, instructions and clues can remain cryptic in spite of their specificity. Consider for instance the sensory indicator that tells silversmiths when molten silver is hot enough to be poured into the mold. At least from Benvenuto Cellini (1500-1571) onwards, silversmiths have 
employed the metaphor of rippling water to describe the behavior of silver that has reached an adequate temperature for casting. While the metaphor itself is perfectly clear, re-enactments showed that transferring the image of rippling water and applying it to different states of molten silver is less straightforward and requires repeated practice. At what point exactly does its behavior start to resemble water? This ambiguity might be why Willem van Laer omitted this metaphor in his Guidebook (1721). Its meaning only becomes apparent after repeated practice - seeing its truth thus implies mastering the very skill itself. Even when authors were competent enough to circumvent the challenges of tacit knowledge, and came up with accurate descriptions of material processes, a new challenge arose with the reader who could only understand this knowledge by embodying it. Perfectly clear instructions could thus remain cryptic as long as their reading was not grounded in practice.

A similar argument can be made concerning the manual choreographies needed to properly assemble the molds for casting. How do you communicate and understand the orderly sequence of hand movements by which the different parts should be put together? When should the pattern, the replica, be introduced to make the imprint? Here too, the Guidebook provided little information. While there are contemporary examples of authors who visualized, dissected, and analyzed movement as a series of separate poses, Van Laer did not include such information. ${ }^{1}$ Why? Again, we can only guess, but re-enactments of this procedure revealed that the assembly order is not a standardized procedure. Instead, the order in which the different choreographical steps are executed is ideally informed by an understanding of how each of these different steps affects the end-result. Assembling a mold is not a matter of thoughtlessly going forward, but of reasoning back from the desired outcome. Precisely this sense of temporality, this anticipation cannot be grasped from text. It needs to grow in practice.

Another difficulty arises with the sometimes unpredictable and capricious nature of materials. Indeed, when Johannes Kunckel's predecessor Antonio Neri described how color is achieved in glass, he remarked that it is impossible to codify this process in terms of weights and doses of colorants: "exact and determined amounts cannot be given". ${ }^{2}$ The problem here lies not so much with the explication of practical knowledge itself. Rather, Neri's point is that following a recipe to the letter, even using the exact amounts that are prescribed, does not guarantee that the glass will end up having the same color each time the recipe is performed. Textual explications could be rendered pointless by capricious and recalcitrant materials, thus requiring readers to personally grow into this knowledge instead.

1 Wellman, "Hand Und Leib".

2 Neri in Engle, The Art of Glass, vol. 1, p. 7. 
A new challenge is found in the absence of a shared frame of reference between author and reader. How do you communicate colors in a non-standardized color world? Both Neri and Kunckel seem to avoid this issue in text by repeatedly appealing to their reader's judgement. They speak of the "desired Red color," or mention that the glass should be "colored sufficiently and appropriately". ${ }^{3}$ What this precisely means was left to the judgement of the reader. Communicating colors in text leaves wiggle room, but neither Neri nor Kunckel seem to have found that problematic and simply turned it into an asset instead: "one can have Green as one pleases". ${ }^{4}$ The communication of temperatures creates a similar problem. True, Simon Eikelenberg found a solution to this problem by referring to bodily sensations that everyone must be able to recognize. He described the temperature of his varnish as "slightly too hot to keep my finger in." ${ }^{5}$ Likewise, contemporaries often distinguished between different "grades of fire." The chymist Nicolas Lemery, for example, distinguished four grades that ranged from the gentle warmth of two or three glowing coals to the extreme heat that is provided by wood and coal fires. ${ }^{6}$ But here too things become complicated rather quickly. How do you describe the difference between hot and hot in the context of glassmaking? Kunckel did not go any further than telling his readers to avoid that "the Fire is much too strong". ${ }^{7}$ Learning to distinguish different temperatures in the glass furnace requires lots of practice. Even if Kunckel would have been able to give a more specific description, the reader would still need to personally grow into this knowledge and to learn how to 'read' the furnace in light of Kunckel's remarks.

Moreover, the circumstances under which a text was written often diverged from the circumstances in which it was read. Eikelenberg's Notes, for example, illustrate how much he depended on his environment for good practices, advice, and materials. The materials at hand were not always of superior quality, nor did he always have the tools at his disposal that were prescribed by recipes. The different material realities of authors and readers also played a role in glassmaking. Reproductions of rosichiero glass showed that different furnaces affect the composition of the glass in different ways. As a consequence, one recipe results in different shades of glass when executed using different furnaces at different places. Kunckel was conscious of such differences, and adjusted Neri's recipes to account for local circumstances. Because of an abundance of wood, he stated, the furnaces in Germany are generally stoked hotter than those in Italy,

3 See glass recipes and commentaries in Appendix I. Neri in Engle, The Art of Glass, vol. 1, p. 7 .

4 Kunckel, Ars Vitraria Experimentalis, pp. 64-5.

5 Eikelenberg in Van Schendel, "Simon Eikelenberg's Experiments", p. 130.

6 Lemery, Het Philosoophische Laboratorium.

7 Kunckel, Ars Vitraria Experimentalis, p. 193. 
thus reducing the time that glass needs to stay in the furnaces. ${ }^{8}$ Indeed, things that work in one context, may require adaptation to work in another.

It is inherent to practical texts that they travel distances and that they land in a variety of different situations. They might be representative of one ecology of making but cannot straightforwardly be applied in another. The question remains to what extent authors anticipated and accounted for these different situations and how readers could compensate for these differences. An ecological understanding of practical knowledge emphasizes the situatedness of this knowledge. It is geared towards local circumstances, resources, possibilities and affordances. Productively engaging with a practical text means that the knowledge it conveys must become part of a new reality too, which places a high demand on the reader. Kunckel was well aware of that; he stated in his commentary on rosichiero glass, that reproducing this glass from written instructions "requires as much Art as inventing it". ${ }^{9}$ Successful reproduction of textual instructions is a process of reinvention.

Following Tim Ingold and Richard Sennett, the tacit dimensions of practical knowledge do not necessarily need to be left unvoiced. ${ }^{10}$ There are ways to unpack practical knowledge in words, but successful transmission of this knowledge does not amount to dumping a "ready-made body of information" on the reader. ${ }^{11}$ Rather, giving voice to tacit knowledge means showing how materials behave, pointing out the subtle cues they provide, and demonstrating how a formgenerating process could be adjusted by adequately anticipating and responding to these cues. One needs to see what the other is pointing at, which is significantly easier when two persons stand next to each other. As Geoffrey Gowlland recently argued, processes of enskilment are inherently social: "Interactions between a learner and a mentor involve the back and forth movement of comprehension and production of utterances, deictics such as gestures and eye contact, and actions on materials. [...] Enskilment and communication are integral to mentor-student sociality, and it would be artificial to attempt to pry them apart." ${ }^{12}$ Yet, this is precisely what happens in practical texts. Authors communicate to readers, but readers have to go through processes of enskilment independently. The question remains what strategies authors and readers employed to deal with the challenges that arose.

8 Kunckel, Ars Vitraria Experimentalis, Vorrede, n.p.

9 Kunckel, Ars Vitraria Experimentalis, p. 193.

10 Sennett, The Craftsman, pp. 179-193; Ingold, Making, pp. 109-124.

11 Ingold and Lucas, "The 4 A's", p. 288.

12 Gowlland, "The Sociality of Enskilment", p. 516. 


\section{Writing Strategies}

Perhaps the most intriguing commonality between the three case studies is how they diverged from recipes - i.e. concise sets of prescriptive and rule-like instructions - as the ubiquitous textual format in the communication of practical knowledge in the early modern period. Indeed, Kunckel, Eikelenberg and Van Laer deviated from the "Style of Formulary's of Receipts," as Robert Boyle (16271691) once aptly phrased it. ${ }^{33}$ While they employed different textual formats, their writing strategies resemble each other. Each in their own way, Kunckel, Eikelenberg, and Van Laer provided experimental freedom to their readers in their texts.

Kunckel's strategy in the Ars Vitraria Experimentalis is to explain the 'why' behind Neri's glass recipes. Rather than dissecting glassmaking processes into strict rules that need to be followed to the letter, he shows his readers the underlying mechanisms by which the glass is shaped, manipulated and produced. As a glassmaker, Kunckel was well aware of the many complexities and variables involved in glassmaking. How glass comes out of the furnace depends on the ingredients that are used and their preparation, on furnace design, on the environment and the availability of fuels, and ultimately on the judgment of the glassmaker whose adjustments and interventions are essential for the quality of the end product. To guarantee a successful outcome of a recipe, the reader cannot passively rely on a protocol, but needs to actively engage with the glassmaking process. Kunckel encourages his readers to become active participants and to take matters into their own hands. He helps them gain an experimental understanding of the making processes and shows them where and when to intervene. He puts the spotlight on specific ingredients and their preparations, explaining for instance how they enhance the color of the glass. And he explains how a furnace affects the glass properties by underscoring the importance of temperature management and timing. In doing so, he provides his readers with various levers they can pull to take control of the making process and to make Neri's recipes work in the locality of their own workshop. Kunckel cast his writing strategies in the form of commentaries, which he modelled after the commentary tradition in natural philosophy. This learned format allowed him to discuss multiple recipes at once, to compare them, and to reveal their underlying mechanisms. Kunckel thus opened the door to intra-recipe experimentation and showed readers that recipes can be understood as different experimental routes through which the material conditions of glass are explored. Moreover, the commentary format gave Kunckel the opportunity to add new layers to Neri's recipes. For example, 
while Neri did not touch on the color-enhancing effects of furnace management, Kunckel introduced this pyrotechnical perspective.

The writing strategy Eikelenberg adopted in his Notes on the Art of Paining is one in which he sympathized with his readers. He narrated in meticulous and detailed accounts how painters' ingredients such as varnishes are prepared and gave himself a central role in these stories. The centrality of his own experience is an important feature of Eikelenberg's writing strategy, because it enabled him to show that reading and performing recipes is a work in progress, a continuous search for how to best approach the instructions. A recipe does not 'work' right away but needs to be made operational in the specific context of a workshop, which involves trial-and-error, failure, vulnerability, and improvisation. Indeed, Eikelenberg did not hesitate to tell his readers that one of his varnishes caught on fire or that he scorched materials on the stove. Eikelenberg mentioned how he forgot to do things and how he feared worst possible outcomes. He recounted how he responded to unexpected contingencies by trying to improvise his way out. In sum, Eikelenberg was not an omniscient director of making processes, but showed that performing recipes is an experimental quest instead. As Richard Sennett has argued, such a focus on the practitioner's engagement with materials, rather than on material transformation alone, helps readers envision their own role in practices of making. ${ }^{14}$ Indeed, Eikelenberg does not employ an authoritative tone but stands next to his readers, pointing out pitfalls, drawing attention to the behavior of materials, allowing them to see the things that he sees and showing them how he responds to them. His writing strategy was inextricably intertwined with the textual format he employed. Eikelenberg included ervarenissen, which he modelled after the experimental essay used by proponents of the New Sciences. The experimental essays combined a first-person perspective with a meticulous recounting of experiments as events anchored in a particular time and place..$^{15}$ It was precisely the central role of the practitioner and the increased attention to personal and situated experience that gave Eikelenberg the tools to steer away from the recipe's generalized and rule-like character and to show how textual instructions must be integrated into an intricate meshwork of distinct experiences, tools, and resources that intersect on the shop floor.

Similar to Eikelenberg, Willem van Laer placed emphasis on his personal experience and employed a first-person voice in his Guidebook for upcoming gold- and silversmiths. His writing strategy diverged from Eikelenberg's in that he achieved this effect by contrasting his own preferences and practices with those of his colleagues. Van Laer thus underscored the relativity of his own position and illustrated that there is no general and universal approach to

14 Sennett, The Craftsman, pp. 179-193.

15 Dear, "Totius in Verba"; Shapin and Schaffer, Leviathan and the Air-Pump. 
gold- and silversmithing. At the same time, Van Laer's tone was didactic and experienced. He showed that his preferences are anything but the product of random and arbitrary choices. On the contrary, they can be explained by and result from an intimate understanding of materials and their behavior, which speaks through the entire book. Van Laer not only stipulated what materials to use but explained what happens when a material is not properly prepared or handled. For example, the sand that Van Laer prescribed to make the molds for casting should be prepared through an elaborate heating procedure. If not, the combustible materials in the sand would create smoke as soon as the molten metal flows into the mold, thus creating coarse pitting and porosity in the cast. By explaining what could potentially go wrong, Van Laer helped his readers grow into a more complete understanding of materials and showed how their properties have a lasting effect on the making process. Encountering pitting in a cast object, a reader now knows that this might be the result of ill-prepared sand, rather than something else. Of particular interest is Van Laer's use of two different textual formats. The major part of the Guidebook is presented in a first-person voice, but occasionally, recipes in a different voice pop up in Van Laer's story. These recipes present alternative methods, not Van Laer's preferred practices but those of his colleagues. Two things are important here. By providing alternatives, Van Laer gave his readers options to choose from, thus encouraging them to experiment and to develop their own preferences. Second, Van Laer made clear that these alternatives are suboptimal compared with his own practices. He used the recipe format to quickly convey know-how that might be insightful, but that is inessential at the same time. Recipes provided knowledge 'in case you want to know, but only after the making process had been thoroughly discussed in a first-person voice.

Why look at writing strategies? What I have shown in this dissertation, is that authors were concerned with their readers and sought ways to effectively communicate their knowledge. These efforts are not directly visible on the level of textual format. Indeed, seeing how Kunckel, Eikelenberg and Van Laer organized their knowledge in text, the differences could not be any bigger. But the differences between commentaries, ervarenissen and manuals disappear as soon as we look at what the authors tried to achieve in their respective texts. Kunckel, Eikelenberg and Van Laer sought ways to help readers grow beyond written instructions. They encouraged readers to actively explore the material conditions that undergird the processes described in text; they showed the freedom of experimentation one should employ to make written instructions work in specific and individual contexts; and they emphasized the relativity of practices by showing the other approaches that are out there. In sum, the hotchpotch of textual formats that ranged from adopted epistemic genres (commentaries and experimental essays) 
to hybrid texts (manuals containing recipes) evolved in response to the strategies that early modern authors employed to effectively get their message across.

\section{Readers' Resources}

While authors of practical texts employed diverse strategies to anticipate the needs of their readers, there was only so much they could do to help them. Readers, on their end, needed to actively engage with these texts to make them work. Productively engaging with a practical text requires the reader to bring it into harmony with his/her environment and with the material and cognitive resources that are available in that context. The case studies illustrate the various ways in which this could be done. One could, for example, rely on others to fill in the explanatory gaps in texts. Willem van Laer explicitly stated in his preface that additional hands-on instruction is necessary to fully understand his Guidebook. One might think of a master craftsman who could supply these instructions, but colleagues and friends could fulfill this role too. Eikelenberg, for instance, narrated how someone corrected him when he initially forgot to powder the gums that he used for one of his varnishes. One could also turn to first-hand witnesses to further explain the processes and materials discussed in text. Christopher Merret, when translating Antonio Neri's glass treatise into English, sought out the help of glassmakers who had "wrought at Muran and other parts of Italy" to understand the "materials not used nor known here". ${ }^{16}$ Another way to fill in the explanatory gaps in texts is through prior experience. This appeared to be the principle approach of Eikelenberg when he was confronted with extremely concise but unspecific instructions for a varnish. One of his ervarenissen narrates how he unpacked this recipe by modelling it after earlier and comparable varnish experiences, including the safety precautions that he took to avoid the fire hazards that he once had to deal with. Additional readings too could support the interpretation of written instructions. Eikelenberg's Notes are packed not only with recipes, but also with notes from natural historical, botanical, and travel accounts that narrate the processing and preparation of exotic ingredients such as indigo - those things, in other words, "of which one can have no personal experience" ${ }^{17}$ Christopher Merret opted for a similar approach in his commentary and embedded in Neri's glass recipes quotes and references to things he read "in any good Author concerning whatsoever Neri treats of". ${ }^{18}$ Making written instructions operational was also a matter of trial-and-error and improvisation. This process of trial-and-error is clearly seen at work in

16 Merret, "To the ingenuous Reader" in The Art of Glass, n.p.

17 Eikelenberg, "Aantekeningen Betreffende Schilderen", MS 391, fol. 5. My translation.

18 Merret, "To the ingenuous Reader" in The Art of Glass, n.p. 
Eikelenberg's ervarenissen. He performed recipes not once, but multiple times. He adjusted his interpretations after failure, optimized the making process and even strove to make it more cost-efficient. Eikelenberg made recipes work for him in his specific environment.

Hands-on approaches and reworking practical texts proved an essential tool to explore the reader's perspective and to map the resources needed to engage with written instructions. Trial-and-error, for example, was not only an important resource for Eikelenberg, but returned as an important instrument in the interpretation of Van Laer's Guidebook. Hands-on workshops in which participants were asked to follow and execute Van Laer's instructions for moldmaking revealed that participants were able to significantly improve their respective approaches after just a few trials. These improvements did not result from sheer luck or some arbitrary choices. On the contrary, progress was made by systematically exploring the limits and affordances of materials and tools, which helped participants to understand how certain actions affected the making process in the long run. The workshops also demonstrated that the Guidebook was far from a DIY crash course: next to processes of trial-and-error, additional manual instruction remained essential for these novice participants to take the mold-making process to the next level.

Hands-on approaches not only illustrated the importance of trial-and-error in unpacking instructions, they also provided a deeper understanding of the material, and often local, resources that readers brought to their texts. Reworking practical texts showed, in other words, that these texts cannot simply be imposed onto a material reality but become integrated into an intricate meshwork of materials, tools, people, experiences and practices. Reader and resources - e.g. the furnace one uses, or the environment one works in - resonate in each performance of a practical text. It is in close correspondence of text, reader and resources that a certain outcome takes shape.

The above stories exemplify different ways by which readers engaged with practical texts. Readers filled in the gaps, interpreted instructions, and adjusted processes as they went along, fitting them into their own practices with the material and cognitive resources they had. Practical texts, therefore, should not be understood as technical blueprints or one-dimensional reflections of historical material practices. Neither should we take readers as passive consumers of practical knowledge; they had to engage with the instructions to make them work. But this is not just a historical point; there is also a lesson for today. In studying historical practical texts and by subjecting them to hands-on approaches, we too bring our own resources to these texts. If we engage with a recipe in a fume hood, dressed in a lab coat, using glass beakers and chemically pure ingredients, then those are the resources that will resonate with the recipe. Reading is writing for historians and conservators as much as it was for Eikelenberg. Whether this is a 
good or bad thing is not the issue here, instead this point underscores the need to continuously question the resources that we employ when we engage with historical practical texts.

\section{Final Remarks}

The case studies in this dissertation indicate that the usefulness of practical texts lies in the experimental framework they provide. They have an orienting function and help set the boundaries within which experimentation takes place. Seen in this light, the writing strategies that authors employ become crucial elements that enable and facilitate the reader's experimental quest. Writing strategies facilitate readers to personally develop knowledge that texts could never explicate and convey as such. Perhaps the term Guidebook, Van Laer's chosen title, is the best fitting description of what practical texts afford; they provide directions, set out the landscape, point out landmarks, and put up signs to help readers find their way.

The analogy of practical knowledge as a landscape to be explored is also useful for another reason. I have viewed historical making practices as ecological practices. Making processes are not just generic processes, but situated and local events that draw on a unique arrangement of materials, tools, people, experiences, texts, and other material and cognitive resources. This meshwork of things is not a silent decor against which making processes take place; each of these resources actively engages in the form-generating process. An ecological perspective revealed furnaces as tools that interfered with glass beyond supplying heat. It laid bare the importance of furnace design, temperature management and timing as variables that both authors and readers of glass recipes had to reckon with. Many of these variables are not (immediately) visible in the historical texts themselves. Historical authors did not necessarily draw attention to the ways in which furnace design affected glass compositions, nor did they always mention the importance of humble and improvised tools such as rammers and scrapers in preparing molds for silver-casting. It is exactly here that hands-on approaches such as reconstructions, reproductions and re-enactments become invaluable and essential tools for researchers who wish to gain access to the unarticulated and silent dimensions of practical texts. Performative methods help explore the ecologies in which practical texts were embedded. Such explorations are inherently interdisciplinary and collaborative adventures. They involve conservators specialized in painting, metal and glass, historians of science, technology and art, chemists and experimental archaeologists. And while such collaborations undoubtedly involve moments of friction due to diverging interests, methods and approaches, it is also because of these differences that we can begin 
Chapter 6

to perceive the richness and many layers of historical ecologies and the ways in which they resonate in historical practical texts. 

Appendices 


\section{Appendix I - Rosichiero Recipes and Commentaries}

\begin{tabular}{|c|c|}
\hline Page & Transcription $^{1}$ \\
\hline \multirow[t]{3}{*}{$27-28$} & $\begin{array}{l}\text { Das 16. Capitel. } \\
\text { Wie der Crocus Martis, zum Glas-fårben foll bereitet } \\
\text { werden. }\end{array}$ \\
\hline & $\begin{array}{l}\text { DEr Crocus Martis ift nichts anders/ als eine fubtile Calcinirung } \\
\text { des Eifens/ dadurch die Farbe deffelben/ welche im Glas fcho̊n roth } \\
\text { fcheinet/ alfo auffgefchloffen wird/ daß fie/ nachdem folche dem Glas zu- } \\
\text { gefetzet/ nicht allein fich felbft/ fondern auch andere metallifche Far- } \\
\text { ben/ welche fonft im Glas verborgen/ und gleichfam todt wåren/ herrlich } \\
\text { fcheinend und glåntzend vorftellet: Denn der Crocus Martis ift eben } \\
\text { das Mittel/ dadurch die verborgenen metallifchen Farben ans Licht } \\
\text { gebracht/ und fichtbar gemacht werden; will ihn derowegen auff vier- } \\
\text { erley Wege zu præpariren befchreiben/ deren erfter ift diefer: }\end{array}$ \\
\hline & $\begin{array}{l}\text { Man nehme Eifen/ oder welches beffer ift/ Stahlfeyl-Spåne/ } \\
\text { folche mit 3. Theil gepůlverten Schwefel vermifchet/ und in einen Tie- } \\
\text { gel gethan/ auff Art/ wie droben vom Ferreto gefaget worden/ calcinire } \\
\text { man/ biß daß aller Schwefel verbrennet ift/ und laffe es 4. Stunden } \\
\text { lang auff den glů henden Kohlen ftehen; Denn nimms heraus/ laß er- } \\
\text { kalten/ pulverifirs/ und fchlags durch ein enges Sieb; thue es alsdenn } \\
\text { in einen offenen und lutirten Tiegel/ und laß es in der Glas-Ofen-Kam- } \\
\text { mer beym Auge oder Loch (Occhio.) 14. oder mehr Tage ftehen/ fo wird } \\
\text { es eine braunroth auff Purpur fich neigende Farb bekommen; diefe ver- } \\
\text { wahre in einen verfchloffenen Gefåß zum Glåfer-tingiren; denn es vie- } \\
\text { lerley fcho̊ne Wůrckungen verrichtet. }\end{array}$ \\
\hline \multirow[t]{2}{*}{28} & $\begin{array}{l}\text { Das 17. Capitel. } \\
\text { Wie der Crocus Martis auff eine andere Art zu machen. }\end{array}$ \\
\hline & $\begin{array}{l}\text { DJefe zweyte Art den Crocum Martis zu præpariren/ wiewohl fie } \\
\text { fehr leicht und gering ift/ fo ift fie doch darumb nicht zu verachten; } \\
\text { denn er dem Glas eine Blutrothe Farbe giebt/ feine Bereitung ift wie fol- } \\
\text { get: Nimb Eifen/ oder welches beffer ift/ Stahl-Feylfpåhn/ folche befpren- } \\
\text { ge oder vermifche/ in einem irdenen Gefchirr/ mit einem guten ftarcken } \\
\text { Effig/ fo/ daß die gantze Maffa feucht und naß werde: Alsdann breite } \\
\text { die Feylfpåhne wohl aus einander/ und laß es an der Sonnen oder } \\
\text { Lufft trocknen: Wann fie trocken worden/ muß man fie zerftoffen/ weil fie } \\
\text { fich im klůmpgẽ geballet; nach diefem foll mans abermahl mit frifchem Ef- } \\
\text { fig anfeuchten/ trocknen/ und zerreiben wie vorhero/ folches wird 8. mal } \\
\text { wiederholet/ und nachdem diefe Maffa klein zerftoffen/ und durch ein } \\
\text { enges Sieb gefchlagen worden/ fo wird es ein fehr fubtiles Pulver geben/ } \\
\text { an der Farb wie ein Ziegelmehl anzufehen/ welches in einem wohlver- } \\
\text { machten Gefås zum Glas-Fårben kan auffbehalten werden. }\end{array}$ \\
\hline
\end{tabular}

1 Transcriptions were obtained from the Deutches Textarchiv. Johann Kunckel, Ars Vitraria Experimentalis, Oder Vollkommene Glasmacher-Kunst. (Franckfurt und Leipzig, 1679), in: Deutsches Textarchiv < http://www.deutschestextarchiv.de/kunckel glasmacher_1679>, accessed 3 December 2019. 


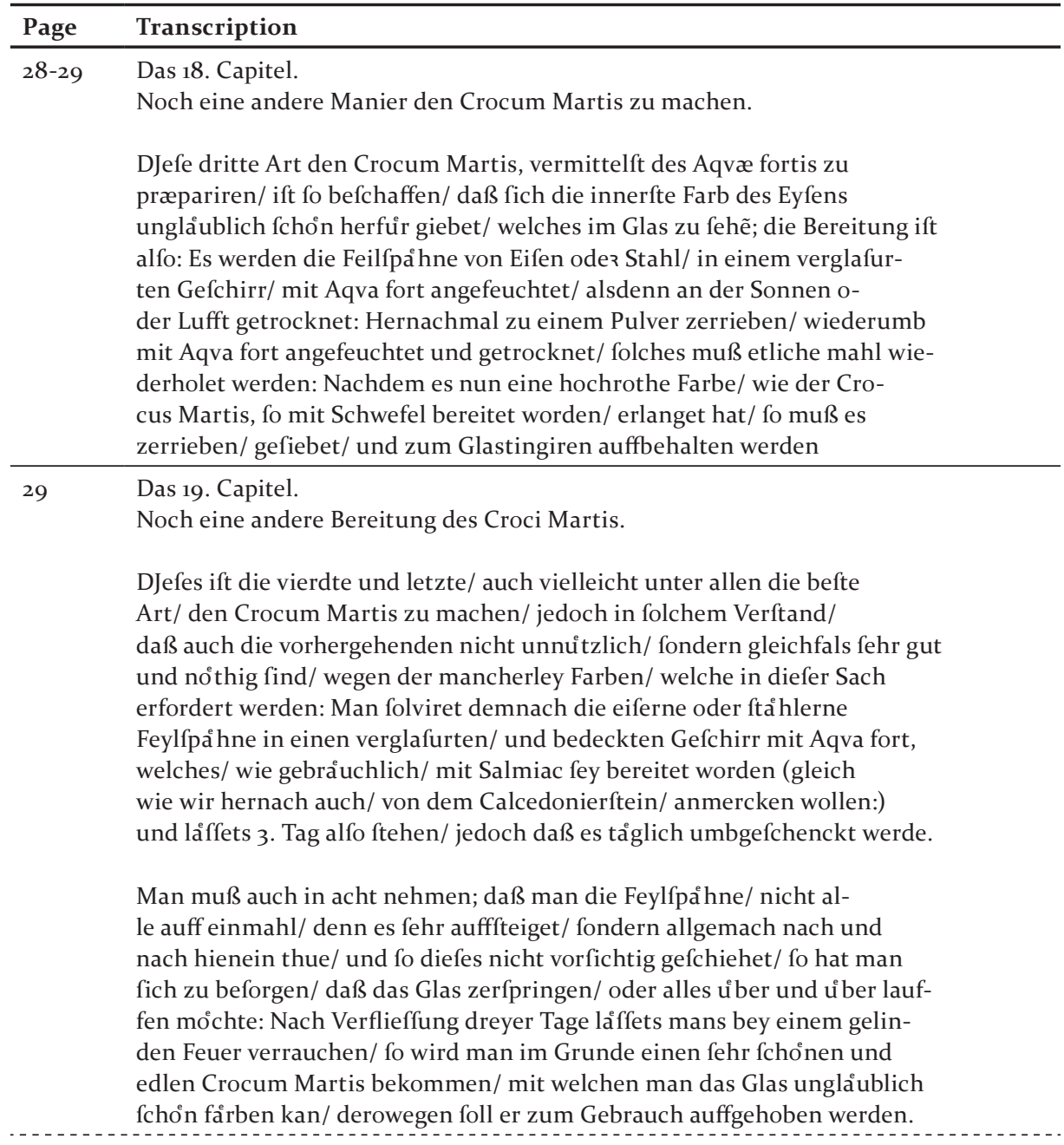




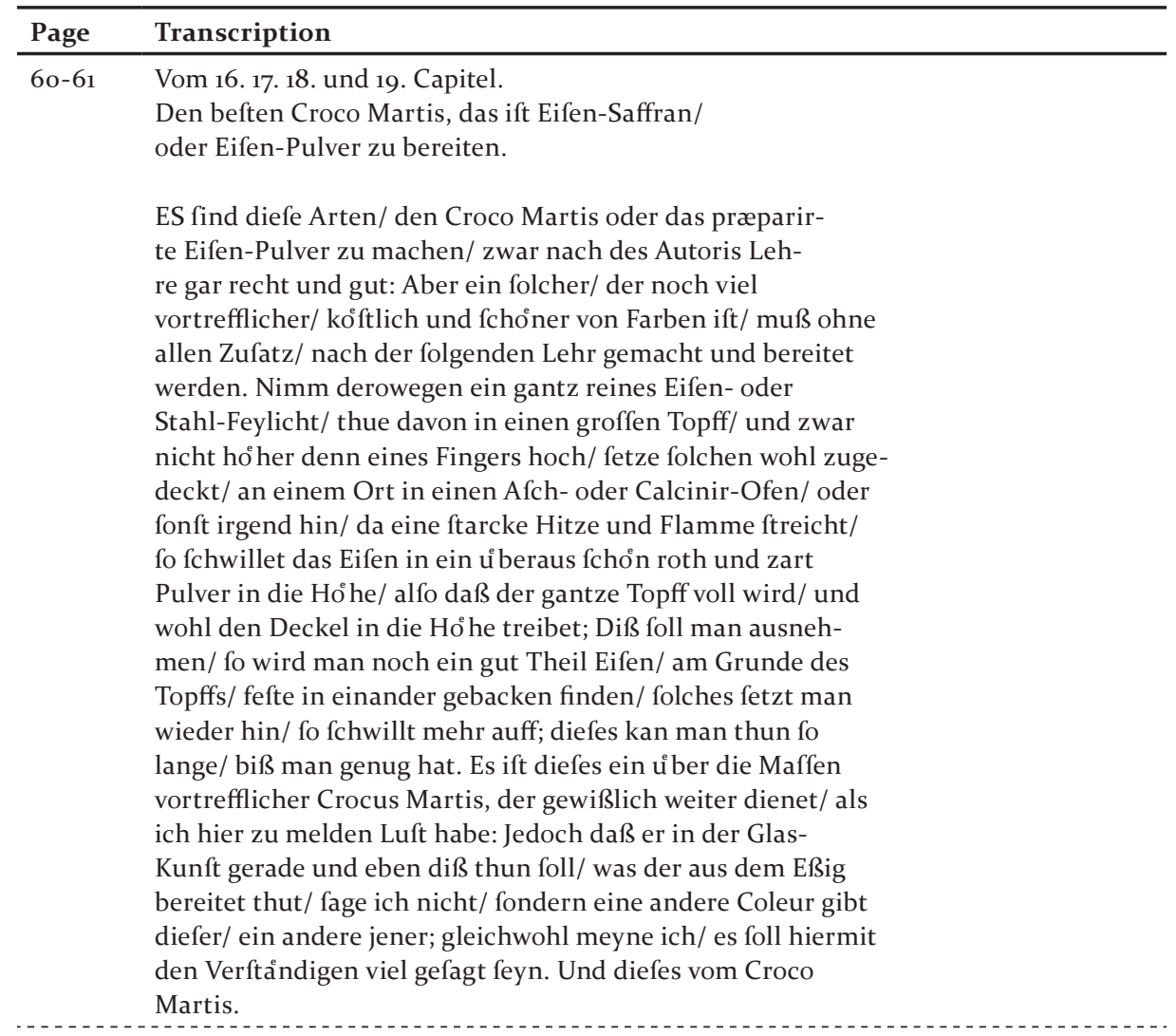




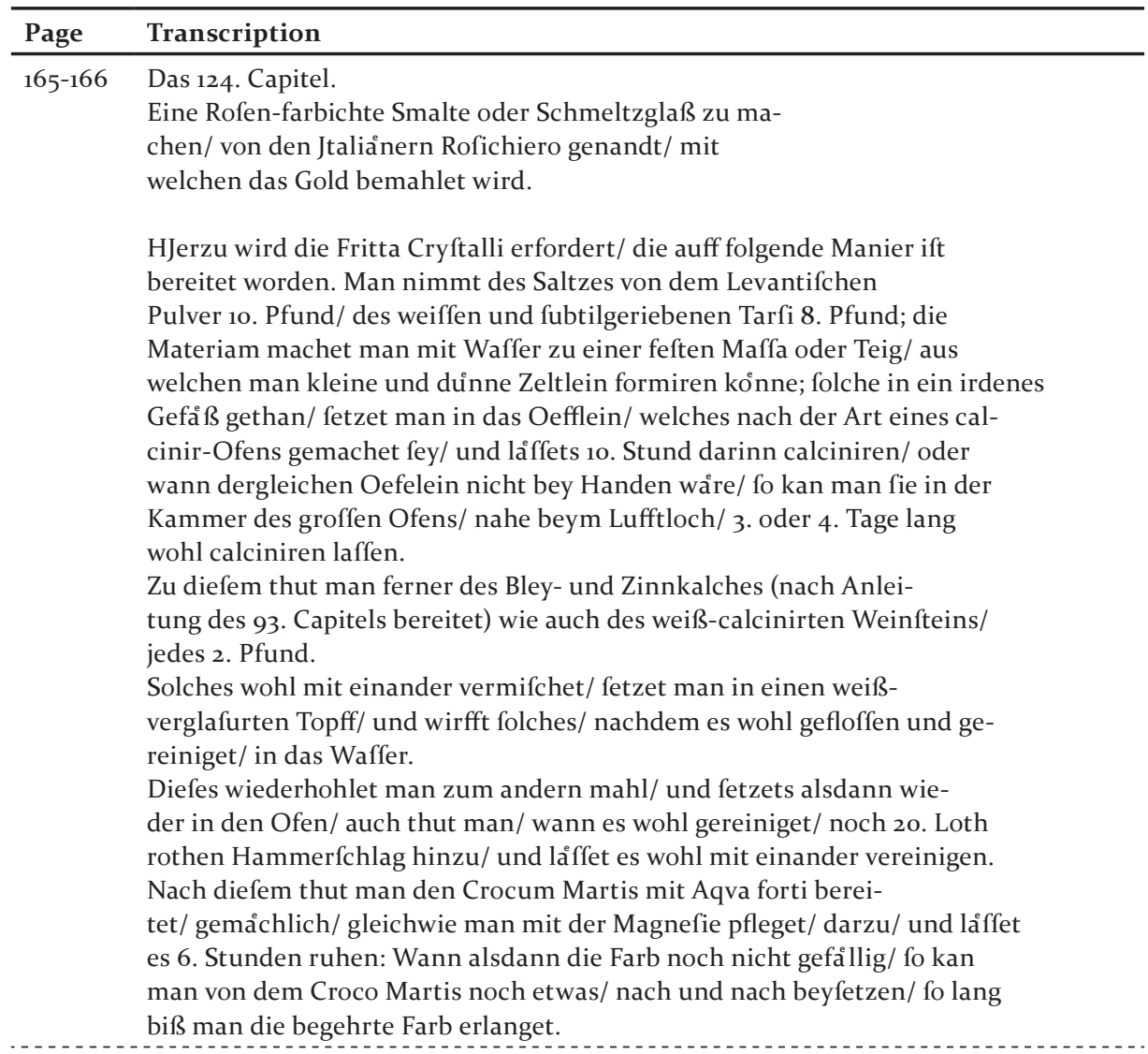




\begin{tabular}{|c|c|}
\hline Page & Transcription \\
\hline \multirow[t]{3}{*}{$166-167$} & $\begin{array}{l}\text { Das 125. Capitel. } \\
\text { Eine andere Rofen farbichte Smalte oder Schmeltzglas } \\
\text { zum Gold. }\end{array}$ \\
\hline & $\begin{array}{l}\text { MAn nimmt von der pråparirten Fritta Cryftalli des vorigen 124. Ca- } \\
\text { pitels 4. Pfund; folche in einen reinen und verglafurten Topff gefchmol- } \\
\text { tzen und gereiniget/ fchittet man ins Waffer/ und fetzets als dann wieder } \\
\text { in den Ofen: zu folcher/ nachdem fie wohl gereiniget/ thut man noch des } \\
\text { Bley- und Zinnafchens/ nach Jnhalt des 93. Capitels pråpariret/ auff } \\
\text { einmahl allezeit 1. Loth/ nach und nach darzu; und låffets wohl mit einan- } \\
\text { der incorporiren; alsdenn fiehet man/ ob die Materia im Tiegel/ Afchen- } \\
\text { farbicht feye: wann deme alfo/ fo hålt man mit dem Hineintragen inne/ } \\
\text { und thut von dem Pulver nichts mehr darzu/ damit diefe Afchen-Farb } \\
\text { nicht weiß werde/ denn folche Farb ift nicht gut. }\end{array}$ \\
\hline & $\begin{array}{l}\text { Hernach fetzt man dem gereinigten Kalch und Glas noch 4. Loth von } \\
\text { der Menig hinzu; Solches/ nachdeme fichs wohl mit einander incorpori- } \\
\text { ret/ wirfft man ins Waffer/ fetzets nach folchem wieder in den Ofen/ und } \\
\text { låfts noch 8. Stund lang darinnen ftehen: Hernach thut man des gecalci- } \\
\text { nirten Kupffers/ oder rothen Kupffer-Hammerfchlags/ wie auch des ro- } \\
\text { hen weiffen Weinfteins/ von iedwedern 1. Loth darzu; Zu diefem/ wann } \\
\text { es wohl unter einander gemifchet/ wirfft man noch von dem gepůlverten } \\
\text { Blutftein/ den die Schwertfeger zum poliren gebrauchen/ wie auch des } \\
\text { fixen Schwefels/ iedweders 1. Quintlein darzu. } \\
\text { Wann diefes wohl miteinander vermifchet/ und incorporiret wor- } \\
\text { den/ fo fiehet man/ ob die Farb recht feye? zu folcher/ wann fie gar zu dick wå- } \\
\text { re/ thut man etwas von der Magnefie/ fo wird fie heller werden. } \\
\text { Wann fie aber im Gegentheil gar zu hell wåre/ fo thut man des fi- } \\
\text { xen Schweffels/ wie auch des Blutfteins/ fammt ein wenig von dem ro- } \\
\text { then Kupfer-Hammerfchlag und weiffen Weinfteins noch darzu/ biß die } \\
\text { Farb nach Belieben recht und anftåndig ift. }\end{array}$ \\
\hline \multirow[t]{2}{*}{167} & $\begin{array}{l}\text { Das 126. Capitel. } \\
\text { Wie man den Schwefel zu obgedachten Gebrauch figiren } \\
\text { múffe. }\end{array}$ \\
\hline & $\begin{array}{l}\text { MAn kochet die Flores Sulphuris, eine Stund lang im gemeinen } \\
\text { Oehl; nachdem nimmt mans vom Feuer/ und gieffet den aller- } \\
\text { fchårffften Eßig daran/ fo wird der Schwefel zu Boden fallen/ und hin- } \\
\text { gegen das Oehl auff den Eßig fchwimmen: Diefes Oehl und Eßig gieffet } \\
\text { man vom Schwefel ab/ und fchittet ein frifches Oehl darauff/ und ver- } \\
\text { få hret damit wie zuvor; folches wird zum dritten mahl wiederhohlet/ fo er- } \\
\text { langet man zu obigen Gebrauch den fixen Schwefel. }\end{array}$ \\
\hline
\end{tabular}




\begin{tabular}{|c|c|}
\hline Page & Transcription \\
\hline $167-168$ & $\begin{array}{l}\text { Das 127. Capitel. } \\
\text { Ein Blut-rothes Glas/ welches an ftatt der Rofen-far- } \\
\text { bichten Smalte dienen kan. }\end{array}$ \\
\hline & $\begin{array}{l}\text { MAn nimmt des Bley-Glafes } 6 \text {. Pfund/ und von der Fritta Cryftalli } \\
\text { 1o. Pfund/ folche/ damit fie gereiniget werden/ låffet man in einen } \\
\text { Topff oder Tiegel fliffen/ fchittet fie ins Waffer/ thuts aus dem Waffer } \\
\text { wieder in den Topff/ damit es wohl gereiniget werde: Nachdeme es nun } \\
\text { wohl gereiniget worden/ fo thut man des rothgecalcinirten Kupffer-Ham- } \\
\text { merfchlags } 8 \text {. oder 12. Loth darzu/ låffet folches wohl mit einander kochen } \\
\text { und reinigen: hernach thut man roth-gepue lverten Weinftein darzu/ und } \\
\text { låffets abermahl reinigen und wohl mit einander incorporiren; alsdann be- } \\
\text { fiehet man/ ob die Farb gefå llig oder nicht: wann es noch nicht vo̊llig genug } \\
\text { wåre/ fo thut man von den rothen Kupffer-Hammerfchlag und Wein- } \\
\text { ftein fo viel darzu/ als man nơthig zu feyn erachtet; Nachdeme man aber- } \\
\text { mahls eine Prob genommen/ fo låft mans wieder erhitzen/ biß es genug- } \\
\text { fam-roth werde/ denn es wird hiervon die Farbe verftårcket und erho het } \\
\text { werden. }\end{array}$ \\
\hline
\end{tabular}




\begin{tabular}{|c|c|}
\hline Page & Transcription \\
\hline $168-169$ & 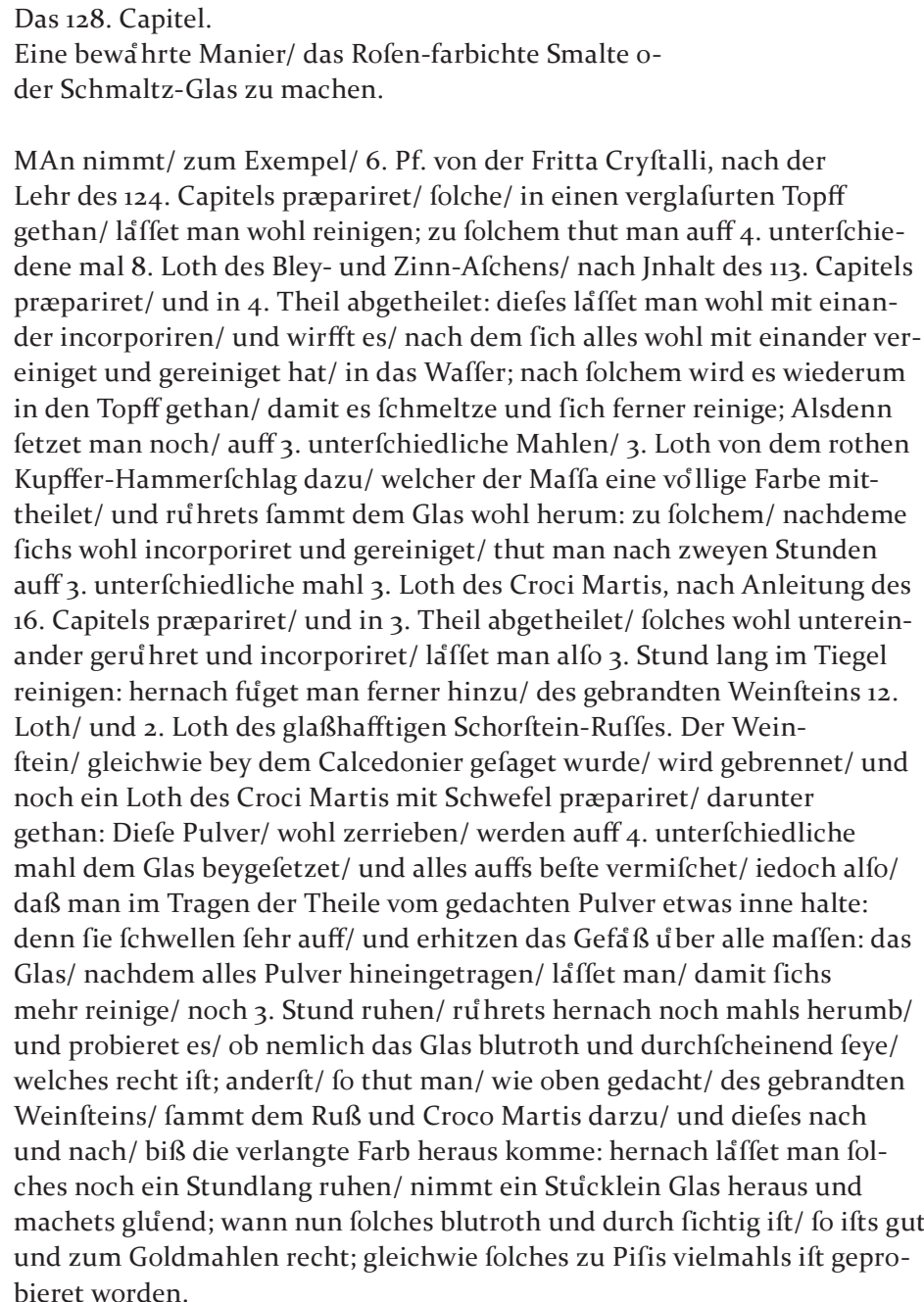 \\
\hline
\end{tabular}




\begin{tabular}{|c|c|}
\hline Page & Transcription \\
\hline 193 & $\begin{array}{l}\text { Jm 124. und 125. Capitel } \\
\text { MUß diefes wohl in acht genommen werden/ daß/ weiln } \\
\text { der Autor mehr Saltz als Sand zu machen befiehlet/ } \\
\text { man die Pofta, wann folche gefchmoltzen/ zu etlich mah- } \\
\text { len im Waffer ablöfche/ denn fo folches nicht gefchicht/ und } \\
\text { man hernach damit ameliren und mahlen will/ fo fihet alles } \\
\text { unangenehm uñ blåtterigt aus/ und will nichts rechts feines } \\
\text { und fcho̊nes daraus werden. } \\
\text { Es kan auch eben folches mit dem gemeinẽ Glas der Pott- } \\
\text { Afche gefchehen/ nur daß diefes (nemlich in diefem Capitel) } \\
\text { darumb/ weil mehr Saltz dazu ko̊mmt/ weicher und ge- } \\
\text { fchmeidiger wird. Es ift zu wiffen/ daß man bey allen } \\
\text { Schmeltz-Glåfern fich nur nach den Feuern muß richten: } \\
\text { denn ift das Feuer gar zu ftarck/ fo vergeht ihnen die Farb/ die } \\
\text { fie haben follen/ und kommt eine andere hervor/ die man nie } \\
\text { begehrt noch haben will. Der figirte Schwefel dient hier } \\
\text { zur Sache gar nichts/ er mag fo leicht davon bleiben/als da- } \\
\text { zu kommen: und weil hier fein Gebrauch nichts nutzet/ fo ift } \\
\text { auch nicht no̊thig }\end{array}$ \\
\hline 193 & $\begin{array}{l}\text { Jm 126. Capitel } \\
\text { DEßwegen ein Wort zu verlieren/ fondern Dinten und } \\
\text { Federn weiter zu fparen. Was aber }\end{array}$ \\
\hline 193-194 & $\begin{array}{l}\text { Das 127. Capitel } \\
\text { ANbelangt/ fo braucht diefelbe Schmeltze fürwar eben fo } \\
\text { viel Kunft nach zu finden/ als zu erfinden. Man muß } \\
\text { wohl zufehen/ daß/ fo bald das rechte Tempo einer ver- } \\
\text { langten Röthe getroffen/ man es alfobald aus dem Feuer } \\
\text { nehme/ fonft veråndert fichs in einer halben Viertel-Stunde. } \\
\text { Man kan aber diefe Farbe nicht gefchwinder kriegẽ/ als } \\
\text { wann man des gelben Staubs/ der in den Eychen liegt/ et- } \\
\text { was unter den Weinftein mifchet; und fo der Weinftein nicht } \\
\text { felbft fehr dicke von Farbe ift/ fo thut es auch wenig. Es bleibt } \\
\text { dabey/ diefe Farbe geråth felten wohl/ aber die nachfolgende } \\
\text { wird fehr fcho̊n/ und hat nicht fo viel Mů he/ als diefe. Sum- } \\
\text { ma/ das Feuer ift hierinn das Hauptftůcke zu beobachten. }\end{array}$ \\
\hline
\end{tabular}




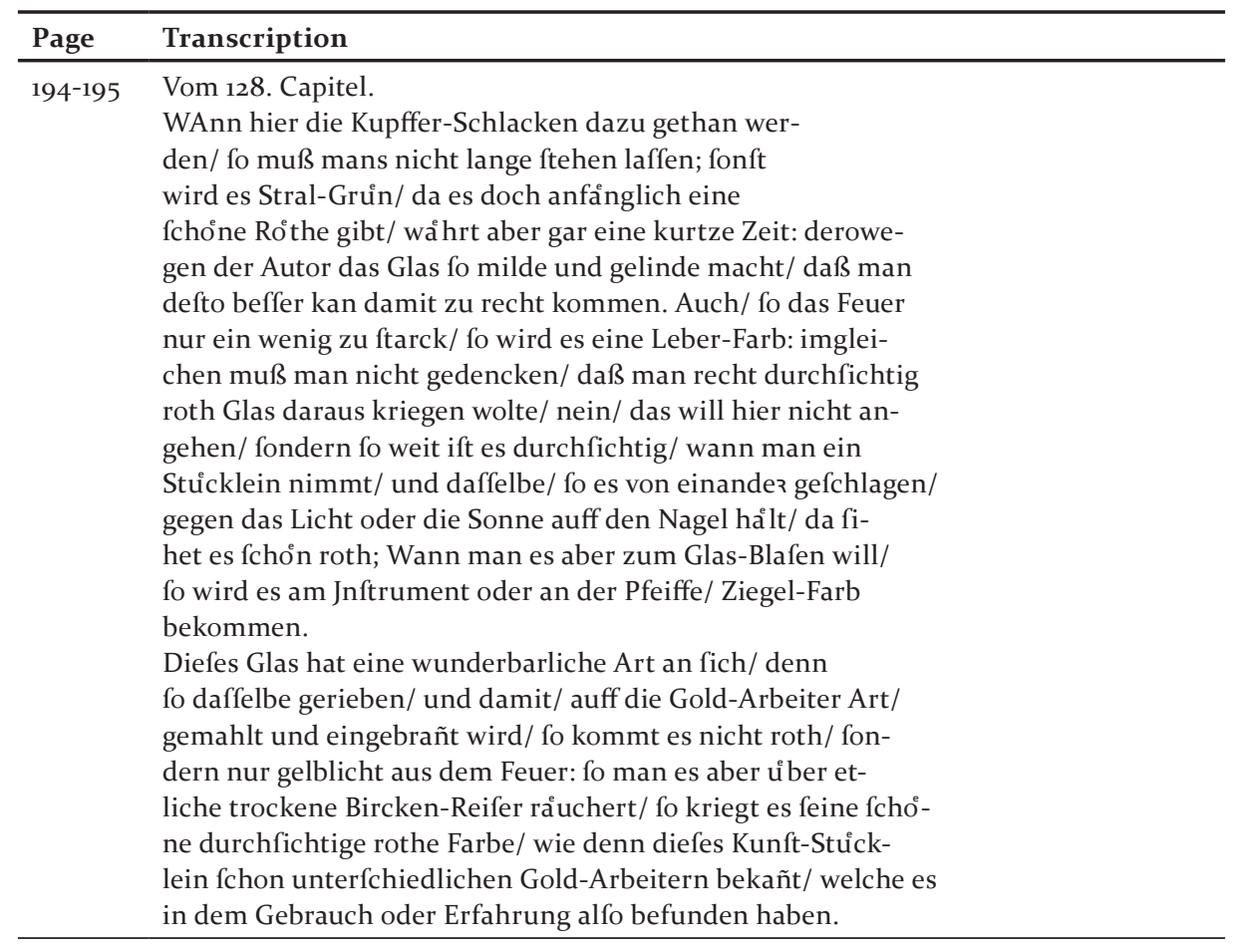




\section{Appendix II - Overview of Eikelenberg's Ervarenissen}

\begin{tabular}{|c|c|c|c|c|}
\hline Topic & Year & Date & Fols. & Cross References \\
\hline Blacking & & & $745\left(\mathrm{MS}_{390}\right)$ & $\begin{array}{l}\text { Recipe for } \\
\text { lampblack, fol. } 740 \\
(\mathrm{MS} 390)\end{array}$ \\
\hline Brazilwood & & & 83 (MS 391) & \\
\hline $\begin{array}{l}\text { Brown Dutch } \\
\text { Pinke }\end{array}$ & 1702 & Midsummer & $782(\mathrm{MS} 390)$ & \\
\hline Drying Paints & 1701 & Summer & $755^{-75} 8\left(\mathrm{MS}_{390}\right)$ & \\
\hline Indigo (I) & 1704 & & $783-785\left(\mathrm{MS}_{390}\right)$ & $\begin{array}{l}\text { Recipes for indigo, } \\
\text { fols. 666, } 741 \text { (MS } \\
\text { 390) }\end{array}$ \\
\hline Indigo (II) & 1704 & $\begin{array}{l}\text { From } 9 \text { Januari } \\
\text { until } 30 \text { April }\end{array}$ & 786-787 (MS 39o) & Ervarenis Indigo (I) \\
\hline Invisible Inks & & & 25 (MS 393) & \\
\hline $\begin{array}{l}\text { Lignum } \\
\text { Nephriticum }\end{array}$ & & & 24 (MS 391) & \\
\hline Linseed Oil & & & $658-660$ (MS 390) & \\
\hline $\begin{array}{l}\text { Linseed Oil and } \\
\text { Oil Paint }\end{array}$ & & & $685\left(\mathrm{MS}_{390}\right)$ & \\
\hline Massicot (I) & 1701 & Until 1702 & 748-749 (MS 39o) & \\
\hline Massicot (II) & & & $750(\mathrm{MS} 390)$ & \\
\hline $\begin{array}{l}\text { Massicot and } \\
\text { Honey }\end{array}$ & 1703 & 28 December & 749 (MS 39o) & \\
\hline Minium & 1704 & October & $805-806$ (MS 390) & Ervarenis Smalt \\
\hline $\begin{array}{l}\text { Minium and } \\
\text { Orpiment }\end{array}$ & 1701 & Summer & 754 (MS 39o) & \\
\hline On soot & & & 679 (MS 390) & \\
\hline Rainbow & & 16 September, 8 PM & 35 (MS 393) & \\
\hline Smalt & 1701 & November & $760-761$ (MS 39o) & \\
\hline Smalt and Honey & 1703 & & 761 (MS 39o) & Ervarenis Smalt \\
\hline Smell Varnishes & & & 679 (MS 390) & \\
\hline $\begin{array}{l}\text { Varnish Gum } \\
\text { Copal (I) }\end{array}$ & 1707 & 29 April & $821-824(\mathrm{MS} 390)$ & $\begin{array}{l}\text { Ervarenis Varnish } \\
\text { Gum Copal (III) and } \\
\text { recipe for Chinese } \\
\text { Varnish, fol. } 721 \text { (MS } \\
\text { 390) }\end{array}$ \\
\hline $\begin{array}{l}\text { Varnish Gum } \\
\text { Copal (II) }\end{array}$ & & & $821-822(\mathrm{MS} 390)$ & $\begin{array}{l}\text { Ervarenis Varnish } \\
\text { Van Hoogstraten }\end{array}$ \\
\hline $\begin{array}{l}\text { Varnish Gum } \\
\text { Copal (III) }\end{array}$ & 1708 & 17 May & $829-830\left(\mathrm{MS}_{390}\right)$ & $\begin{array}{l}\text { Ervarenis Gum } \\
\text { Copal (I) }\end{array}$ \\
\hline
\end{tabular}




\begin{tabular}{|c|c|c|c|c|}
\hline Topic & Year & Date & Fols. & Cross References \\
\hline $\begin{array}{l}\text { Varnish Gum } \\
\text { Copal (IV) }\end{array}$ & 1708 & 12 August & $830-832(\mathrm{MS} 390)$ & $\begin{array}{l}\text { Ervarenis Gum } \\
\text { Copal (I) and (III) }\end{array}$ \\
\hline $\begin{array}{l}\text { Varnish Nicolaas } \\
\text { de Vree (I) }\end{array}$ & 1707 & 24 March & $800(\mathrm{MS} 390)$ & $\begin{array}{l}\text { Ervarenis Varnish } \\
\text { Nicolaas de Vree (II) } \\
\text { and corresponding } \\
\text { recipe for varnish, } \\
\text { fol. } 801 \text { (MS 390) }\end{array}$ \\
\hline $\begin{array}{l}\text { Varnish Nicolaas } \\
\text { de Vree (II) }\end{array}$ & & & $802(\mathrm{MS} 390)$ & $\begin{array}{l}\text { Ervarenis Varnish } \\
\text { Nicolaas de Vree (I) }\end{array}$ \\
\hline $\begin{array}{l}\text { Varnish Van } \\
\text { Hoogstraten }\end{array}$ & 1707 & 3o September & $825-828(\mathrm{MS} 390)$ & $\begin{array}{l}\text { Ervarenis Varnish } \\
\text { Nicolaas de Vree } \\
\text { (II), Ervarenis } \\
\text { Varnish Gum Copal } \\
\text { (I) and IV) and } \\
\text { Van Hoogstraten's } \\
\text { varnish recipe, fol. } \\
677 \text { (MS 390) }\end{array}$ \\
\hline Verdigris & & & 661 (MS 390) & \\
\hline Vermilion & 1704 & Late October & 808 (MS 390) & Ervarenis Minium \\
\hline West Indies Red & 1703 & December & 790 (MS 390) & $\begin{array}{l}\text { Ervarenis Massicot } \\
\text { (II) }\end{array}$ \\
\hline Yellow Ochre & 1701 & November & $762-764$ (MS 39o) & $\begin{array}{l}\text { Ervarenis Smalt and } \\
\text { Honey }\end{array}$ \\
\hline
\end{tabular}




\section{Appendix III - Van Laer's Remarks on Casting}

\begin{tabular}{|c|c|c|}
\hline Page & Dutch transcription $^{2}$ & English translation \\
\hline $133-134$ & $\begin{array}{l}\text { Voorts werd tot het gieten in zand, eerst } \\
\text { Koopere, Ysere, of Houten zogenaamde } \\
\text { gietflessen vereist, die wel vast en } \\
\text { digt op malkander sluyten, en by 't } \\
\text { opneemen gemackelyk los gaan. }\end{array}$ & $\begin{array}{l}\text { To cast in sand, it is first of all required } \\
\text { to use so-called copper, iron or wooden } \\
\text { casting flasks that closely fit onto each } \\
\text { other and will come off easily when taken } \\
\text { apart. }\end{array}$ \\
\hline 135 & $\begin{array}{l}\text { Goede stofzand is by 't drucken van } \\
\text { groote aangeleegentheyd, deze werd } \\
\text { op de eene helft van een gedrukte } \\
\text { vles gestrooit of gestooven, voor dat } \\
\text { de ander helft daar werd opgedrukt, } \\
\text { om reeden; dat anders de te zaamen } \\
\text { geparste zand niet weer van malkander } \\
\text { te krygen is. Dit stof werd van een ieder } \\
\text { by na byzonder gemaakt en gebruykt. } \\
\text { Veele neemen stof van houds-koolen, } \\
\text { doen dat in een fyn linnen zakje, en } \\
\text { stuyven dat zo over de Vles met zand } \\
\text { en patroonen, andere vylen met een vyl, } \\
\text { van een houds-kool booven de Vles en } \\
\text { Patroonen, welke beyde manieren de } \\
\text { zand en patroonen heel wel doet lossen. }\end{array}$ & $\begin{array}{l}\text { Good dusting sand is of great importance } \\
\text { when pressing. The sand is scattered on } \\
\text { one half of the pressed flask, before the } \\
\text { other half is pressed upon it. For this } \\
\text { reason: otherwise the sand that has been } \\
\text { pressed together cannot be separated } \\
\text { anymore. The dust is made and used by } \\
\text { almost everyone in particular. Many take } \\
\text { the dust of charcoal, put it in a fine and } \\
\text { tiny linen bag, and scatter it onto the flask } \\
\text { with the sand and patterns, others file } \\
\text { it with a file off a piece of charcoal while } \\
\text { holding it above the flask and patterns. } \\
\text { Both methods make the sand and patterns } \\
\text { come loose well. }\end{array}$ \\
\hline 136 & $\begin{array}{l}\text { Zulken stof dan op de eene helft der vles } \\
\text { gestrooyd zynde, dan werd de ander } \\
\text { helft, daar op geleyd, met zand gevuld, } \\
\text { en zo vol drukt. }\end{array}$ & $\begin{array}{l}\text { After the sand has been scattered onto } \\
\text { one half of the flask, the other half is put } \\
\text { on top, filled with sand and pressed until } \\
\text { full. }\end{array}$ \\
\hline
\end{tabular}

2 Excerpts from the chapter "On the casting of both silver and gold." Van Laer, Weg-wyzer $(1721)$. 


\begin{tabular}{|c|c|c|}
\hline Page & Dutch transcription & English translation \\
\hline $136-137$ & $\begin{array}{l}\text { En het overige der vles, kan met zandt, } \\
\text { die vogtig fyn gevreven is, gevolt } \\
\text { werden, om de minste moeiten. Veele } \\
\text { maaken de drooge zand nadt, met } \\
\text { zwaar bier, waater daar Salarmoniak, } \\
\text { of Lym in gesmolten is, waater met } \\
\text { stroop, zout, pis, en veele verhittende, } \\
\text { en kleevende middelen. De kleevende } \\
\text { zyn heel goed om de zandt wel te doen } \\
\text { houden en net drukken, de verhittende } \\
\text { (om 't Zilver of Goud) by 't gieten in } \\
\text { de vles, eenige vlugheyd by te zetten, } \\
\text { het welke beyde wel waar is, dogh zo } \\
\text { houde ik die hinderlyk in 't gieten, om } \\
\text { dat de vettigheyd by't ingieten rook in } \\
\text { de vles geeft, en de verhittende eenige } \\
\text { beweeginge aan 't ingegotene toebrengt, } \\
\text { welke beyde dikwils oorzaak moeten } \\
\text { zyn, dat het Zilver of Goud, op de een of } \\
\text { andere plaats in zyn loop werd gestuyt, } \\
\text { en ook veele ruyg-putten in 't gegootene } \\
\text { veroorzaaken, vast gesteldt zynde dat } \\
\text { alle rook of beweeginge in een vles quaat } \\
\text { doet. Daarom meen ik het zeekerste te } \\
\text { gieten, als de zandt (niet anders als) met } \\
\text { schoon water is aangemaakt, wel door } \\
\text { malkander gevreeven, (op dat die taay } \\
\text { werd) en niet natter als dat die met een } \\
\text { handt bequaam tot ballen kan werden } \\
\text { gedrukt. }\end{array}$ & $\begin{array}{l}\text { The remainder of the flask can be filled, } \\
\text { without effort, with sand that has been } \\
\text { pulverized while moist. Many moisten } \\
\text { dry sand with strong beer, water in which } \\
\text { salarmoniak or glue has been melted, } \\
\text { water with syrup, salt, piss, and many } \\
\text { heating and sticky substances. The } \\
\text { sticky substances are very useful to let } \\
\text { the sand hold well and to press neatly, } \\
\text { the heating substances to add some } \\
\text { rapidity when (silver or gold) is cast in } \\
\text { a flask. Both are true, but I take them } \\
\text { to be disturbing in casting, because the } \\
\text { greasiness yields smoke in the flask while } \\
\text { pouring in, and the heating substances } \\
\text { will inflict some movements to that-what- } \\
\text { has-been-poured-in. Both must often be } \\
\text { the cause of silver or gold being stopped } \\
\text { somewhere in its course and the many } \\
\text { pits that are caused in that-what-is-cast, } \\
\text { provided that all the smoke or movements } \\
\text { in a flask are harmful. That is why I cast } \\
\text { with most confidence, when the sand is } \\
\text { prepared with clean water (not otherwise), } \\
\text { mixed thoroughly by rubbing it (so that } \\
\text { it becomes stiff) and not moister than } \\
\text { necessary to competently press it into } \\
\text { balls using your hand. }\end{array}$ \\
\hline 137 & $\begin{array}{l}\text { Van zulken zandt dan een vles gedrukt } \\
\text { zynde, zo moeten daar gooten, } \\
\text { tot passasie van 't Zilver, werden } \\
\text { ingesneeden [...] }\end{array}$ & $\begin{array}{l}\text { After a flask has been pressed with this } \\
\text { sand, runners need to be cut for passage of } \\
\text { the silver [...] }\end{array}$ \\
\hline $137-138$ & $\begin{array}{l}{[\ldots] \text { dog voor aan de mond van de vles, }} \\
\text { moet de goot zo wyt werden gemaakt als } \\
\text { geschieden kan, dan dringt het zilver by } \\
\text { 't ingieten stark deur en het zilver wel } \\
\text { heet zynde, zo zal zelden mis gegooten } \\
\text { werden. }\end{array}$ & $\begin{array}{l}\text { [...] however, close to the mouth of the } \\
\text { flask the runner needs to be cut as wide as } \\
\text { possible. As such, the silver will strongly } \\
\text { flow into the flask when cast, and when it } \\
\text { is hot enough, the casting will hardly ever } \\
\text { go wrong. }\end{array}$ \\
\hline 139 & $\begin{array}{l}\text { Voorts de Vlessen te zamen gelegt, in } \\
\text { de Giet-pars gezegt, en het wel heet } \\
\text { gesmolten Zilver, daar stoutmoedigh } \\
\text { in gegooten; by deze manier, heb ik } \\
\text { myn ten allen tyden het best bevonden, } \\
\text { en 't gebruyk van heete, natte, of } \\
\text { gegloeyde Vlessen, laaten varen, } \\
\text { hoewel ik verzeekert ben dat andere het } \\
\text { beminnen. }\end{array}$ & $\begin{array}{l}\text { The flasks put together and placed in the } \\
\text { casting-press, and the Silver cast in a } \\
\text { bold manner: this I found to be the best } \\
\text { way each and every time, and I stopped } \\
\text { using heated, moist or glowed flasks, even } \\
\text { though I am sure others love it. }\end{array}$ \\
\hline
\end{tabular}


Appendices

\begin{tabular}{lll}
\hline Page & Dutch transcription & English translation \\
\hline 140 & $\begin{array}{l}\text { En nogh beeter, als men [...] eenige } \\
\text { lught gooten maakt, die haar uytkomst } \\
\text { booven bezyden de mondt der Gietvles } \\
\text { hebben [...] }\end{array}$ & $\begin{array}{l}\text { And even better, if one [...] makes air vents } \\
\text { that end up near the mouth of the casting } \\
\text { flask [...] }\end{array}$ \\
\hline
\end{tabular}



Bibliography 
Abney Salomon, Charlotte A. "The Pocket Laboratory. The Blowpipe in EighteenthCentury Swedish Chemistry." Ambix 66 (2019): 1-22.

Agricola, Georgius. De Re Metallica. Translated by Herbert Clark Hoover and Lou Henry Hoover. New York: Dover Publications, 1950.

Alonso-Almeida, Francisco. "Genre Conventions in English Recipes, 160o-18oo." In Reading and Writing Recipe Books, 1550-180o, edited by Michelle DiMeo and Sara Pennell, 68-92. Manchester: Manchester University Press, 2013.

Anderson, R.G.W. "Joseph Black and His Chemical Furnace." In Making Instruments Count. Essays on Historical Scientific Instruments Presented to Gerard L'Estrange Turner, edited by R.G.W. Anderson, J.A. Bennett, and W.F. Ryan, 118-26. Aldershot: Variorum, 1993.

Asmussen, Tina. Scientia Kircheriana. Die Fabrikation von Wissen Bei Athanasius Kircher. Affalterbach: Didymos-Verlag, 2016.

Atkinson, Paul. "Blowing Hot. The Ethnography of Craft and the Craft of Ethnography." Qualitative Inquiry 19 (2013): 397-404.

-_- "Ethnography and Craft Knowledge." Qualitative Sociology Review 9 (2013): 56-63.

Auch, Monika. "De Kennis Zit in de Handen.” KM 102 (2017): 24-26.

Author unknown. "Advertisement." Amsterdamse Courant, July 1, 1721.

Bandiera, Mario, Patrice Lehuédé, Marco Verità, Luis Alves, Isabelle Biron, and Márcia Vilarigues. "Nanotechnology in Roman Opaque Red Glass from the 2nd Century AD. Archaeometric Investigations in Red Sectilia from the Decoration of the Lucius Verus Villa in Rome." Heritage 2 (2019): 2597-2611.

Beentjes, Tonny, and Pamela H. Smith. "Sixteenth-Century Life-Casting Techniques. Experimental Reconstructions Based on a Preserved Manuscript.” In The Renaissance Workshop, edited by David Saunders, Marika Spring, and Andrew Meek, 144-51. London: Archetype, 2013.

Benschop, Ruth. “De Eland Is Een Eigenwijs Dier.” Inaugural lecture, Zuyd University of Applied Sciences, Maastricht, 2015. http://lectoraataok.nl/wp-content/ uploads/2016/o6/Inaugurele-rede-Ruth-Benschop.pdf.

Beretta, Marco. "Between the Workshop and the Laboratory. Lavoisier's Network of Instrument Makers." Osiris 29 (2014): 197-214.

- - - "Glassmaking Goes Public. The Cultural Background to Antonio Neri's L'Arte Vetraria (1612).” Technology and Culture 58 (2017): 1046-70.

- - _. "Material and Temporal Powers at the Casino Di San Marco (1574-1621)." In Laboratories of Art. Alchemy and Art Technology from Antiquity to the 18th Century, edited by Sven Dupré, 128-56. Cham: Springer, 2014.

Biagioli, Mario. "From Print to Patents. Living on Instruments in Early Modern Europe." History of Science 44 (2006): 139-86.

Bilak, Donna, Jenny Boulboullé, Joel Klein, and Pamela H. Smith. "The Making and Knowing Project. Reflections, Methods, and New Directions.” West 86th 23 (2016): 35-55.

Birkenhagen, Bettina, and Frank Wiesenberg. "Der Experimentalarchäologische Werkstattbereich Im Archäologiepark Römische Villa Borg.” In Experimentelle Archäologie in Europa 18, edited by Gunter Schöbel, 245-56. Unteruhldingen, 2019.

Biron, Isabelle. Émaux Sur Métal Du IXe Aux XIXe Siècle. Histoire, Technique et Matériaux. Dijon: Faton, 2015. 
Blanc, Jan. “Van Hoogstraten's Theory of Theory of Art.” In The Universal Art of Samuel Van Hoogstraten (1627-1678). Painter, Writer, and Courtier, edited by Thijs Weststeijn, 35-51. Amsterdam: Amsterdam University Press, 2013.

Blankaart, Steven. De Kartesiaanse Academie Ofte Institutie Der Medicyne. Amsterdam: Johannes ten Hoorn, 1683.

- - - Theatrum Chimicum, Ofte Geopende Deure Der Chymische Verborgntheden Ontsloten. Amsterdam, 1693.

Boulboullé, Jenny. "Drawn up by a Learned Physician from the Mouths of Artisans. The Mayerne Manuscript Revisited.” Netherlands Yearbook for History of Art / Nederlands Kunsthistorisch Jaarboek 68 (2019): 204-49.

_- _. "The Manual as Artifact. On Artists' Manuals and Craftmen's Handbooks." History of Knowledge. Research, Resources, and Perspectives (blog), 2018. https:// historyofknowledge.net/2018/06/04/manual-as-artifact/.

Boyle, Robert. The Works of Robert Boyle. Edited by Michael Hunter and Edward B. Davis. Vol. 10. London: Pickering \& Chatto, 2000.

Brill, Robert H., and Nicholas D. Cahill. "A Red Opaque Glass From Sardis and Some Thoughts on Red Opaques in General.” The Journal of Glass Studies 30 (1988): 16-27.

Broecke, L. Cennino Cennini. Il Libro Dell'Arte. London: Archetype, 2015.

Bucklow, Spike. "Paradigms and Pigment Recipes. Vermilion, Synthetic Yellows and the Nature of Egg." Zeitschrift Für Kunsttechnologie Und Konservierung 13 (1999): 140-49.

Carlyle, Leslie. "Exploring the Grammar of Oil Paint through the Use of Historically Accurate Reconstructions.” In Conservation of Easel Paintings, edited by Joyce Hill Stoner and Rebecca Rushfield, 33-38. London: Routledge, 2012.

- - - "Historical Accuracy in the Production of Reconstructions of Oil Painting Materials and Techniques." In Reconstruction, Replication and Re-Enactment in the Humanities and Social Sciences, edited by Sven Dupré, Anna Harris, Patricia Lulof, Julia Kursell, and Maartje Stols-Witlox. Amsterdam: Amsterdam University Press, forthcoming.

- - - "Practical Considerations for Creating Historically Accurate Reconstructions." In Fatto d'archimia. Historia e Identificación de Los Pigmentos Artificial, edited by S. Kroustallis and M. del Egido, 105-17. Madrid: Ministerio de Educacion Cultura Y Deporte, Secretaria General Técnica, 2012.

Carlyle, Leslie, and Maartje Witlox. "Historically Accurate Reconstructions of Artists' Oil Painting Materials." In Art of the Past. Sources and Reconstructions. Proceedings of the First Symposium of the Art Technological Source Research Study Group, edited by Mark Clarke, Joyce H. Townsend, and Ad Stijnman, 53-59. London: Archetype, 2005. Carlyle, Leslie, Christina Young, and Suzanne Jardine. "The Mechanical Response of FlourPaste Grounds.” In Preparation for Painting. The Artist's Choice and Its Consequences, edited by Joyce H. Townsend, Tiarna Doherty, Gunnar Heydenreich, and Jacqueline Ridge, 123-31. London: Archetype, 2008.

Cavicchi, E. "Faraday and Piaget. Experimenting in Relation with the World." Perspectives on Science 14 (2006): 66-96.

Cellini, Benvenuto. The Treatises of Benvenuto Cellini on Goldsmithing and Sculpture. Translated by Charles R. Ashbee. London: Arnold, 1898.

Chang, Hasok. "How Historical Experiments Can Improve Scientific Knowledge and Science Education. The Cases of Boiling Water and Electrochemistry." Science and Education 20 (2011): 317-41. 
Charleston, Robert J. “Glass Furnaces through the Ages.” Journal of Glass Studies 20 (1978): 9-33.

Clarke, Mark. "Asymptotically Approaching the Past. Historiography and Critical Use of Sources in Art Technological Source Research.” In Art Technology. Sources and Methods, edited by Stefanos Kroustallis, Joyce H. Townsend, Elena Cenalmor Bruquetas, Ad Stijnman, and Margarita San Andres Moya, 16-22. London: Archetype Publications, 2008.

Clarke, Mark, and Leslie Carlyle. "Page-Image Recipe Databases. A New Approach to Making Art Technological Manuscripts and Rare Printed Sources Accessible." In Art of the Past. Sources and Reconstructions. Proceedings of the First Symposium of the Art Technological Source Research Study Group, edited by Mark Clarke, Joyce H. Townsend, and Ad Stijnman, 49-52. London: Archetype, 2005.

Clarke, Mark, Joyce H. Townsend, and Ad Stijnman, eds. Art of the Past. Sources and Reconstructions. Proceedings of the First Symposium of the Art Technological Source Research Study Group. London: Archetype, 2005.

Clow, Archibald, and Nan L. Clow. The Chemical Revolution. A Contribution to Social Technology. London: Batchworth Press, 1952.

Collins, Harry. Tacit and Explicit Knowledge. Chicago: Chicago University Press, 2010.

Cook, Harold J. Matters of Exchange. Commerce, Medicine, and Science in the Dutch Golden Age. New Haven: Yale University Press, 2008.

Cornell, R.M., and U. Schwertmann. The Iron Oxides. Weinheim: VCH Verlagsgesellschaft, 1996.

Crawford, E. "A Critique of Curriculum Reform. Using History to Develop Thinking." Physics Education 28 (1993): 204-8.

Daston, Lorraine. "Mechanical Rules before Machines. Rules and Paradigms.” presented at the 2019 Social Science Research Council Fellow Lecture, New York, February 5, 2019. https://youtu.be/6xErFnyiMAA.

- - - "The History of Science and the History of Knowledge." KNOW. A Journal on the Formation of Knowledge 1 (2017): 131-54.

Davids, Karel. "Apprenticeship and Guild Control in the Netherlands, c. 1450-180o." In Learning on the Shop Floor. Historical Perspectives on Apprenticeship, edited by Bert De Munck, Steven L. Kaplan, and Hugo Soly, 66-84. New York: Berghahn Books, 2007.

- - - "Craft Secrecy in Europe in the Early Modern Period. A Comparative View." Early Science and Medicine 10 (2005): 341-48.

Davison, Sandra. Conservation and Restoration of Glass. 2nd ed. Oxford: Butterworth Heinemann, 2003.

De Heide, Antonius. Ontledinge Des Mossels. Amsterdam: Joannes en Gillis Janssonius van Waasberge, 1684 .

De Munck, Bert. "Artisans as Knowledge Workers. Craft and Creativity in a Long Term Perspective." Geoforum 99 (2019): 227-37.

- - - "Corpses, Live Models, and Nature. Assessing Skills and Knowledge before the Industrial Revolution (Case: Antwerp)." Technology and Culture 51 (2010): 332-56.

- - - Technologies of Learning. Apprenticeships in Antwerp Guilds from the 15th Century to the End of the Ancien Régime. Turnhout: Brepols, 2007.

De Munck, Bert, Steven L. Kaplan, and Hugo Soly. Learning on the Shop Floor. Historical Perspectives on Apprenticeship. New York: Berghahn Books, 2007. 
De Munck, Bert, and Hugo Soly. "Learning on the Shop Floor' in Historical Perspective." In Learning on the Shop Floor. Historical Perspectives on Apprenticeship, edited by Bert De Munck, Steven L. Kaplan, and Hugo Soly, 3-31. New York: Berghahn Books, 2007.

De Vries, Lyckle. How to Create Beauty. De Lairesse on the Theory and Practice of Making Art. Leiden: Primavera Press, 2011.

Dear, Peter. Discipline E Experience. The Mathematical Way in the Scientific Revolution. Chicago: Chicago University Press, 1995.

——_. "Totius in Verba. Rhetoric and Authority in the Early Royal Society." Isis 76 (1985): $144-61$.

Den Otter, Herman. Naar Inzicht En Vakmanschap. A.-J. Roubo's L'Art Du Menuisier over Interieurbouw En Meubelmakerij in de Achttiende Eeuw. Badhoevedorp, 2016.

Descartes, Renatus. Brieven. Derde Deel. Neffens Een Nette Verhandeling van Het Licht. Translated by J.H. Glasemaaker. Amsterdam: Jan Rieuwertsz, 1684.

Dietz, Feike, and Sven Dupré. "Introduction. Youthful Minds and Hands. Learning Practical Knowledge in Early Modern Europe." In "Youthful Minds and Hands. Learning Practical Knowledge in Early Modern Europe.” Edited by Feike Dietz and Sven Dupré. Special issue. Science in Context 32, no. 2 (2019): 113-18.

- - , eds. "Youthful Minds and Hands. Learning Practical Knowledge in Early Modern Europe." Special Issue. Science in Context 32, no. 2 (2019): 113-236.

DiMeo, Michelle. "Communicating Medical Recipes. Robert Boyle's Genre and Rhetorical Strategies for Print." In The Palgrave Handbook of Early Modern Literature and Science, edited by Howard Marchitello and Evelyn Tribble, 209-28. London: Palgrave Macmillan, 2017.

_- _. 'Openness vs. Secrecy in the Hartlib Circle. Revisiting 'Democratic Baconianism' in Interregnum England." In Secrets and Knowledge in Medicine and Science, 1500-1800, edited by Elaine Leong and Alisha Rankin, 105-21. Farnham: Ashgate, 2011.

DiMeo, Michelle, and Sara Pennell, eds. Reading and Writing Recipe Books, 1550-180o. Manchester: Manchester University Press, 2013.

Dodwell, C.R. The Various Arts. De Diversis Artibus. Oxford: Oxford Clarendon Press, 1961. Dubbe, Bert. Zwols Zilver. Het Zwolse Goud-En Zilversmidambacht En Zijn Meesters. Zwolle: Uitgeverij Waanders, 1999.

Dupré, Sven. "Doing It Wrong. The Translation of Artisanal Knowledge and the Codification of Error." In The Structures of Practical Knowledge, edited by Matteo Valleriani, 167-88. Cham: Springer International Publishing, 2017.

_-_. "Introduction." In Laboratories of Art. Alchemy and Art Technology from Antiquity to the 18th Century, edited by Sven Dupré, vii-xix. Cham: Springer, 2014.

_- - "Introduction. Science and Practices of Translation." Isis 109 (2018): 302-7.

- - - ed. Laboratories of Art. Alchemy and Art Technology from Antiquity to the 18th Century. Cham: Springer, 2014.

_- - "Re-Working with Makers (Part 2)." ARTECHNE (blog), 2018. https://artechne. wp.hum.uu.nl/re-working-with-makers-part-2/.

_—_. "The Role of Judgment in the Making of Glass Colors in the Seventeenth Century." Ferrum 90 (2018): 8-17.

- - - "The Value of Glass and the Translation of Artisanal Knowledge in Early Modern Antwerp." Netherlands Yearbook for History of Art / Nederlands Kunsthistorisch Jaarboek 64 (2014): 138-61. 
Dupré, Sven, Anna Harris, Patricia Lulof, Julia Kursell, and Maartje Stols-Witlox, eds. Reconstruction, Replication and Re-Enactment in the Humanities and Social Sciences. Amsterdam: Amsterdam University Press, forthcoming.

Dupré, Sven, and Geert Somsen. "The History of Knowledge and the Future of Knowledge Societies." "History of Science or History of Knowledge?" Edited by Christian Joas, Dominik Knaupp, Fabian Krämer, and Kärin Nickelsen. Special Issue. Berichte Zur Wissenschaftsgeschichte 42, no. 2-3 (2019): 186-99.

Durán, A., J.M. Fernández Navarro, J. García Solé, and F. Agulló-López. "Study of the Colouring Process in Copper Ruby Glasses by Optical and EPR Spectroscopy.” Journal of Materials Science 19 (1984): 1468-75.

Eamon, William. "How to Read a Book of Secrets." In Secrets and Knowledge in Medicine and Science, 1500-180o, edited by Elaine Leong and Alisha Rankin, 23-46. Farnham: Ashgate, 2011.

- - - Science and the Secrets of Nature. Books of Secrets in Medieval and Early Modern Culture. Princeton: Princeton University Press, 1994.

Eikelenberg, Simon. "Aantekeningen Betreffende de Financiële Toestand van Simon Eikelenberg.” Alkmaar, ca 1700. MS 558 Collectie Aanwinsten. Regionaal Archief Alkmaar.

_-_. "Aantekeningen Betreffende Het Leven van Simon Eikelenberg." Alkmaar, c. 1700. MS 557 Collectie Aanwinsten. Regionaal Archief Alkmaar.

_-_. "Aantekeningen Betreffende Schilderen." Alkmaar, c. 170o. MS 390-394 Collectie Aanwinsten. Regionaal Archief Alkmaar.

-_- Alkmaar En Zyne Geschiedenissen. Alkmaar: Simon van Hoolwerf, 1739.

___. "Brieven van en aan Simon Eikelenberg." Alkmaar, c. 170o. MS 556 Collectie Aanwinsten. Regionaal Archief Alkmaar.

- - - Gedaante En Gesteldheid van Westvriesland Voor Den Jaare MCCC. En Teffens Den Ondergang van Het Dorp Vroone. Alkmaar: Klaas Mol, 1716.

_-_. "Ontwerp Volgens't Welke Men Een Collegie van de Liefhebbers Der Schilderkonst Soude Konnen Formeren.” Alkmaar, c. 170o. MS 396 Collectie Aanwinsten. Regionaal Archief Alkmaar.

- - - "Wetten En Ordonnantys Aengaende 't Coleegje Der Liefhebbers van de Loffelijke Schilderkonst, Tot Alkmaer Vastgesteld Op Den November 170o.” Alkmaar, c. 1700. MS 396 Collectie Aanwinsten. Regionaal Archief Alkmaar.

Engle, Paul. The Art of Glass by Antonio Neri. 3 vols. Hubbardston: Heiden \& Engle, 2003. Epstein, Stephen R. "Craft Guilds, Apprenticeships and Technological Change in PreIndustrial Europe.” In Guilds, Innovation and the European Economy, 1400-180o, edited by Stephen R Epstein and Maarten Prak, 52-8o. Cambridge: Cambridge University Press, 2008.

- — - "Craft Guilds in the Pre-Modern Economy. A Discussion." The Economic History Review 61 (2008): 155-74.

Epstein, Stephen R, and Maarten Prak, eds. Guilds, Innovation and the European Economy, 1400-180o. Cambridge: Cambridge University Press, 2008.

- - . "Introduction. Guilds, Innovation, and the European Economy, 1400-180o." In Guilds, Innovation and the European Economy, 1400-180o, edited by Stephen R Epstein and Maarten Prak, 1-24. Cambridge: Cambridge University Press, 2008.

Ercker, Lazarus. Beschreibung Aller Fürnemsten Mineralischen Erzt Unnd Berckwercksarten. Prag: Černý Jiří, 1574. 
Exarchakos, Kostas, and Kostas Skordoulis. "The Educational Applications of the Historical Material and the Reproduction of Alchemical Procedures." In Greek Alchemy from Late Antiquity to Early Modernity, edited by E. Nicolaidis, 170-85. Turnhout: Brepols, 2018.

Fidom, Hans. "Making Musicians Think. The Problem with Organs." In Reconstruction, Replication and Re-Enactment in the Humanities and Social Sciences, edited by Sven Dupré, Anna Harris, Patricia Lulof, Julia Kursell, and Maartje Stols-Witlox. Amsterdam: Amsterdam University Press, forthcoming.

Fleisher, Jeffrey. "Building Medieval Worlds. A Classroom Experience in Digitally Reconstructing Ancient Buildings.” Journal of Medieval Worlds 1 (2019): 107-16.

Fors, Hjalmar, Lawrence M. Principe, and Heinz Otto Sibum. "From the Library to the Laboratory and Back Again. Experiment as a Tool for Historians of Science.” Ambix 63 (2016): 85-97.

Freestone, Ian C. "Composition and Microstructure of Early Opaque Red Glass." Early Vitreous Materials. British Museum Occasional Paper 56 (1987): 173-91.

Freestone, Ian C., Colleen P. Stapleton, and Valery Rigby. "The Production of Red Glass and Enamel in the Late Iron Age, Roman and Byzantine Periods." In Through a Glass Brightly - Studies in Byzantine and Medieval Art and Archaeology Presented to David Buckton, 142-54. Oxford: Oxbow, 2003.

Frumer, Yulia. "Translating Words, Building Worlds. Meteorology in Japanese, Dutch, and Chinese." Isis 109 (2018): 302-7.

Garfinkel, Harold. "Studies of the Routine Grounds of Everyday Activities." Social Problems 11 (1964): 225-50.

Geißler, Friedrich. Glaßmacher-Kunst Und Alle Dem Jenigen Was Dazu Gehöret. Frankfurt und Leipzig, 1678.

Gibson, James J. The Ecological Approach to Visual Perception. Boston: Houghton Mifflin Company, 1979.

Giglioni, Guido. "From the Woods of Experience to the Open Fields of Metaphysics. Bacon's Notion of Silva." Renaissance Studies 28 (2014): 242-61.

Glaisyer, Natasha, and Sara Pennell. "Introduction.” In Didactic Literature in England 1500-180o. Expertise Constructed, edited by Natasha Glaisyer and Sara Pennell, 1-18. London: Ashgate, 2003.

Goedings, Truusje. “De 'Vrijerijboeken' En 'Pareltjes' van Simon Eikelenberg (1663-1738). I. Iets over de Erotische Belangstelling van een 17de-Eeuwer.” De Boekenwereld 2 (1986 1985): 47-57.

_- - 'Deurslepe Vryers En Be- Minnelyke Meysjes'. De 'Vrijerijboeken' En 'Pareltjes' van Simon Eikelenberg (1663-1738), II.” De Boekenwereld 2 (1986 1985): 80-92.

Goody, Jack. The Domestication of the Savage Mind. Cambridge: Cambridge University Press, 1978.

Gowlland, Geoffrey. “The Sociality of Enskilment.” Ethnos 84 (2019): 508-24.

_-_. "Thinking through Materials. Embodied Problem Solving and the Values of Work in Taiwanese Ceramics.” In Craftwork as Problem Solving. Ethnographic Studies of Design and Making, edited by Trevor H.J. Marchand, 183-96. Farnham: Ashgate, 2016.

Grasseni, Cristina. "Skilled Vision. An Apprenticeship in Breeding Aesthetics." Social Anthropology 12 (2014): 41-55.

- — , ed. Skilled Visions. Between Apprenticeship and Standards. New York: Berghahn Books, 2009. 
Grazzini, M.G. "Discorso Sopra La Chimica. The Paracelsian Philosphy of Antonio Neri." Nuncius 27 (2012): 411-67.

Guerrini, Anita. "The Material Turn in the History of Life Science.” Literature Compass 13 (2016): 469-8o.

Guichard, Charlotte. "Taste Communities. The Rise of the Amateur in Eighteenth-Century Paris." Eighteenth-Century Studies 45 (2012): 519-47.

Hagendijk, Thijs. "Learning a Craft from Books. Historical Re- Enactment of Functional Reading in Gold- and Silversmithing." Nuncius 33 (2018): 198-235.

_-_. "Maken Als Groeien. Wat de Meester Niét in de Hand Heeft." Article 9 (2017): 4-7.

- - _. "Rock-Paper-Scissors. Bending Tools and the Rules." ARTECHNE (blog), 2017. https://artechne.wp.hum.uu.nl/rock-paper-scissors-bending-tools-and-the-rules/.

- - - "Unpacking Recipes and Communicating Experience. The Ervarenissen of Simon Eikelenberg (1663-1738) and the Art of Painting." Early Science and Medicine 24 (2019): 248-82.

Hagendijk, Thijs, and Tonny Beentjes. "Vicissitudes in Soldering. Reading and Working with a Historical Gold- and Silversmithing Manual." History of Knowledge (blog), 2018. https:/historyofknowledge.net/2018/05/10/vicissitudes-in-soldering/.

Hagendijk, Thijs, Peter Heering, Lawrence M. Principe, and Sven Dupré. "Reworking Recipes and Experiments in the Classroom." In Reconstruction, Replication and ReEnactment in the Humanities and Social Sciences, edited by Sven Dupré, Anna Harris, Patricia Lulof, Julia Kursell, and Maartje Stols-Witlox. Amsterdam: Amsterdam University Press, forthcoming.

Hallam, Elizabeth, and Tim Ingold. Making and Growing. Anthropological Studies of Organisms and Artefacts. Farnham: Ashgate, 2014.

Hanson, Marta, and Gianna Pomata. "Medicinal Formulas and Experiential Knowledge in the Seventeenth-Century Epistemic Exchange between China and Europe." Isis 108 (2017): 1-25.

Hawthorne, John G., and Cyril Stanley Smith. Theophilus on Diverse Arts. The Foremost Medieval Treatise on Painting, Glassmaking and Metalwork. New York: Dover Publications, 1979.

Henderson, Julian. Ancient Glass. An Interdisciplinary Exploration. Cambridge: Cambridge University Press, 2013.

Hendriks, Jac. Vakboek Voor Den Juwelier, Goud-, En Zilversmid. Nijmegen: self-pub, 1936.

Hendriksen, Marieke M.A. “'Art and Technique Always Balance the Scale'. German Philosophies of Sensory Perception, Taste, and Art Criticism, and the Rise of the Term Technik, ca. 1735-ca. 1835." History of Humanities 2 (2017): 201-19.

- - - "Necessary, Not Sufficient. The Circulation of Knowledge about Stained Glass in the Northern Netherlands, 1650-1821." Nuncius 31 (2016): 332-6o.

- - , ed. "Rethinking Performative Methods in the History of Science." Special issue. Berichte Zur Wissenschaftsgeschichte 43 (forthcoming fall 2020).

Hendriksen, Marieke M.A., and Ruben Verwaal. "A Cool Oven. Boerhaave's Little Furnace, Part II.” The Recipes Project (blog), 2018. https://recipes.hypotheses.org/13661.

_- _. "The 'Gentle Heat' of Boerhaave's Little Furnace.” The Recipes Project (blog), 2018. https://recipes.hypotheses.org/11386. 
Hermens, Erma. "Technical Art History. The Synergy of Art, Conservation and Science." In Art History and Visual Studies in Europe. Transnational Discourses and National Frameworks, edited by Matthew Rampley, Thierry Lenain, Hubert Locher, Andrea Pinotti, Charlotte Schoell-Glass, and Kitty Zijlmans, 151-65. Leiden: Brill, 2012.

Hesselink, Lidewij. "Goud- en Zilversmeden en hun Gilde in Amsterdam in de 17e en 18e Eeuw." Holland Historisch Tijdschrift 31 (1999): 127-47.

Hilditch, Jill. "Bringing the Past to Life: Material Culture Production and Archaeological Practice.” In Reconstruction, Replication and Re-Enactment in the Humanities and Social Sciences, edited by Sven Dupré, Anna Harris, Patricia Lulof, Julia Kursell, and Maartje Stols-Witlox. Amsterdam: Amsterdam University Press, forthcoming.

Hirschauer, Stefan. "Putting Things into Words. Ethnographic Description and the Silence of the Social." Human Studies 29 (2006): 413-41.

Honig, Elizabeth A. Jan Brueghel and the Senses of Scale. University Park PA: Pennsylvania State University Press, 2016.

Hopkins, John N. The Genesis of Roman Architecture. New Haven: Yale University Press, 2016.

Höttecke, Dietmar. "How and What Can We Learn from Replicating Historical Experiments? A Case Study." Science E Education 9 (2000): 343-62.

Ingersoll, Daniel, John E. Yellen, and William Macdonald, eds. Experimental Archeology. New York: Columbia University Press, 1977.

Ingold, Tim. Being Alive. Essays on Movement, Knowledge and Description. London: Routledge, 2011.

- - - "From the Transmission of Representations to the Education of Attention." In The Debated Mind, edited by Harvey Whitehouse, 113-53. Oxford: Berg, 2001.

- - Making. Anthropology, Archaeology, Art and Architecture. London: Routledge, 2013.

- _- "On Human Correspondence." Journal of the Royal Anthropological Institute 23 (2016): 9-27.

- - - The Perception of the Environment. Essays on Livelihood, Dwelling and Skill. London: Routledge, 2000.

- - . "The Textility of Making." Cambridge Journal of Economics 34 (2010): 91-102.

Ingold, Tim, and Ray Lucas. "The 4 A's (Anthropology, Archaeology, Art and Architecture). Reflections on a Teaching and Learning Experience.” In Ways of Knowing. Anthropological Approaches to Crafting Experience and Knowledge, edited by Mark Harris, 287-305. New York: Berghahn Books, 2007.

Ishida, Shingo, Masahiko Hayashi, Nobuyuki Takeuchi, and Mitsuru Wakamatsu. "Role of Snz+ in Development of Red Color during Reheating of Copper Glass.” Journal of Non-Crystalline Solids 95-96 (1987): 793-8oo.

Jaubert, Abbé. Dictionnaire Raisonné Universel Des Arts et Métiers. Vol. 2. Paris, 1773.

Keller, Vera. "Re-Entangling the Thermometer. Cornelis Drebbel's Description of His Self-Regulating Oven, the Regiment of Fire, and the Early History of Temperature." Nuncius 28 (2013): 243-75.

Kieffer, Fanny. "The Laboraties of Art and Alchemy at the Uffizi Gallery in Renaissance Florence. Some Material Aspects.” In Laboratories of Art. Alchemy and Art Technology from Antiquity to the 18th Century, edited by Sven Dupré, 105-27. Cham: Springer, 2014.

Kirby, Jo. “The Painter's Trade in the Seventeenth Century. Theory and Practice.” National Gallery London Technical Bulletin 20 (1999): 5-49. 
Kirby, Jo, Maarten Van Bommel, and André Verhecken. Natural Colorants for Dyeing and Lake Pigments. Practical Recipes and Their Historical Sources. London: Archetype Publications, 2013.

Kircherus, Athanasius. D'Onder-Aardse Weereld in Haar Goddelijk Maaksel En Wonderbare Uitwerkselen Aller Dingen [...]. Amsterdam: Joannes Janssonius van Waasberge, 1682.

- - . Mundus Subterraneus [...]. Amsterdam: Joannes Janssonius \& Elizeus Weyerstraten, 1665.

Klein, Ursula. "Chemical Experts at the Royal Prussian Porcelain Manufactory." Ambix 6o (2013): 99-121.

- - - "Introduction. Artisanal-Scientific Experts in Eighteenth-Century France and German.” "Artisanal-Scientific Experts in Eighteenth-Century France and German." Edited by Ursula Klein. Special issue. Annals of Science 69, no. 3 (2012): 303-6.

_-_. "Technoscience Avant La Lettre." Perspectives on Science 13 (2005): 226-66.

Knappett, Carl. "Materiality." In Archaeological Theory Today, edited by Ian Hodder, 115-31. Cambridge: Polity Press, 2014.

Koinm, Albert J. “Christopher Merret's Use of Experiment." Notes and Records of the Royal Society of London 54 (2000): 23-32.

Kremnitzer, Kathryn, and Siddharta V. Shah. "Making Emerald. Imitation as Working Method." presented at the SHAC Postgraduate Workshop on Colouring \& Making in Alchemy and Chemistry, Utrecht University, October 26, 2016.

Kruse, Hans-Joachim. "Johann Kunckel. Der Bedeutendste Plöner?" Jahrbuch Für Heimatkunde Im Kreis Plön 42 (2012): 89-150.

Kuijpers, Maikel H.G. "A Sensory Update to the Chaîne Opératoire in Order to Study Skill. Perceptive Categories for Copper-Compositions in Archaeometallurgy." Journal of Archaeological Method and Theory 25 (2018): 863-91.

- - - An Archaeology of Skill. Metalworking Skill and Material Specialization in Early Bronze Age Central Europe. London: Routledge, 2018.

Kunckel, Johann. Ars Vitraria Experimentalis, Oder Vollkommene Glasmacher-Kunst. Franckfurt, Leipzig, 1679 .

Kunkel von Löwensterns, Johann. Collegium Physico-Chymicum Expertimentale. Oder Laboratorium Chymicum. Hamburg, Leipzig: Johann Caspar Engelleder, 1716.

Kursell, Julia, and Peter Peters. "Making Sound Present. Re-enactment and Reconstruction in Historical Organ Building Practices." In Reconstruction, Replication and ReEnactment in the Humanities and Social Sciences, edited by Sven Dupré, Anna Harris, Patricia Lulof, Julia Kursell, and Maartje Stols-Witlox. Amsterdam: Amsterdam University Press, forthcoming.

Lancilot, Carel. De Brandende Salamander. Amsterdam: Johannis ten Hoorn, 1680.

Lane, Joan. Apprenticeship in England. London: University College London Press, 1996.

Latour, Bruno. Pandora's Hope. Essays on the Reality of Science Studies. Cambridge MA: Harvard University Press, 1999.

- - - Reassembling the Social. An Introduction to Actor-Network-Theory. Oxford: Oxford University Press, 2005.

Lemery, Nicolas. Cours de Chymie. 5th ed. Paris, 1683.

- - - Het Philosoophische Laboratorium Of Der Chymisten Stook-Huis. Amsterdam: Jan ten Hoorn, 1683. 
Leong, Elaine. "Brewing Ale and Boiling Water in 1651." In The Structures of Practical Knowledge, edited by Matteo Valleriani, 55-75. Cham: Springer International Publishing, 2017.

- _ - "Collecting Knowledge for the Family. Recipes, Gender and Practical Knowledge in the Early Modern English Household." Centaurus 55 (2013): 81-103.

-_- Recipes and Everyday Knowledge. Medicine, Science, and the Household in Early Modern England. Chicago: Chicago University Press, 2018.

Leong, Elaine, and Sara Pennell. "Recipe Collections and the Currency of Medicinal Knowledge in the Early Modern 'Medical Marketplace.” In Medicine and the Market in England and Its Colonies c. 1450-c. 1850, edited by Mark Jenner and Patrick Wallis, 133-52. London: Palgrave Macmillan, 2007.

Leong, Elaine, and Alisha Rankin. "Introduction. Secrets and Knowledge." In Secrets and Knowledge in Medicine and Science, 1500-1800, edited by Elaine Leong and Alisha Rankin, 1-20. Farnham: Ashgate, 2011.

- - , eds. Secrets and Knowledge in Medicine and Science, 1500-180o. Farnham: Ashgate, 2011.

- - , eds. "Testing Drugs and Trying Cures." Special issue. Bulletin of the History of Medicine 91, no. 2 (2017).

_- _. "Testing Drugs and Trying Cures. Experiment and Medicine in Medieval and Early Modern Europe." “Testing Drugs and Trying Cures." Edited by Elaine Leong and Alisha Rankin. Special issue. Bulletin of the History of Medicine 91 (2017): 157-82.

Long, Pamela O. Artisan/Practitioners and the Rise of the New Sciences, 1400-1600. Corvallis: Oregon State University Press, 2011.

- - Openness, Secrecy, Authorship. Technical Arts and the Culture of Knowledge from Antiquity to the Renaissance. Baltimore: The Johns Hopkins University Press, 2001.

- - - "Power, Patronage, and the Authorship of Ars. From Mechanical Know-How to Mechanical Knowledge in the Last Scribal Age.” Isis 88 (1997): 1-41.

_—_. "Trading Zones in Early Modern Europe." Isis 106 (2015): 840-47.

Lulof, Patricia. "Recreating Reconstructions. Archaeology, Architecture and 3D Technologies." In Reconstruction, Replication and Re-Enactment in the Humanities and Social Sciences, edited by Sven Dupré, Anna Harris, Patricia Lulof, Julia Kursell, and Maartje Stols-Witlox. Amsterdam: Amsterdam University Press, forthcoming.

Mäkinen, Martti. “Efficacy Phrases in Early Modern English Medical Recipes." In Medical Writing in Early Modern English, edited by Irma Taavitsainen and Päivi Pahta, 158-79. Cambridge: Cambridge University Press, 2011.

Making and Knowing Project. "Minimal Edition of BnF Ms Fr 640." Accessed January 28, 2020. https://cu-mkp.github.io/GR8975-edition/.

Mann, Anna M., Annamarie M. Mol, Priya Satalkar, Amalinda Savirani, Nasima Selim, Malini Sur, and Emily Yates-Doerr. "Mixing Methods, Tasting Fingers. Notes on an Ethnographic Experiment." HAU. Journal of Ethnographic Theory 1 (2011): 221-43.

Marchand, Trevor H.J. "Muscles, Morals and Mind. Craft Apprenticeship and the Formation of Person." British Journal of Educational Studies 56 (2008): 245-71.

Margócsy, Dániel. Commercial Visions. Science, Trade and Visual Culture in the Dutch Golden Age. Chicago: Chicago University Press, 2014.

Martelli, Matteo. "Greek Alchemists at Work. 'Alchemical Laboratory' in the Greco-Roman Egypt.” Nuncius 26 (2011): 271-311. 
- "The Alchemical Art of Dying. The Fourfold Division of Alchemy and the Enochian Tradition." In Laboratories of Art. Alchemy and Art Technology from Antiquity to the 18th Century, edited by Sven Dupré, 1-22. Cham: Springer, 2014.

Martinón-Torres, Marcos. Review of Laboratories of Art. Alchemy and Art Technology from Antiquity to the 18th Century, Edited by Sven Dupré. Ambix 62 (2015): 386-87.

Martinón-Torres, Marcos, and Thilo Rehren. “Technical Ceramics.” In Archaeometallurgy in Global Perspective, edited by B.W. Roberts and C.P. Thornton, 107-31. New York: Springer, 2014 .

McEwan, Ian. Saturday. London: Vintage, 2016.

Merret, Christopher. The Art of Glass, Wherein Are Shown the Wayes to Make and Colour Glass, Pastes, Enamels, Lakes, and Other Curiosities. London, 1662.

Mokyr, Joel. The Gifts of Athena. Historical Origins of the Knowledge Economy. Princeton: Princeton University Press, 2002.

Moretti, Cesare, and Tullio Toninato. Ricette Vetrarie Del Rinascimento. Trascrizione Da Un Manoscritto Anonimo Veneziano. Venezia: Marsilio Editori, 2001.

Moureau, Sébastien, and Nicolas Thomas. "Understanding Texts with the Help of Experimentation. The Example of Cupellation in Arabic Scientific Literature.” Ambix 63 (2016): 98-117.

Nadolny, Jilleen, Mark Clarke, Erma Hermens, Ann Massing, and Leslie Carlyle. "Art Technological Source Research. Documentary Sources on European Painting to the Twentieth Century, with Appendices I-VII." In Conservation of Easel Paintings, edited by Joyce Hill Stoner and Rebecca Rushfield, 3-32. London: Routledge, 2012.

Neri, Antonio. L'Arte Vetraria Distinta in Libri Sette. Firenze: Stamperia de' Giunti, 1612.

Neven, Sylvie. "Transmission of Alchemical and Artisanal Knowledge in German Mediaeval and Premodern Recipe Books." In Laboratories of Art. Alchemy and Art Technology from Antiquity to the 18th Century, edited by Sven Dupré, 23-51. Cham: Springer, 2014 .

Newman, William R. "Alchemy, Assaying, and Experiment." In Instruments and Experimentation in the History of Chemistry, edited by Frederic L. Holmes and Trevor H. Levere, 35-54. Cambridge MA: MIT Press, 2000.

- - - Atoms and Alchemy. Chicago: Chicago University Press, 2006.

- - - Gehennical Fire. The Lives of George Starkey, an American Alchemist. Cambridge MA: Harvard University Press, 1994.

Newman, William R., and Lawrence M. Principe. "Alchemy vs. Chemistry. The Etymological Origins of a Historiographical Mistake." Early Science and Medicine 3 (1998): 32-65.

Nonaka, Ikujiro, and Georg von Krogh. "Tacit Knowledge and Knowledge Conversion. Controversy and Advancement in Organizational Knowledge Creation Theory." Organization Science 20 (2009): 635-52.

Nyden, Tammy. "De Volder's Cartesian Physics and Experimental Pedagogy." In Cartesian Empiricisms, edited by Mihnea Dobre and Tammy Nyden, 227-49. Dordrecht: Springer, 2013.

- - - "Living Force at Leiden. De Volders, 's Gravensande, and the Reception of Newtonianism." In Newton and Empiricism, edited by Zvi Biener and Eric Schliesser, 207-22. Oxford: Oxford University Press, 2014.

O'Connor, Erin. “Embodied Knowledge. The Experience of Meaning and the Struggle Towards Proficiency in Glassblowing." Ethnography 61 (2005): 183-204. 
Oltrogge, Doris. “The Cologne Database for Painting Materials and Reconstructions." In Art of the Past. Sources and Reconstructions. Proceedings of the First Symposium of the Art Technological Source Research Study Group, edited by Mark Clarke, Joyce H. Townsend, and Ad Stijnman, 9-15. London: Archetype, 2005.

Outram, Alan K. "Introduction to Experimental Archaeology." World Archaeology 40 (2008): 1-6.

Park, Katharine. "Observation in the Margins, 500-1500." In Histories of Scientific Observations, edited by Lorraine Daston and Elizabeth Lunbeck, 16-44. Chicago: Chicago University Press, 2011.

Peels, Rik. "Replicability and Replication in the Humanities." Research Integrity and Peer Review 4 (2019): 1-12.

Pennell, Sara. "Perfecting Practice? Women, Manuscript Recipes and Knowledge in Early Modern England." In Early Modern Women's Manuscript Writing. Selected Papers from the Trinity/Trent Colloquium, edited by Jonathan Gibson and Victoria E. Burke, 237-58. London: Routledge, 2004.

Pennell, Sara, and Michelle DiMeo. "Introduction." In Reading and Writing Recipe Books, 1550-180o, edited by Michelle DiMeo and Sara Pennell, 1-22. Manchester: Manchester University Press, 2013.

Piemontese, Alessio. The Secrets of the Reuerend Maister Alexis of Piemont ... Newly Corrected and Amended, and Also Somewhat Inlarged in Certaine Places, Which Wanted in the First Edition. Translated by William Ward. London: Peter Short, 1595.

Pink, Sarah. Doing Sensory Ethnography. London: Sage Publications, 2009.

Polanyi, Michael. Personal Knowledge. Towards a Post-Critical Philosophy. London: Routledge, 1962.

_—_. "The Logic of Tacit Interference." Philosophy 41 (1966): 1-18.

- - - The Tacit Dimension. Chicago: Chicago University Press, 2009.

Pollen, Steven. "Goldsmiths \& Metalworkers." Making Space. Sensing Place (blog), February 18, 2010. http://msspfollen.blogspot.com/2010/02/goldsmiths.html.

Pomata, Gianna. "Observation Rising. Birth of an Epistemic Genre, 1500-1650." In Histories of Scientific Observations, edited by Lorraine Daston and Elizabeth Lunbeck, 45-80. Chicago: Chicago University Press, 2011.

- - - "Sharing Cases. The Observationes in Early Modern Medicine." Early Science and Medicine 15 (2010): 193-236.

- - - "The Recipe and the Case. Epistemic Genres and the Dynamics of Cognitive Practices." In Wissenschaftsgeschichte Und Geschichte Des Wissen Im Dialog Connecting Science and Knowledge, edited by Kaspar Von Greyerz, Silvia Flubacher, and Philipp Senn, 131-54. Göttingen: Vandenhoeck \& Ruprecht Verlage, 2013.

Prak, Maarten. "Painters, Guilds, and the Art Market during the Dutch Golden Age." In Guilds, Innovation and the European Economy, 1400-180o, edited by Stephen R Epstein and Maarten Prak, 143-71. Cambridge: Cambridge University Press, 2008.

Prak, Maarten, and Patrick Wallis. Apprenticeship in Early Modern Europe. Cambridge: Cambridge University Press, 2019.

Principe, Lawrence M. "Apparatus and Reproducibility in Alchemy." In Instruments and Experimentation in the History of Chemistry, edited by Frederic L. Holmes and Trevor H. Levere, 55-78. Cambridge MA: MIT Press, 2000.

- - - "'Chemical Translation' and the Role of Impurities in Alchemy. Examples from Basil Valentine's Triumph-Wagen.” Ambix 34 (1987): 21-30. 
- - - "Chymical Exotica in the Seventeenth Century, or, How to Make the Bologna Stone." Ambix 63 (2016): 118-44.

- - - "Texts and Practices. The Promises and Problems of Laboratory Replication and the Chemical Explanation of Early Alchemical Processes." In Greek Alchemy from Late Antiquity to Early Modernity, edited by E. Nicolaidis, 159-69. Turnhout: Brepols, 2018.

- - - The Secrets of Alchemy. Chicago: Chicago University Press, 2013.

- - _. "Virtuous Romance and Romantic Virtuoso. The Shaping of Robert Boyle's Literary Style." Journal of the History of Ideas 56 (1995): 377-97.

Pugliano, Valentina. "Pharmacy, Testing, and the Language of Truth in Renaissance Italy." Bulletin of the History of Medicine 91 (2017): 233-73.

Ragland, Evan. "Chymistry and Taste in the Seventeenth Century. Franciscus Dele Boë Sylvius as a Chymical Phyisician Between Galenism and Cartesianism.” Ambix 59 (2012): 1-21.

- - - "'Making Trials' in Sixteenth- and Early Seventeenth-Century European Academic Medicine." Isis 108 (2017): 503-28.

Rau, Günter. "Das Glaslaboratorium Des Johann Kunckel Auf Der Pfaueninsel in Berlin. Ergebnisse Der Probegrabung 1972." In Ausgrabungen in Berlin, 3:148-71, 1972.

- - - "Johann Kunckel, Geheimer Kammerdiener Des Großen Kurfürsten, Und Sein Glaslaboratium Auf Der Pfaueninsel in Berlin.” Medizinhistorisches Journal 2 (1976): 129-48.

Rehder, J.E. The Mastery and Uses of Fire in Antiquity. Montreal: McGill-Queen's University Press, 2000.

Reith, Reinhold. "Circulation of Skilled Labour in Late Medieval and Early Modern Central Europe." In Guilds, Innovation and the European Economy, 1400-180o, edited by Stephen R Epstein and Maarten Prak, 114-42. Cambridge: Cambridge University Press, 2008.

- - - "Know-How, Technologietransfer Und Die Arcana Artis Im Mitteleuropa Der Frühen Neuzeit." Early Science and Medicine 10 (2005): 349-77.

Roberts, Lisa, Simon Schaffer, and Peter Dear, eds. The Mindful Hand. Inquiry and Invention from the Late Renaissance to Early Industrialization. Amsterdam: Edita-KNAW, 2007.

Royce-Roll, Donald. “The Colors of Romanesque Stained Glass.” Journal of Glass Studies 36 (1994): 71-8o.

Santos, Ângela, and Márcia Vilarigues. "Sanguine Paint. Production, Characterization, and Adhesion to the Glass Substrate." Studies in Conservation 64 (2019): 221-39.

Schalk, Ruben. "Apprenticeships with and without Guilds. The Northern Netherlands." In Apprenticeship in Early Modern Europe, edited by Maarten Prak and Patrick Wallis. Cambridge: Cambridge University Press, 2019.

Schlüter, Mogens. "The Use of Peat in Danish Glassworks, 1825-1945.” Journal of Glass Studies 30 (1988): 94-101.

Schoen, Peter. Tussen Hamer En Aambeeld. Edelsmeden in Friesland Tijdens de Gouden Eeuw. Hilversum: Uitgeverij Verloren, 2016.

Schulze, Gerhard. "Kunckels Glaslaboratorium Auf Der Pfaueninsel. Bericht Über Chemische Untersuchungen an Einigen Fundobjekten.” Medizinhistorisches Journal 2 (1976): 149-56.

Sennett, Richard. The Craftsman. London: Penguin, 2009.

Shapin, Steven, and Simon Schaffer. Leviathan and the Air-Pump. Hobbes, Boyle, and the Experimental Life. Princeton: Princeton University Press, 1985. 
Sibum, H. Otto. "Science and the Knowing Body. Making Sense of Embodied Knowledge in Scientific Experiment." In Reconstruction, Replication and Re-Enactment in the Humanities and Social Sciences, edited by Sven Dupré, Anna Harris, Patricia Lulof, Julia Kursell, and Maartje Stols-Witlox. Amsterdam: Amsterdam University Press, forthcoming.

Sibum, Heinz Otto. "Reworking the Mechanical Value of Heat. Instruments of Precision and Gestures of Accuracy in Early Victorian England." Studies in History and Philosophy of Science 26 (1995): 73-106.

Skogh, Lisa, ed. “The Varied Role of the Amateur in Early Modern Europe." Special issue. Nuncius 31, no. 3 (2016): 485-675.

Smith, Cyril Stanley, and Martha Teach Gnudi. The Pirotechnia. New York: The American Institute of Mining and Metallurgical Engineers, 1943.

Smith, Pamela H. "In the Workshop of History. Making, Writing, and Meaning." West 86th 19 (4-31): 2012.

- - - The Body of the Artisan. Art and Experience in the Scientific Revolution. Chicago: Chicago University Press, 2004.

_- - " "The Codification of Vernacular Theories of Metallic Generation in SixteenthCentury European Mining and Metalworking." In The Structures of Practical Knowledge, edited by Matteo Valleriani, 371-92. Cham: Springer International Publishing, 2017.

_- _. "Vermilion, Mercury, Blood, and Lizards. Matter and Meaning in Metalworking." In Materials and Expertise in Early Modern Europe. Between Market and Laboratory, edited by Ursula Klein and E.C. Spary, 29-49. Chicago: Chicago University Press, 2010.

- - - "What Is a Secret? Secrets and Craft Knowledge in Early Modern Europe." In Secrets and Knowledge in Medicine and Science, 1500-1800, edited by Elaine Leong and Alisha Rankin, 47-66. Farnham: Ashgate, 2011.

- - - "Why Write a Book? From Lived Experience to the Written Word in Early Modern Europe." Bulletin of the German Historical Institute 47 (2010): 25-50.

Smith, Pamela H., and Tonny Beentjes. "Nature and Art, Making and Knowing. Reconstructing Sixteenth-Century Life-Casting Techniques.” Renaissance Quarterly 63 (2010): 128-79.

Smith, Pamela H., and The Making and Knowing Project. "Historians in the Laboratory. Reconstruction of Renaissance Art and Technology in the Making and Knowing Project." Art History 39 (2016): 210-33.

Smith, Steven R. “The London Apprentices as Seventeenth-Century Adolescents." Past E Present 61 (1973): 149-61.

Stand, Jan. "Advertisement." Amsterdamse Courant, May 3, 1731.

Star, Susan Leigh. "This Is Not a Boundary Object. Reflections on the Origin of a Concept." Science, Technology, \& Human Values 35 (2010): 601-17.

Star, Susan Leigh, and James R. Griesemer. "Institutional Ecology, 'Translations' and Boundary Objects. Amateurs and Professionals in Berkeley's Museum of Vertebrate Zoology." Social Studies of Science 19 (1989): 387-420.

Staubermann, Klaus, ed. Reconstructions. Recreating Science and Technology. Edingburgh: National Museums Scotland Enterprises Limited, 2011.

Steinle, Friedrich. "Colour Knowledge in the Eighteenth Century. Practice, Systematisation, and Natural Philosophy." In Colour Histories. Science, Art, and Technology in the 17th and 18th Centuries, edited by Friedrich Steinle and Magdalena Bushart. Berlin, Boston: De Gruyter, 2015. 
Stijnman, Ad. "Reconstructions of Iron-Gall Ink Recipes for the InkCor Project." In Art of the Past. Sources and Reconstructions. Proceedings of the First Symposium of the Art Technological Source Research Study Group, edited by Mark Clarke, Joyce H. Townsend, and Ad Stijnman, 125-34. London: Archetype, 2005.

- _ - "Style and Technique Are Inseparable. Art Technological Sources and Reconstructions." In Art of the Past. Sources and Reconstructions. Proceedings of the First Symposium of the Art Technological Source Research Study Group, edited by Mark Clarke, Joyce H. Townsend, and Ad Stijnman, 1-8. London: Archetype, 2005.

Stijnman, Ad, Mark Clarke, and Joyce H. Townsend. "Foreword." In Art of the Past. Sources and Reconstructions. Proceedings of the First Symposium of the Art Technological Source Research Study Group, edited by Mark Clarke, Joyce H. Townsend, and Ad Stijnman. London: Archetype Publications, 2005.

Stols-Witlox, Maartje. A Perfect Ground. Preparatory Layers for Oil Paintings, 1500-19oo. London: Archetype Publications, 2017.

_-_. "Final Varnishes for Oil Paintings in Holland, 1600-190o. Evidence in Written Sources." Zeitschrift Für Kunsttechnologie Und Konservierung 15 (2001): 241-84.

- - - "From Reading to Painting'. Authors and Audiences of Dutch Recipes for Preparatory Layers for Oil Painting." Early Modern Low Countries 1 (2017): 71-134.

- - - "Imperfect Copies. Reconstructions in Conservation Research and Practice." In Reconstruction, Replication and Re-Enactment in the Humanities and Social Sciences, edited by Sven Dupré, Anna Harris, Patricia Lulof, Julia Kursell, and Maartje StolsWitlox. Amsterdam: Amsterdam University Press, forthcoming.

Stols-Witlox, Maartje, Luc Megens, and Leslie Carlyle. “'To Prepare White Excellent.... Reconstructions Investigating the Influence of Washing, Grinding and Decanting of Stack-Process Lead White on Pigment Composition and Particle Size." In The Artist's Process. Technology and Interpretation, edited by Sigrid Eyb-Green, Joyce H. Townsend, Mark Clarke, Jilleen Nadolny, and Stefanos Kroustallis, 112-29. London: Archetype, 2012.

Sullivan, Marin R. Sculptural Materiality in the Age of Conceptualism. International Experiments in Italy. London: Routledge, 2017.

Taylor, Paul. "The Birth of the Amateur." “The Varied Role of the Amateur in Early Modern Europe.” Edited by Lisa Skogh. Special issue. Nuncius 31, no. 3 (2016): 499-522.

Thibaut, Pierre. Cours de Chymie. Leyde, 1672.

Thompson, Daniel V. The Craftman's Handbook. "Il Libro Dell" Arte' by Cennino d'A. Cennini. New Haven: Yale University Press, 1933.

Triotzsch, Ulrich. “Kunckel von Löwenstern, Johann.” In Neue Deutsche Biographie, 13:287f, 1982. https://www.deutsche-biographie.de/pnd11872536X.html\#ndbcontent.

Tump, Janneke. “Ambachtelijk Geschoold. Haarlemse en Rotterdamse Ambachtslieden en de Circulatie van Technische Kennis, ca. 1400-1720." Dissertation, VU University Amsterdam, 2012.

Ussulman, Melvyn, Alan Rocke, Christina Reinhart, and Kelly Foulser. "Restaging Liebig. A Study in the Replication of Experiments." Annals of Science 62 (2005): 1-55.

Valleriani, Matteo. "The Epistemology of Practical Knowledge." In The Structures of Practical Knowledge, edited by Matteo Valleriani, 1-19. Cham: Springer International Publishing, 2017. 
Van Bommel, Maarten, and Enrica Fantini. "Unravelling the Colour Palette. The Reconstruction and Analysis of Synthetic Colour Stains." E-Preservation Science 10 (2013): 50-58.

Van Helden, Anne C. "The Age of the Air-Pump." Tractrix 3 (1991): 149-72.

Van Hoogstraten, Samuel. Inleyding Tot de Hooge Schoole Der Schilderkonst. Anders de Zichbaere Werelt. Rotterdam, 1678.

Van Laer, Willem. Weg-Wyzer Voor Aankomende Goud En Zilversmeden. Verhandelende Veele Wetenschappen, Die Konsten Raakende, Zeer Nut Voor Alle Jonge Goud En Zilversmeeden. Mechelen: J.F. Vander Elst, 175o?.

-_- Weg-Wyzer Voor Aankoomende Goud En Zilversmeeden. Verhandelende Veele Wetenschappen, Die Konsten Raakende, Zeer Nut Voor Alle Jonge Goud En ZilverSmeeden. Amsterdam: Fredrik Helm, 1721.

- - - Weg-Wyzer Voor Aankoomende Goud En Zilversmeeden. Edited by Bert Dubbe. Lochem: De Tijdstroom, 1967.

-_- Weg-Wyzer Voor Aannkomende Goud En Zilversmeeden. Verhandelende Veele Weetenschappen, Die Konsten Raakende, Zeer Nut Voor Alle Jonge Goud En ZilverSmeeden. Amsterdam: Weduwe Jan Stant, 1768.

Van Rentergem, Johannes. "Advertisement." Middelburgse Courant, July 5, 1759.

Van Schendel, Arthur. "Een Briefwisseling over de Leidse Schildersacademie En over Schilderijenhandel." Leids Jaarboekje 47 (1955): 133-46.

_-_ . "Simon Eikelenberg's Experiments on the Preparation of Varnishes." Studies in Conservation 3 (1958): 125-31.

Vande Voorde, Cornelis. Nieuw Lichtende Fakkel Der Chirurgie Of Hedendaagze Heel-Konst. Amsterdam: Wilhelmus Goeree, 1680.

Verità, Marco, and Sandro Zecchin. "Scientific Investigations of a Venetian Polychrome Goblet of the 16th Century." Journal of Glass Studies 50 (2008): 105-15.

Veronesi, Umberto, and Marcos Martinón-Torres. "Glass and Alchemy in Early Modern Europe. An Analytical Study of Glassware from the Oberstockstall Laboratory in Austria." Angewandte Chemie International Edition 57 (2018): 7346-50.

Vilarigues, Márcia. "Choreographies of Glassmaking. An Impression.” ARTECHNE (blog), 2019. https://artechne.wp.hum.uu.nl/choreographies-of-glassmaking-an-impression/.

Vogel, Werner. Glass Chemistry. 2nd ed. Heidelberg: Springer Verlag, 1994.

Von Kerrsenbrock-Krosigk, Dedo. Rubinglas Des Ausgehenden 17. Und Des 18. Jahrhunderts. Mainz: Verlag Phillip von Zabern, 2001.

Wall, Wendy. Recipes for Thought. Knowledge and Taste in the Early Modern English Kitchen. Philadelphia: University of Pennsylvania Press, 2016.

Wallert, Arie. "Alchemy and Medieval Art Technology." In Alchemy Revisited, edited by Z.R.W.M. Von Martels, 154-61. Leiden: Brill, 1990.

_-_. "De Groote Waereld in't Kleen Geschildert (The Big World Painted Small). A Dutch 17th-Century Treatise on Oil Painting Technique." In The Artist's Process. Technology and Interpretation, edited by Sigrid Eyb-Green, Joyce H. Townsend, Mark Clarke, Jilleen Nadolny, and Stefanos Kroustallis, 130-37. London: Archetype, 2012.

- - - "Reading Technical Sources." In Art of the Past. Sources and Reconstructions. Proceedings of the First Symposium of the Art Technological Source Research Study Group, edited by Mark Clarke, Joyce H. Townsend, and Ad Stijnman, 39-43. London: Archetype, 2005. 
Wallert, Arie, Erma Hermens, and Marja Peek, eds. Historical Painting Techniques, Materials, and Studio Practice. Malibu: Getty Conservation Institute, 1995.

Wallis, Patrick. "Apprenticeship and Training in Premodern England." The Journal of Economic History 68 (2008): 832-61.

- - - "Between Apprenticeship and Skill. Acquiring Knowledge Outside the Academy in Early Modern England." presented at the Conference on Knowledgeable Youngsters. Youth, Media and Early Modern Knowledge Societies, Utrecht University, June 26, 2015.

- - - "Between Apprenticeship and Skill. Acquiring Knowledge Outside the Academy in Early Modern England.” In "Youthful Minds and Hands. Learning Practical Knowledge in Early Modern Europe.” Edited by Feike Dietz and Sven Dupré. Special issue. Science in Context 32, no. 2 (2019): 155-70.

Walton, M.S., E. Doehne, K. Trentelman, G. Chiari, J. Maish, and A. Buxbaum. "Characterization of Coral Red Slips on Greek Attic Pottery." Archaeometry 51 (2009): 383-96.

Wellman, Janina. "Hand Und Leib, Arbeiten Und Üben. Instruktionsgraphiken Der Bewegung Im 17. Und 18. Jahrhundert.” In Bewegtes Leben. Körpertechniken in Der Frühen Neuzeit, edited by Rebekka Von Mallinckrodt, 15-38. Wiesbaden: Harrassowitz, 2008.

Werrett, Simon. Thrifty Science. Making the Most of Materials in the History of Experiment. Chicago: University of Chicago Press, 2019.

Weststeijn, Thijs. The Visible World. Samuel van Hoogstraten's Art Theory and the Legitimation of Painting in the Dutch Golden Age. Amsterdam: Amsterdam University Press, 2008.

Weyl, W.A. Coloured Glasses. Sheffield: Society of Glass Technology, 1951.

White, Bruce D., and Walter W. Woodward. "A Most Exquisite Fellow'. William White and an Atlantic World Perspective on the Seventeenth-Century Chymical Furnace." Ambix 54 (2007): 285-98.

Wypyski, Mark T. “Chemical Analyses of Renaissance Enamelled Jewellery.” In Glass and Ceramics Conservation 2007. Interim Meeting of the ICOM-CC Working Group, edited by Lisa Pilosi, 47-59. Nova Gorica: Goriški muzej Kromberk, 2007.

Yeo, Richard. Notebooks, English Virtuosi, and Early Modern Science. Chicago: Chicago University Press, 2014.

Zecchin, L. “Le Ricette Vetrarie Di Montpellier.” In Vetro e Vetrai Di Murano, 1:247-76. Venezia: Arsenala editrice, 1987.

Zilsel, Edgar. The Social Origins of Modern Science. Dordrecht: Springer, 2003.

Zuidervaart, Huib J. "Het in 1658 Opgerichte 'Theatrum Anatomicum' Te Middelburg. Een Medisch-Wetenschappelijk \& Cultureel Convergentiepunt in Een Vroege Stedelijke Context." Archief. Mededelingen van Het Koninklijk Zeeuwsch Genootschap Der Wetenschappen, 2009, 73-140. 
Bibliography 

Nederlandse samenvatting Acknowledgements Curriculum Vitae 


\section{Nederlandse samenvatting}

Keukens staan vol met kookboeken. Een nieuw bed wordt geleverd met een montagehandleiding. En scheikundepractica op school worden keurig georkestreerd met protocollen. De genoemde voorbeelden gaan over praktische teksten. Ze zetten lezers aan tot actie. Ze leggen uit hoe bepaalde objecten, materialen en effecten kunnen worden geproduceerd. En ze faciliteren in het uitvoeren van taken of processen. Praktische teksten zijn overal. Maar hoe werken ze precies? Hoe wordt praktische kennis effectief gecommuniceerd in tekst? En hoe steken we eigenlijk iets op door het lezen van geschreven instructies? Deze vragen hebben een lange en rijke geschiedenis.

In hoofdstuk 1 introduceer ik de historische achtergrond waartegen dit proefschrift moet worden begrepen. Hoewel het lezen en schrijven van praktische teksten van alle tijden is - de vroegste recepten die bekend zijn stammen uit de oudheid - nam de interesse in geschreven instructies een hoge vlucht vanaf de vijftiende eeuw. Deze teksten gingen over van alles, zoals cosmetica, geneeskunst, kookkunst, alchemie, metallurgie en de visuele en decoratieve kunsten. De instructies werden ijverig verzameld, uitgewisseld, gepubliceerd, en geannoteerd. Daarnaast circuleerden ze in en tussen verschillende lagen van de samenleving, van huishoudens en ambachtslieden tot aan wetenschappelijke kringen. Niet alleen nam vanaf de vijftiende eeuw de interesse in geschreven instructies toe, men werd zich ook meer en meer bewust van de potentiële problemen en uitdagingen die samenhingen met het gebruik van teksten in de communicatie van praktische kennis. Zo waarschuwde de schrijvende zilversmid Willem van Laer in 1721 dat het onmogelijk is "alles zo klaar, op 't Papier te brengen, dat men 't, zonder handdadig onderwys ten vollen kan verstaan.” En Van Laer was lang niet de enige die er zo over dacht.

In dit proefschrift beantwoord ik de volgende vraag. Welke lees- en schrijfstrategieën werden gebruikt en ontwikkeld in de vroegmoderne kunsten als antwoord op de uitdagingen die de schriftelijke communicatie van praktische kennis met zich meebracht? Hierin komen enkele thema's samen die in het historisch onderzoek tot vandaag de dag onderbelicht zijn gebleven. Zo werd tot nu toe de problematiek van praktische teksten voornamelijk beschouwd in termen van moeilijk te verwoorden, onbewuste kennis (tacit knowledge), terwijl hiermee andere gebruiksproblemen en vooral ook het perspectief van de lezer buiten beschouwing blijft. Ik doe een poging om dit recht te zetten. Wanneer het helder is wat de uitdagingen waren waar de schrijvers en lezers van praktische teksten zich voor geplaatst wisten, kan vervolgens worden gekeken naar de wijze waarop beide groepen gebruikers daarmee omgingen. Voor een beter begrip van het schrijversperspectief hanteer ik het concept schrijfstrategie. Ik analyseer welke 
verbale middelen en tekstvormen schrijvers gebruikten om hun boodschap zo effectief mogelijk over te brengen. Tegelijkertijd biedt de schrijfstrategie een nieuwe manier om de grote verscheidenheid binnen het corpus van historische praktische teksten beter te begrijpen. Door niet alleen te kijken naar de tekstvorm zelf, maar door ook op zinsniveau te analyseren hoe iets wordt gezegd, komen nieuwe overeenkomsten en contrasten tevoorschijn. Tot slot behandel ik het lezersperspectief. Met een praktische tekst heeft de lezer nog geen garantie op een succesvolle uitkomst. Om een tekst functioneel in een werkplaats te kunnen gebruiken zal de lezer actief aan het werk moeten om de tekst naar zijn hand te zetten. Ik breng in kaart hoe historische lezers dat hebben aangepakt en welke middelen ze daartoe hebben gebruikt.

De methode die ik in dit proefschrift gebruik, verdient speciale aandacht. In hoofdstuk 2 laat ik zien dat een goed begrip van praktische teksten lastig blijft zolang men niet zelf met de instructies aan de slag gaat. Naast de traditionele middelen waarover een historicus beschikt, zoals bijvoorbeeld archiefonderzoek, maak ik daarom gebruik van performatieve methodes. Hierbij lees ik niet alleen historische praktische teksten, maar reproduceer ik ook de materialen en objecten die worden beschreven en speel ik de processen na die hieraan ten grondslag liggen. Hoewel dit soort methodes al langer wordt gebruikt binnen verschillende academische disciplines, is de interesse hiervoor in de afgelopen jaren flink toegenomen. Ik bespreek specifiek hoe performatieve methodes ingezet kunnen worden om grip te krijgen op de historische leerprocessen, pedagogische omstandigheden en vaardigheden die samenhingen met het gebruik van praktische teksten. Daarnaast kader ik mijn keuzes binnen het huidige academische debat. Kenmerkend voor de manier waarop ik de performatieve methodes inricht, is dat ik bewust ruimte creëer voor materialen, gereedschappen en zelfs de omgeving om invloed uit te oefenen op het verloop van de uitvoering (wat ik een ecologische benadering noem). Zo maakt het bijvoorbeeld verschil of een historisch glasrecept wordt gereproduceerd in een elektrische of een houtgestookte oven - niet alleen voor het glas zelf, maar juist ook voor de wijze waarop de praktische tekst wordt geïnterpreteerd. Ook een laboratoriumomgeving kan de interpretatie van praktische teksten onbewust sturen. Samen met Maartje StolsWitlox (Universiteit van Amsterdam) heb ik historische instructies voor vernis in twee verschillende omgevingen uitgevoerd: binnen in een zuurkast met een elektrische verwarmingsplaat en buiten op een houtoventje. Het verloop van het proces was in beide gevallen anders. Binnen in het laboratorium kwamen onze observaties maar gedeeltelijk overeen met de aanwijzingen van de schrijver en was ik geneigd de tekst met een korreltje zout te nemen. Buiten, daarentegen, bleken onze ervaringen verrassend goed te kloppen met de tekst. Achteraf laat het verschil zich uitstekend verklaren - zo verdampte bijvoorbeeld de vernis buiten 
sneller dan binnen - maar het blijft onmogelijk om dit soort variabelen goed van tevoren in te schatten.

Hoofdstuk 3 is een studie naar lezen en schrijven in de glaskunst. Hierbij staat een belangrijke zeventiende-eeuwse verhandeling centraal: de Ars Vitraria Experimentalis (1679) van de Duitse alchemist en glasmaker Johann Kunkel (16301703). Kunckels boek is een uitgebreide Duitse vertaling van eerdere Italiaanse (1612) en Engelse (1662) edities, wat het geheel tot een complexe en gelaagde tekst maakt. Niet alleen bevat het boek een grote hoeveelheid glasrecepten, van bijzonder belang is ook dat Kunckel deze recepten grondig annoteert en becommentarieert. Hij maakt hiervoor handig gebruik van een tekstvorm die van oudsher thuishoorde in de humanistische traditie: het commentaar. Kunckel stoft dit geleerde, epistemische genre af en geeft het een nieuwe plek binnen de kunsten. Om erachter te komen op welke wijze Kunckel zijn lezers helpt om zich de glasrecepten eigen te maken, heb ik in samenwerking met Márcia Vilargues (Universidade NOVA de Lisboa, Portugal) en Sven Dupré (Universiteit Utrecht) vier recepten voor rosichiero-glas gereproduceerd. Rosichiero is een transparant rood glas dat voornamelijk werd gebruikt als email. Het reproduceren bood niet alleen inzicht in de technische kanten van de historische glaspraktijk, maar ook in de verschillende schrijfstrategieën die Kunckel inzet om praktische kennis over te dragen. Zo leerden we door de reproducties dat Kunckels commentaar een ambivalent karakter heeft. Enerzijds bleek Kunckel lang niet altijd de originele Italiaanse recepten te hebben getest en ook zijn de correcties die hij aanbracht niet altijd verbeteringen. Merkwaardig is dat wel, omdat Kunckel herhaaldelijk hamert op het grote belang van eigen tests en benadrukt dat de kennis in zijn boek louter ervaringskennis is. Anderzijds gebruikt Kunckel de commentaren om fundamentele mechanismen bloot te leggen die aan de recepten ten grondslag liggen. Hij vertelt zijn lezers waar ze precies in moeten grijpen om de kleur van het glas te beïnvloeden en laat hen zien wat ze moeten doen om verder grip te krijgen op het maakproces. Kunckel legt bijvoorbeeld uit dat de kleur van het glas afhankelijk is van de wijze waarop de ingrediënten worden gewonnen en bereid, en benadrukt het belang van een goede beheersing van het vuur in de oven. Uitgerekend deze aspecten komen niet aan bod in de recepten zelf, maar het commentaar bood Kunckel een nieuwe mogelijkheid om deze verdiepende lagen alsnog aan te brengen.

Hoofdstuk 4 is een onderzoek naar lezen en schrijven in de schilderkunst. Hier draait het verhaal om Simon Eikelenberg (1663-1738), een breed geïnteresseerde amateurschilder uit Alkmaar. Eikelenberg liet een flink pak papier na met aantekeningen over de schilderkunst, waarin hij een grote hoeveelheid recepten, theoretische verhandelingen en praktische adviezen en ervaringen had verzameld. In de eerste plaats geeft het manuscript een beeld van Eikelenberg als lezer. Het laat onder andere zien dat Eikelenberg problemen tegenkwam wanneer hij met 
andermans recepten aan de slag ging. Daarnaast schreef Eikelenberg ook zelf. Net als Kunckel haalt ook hij een geleerd genre van stal en geeft het een nieuwe plek in zijn aantekeningen. Geïnspireerd op het experimentele essay - een tekstvorm die rond 1660 ingang vond met de opkomst van de Nieuwe Wetenschappen schreef Eikelenberg 'ervarenissen' om uit te leggen hoe schildersmaterialen zoals vernissen bereid moeten worden. Hoewel het recept veruit de belangrijkste geschreven vorm was waarmee praktische kennis werd gecommuniceerd in de vroegmoderne tijd, bleven schrijvers onophoudelijk zoeken naar nieuwe manieren om schriftelijk uitdrukking te geven aan de moeilijk te verwoorden dimensies van knowhow. Eikelenberg is illustratief voor deze zoektocht en zijn ervarenissen kunnen als een innovatieve communicatieve strategie worden beschouwd. Hij adopteert het experimentele essay om zijn instructies te laten spreken en benadrukt het unieke en particuliere karakter van maakprocessen. Hij probeert zich te verplaatsen in zijn lezers en laat zien hoe kwetsbaarheid, mislukking en improvisatie thuishoren op de werkvloer. Het particuliere karakter van de ervarenissen staat hiermee in schril contrast met de sterk generaliserende eigenschappen van het recept en brengt aspecten van praktische kennis voor het voetlicht die anders onzichtbaar zouden blijven.

In hoofdstuk 5 onderzoek ik het lezen en schrijven in de goud- en zilversmeedkunst. Centraal staat een vroege en veelomvattende handleiding die de Zwolse zilversmid Willem van Laer (1674-1722) net voor zijn dood publiceerde: Weg-wyzer voor aankoomende goud en zilversmeeden (1721). Het boekje was een succes. Binnen vijftig jaar werd het drie keer herdrukt (waaronder een Mechelse roofdruk) en het was verkrijgbaar in de meeste Hollandse en Zeeuwse steden. Van Laer bespreekt een scala aan technieken, variërend van drijven tot essayeren, en van gieten tot solderen. Hij vertelt voornamelijk vanuit zijn eigen praktijk als zilversmid en vermijdt het gebruik van recepten zoveel mogelijk. Om te begrijpen hoe de Weg-wyzer ingezet kan zijn geweest binnen opleidingstrajecten van jonge goud- en zilversmeden heb ik samen met Tonny Beentjes (Universiteit van Amsterdam) zo'n historisch opleidingstraject nagespeeld. Tonny heeft mij geleerd om zilveren objecten in zand te gieten en deze eigentijdse pedagogische ervaring heb ik vervolgens weer over Van Laers instructies uit de Weg-wyzer heen gelegd. Niet alleen bleek dat effectief gebruik van de Weg-wyzer afhing van aanvullende praktische uitleg van een meester; ik was nu ook in staat om vanuit het perspectief van een leerling de lacunes te identificeren in Van Laers instructies. Zo legt Van Laer niet uit wat de juiste volgorde is om een zandmal te assembleren (wat ik manuele choreografie noem) en helpt hij nauwelijks bij het leren 'lezen' van de materialen en hun gedrag (wat ik zintuigelijke indicatoren noem). Helemaal gek is dit niet, want dit soort praktische kennis krijgt zijn betekenis pas wanneer een leerling daar persoonlijk ervaring mee opdoet. Het bestaan van deze lacunes in Van Laers uitleg laat zien dat de Weg-wyzer niet zomaar 
een snelle doe-het-zelfcursus was. De overdracht van praktische kennis in tekst vormde dus niet zozeer een substituut voor een traditioneel opleidingstraject, maar was er eerder complementair aan. Zodra leerlingen echter over voldoende basiskennis beschikten, bood de Weg-wyzer hen de mogelijkheid om eigenhandig en onafhankelijk van een meester hun kennishorizon te verbreden.

Welke uitdagingen bracht de schriftelijke communicatie van praktische kennis met zich mee? Welke strategieën werden door schrijvers gebruikt om hun boodschap zo effectief mogelijk over te brengen? En welke middelen moesten lezers aanwenden om de geschreven instructies daadwerkelijk uit te kunnen voeren in hun werkplaats? In de conclusie, hoofdstuk 6, beantwoord ik deze vragen en breng ik de voorgaande hoofdstukken met elkaar in verband.

De grootste problemen die schrijvers en lezers tegenkwamen hadden te maken met onderlinge afstand, de grilligheid van materialen en het belang om in eigen persoon in kennis te kunnen groeien. Zo waarschuwt Kunckel zijn lezers om er rekening mee te houden dat de ovens in Duitsland heter worden gestookt dan in Italië en was precieze communicatie van kleuren in de Ars Vitraria Experimentalis nagenoeg onmogelijk. In de zeventiende eeuw bestonden namelijk nog geen gestandaardiseerde kleursystemen zoals wij die vandaag de dag wel kennen. Daarnaast blijkt de moeizame verwoording van onbewuste kennis maar het begin van de problemen te zijn. Ook wanneer praktische kennis wél expliciet kon worden gemaakt ontstonden er nieuwe moeilijkheden. De uitwerking van ingrediënten op het eindresultaat was bijvoorbeeld niet altijd te voorspellen. Zelfs het beschrijven van precieze hoeveelheden in de tekst bood hier geen oplossing voor. Ook konden perfect heldere instructies cryptisch blijven omdat een goed begrip van de lezer eigenlijk alleen vanuit de praktijk kon ontstaan. Het moet daarom niet verbazen wanneer Kunckel schrijft dat het reproduceren van sommige recepten "evenveel Kunst vereist als het uitvinden ervan".

Schrijvers zochten daarom naar manieren om hun lezers zo goed en kwaad als het ging op weg te helpen en ontwikkelden daarvoor nieuwe schrijfstrategieën. Op het eerste gezicht lijken de verschillen groot tussen Kunckels commentaar, Eikelenbergs ervarenissen en Van Laers handleiding, maar de schrijvers hadden hetzelfde doel voor ogen. Ieder op eigen wijze moedigde de lezer aan om los te komen van de tekst en de geschreven instructies. Ze hielpen de lezer om actief op zoek te gaan naar de materiële condities die aan de beschreven processen ten grondslag liggen; ze illustreerden de experimentele vrijheid die de lezer zichzelf moet permitteren om de instructies succesvol in te kunnen zetten in de eigen praktijk; en ze benadrukten de betrekkelijkheid van hun adviezen door ook alternatieve technieken en maakmethodes te bespreken. De meest intrigerende overeenkomst tussen de schrijvers is misschien wel dat ze alle drie afstand namen van het recept als vorm. Deze beknopte en generaliserende tekstvorm mocht 
dan weliswaar de meest populaire manier zijn geweest om praktische kennis te communiceren in de vroegmoderne periode, voor Kunckel, Eikelenberg en Van Laer volstond het recept niet langer om de complexiteit van maakprocessen te kunnen duiden.

De lezer heeft als taak om de geschreven instructies in harmonie te brengen met zijn omgeving en de materiële en cognitieve hulpbronnen die daar aanwezig zijn. Hoe die omgeving eruitziet en wat de hulpbronnen zijn, verschilt van lezer tot lezer. In zijn ervarenissen geeft Eikelenberg een zeer gedetailleerd beeld van het werk dat hij als lezer verricht bij het interpreteren en uitvoeren van andermans recepten. Zo blijken de instructies bijvoorbeeld onvolledig te zijn en vult hij lacunes aan op basis van eerdere ervaringen, uitputtende bloemlezingen van andere teksten, of door trial-and-error en improvisatie. Soms wordt iemand anders om advies gevraagd of wordt hem ongevraagd advies verstrekt. Eikelenberg laat ook zien dat geschreven instructies voor verbetering vatbaar zijn. Hij onderwerpt ze aan cycli van verbeterpogingen en blijft net zolang aan recepten sleutelen tot ze doen wat hij wil. Het interpreteren en toepassen van geschreven instructies is dus een actief proces. Dit zegt ook iets belangrijks over de aard van praktische teksten zelf. Praktische teksten kunnen niet zonder meer worden begrepen als technische blauwdrukken of eendimensionale reflecties van historische materiële praktijken. Een praktische tekst is eerder een halfproduct, waarbij de betekenis in heel concrete zin afhangt van degene die de tekst leest. Weg-wyzer, de titel van Van Laers boekje, is om die reden wellicht de meest accurate benaming van datgene wat praktische teksten zijn: ze geven de richting aan en beschrijven een aantal oriëntatiepunten, maar het is uiteindelijk de lezer zelf die binnen deze grenzen zijn eigen weg zal moeten vinden. 


\section{Acknowledgements}

This is a book full of memories. I am proud to have been involved in the ARTECHNE-project: what better place might there have been for doing what I love most? Reading old books and getting my hands dirty (always in this order) would not have been the same without my dear colleagues. Jenny, your neverending enthusiasm is truly contagious. Jessie, botanical illustrations will never be the same. Jill, the train is a desolate place without your company. Mariana, laboring away at a dissertation is best done in the company of peers; the back of the office was our stronghold. Marleen, we only recently became colleagues. Thank you for putting up with all the urgent requests I sent your way during the last maddening weeks before the mother of all deadlines.

Sven, thank you for letting me write this book. I know I make much of ecologies in making processes; you made sure that this dissertation could grow under the best circumstances imaginable. I hope we get to continue what we have built over the past years. Maartje, I enjoyed brewing varnishes with you. But more importantly, you brokered the world of conservation and restoration and always gave me good advice. Marieke, you gave me the confidence to pull this off. It is perhaps the best gift of all. And yes, having three supervisors at once was not always easy, but now I can rest assured that this dissertation is truly the best of all possible versions.

I am also indebted to the great many people who enabled the invaluable experiences and insights that in one way or another ended up in this book. Tonny, you made me think like a craftsman. Márcia and Mario, glassmaking was not only a lot of fun, it was a cutting-edge interdisciplinary experience that raised the stakes for future projects. Larry, I fondly remember our morning walks to campus, headed to make some rust. You reminded me of why I wanted to study chemistry in the first place. Lisa, Marjolijn and Mireille, we not only taught together, above everything else, you taught me. Thank you for the crash courses in art history. Gert Jan, Dominique and Paul, I cherish the chemistry we had. Pun intended. Last but not least, I would like to thank Donna Bilak, Bettina Birkenhagen, Maaike Bleeker, Ellen van Bork, Anna Carlgren, Anna Harris, Erma Hermens, Wim Hijdra, Jill Hilditch, Ernst Homburg, Indra Kneepkens, Kate van Lookeren, Wijnand Mijnhardt, Maarten Prak, Harry de Raad, João Rolaça, Pamela Smith, Durk Valkema and Frank Wiesenberg - not to mention the several institutions that facilitated this research: the Department of History and Art History at Utrecht University and the Conservation and Restoration Program at the University of Amsterdam, the Regionaal Archief Alkmaar, the research unit VICARTE at the Universidade Nova de Lisboa, the Glass Furnace project at Roman Villa Borg, the Recipes Project, the Descartes Centre and the European Research Council. 
Good company is one of those ingredients that goes into a fine dissertation. I am particularly grateful to my paranymphs Anne-Fleur and Lars, and to my dear friends and family. Thank you Ron, Suzanne, Hermen, Joas, Caroline, Annerieke, Usama, Johan, Alies, Jorrit, Tijmen, Daniëlle, Jeroen, Christely, Auke, Marloes, Oma, Madelon, Rosanne, Hans, Corjan and Margriet.

Mom and dad, it was over twenty-five years ago that you took me to school for the first time. I am finally done now. I owe this book to you.

Dearest Kim, looking back I can only see the lightness and happiness of being with you. Not once did this book come between us. You would not let it. I love you.

En jij, Kaatje, met je twee jaar ben je vaak al wijzer dan ik. Dankjewel dat je me opnieuw de wereld geeft. 


\section{Curriculum Vitae}

Thijs Hagendijk was born in Rotterdam on October 2oth, 1989. He holds bachelor's degrees in Chemistry (2012) and Philosophy (2012) from Utrecht University. He enrolled in the research master History and Philosophy of Science at the same university and was a visiting student at the López Piñero Institute for the History of Medicine and Science in Valencia, Spain. In 2015, he graduated with distinction (cum laude) on a thesis concerning the discovery of osmosis in the early nineteenth century. After teaching chemistry at secondary schools for a while, Thijs started as a $\mathrm{PhD}$ candidate in 2016 within the ERC-funded ARTECHNE project 'Technique in the Arts. Concepts, Practices, Expertise, 1500-1950.' His dissertation is about reading and writing practices in the early modern arts, with a specific focus on text usage in historical glassmaking, painting, and metalworking. He works at the intersection of technical art history and the history of chemistry, and is interested in performative methods, such as reworking, re-enacting and reproducing historical techniques, materials and processes.

\section{List of Publications}

Thijs Hagendijk, Márcia Vilarigues, Sven Dupré. "Materials, Furnaces, and Texts. How to Write about Making Glass Colours in the Seventeenth Century." Ambix 67 , forthcoming fall 2020.

Thijs Hagendijk, Peter Heering, Lawrence M. Principe, Sven Dupré. "Reworking Recipes and Experiments in the Classroom." In Reconstruction, Replication and Re-enactment in the Humanities and Social Sciences, edited by Sven Dupré, Anna Harris, Patricia Lulof, Julia Kursell, Maartje Stols-Witlox. Under contract with Amsterdam University Press, forthcoming 2020.

Thijs Hagendijk. "Unpacking Recipes and Communicating Experience. The Ervarenissen of Simon Eikelenberg (1663-1738) and the Art of Painting." Early Science and Medicine 24 (2019): 248-282.

Thijs Hagendijk. "Learning a Craft from Books. Historical Re-enactment of Functional Reading in Gold- and Silversmithing." Nuncius 33 (2018): 198-235. 


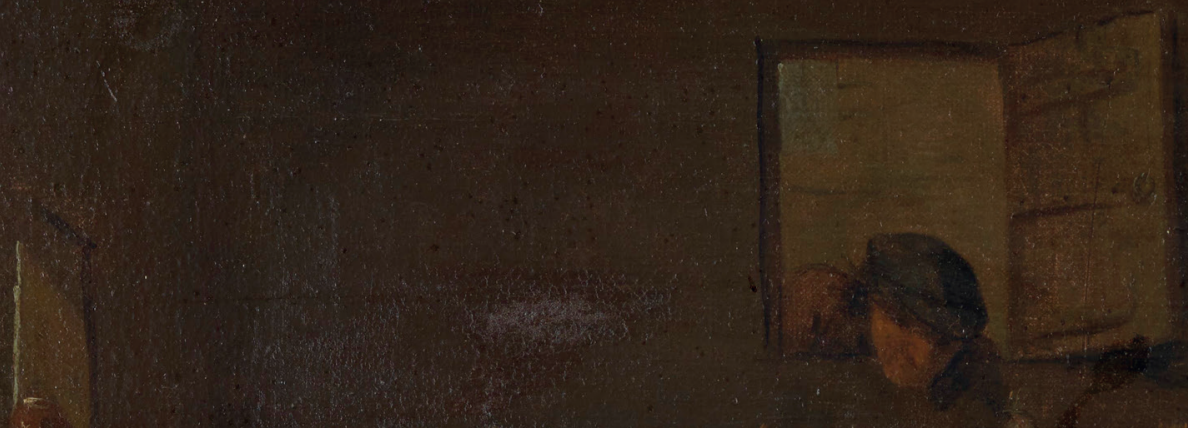

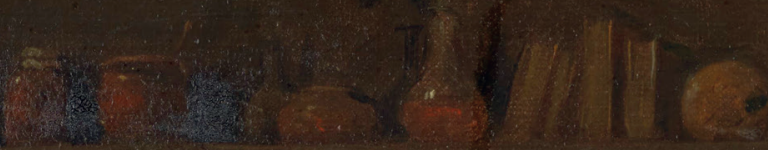

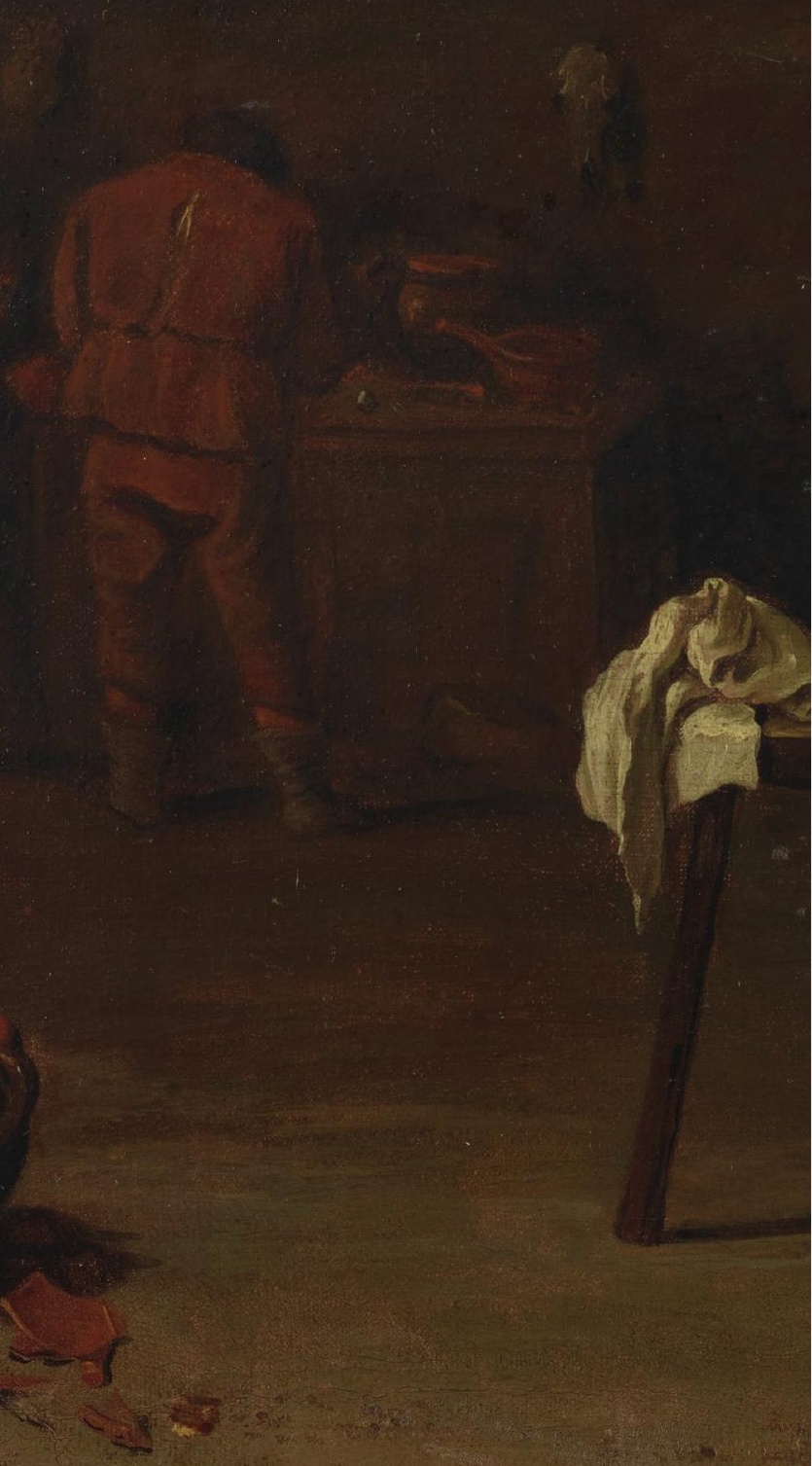

